Universidad deValladolid

PROGRAMA DE DOCTORADO EN PATRIMONIO CULTURAL Y NATURAL. HISTORIA, ARTE Y TERRITORIO.

TESIS DOCTORAL:

\title{
TRANSFORMACIÓN Y PERMANENCIA DEL PATRIMONIO CULTURAL URBANO EN EL SIGLO XXI, EL BARRIO DE ANALCO EN LA CIUDAD DE PUEBLA (MÉXICO)
}

\author{
Presentada por: \\ José Alejandro Reyes Granados para optar al \\ grado de \\ Doctor por la Universidad de Valladolid
}

Dirigida por:

DR. Dn. Basilio Calderón Calderón

Codirigida por:

DRA. Dña. Norma Leticia Ramírez Rosete

2021 


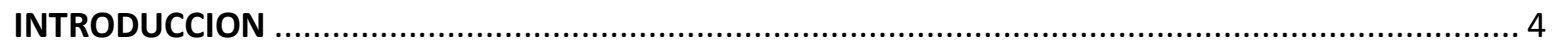

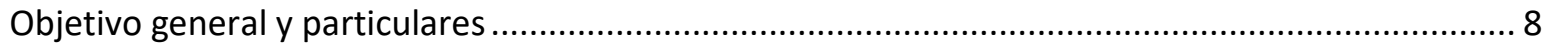

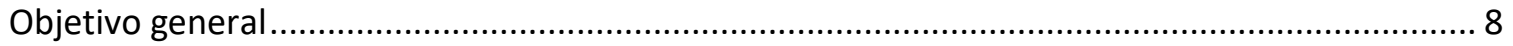

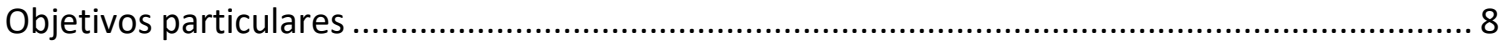

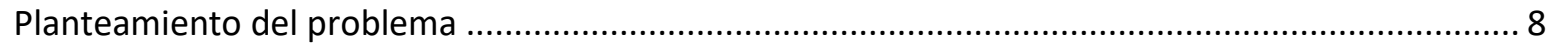

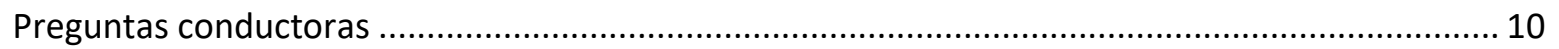

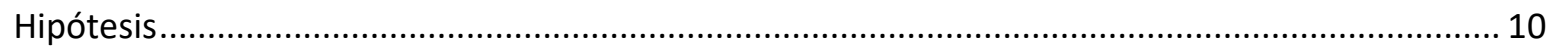

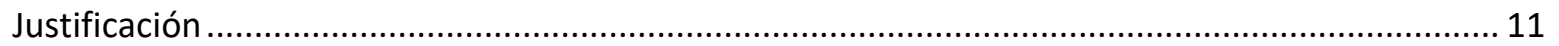

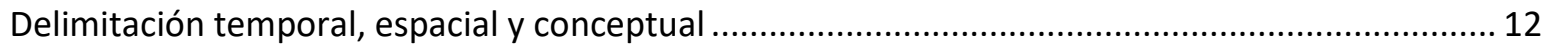

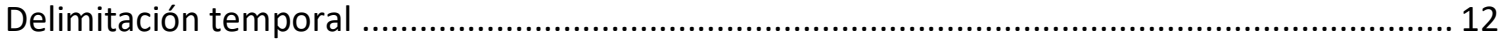

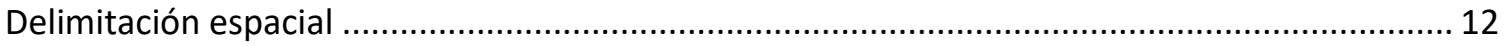

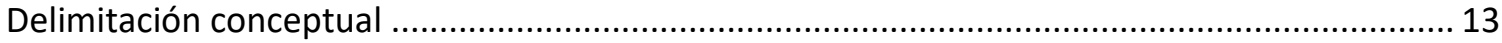

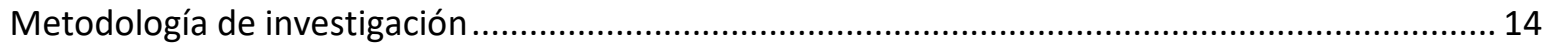

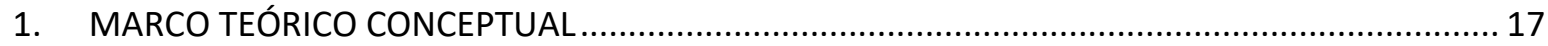

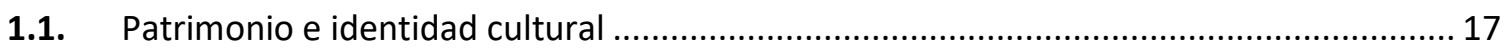

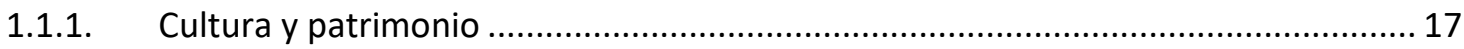

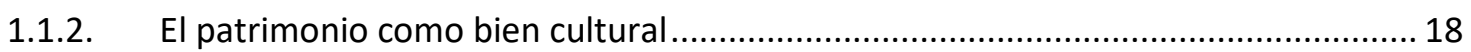

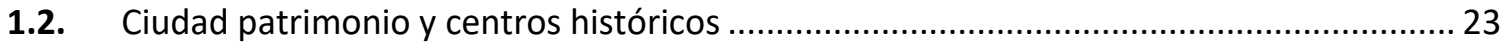

1.2.1. Centros históricos ¿herencia del pasado o construcción del presente?.................... 25

1.2.1.1. El proceso de transformación en los centros urbanos.....................................26

1.2.1.2. El cambio de paradigma sobre el patrimonio edificado ................................... 27

1.2.2. Las políticas sobre rehabilitación de los centros históricos: hacia un nuevo modelo de ciudad 29

1.3. El turismo cultural como factor de transformación de la ciudad histórica....................... 31

1.3.1. El turismo y su relación con el patrimonio cultural................................................. 31

1.3.2. Patrimonio, turismo cultural y recuperación urbana.............................................. 34

1.3.3. El centro histórico, patrimonio tradicional y las infraestructuras modernas ........... 35

1.3.4. El turismo cultural como factor de valoración o degradación del patrimonio ..........37

1.3.5. De patrimonio cultural, arquitectónico y urbanístico, a recurso turístico: problemas y limitaciones.

1.3.6. Los efectos del turismo en los componentes del medio ambiente y en el patrimonio 42

1.4. Gentrificación, origen y definición del concepto 


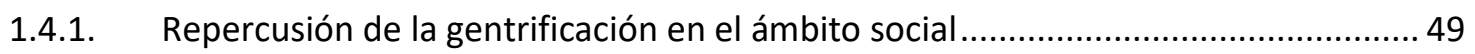

1.4.2. El proceso de gentrificación en barrios históricos ............................................... 50

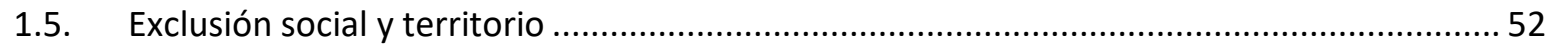

1.5.1. Desigualdad, exclusión y segregación social ........................................................ 52

1.5.2. Escenarios de exclusión social, referencias latinoamericanas reflexiones cruzadas

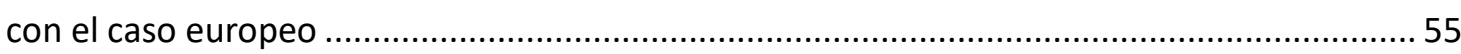

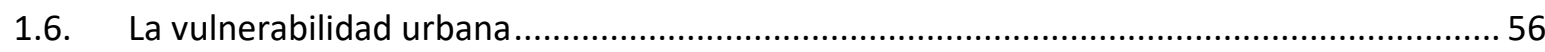

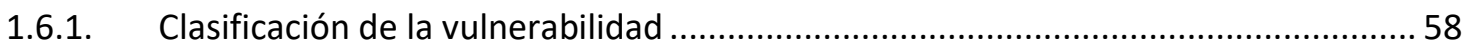

2. ANTECEDENTES HISTORICOS, FUNDACIÓN Y NOMBRAMIENTO DE LA CIUDAD PATRIMONIO 61

2.1. Centro histórico de la ciudad de Puebla y la conformación de barrios ............................61 61

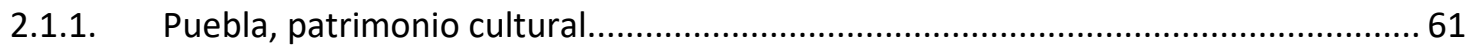

2.1.2. Antecedentes históricos de la ciudad de Puebla .................................................... 62

2.1.3. Declaratoria como Patrimonio Cultural de la Humanidad ........................................63 63

2.2. Historia urbano-arquitectónica del barrio de Analco a partir del nombramiento de ciudad Patrimonio Cultural de la Humanidad.

2.2.1. Transformación en la primera década del siglo XXI: el origen de la gentrificación en el barrio de Analco. 67

3. POLÍTICAS DE INTERVENCIÓN PARA EL RESCATE DEL PATRIMONIO CULTURAL POBLANO ..... 74

3.1. Legislación Internacional del Patrimonio Cultural y Desarrollo Urbano............................ 75

3.2. Legislación Nacional Mexicana de Patrimonio Cultural y Desarrollo Urbano.................... 83

3.3. Legislación Estatal de Patrimonio Cultural y Desarrollo Urbano en Puebla ..................... 87

3.4. Legislación Municipal del Patrimonio Cultural y Desarrollo Urbano en Puebla................... 92

4. ANTECEDENTES DEL PATRIMONIO Y TURISMO CULTURAL EN PUEBLA .............................. 106

4.1. Patrimonio y turismo cultural en México....................................................................... 106

4.2. Servicios e infraestructura turística en Puebla............................................................. 111

4.2.1. Perfil del visitante e indicadores de la actividad turística en Puebla ..................... 112

4.3. Equipamiento turístico su impacto económico y sociocultural .................................... 118

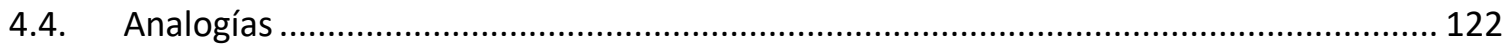

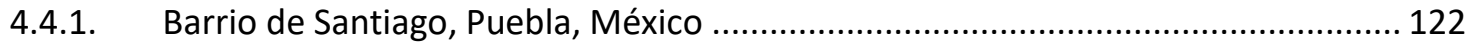

4.4.2. San Miguel de Allende Guanajuato, México ......................................................... 124

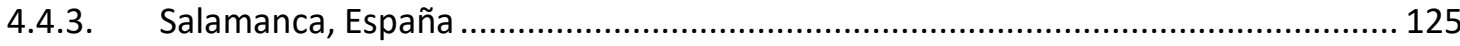

5. DIAGNOSTICO URBANO ARQUITECTONICO DEL AREA DE ESTUDIO ................................... 130

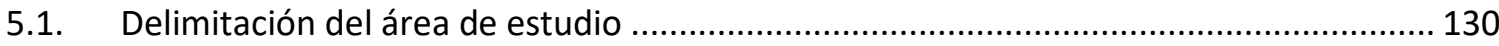

5.1.1. Delimitación de la Zona de Monumentos Históricos ......................................... 130 


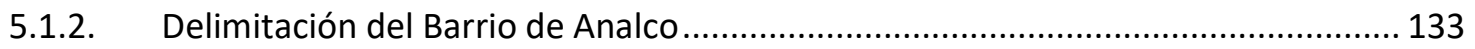

5.2. Análisis de los componentes urbano - arquitectónicos ............................................. 133

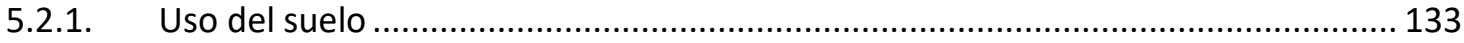

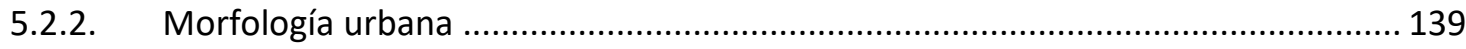

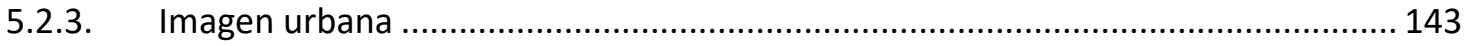

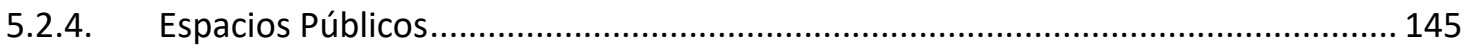

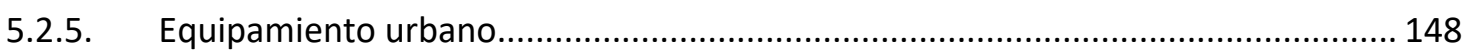

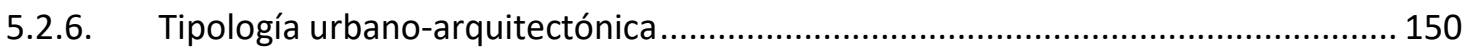

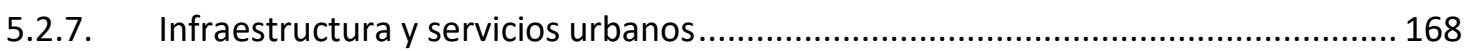

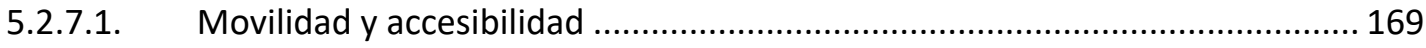

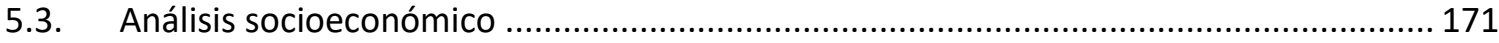

5.3.1. Demografía en la Zona de Monumentos ............................................................ 172

5.3.1.1. Población del barrio de Analco .................................................................... 173

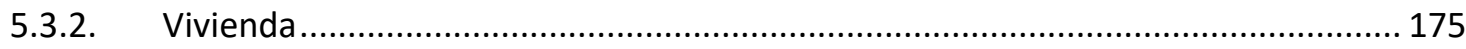

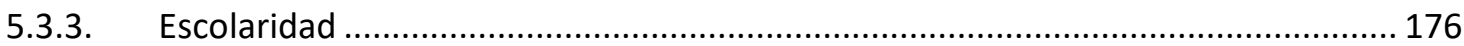

6. REFLEXIONES FINALES - La percepción de vulnerabilidad urbana en Analco ........................ 179

6.1. Análisis de la transformación, cambios y permanencias en el Barrio de Analco ............ 179

7. CONCLUSIONES - TRANSFORMACION DEL BARRIO DE ANALCO ......................................... 192

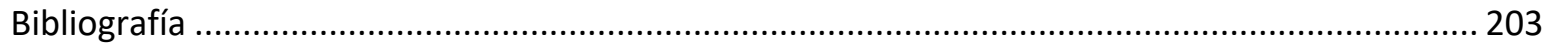

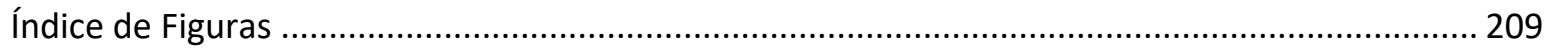

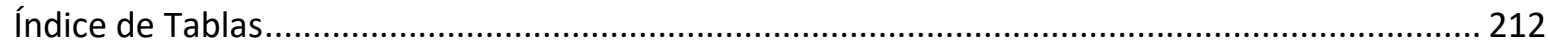

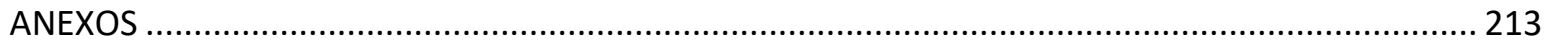




\section{INTRODUCCION}

El turismo cultural en la ciudad histórica de Puebla se ha visto beneficiado a partir de su declaración como Patrimonio Cultural de la Humanidad en 1987, incrementando la oferta y posibilidades de crecimiento de este sector por parte de los tomadores de decisiones. En consecuencia, el aprovechamiento de estos recursos culturales contribuye al desarrollo de la economía de la ciudad y del país en general. Sin embargo, se requiere conocer como esta actividad y otras causas han propiciado la transformación o permanencia del patrimonio cultural arquitectónico y urbano durante las dos primeras décadas del siglo XXI en el barrio de Analco. De esta manera, identificamos factores relacionados a diversas situaciones de naturaleza social, cultural, política, urbana, económica o ambiental, encaminados a un proceso de gentrificación que parece ser irreversible. Además, es necesario analizar la factibilidad de las políticas públicas para la conservación, preservación y salvaguarda del patrimonio dentro del barrio de Analco, así como de las tramas y características urbanoarquitectónicas tradicionales, ya que por su ubicación central aumenta la especulación de inmuebles, trayendo consigo la disminución de uso habitacional que pone en riesgo la identidad del barrio.

De esta manera, partimos de la hipótesis de que la transformación o permanencia del patrimonio cultural en el barrio se ha acelerado hacia el siglo XXI, ya que las estrategias y políticas de gobierno apuntan a la revalorización económica de los inmuebles, situación que va dado origen a un proceso de gentrificación. Por lo tanto, en los últimos veinte años, se ha avalado la destrucción o intervención de los inmuebles por parte del sector inmobiliario, como parte de un proceso especulativo que no fortalece la redensificación del barrio, ni respeta su paisaje cultural y valor histórico material e inmaterial. El turismo es, en sí mismo, una actividad cuya dinámica actual integra gradualmente al ocio cultural principalmente en las ciudades históricas. Así, turismo y ocio son "prácticas sociales que cada día tienen más fuerza en un mundo global donde los ritmos vitales son rápidos y las experiencias efímeras” (TROITIÑNO VINUESA \& TROITIÑNO VILLALBA, 2016, pág. 34). De este modo el turismo cultural es "una actividad productiva e implicada cada vez más en la economía local de las ciudades históricas" (TROITIÑO VINUESA M., 1996, pág. 116). Es por ello que se 
considera a los valores históricos y culturales, como recursos estratégicos con que cuentan las ciudades históricas y que a medida que pasa el tiempo van tomando más importancia por su capacidad de integración y aprovechamiento para el turismo de masas. En este contexto, es importante analizar la estrecha relación entre el patrimonio cultural y el turismo como uno de los recursos económicos más importantes en las ciudades históricas, que ha hecho necesario poner en práctica políticas para su protección, conservación y rehabilitación en el ámbito nacional e internacional, para preservar sus valores de cultura e identidad.

No obstante, el impacto del turismo en la ciudad histórica de Puebla está generando distintos tipos de conflictos urbanos como segregación urbana, gentrificación, vulnerabilidad social, mercantilización, etc., a través de la división socio económica del espacio. Por lo tanto, haremos evidente la forma en que impacta el turismo en la transformación del patrimonio y paisaje cultural del barrio histórico de Analco. Además, haremos una revisión de los instrumentos y políticas de rescate o control en la transformación del patrimonio cultural en Puebla en los últimos veinte años, para finalmente determinar el riesgo del patrimonio cultural ante su conservación y preservación. La finalidad, consiste en proponer algunas recomendaciones orientadas hacia acciones y políticas de intervención que promuevan la conservación de dicho patrimonio en una relación armónica con el turismo cultural y en beneficio de su población residente, ya que es la principal preocupación investigativa en este trabajo.

Por ser un tema amplio y complejo, esta tesis se integra en 7 capítulos, cuya delimitación temporal parte de la inclusión a la lista del Patrimonio de la Humanidad de esta ciudad histórica a la que pertenece el barrio de Analco, para finalizar en el año 2019. En el primer capítulo, se analizan conceptos referentes a patrimonio, haciendo énfasis en el turismo cultural, así como las consecuencias que trae consigo el proceso de gentrificación ante la valoración del patrimonio para su conservación o transformación, donde convergen diversos autores expertos en centros históricos. Por lo anterior, cabe destacar de qué manera dichos procesos influyen en la revalorización urbana y arquitectónica, o en su caso en la explotación y/o conservación del patrimonio cultural en el barrio. De igual manera, se abordan situaciones sociales, políticas, económicas y culturales, que surgen tomando como base la lectura de 
analogías que muestren con claridad la misma problemática, así como las estrategias que se han implementado para detener el proceso de gentrificación tomando.

En el segundo capítulo, se abordarán algunos de los aspectos históricos más relevantes de la Ciudad de Puebla, que enmarcan el origen de gran parte del patrimonio cultural poblano que data de la época de la Colonia; la delimitación de la Zona de Monumentos hasta el nombramiento como Patrimonio Cultural de la Humanidad en 1987. Así como su integración como miembro de la Organización de Ciudades Patrimonio Mundial con el único fin de conservar el conjunto patrimonial de las ciudades históricas bajo la protección de la UNESCO. Además, incluye una descripción de la historia urbanoarquitectónica, así como de su proceso de transformación en la primera década del siglo XXI del barrio de Analco con la finalidad de conocer y enmarcar las pautas que lo conducen hacia un proceso de gentrificación.

En el tercer capítulo, se integrarán temas legislativos en los ámbitos internacional, nacional, estatal y municipal haciendo una breve descripción del escenario del patrimonio cultural en México y destacando la evolución de las políticas de protección y conservación del caso de estudio a lo largo del siglo XX y principios del XXI, que han influido en el proceso de de trasformación del barrio encauzándolo hacia una gentrificación. En este sentido, se mostrarán los efectos tanto negativos como positivos que arrojan las acciones y estrategias implementadas por las instancias gubernamentales respecto a la recuperación del patrimonio cultural, urbano y arquitectónico, el cual es considerado un recurso turístico en el Barrio de Analco.

El cuarto capítulo, describirá los antecedentes del patrimonio y turismo cultural en Puebla y México, así como nos permitirá conocer los servicios e infraestructura turística con que cuenta, misma que sin duda es importante para determinar y conocer el perfil del visitante y como se desenvuelve la actividad turística, por lo que será necesario analizar sus indicadores más relevantes. También se analizará la importancia del equipamiento turístico, así como su impacto económico y sociocultural. Como antecedente, abordaremos tres importantes analogías, desde el Barrio de Santiago a nivel local; en el ámbito nacional San Miguel de Allende, Guanajuato y en el internacional, el caso de la ciudad histórica de Salamanca. 
El quinto capítulo, comprenderá un diagnóstico del área de estudio, considerando la zona de monumentos históricos para finalmente incidir en el barrio de Analco donde se analizarán sus componentes urbanos-arquitectónicos, así como también de los indicadores socioeconómicos y turísticos para determinar los cambios del barrio y la percepción de los habitantes. Además, se retomarán los estudios y el comportamiento de la actividad turística realizada por la Secretaría de Turismo del Estado de Puebla y el Instituto Nacional de Estadística, Geografía e Informática (INEGI).

En el capítulo sexto, como parte de las reflexiones finales, se analizará la percepción de la vulnerabilidad urbana en el barrio de Analco, así como se también se estudiarán, las transformaciones que ha vivido el barrio, los cambios reflejados en el periodo de estudio y las valiosas permanencias que indudablemente continúan siendo parte importante de la identidad del barrio.

Finalmente, en el capítulo séptimo, realizaremos algunas conclusiones del proceso de transformación del patrimonio cultural urbano-arquitectónico en el siglo XXI y su impacto al interior del barrio. Resulta evidente la ausencia de políticas orientadas hacia un proyecto de ciudad donde la participación ciudadana sea clave para fortalecer las estrategias urbanísticas que impulsen su mejoramiento continuo. De esta manera, a través de esta investigación se podrá incidir en los ámbitos de desarrollo sustentable: político, económico, social, cultural y ambiental, mostrando el funcionamiento e impacto actual del turismo Puebla en relación al despoblamiento y pérdida de identidad.

Por último, es necesario establecer recomendaciones orientadas hacia una relación armónica entre el turismo y el patrimonio cultural para lo cual se requiere poner en práctica políticas ambientales, sociales, económicas y culturales para la conservación del patrimonio histórico-cultural, que detenga el proceso de gentrificación asegurando así su protección junto con sus valores de cultura e identidad de sus barrios, que cada vez son más atractivos e importantes para las políticas de desarrollo turístico y económico de esta ciudad. 


\section{Objetivo general y particulares}

Objetivo general

Determinar las causas y factores que propician la transformación y permanencia del patrimonio cultural en el barrio de Analco durante el siglo XXI y como el cambio del uso del suelo se vincula con la transformación de inmuebles, identificando su impacto de naturaleza social, cultural, económica y urbana que lo conducen hacia un proceso de gentrificación. Además, de analizar como las políticas actúan ante la disyuntiva por transformar o preservar el patrimonio cultural para las generaciones futuras.

\section{Objetivos particulares}

1. Evidenciar las principales causas y factores que propician y aceleran la transformación y permanencia del patrimonio arquitectónico y urbano en el barrio de Analco durante el siglo XXI.

2. Identificar como el cambio del uso del suelo se vincula con la transformación de inmuebles y su entorno, orientado hacia un proceso de gentrificación.

3. Identificar los impactos de naturaleza social, cultural y económica que se han generado con el proceso de transformación del barrio.

4. Analizar de qué forma afectan o benefician las actuales políticas de turismo cultural a la transformación del patrimonio cultural y paisaje urbano del barrio de Analco.

5. Demostrar como las políticas actúan ante la disyuntiva por transformar o preservar el patrimonio cultural para las generaciones futuras.

\section{Planteamiento del problema}

En los últimos veinte años, el barrio de Analco ha presentado una transformación correspondiente al cambio de uso de suelo y especulación que lo conduce hacia la gentrificación. Por lo tanto, como hipótesis tenemos que la transformación del patrimonio cultural en los barrios de la ciudad histórica de Puebla se ha acelerado hacia el siglo XXI, ya 
que las estrategias y políticas del gobierno van en función de crear grandes equipamientos, comercios y servicios turísticos en zonas degradadas que apuntan a la revalorización económica de los inmuebles por medio de su destrucción o intervención que han dado origen a un proceso de gentrificación que se atribuye a un proceso especulativo que no fortalece la identidad del barrio, ni respeta su valor histórico.

Tomaremos como antecedente el proyecto urbano denominado "Paseo de San Francisco", el cual se ubica dentro del Centro histórico de la ciudad de Puebla, donde históricamente se albergaban algunas fábricas textiles y curtidurías desde el siglo XVII a la orilla del Rio San Francisco (actualmente entubado). No obstante, durante la intervención se destruyó este patrimonio industrial del cual solo se conservaron algunos vestigios, para dar paso al proceso de gentrificación de estos barrios ubicados al oriente de la ciudad de Puebla. Por lo tanto, a partir del cambio de uso del suelo, se detonó su transformación con la pérdida del uso habitacional, ante la resistencia de sus habitantes por conservar su riqueza cultural tangible e intangible. No obstante, este proyecto no logro detonar la economía de la zona, siendo poco atractivo para los inversionistas y sectores de la población de clase media-alta para quienes fue diseñado.

En este sentido, la acelerada transformación ha inducido cambios radicales urbanoarquitectónicos en los primeros veinte años del siglo XXI, al interior del barrio de Analco y en las proximidades a esta zona provocan sentimientos conservacionistas en parte de la población por la añoranza histórica de la permanencia del patrimonio cultural. De esta manera, encontramos una alta degradación de la mayoría de los barrios que pone en riesgo su memoria histórica dentro de una ciudad que asume un proceso irreversible de transformación producto de la globalización. Es así como el barrio de Analco, debido a su ubicación estratégica, ha experimentado cambios y transformaciones, arquitectónicas, urbanas, sociales y económicas que ponen en riesgo su identidad cultural. Por otra parte, en el barrio se concentra el uso turístico en sus primeras manzanas próximas a la iglesia donde se aloja un tianguis de artesanías y una zona gastronómica que beneficia solo a los comerciantes y turistas que son ajenos al barrio. Por lo anterior, podemos decir que se identifica claramente un proceso de especulación y reactivación económica del centro histórico de Puebla y sus barrios en estas dos primeras décadas del siglo XXI, que va 
transformando el patrimonio, adaptándolo a intereses particulares y necesidades del turismo a través de restaurantes grandes complejos y hoteles boutique, cuya inserción detona un proceso gentrificador, rompiendo la armonía del paisaje urbano-histórico e integración arquitectónica de los barrios.

\section{Preguntas conductoras}

¿Qué ha originado la transformación del patrimonio cultural en el barrio de Analco en los últimos veinte años?

¿Qué aspectos y con qué intensidad han incidido en el proceso de gentrificación y transformación del barrio?

¿Quiénes son y qué papel desempeñan los actores implicados en el barrio?

¿En qué estado se encuentra el patrimonio arquitectónico y urbano del barrio de Analco?

¿Se han realizado las intervenciones con grandes promotoras nacionales o internacionales a través de un proceso incluyente con los habitantes del barrio?

¿Se ha controlado legalmente la transformación del patrimonio cultural en el barrio dentro del proceso de gentrificación?

¿Cómo las políticas actúan ante la disyuntiva por transformar o preservar el patrimonio cultural y en qué grado afectan a la población del barrio desde el punto de vista económico, sociológico, urbano y cultural?

\section{Hipótesis}

La transformación o permanencia del patrimonio cultural en el barrio de Analco se ha acelerado hacia el siglo XXI, ya que las estrategias y políticas del gobierno en salvaguarda del patrimonio cultural apuntan a la revalorización económica de los inmuebles, situación 
que ha dado origen a un proceso de gentrificación. Por lo tanto, podríamos deducir que, en los últimos veinte años, se ha avalado la destrucción por parte del sector inmobiliario de forma precipitada, y se considera así porque no se atribuye al abandono de los inmuebles su destrucción o intervención, sino a un proceso especulativo cuya ganancia estriba en construir algo nuevo que no fortalece la redensificación del barrio ni respeta su valor histórico material e inmaterial.

\section{Justificación}

Dentro de la planeación urbana de la ciudad de Puebla, es necesaria una mayor efectividad en los procesos de gestión territorial actual para la generación de políticas que promuevan la revalorización del patrimonio cultural tangible e intangible de los barrios del centro histórico. De esta manera la formulación de estrategias urbano-arquitectónicas permitirá su puesta en valor, bajo el principio de sostenibilidad urbana mediante un proceso incluyente de gestión participativa aplicado en el barrio de Analco que coadyuve a integrar a aquellos actores de la sociedad que incidan en la protección de los inmuebles y espacios culturales, incentivando un turismo cultural consciente y respetuoso de su valor histórico que además contribuya a la economía local promoviendo un desarrollo integral dentro del centro histórico de la ciudad, de tal manera que se incida en el mejoramiento de la habitabilidad y la calidad de vida de la población. De este modo, será fundamental determinar cuáles son los factores que han propiciado la transformación y permanencia del patrimonio cultural en el barrio de Analco durante el siglo XXI y como estos se vinculan al cambio del uso del suelo, a la transformación física de los inmuebles, identificando el origen, causas e impactos que lo están encausando hacia un proceso de gentrificación. Además de conocer la factibilidad de las políticas públicas actuales entre la disyuntiva por transformar o preservar el patrimonio cultural.

Cabe destacar la importancia de conocer cuál ha sido el proceso de transformación actual que ha fomentado la pérdida del patrimonio cultural material e inmaterial, en el barrio provocando problemas del deterioro físico, espacial y ambiental que ponen en riesgo la pérdida de su valor social e identidad. 


\section{Delimitación temporal, espacial y conceptual}

\section{Delimitación temporal}

La delimitación de este proyecto de investigación parte de la inclusión de la ciudad como Patrimonio de la Humanidad por la UNESCO en 1987 haciendo énfasis en la última década del siglo XX por el impacto del proyecto "Paseo de San Francisco", el cual desde el año 1993 da inicio a un proceso de cambio de uso del suelo que se ha acelerado y encaminado a un proceso de gentrificación en las primeras dos décadas siglo XXI en el barrio contiguo y que se ha polarizado y acentuado en la última década en el barrio de Analco. En esta transformación han ido en aumento las iniciativas de compra de los inmuebles para equipamientos educativos y turísticos que promueven nuevas actividades con servicios y comercios para estos sectores en los inmuebles y espacios públicos.

\section{Delimitación espacial}

El barrio de Analco se ubica en el sector oriente la Ciudad histórica de Puebla, donde el proceso de transformación urbana-arquitectónica se ha incrementado durante las dos primeras décadas del siglo XXI, periodo en el que se aceleró el abandono y degradación del barrio, así como las actuaciones por parte del sector inmobiliario avaladas por las instancias gubernamentales poniendo en riesgo la preservación, conservación y resguardo del Patrimonio Cultural Histórico de la Ciudad de Puebla (ver Fig.1). Esta situación ha mostrado el descontento social a través de diversos medios desde la expropiación de inmuebles en el año 1993 en el barrio contiguo del Alto, que, junto con Analco, comprenden los barrios

fundacionales indígenas que aún conservan su identidad y tradiciones a pesar de su vulnerabilidad por la dinámica inmobiliaria, que ha elevado el precio de suelo y viviendas.

Este contexto, se asemeja a lo sucedido en otros barrios de la ciudad y primer cuadro del centro histórico que tras un mejoramiento urbano e inserción de grandes equipamientos comerciales y turísticos van aumentando el valor de los inmuebles y rentas a su entorno, resultando la mayoría de las veces inaccesible para la población residente. 
Se observa espacial y socialmente un fenómeno de expansión centrífugo de transformación urbana, que está alcanzando barrios como Analco cuya morfología y prácticas tradicionales habían permanecido intactas hasta hace dos décadas. Cabe mencionar que para el análisis del contexto inmediato se hará referencia a la delimitación de la Zona de Monumentos de la Ciudad de Puebla, declarada Patrimonio Cultural de la Humanidad desde el año 1987.

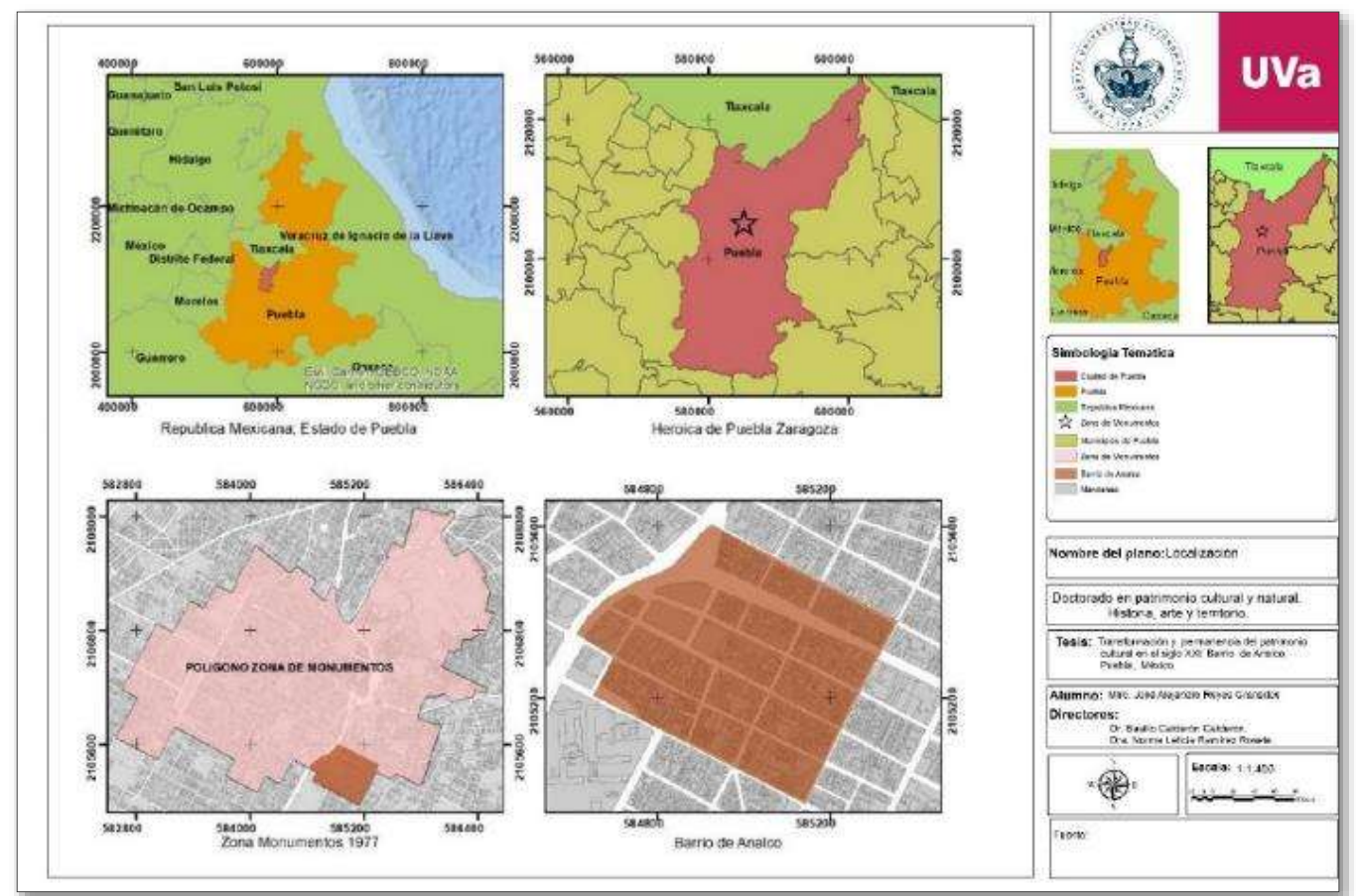

Figura 1 Ubicación de la ciudad de Puebla, elaboración propia con base a datos (INEGI, 2010)

Delimitación conceptual

Para la conformación del marco teórico se analizarán conceptos guía referentes a la relación entre el patrimonio cultural y centros históricos, además analizar el valor e impacto del turismo cultural en la transformación económica, social, urbana y arquitectónica del barrio, que ha favorecido la especulación por parte del sector inmobiliario identificando al ser considerado un motor de desarrollo económico. Además de identificar aquellas políticas mal orientadas que han avalado proyectos que transforman el uso de suelo, siendo uno de los principales factores de vulnerabilidad de la memoria histórica y vocación del barrio. De igual 
forma será importante para este trabajo documentar la transformación del patrimonio edificado a raíz del proceso de gentrificación que en la actualidad está avanzando a una etapa de abandono de la zona, debido a que en estos últimos años se ha producido una desvalorización y desarraigo por parte de los habitantes originarios, lo que ha llevado a algunos propietarios a abandonar, vender o rentar sus inmuebles.

\section{Metodología de investigación}

La metodología de la investigación relacionada al objeto de estudio está conformada por varias etapas que se sustentan en una reflexión teórica bajo un enfoque sistémico que nos permitirá entender y explicar el problema de investigación, además de medir el impacto que tienen las políticas orientadas a priorizar al sector turístico sobre el patrimonio cultural del centro histórico de Puebla evidenciando los efectos que causa en la economía, cultura e identidad del y barrio de Analco. Se considerará la relación entre el patrimonio y turismo cultural en los centros históricos, identificando como a través de políticas mal orientadas puede convertirse en un factor de valoración o riesgo del patrimonio al ser considerado solo como un motor de desarrollo económico en las ciudades de gran valor histórico cultural y natural. Por lo tanto, será necesario analizar conceptos referentes a la categorización de patrimonio e identidad cultural haciendo una referencia general al contexto del caso de estudio respecto al escenario del turismo y el patrimonio cultural en Puebla. Por último, enfocaremos la reflexión al tema de la gentrificación de los centros históricos avalados por políticas gubernamentales actuales cuya polémica gira en torno a la revalorización arquitectónica, económica y social vs. la permanencia de los habitantes originarios de los barrios históricos de Puebla, así como de su memoria histórica e identidad, terminado con una serie de recomendaciones que contribuyan a frenar el impacto de dicha gentrificación.

De esta manera, se destaca la evolución de las políticas de protección y conservación del patrimonio cultural de finales del siglo XX, incluyendo el surgimiento de programas y proyectos, cuyo supuesto compromiso h sido vigilar por la salvaguarda del patrimonio cultural que existe en este territorio. Además de conocer el papel actual las políticas y lineamientos de intervención turística en centro histórico de la ciudad de Puebla y los factores que producen fenómenos como la gentrificación. De esta manera, el cuestionamiento central gira en torno a necesaria y estrecha relación positiva y negativa entre el patrimonio y turismo 
cultural, donde se analizará el factor de valoración y riesgo de degradación del patrimonio al ser considerado solo un recurso económico. Otro aspecto a destacar es la recopilación y análisis de la legislación internacional, nacional y estatal respecto a la salvaguarda del Patrimonio Cultural, así como de los planes, programas, políticas y proyectos vigentes que regulan las intervenciones en la Zona de Monumentos de la Ciudad de Puebla, así como aquellos referentes al turismo cultural.

Por otra parte, siendo necesaria el punto de vista y participación de la población, para este análisis consideramos el diseño de herramientas de investigación como la encuesta, de valor cuantitativo y otras de valor cualitativo por medio del diseño de guías de observación y entrevistas dirigidas a informantes clave (líderes y representantes del barrio), que permitan conocer su percepción respecto al proceso de transformación del barrio desde el punto de vista de los residentes y usuarios. Para la identificación de actores, se pretende conocer los intereses y aspiraciones individuales y de grupo para de este modo resolver con mayor certeza el problema. Asimismo, describiremos los indicadores básicos de la actividad turística en Puebla de los años 2011 al 2019, realizados por la Secretaria de Cultura y Turismo de Puebla con el fin de conocer el desarrollo de esta actividad; así como las acciones y retos en la promoción y gestión del sector turístico.

Por otra parte, será importante elaborar una reconstrucción urbana y arquitectónica histórica que nos permita comprender el valor material y simbólico del barrio. Además, también será importante indagar como se ha desarrollado la gestión y promoción de nuevos espacios educativos, sociales, de recreación y comercio. Siendo necesario realizar dentro del trabajo de campo recorridos por el barrio para identificar su transformación real respecto a sus espacios públicos, edificios y viviendas deteriorados, abandonados, y recientes intervenciones, etc. Además de documentar su transformación, se realizarán fichas técnicas por paramento o frente de manzana que incluya las características de los lotes e inmuebles, más representativos para este caso de estudio. La finalidad será mostrar aquellas intervenciones que se han venido dando en el barrio durante los últimos veinte años, analizando la morfología de los solares y predios antiguos, así como los datos de ocupación, vocación de los espacios públicos y construidos, valor del suelo y espacios en renta. 


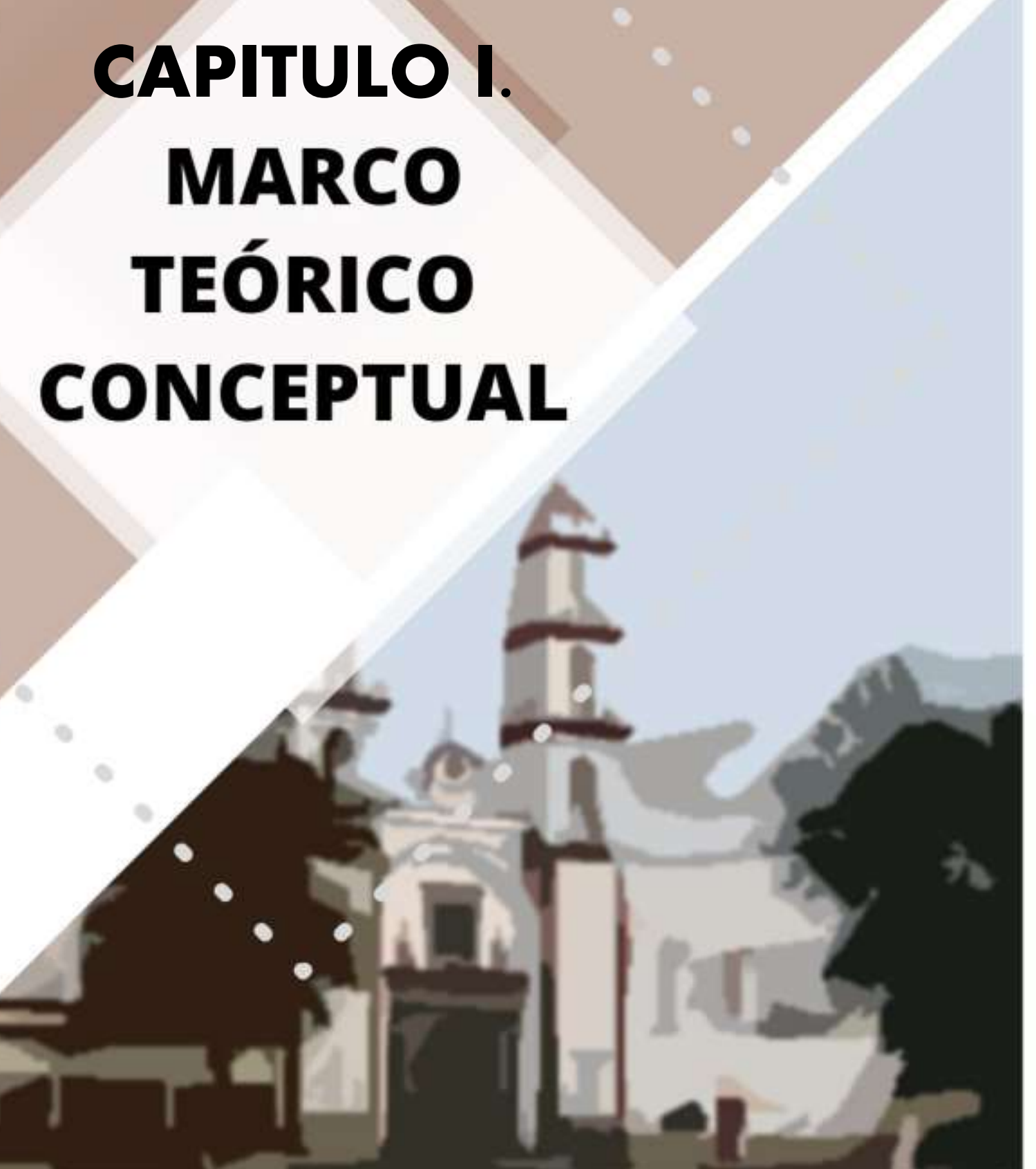




\section{MARCO TEÓRICO CONCEPTUAL}

Para la conformación del marco teórico se analizarán conceptos referentes a la relación entre el patrimonio y turismo cultural en los centros históricos, identificando como a través de políticas turísticas actuales puede convertirse en un factor de valoración o riesgo del patrimonio al ser considerado un motor de desarrollo económico. Por ello, en este primer capítulo realizamos una descripción, basada en el estudio de algunos autores expertos en la materia para conocer la evolución de conceptos tales como bien cultural y las categorías que de él patrimonio cultural material e inmaterial se derivan, incluyendo también elementos que se enlazan necesariamente a las ciudades y centros históricos. De igual forma se integra el concepto de turismo cultural, así como las consecuencias que trae consigo esta actividad para la valoración del patrimonio y su posible utilización como recurso potencial económico basado en los componentes arquitectónicos-urbanísticos y medioambientales con que cuenta la ciudad. Y, por último, se documentará el impacto y vulnerabilidad respecto al tema de gentrificación como estrategia de revitalización actual en los centros históricos que pone en riesgo su identidad.

\subsection{Patrimonio e identidad cultural}

\subsubsection{Cultura y patrimonio}

$\mathrm{Al}$ observar a los seres humanos nos damos cuenta de que estamos determinados por una serie de variaciones que van desde sus rasgos físicos hasta sus diversas costumbres y modos de vivir. El concepto de cultura se ha ido transformando en el tiempo, en el mundo antiguo tuvo una serie de significaciones como: habitar, cultivar, proteger y honrar con veneración. En la segunda mitad del siglo XX, la idea de cultura sirvió para separar los logros humanos de los hechos de la naturaleza, esto dio paso a la idea de que la cultura ha demostrado ser la necesidad de asimilar intelectualmente una experiencia histórica, con la ayuda de la construcción de símbolos que nos permiten entender a las sociedades, su carácter e identidad (Arenas, 2012). Por lo tanto, la cultura es entendida como: "aquel conjunto complejo que comprende conocimientos, creencias, arte, leyes, moral, costumbres, así como otras capacidades y hábitos adquiridos por el hombre como miembro de una sociedad" (Lima, 2003, pág. 45). 
Por otra parte, el patrimonio en la historia antigua era referido a los bienes que heredaban de sus padres y abuelos, hoy en día este vocablo se refiere a las expresiones y productos que tienen valor dentro de un grupo social, derivados de la cultura (Lima, 2003). De esta manera, el patrimonio cultural se refiere a la expresión de la totalidad de conocimientos, creencias y valores, que conforman la tradición de la gente. Por lo tanto, se puede decir que el patrimonio es un elemento cultural del bienestar general y de la calidad de vida de los ciudadanos, así como un instrumento de cohesión social. Por otro lado, en el patrimonio cultural intangible sus manifestaciones son etéreas, no solo la fiesta o la danza, sino los colores, olores, sabores y texturas, y una serie de elementos combinados irrepetibles, que son la materialización de las expresiones culturales, vinculados a la arquitectura y urbanismo de los barrios históricos. Estos dos patrimonios coexisten con una relación simbiótica, en cuanto al proceso, ambas partes se modifican y se transmiten valores nuevos cada vez, acordes a un tiempo y forma de pensamiento (Niglio, Cervantes, \& Sánchez Cruz, 2015).

\subsubsection{El patrimonio como bien cultural}

Este apartado menciona hechos relevantes vinculados al concepto de bien cultural para conocer la evolución histórica de los pueblos y culturas que con el tiempo ha ido definiendo su propia identidad creencias y valores culturales precisada por una diversidad de aspectos, como su lenguaje, comportamientos y relación con otras sociedades, sus costumbres cotidianas y religiosas. Estos son elementos propios de su identidad cultural de carácter inmaterial y perteneciente a una colectividad donde el monumento histórico ${ }^{1}$ adquiere el papel de objeto físico representativo de estos valores intangibles insustituibles de elevado valor simbólico que resume la esencia de la cultura a la que representa que en la actualidad. De este modo a mediados del siglo XX, se destaca la necesidad crear un nuevo concepto que integre todos los objetos culturales, dando lugar al llamado bien cultural, ${ }^{2}$ el cual comprende cualquier manifestación significativa o indicios de cultura humana, obras de arte,

\footnotetext{
${ }^{1}$ Hay que recordar que el reconocimiento del monumento como objeto representativo de los valores de una cultura ha sido un proceso prolongado que culminó en el siglo XIX.

${ }^{2}$ Como sinónimo de este nuevo concepto, también se utilizan otras expresiones como "Patrimonio Cultural" o "Patrimonio Histórico".
} 
antigüedades o documentos históricos ahora inmersos en este nuevo concepto de carácter global (González \& Varas Ibañez, 2006)

El especial interés por los signos de la presencia y actividad humana tuvo auge en la segunda mitad del siglo XX por el valor insustituible que poseen para definir la cultura de un sitio en cualquier parte del mundo considerado como un "bien" al que hay que conservar y salvaguardar. Cabe señalar que el origen del concepto es posterior a la Segunda Guerra Mundial, principalmente en los países tercermundistas quienes iniciaron la búsqueda de su propia identidad cultural, para lo que fue necesario ampliar el concepto incluyendo en él objetos y comportamientos culturales hallados hasta ese momento, donde la historiografía tradicional centraba su interés en los monumentos históricos vulnerables a aquellos conflictos bélicos de la historia mundial. La convención de La Haya ${ }^{3}$ de 1954 fue el primer documento oficial en incluir el término, que posteriormente ha sido utilizado en principios, cartas y normas de carácter internacional, nacional, regional y local. Más tarde en 1964, el ministro de intervención pública del parlamento italiano, en la "Comisión d'idagine per la tutela e la valorizazzione del patrimonio storico, artístico e del paesaggio"4, categoriza y define el "Bien Cultural" como "todo bien que constituya un testimonio material dotado de valor de civilización" (González \& Varas Ibañez, 2006).

\section{Las categorías de bienes culturales}

La clasificación de bien cultural en tres categorías fue proporcionada por la convención de La Haya (1954) (González \& Varas Ibañez, 2006). La primera, corresponde a los bienes muebles e inmuebles de gran importancia para el patrimonio cultural de los pueblos; la segunda, comprende los edificios cuyo destino principal es conservar los bienes culturales muebles; y, por último, en la tercera categoría se incluye a los centros que contienen un número considerable de bienes culturales. Este concepto es reconocido por la UNESCO y

\footnotetext{
${ }^{3}$ Convención convocada por la UNESCO y conocida también como convención para la protección de los "Bienes Culturales" en caso de conflicto armado.

${ }^{4}$ Conocida como "Comisión Franceschini por el nombre del representante que desarrollo los trabajos entre 1964 y 1967.
} 
utilizado desde la Convención de $1972^{5}$ considerando los objetos culturales como ciudades, monumentos, conjuntos o lugares históricos u obras excepcionales como testimonios irremplazables cuya pérdida empobrecería a la humanidad y establece la división de los bienes que integran el patrimonio mundial en culturales y naturales.

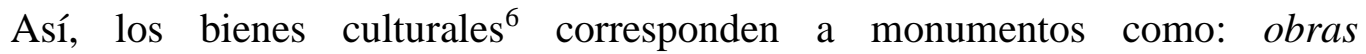
arquitectónicas, de escultura o pinturas monumentales, elementos o estructuras de carácter arqueológico, y grupos de elementos; así como los grupos de construcciones aisladas o reunidas, arquitectura, unidad e integración en el paisaje, todo lo anterior con un valor universal excepcional desde el punto de vista de la historia, del arte o de la ciencia (UNESCO, Convención sobre la protección del patrimonio mundial, cultural y natural, 1972). También se consideran: obras de arte y obras conjuntas del hombre y de la naturaleza, así como las zonas arqueológicas, que tengan un valor excepcional desde el punto de vista histórico, estético, etnológico o antropológico” (UNESCO, Convención sobre la protección del patrimonio mundial, cultural y natural, 1972, págs. 1-16).

No obstante, la "Comisión Franceschini” establece las categorías del patrimonio cultural que incluye como elementos a los bienes ambientales o paisajísticos que circunscriben todas las áreas naturales de carácter geográfico y ecológico y aquellos que legitiman una transformación por el hombre del medio ambiente natural, es decir, los paisajes artificiales (ver Fig. 2) (González \& Varas Ibañez, 2006). De igual forma destacan los bienes urbanísticos constituidos por estructuras de asentamientos en cuanto a testimonios vivos de civilización, lo que hoy llamamos centros o conjuntos históricos.

\footnotetext{
${ }^{5}$ La Convención sobre la protección del patrimonio mundial, cultural y natural, es adoptada en conferencia general por la UNESCO en 1972 y tiene como misión definir el patrimonio mundial, tanto cultural como natural. ${ }^{6}$ Convención sobre la protección del patrimonio mundial, cultural y natural, adoptada en Conferencia General de la Organización de las Naciones Unidas para la Educación, la Ciencia y la Cultura, en su 17 a reunión celebrada en Paris del 17 de octubre al 21 de noviembre de 1972.
} 


\section{Esquema de las categorías de bienes culturales según los informes de la Comisión Franceschini (1964-1967)}

\begin{abstract}
Bienes culturales (patrimonio cultural):

"Pertenecen

al

patrimonio cultural de

la nación los bienes que hagan referencia a la historia de la civilización. Están sujetos a la ley los bienes de interés arqueológico,

Histórico, artístico, ambiental $\quad \mathrm{y}$ paisajístico,

archivístico o librario y todo otro bien que constituya testimonio material dotado de valor de civilización".
\end{abstract}

Bienes arqueológicos: "Se entienden por bienes arqueológicos, a los fines de la ley independientemente de su mérito artístico, las cosas inmuebles y muebles que constituyan testimonio histórico de épocas de civilización, de centros y asentamientos cuyo conocimiento se realiza prominentemente a través de excavaciones y hallazgos".

Bienes artísticos e históricos: “...son bienes culturales de interés artístico o histórico las cosas muebles o inmuebles de singular valor, excepción o representatividad, que tengan relación con la historia cultural de la humanidad".

\section{Bienes ambientales:}

"Se consideran bienes culturales ambientales las zonas corográficas que constituyan paisajes, naturales 0 transformados por la obra del hombre, y las zonas delimitadas que constituyan estructuras de asentamientos urbanos y no urbanos, que, presentando particular valor por sus valores de civilización, deben ser conservados para el disfrute de la colectividad".

\section{Bienes paisajísticos:}

“... bienes específicamente naturales como las zonas territoriales en estado de naturaleza, que tengan carácter geográfico o ecológico unitario y de relevante interés para la historia natural y aquellos bienes culturales que documenten una transformación cívica del ambiente natural por obra del hombre".

\section{Bienes urbanísticos:}

“... bienes constituidos por estructuras de asentamientos de particular valor, en cuanto testimonios vivos de la civilización en las varias manifestaciones de la historia humana".
-ÁREAS

NATURALES

-ÁREAS

ECOLOGICAS

-PAISAJES

ARTIFICIALES

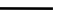


Posteriormente la Secretaría de la Convención del Patrimonio Mundial explica la inclusión conceptual de cultura y naturaleza - llamados "bienes culturales" y "sitios naturales"- por ser la identidad de los pueblos y el medio ambiente en que han evolucionado. No obstante, un “bien cultural” requiere de ciertos criterios (González \& Varas Ibañez, 2006) para incorporarse a la lista del Patrimonio Mundial, entre los que destacan la autenticidad del monumento, haber ejercido una gran influencia o aportar un testimonio único, estar asociado a ideas y creencias universales, así como, constituir un ejemplo de hábitat humano tradicional y representativo de una cultura. En la actualidad la lista del Patrimonio Mundial es amplia y varios países han firmado la convención de 1972.

En México su vasto patrimonio conforma el testimonio de la identidad de sus culturas asentadas en este territorio; colocándolo entre los primeros diez países con más declaraciones patrimonio cultural en el mundo después de España, Italia, China, Alemania, Francia, Inglaterra y la India. Por esta razón, en el en el año 1897 se promulga la primera ley relativa a los Monumentos Arqueológicos en donde se establece que son propiedad de la nación (Bolfy, 2001, págs. 87-89). Más tarde y con el fin de conservar y proteger el patrimonio, en 1939 se crea el Instituto Nacional de Antropología e Historia. De esta manera, la legislación vigente en México se rige por la Ley Federal sobre Monumentos y Zonas Arqueológicas, Artísticos e Históricos, publicada en el Diario Oficial de la Federación en el año1972. Asimismo, menciona que aquellos propietarios de bienes inmuebles declarados monumentos históricos o artísticos, deberán conservarlos y, en su caso, restaurarlos en los términos del artículo 7 de esta ley.

Esta ley no considera el concepto de "bien cultural", sin embargo, se refiere al patrimonio cultural y sus categorías, establece como monumentos arqueológicos, los bienes muebles e inmuebles, producto de culturas anteriores a la hispánica en el territorio nacional. En consecuencia, en el artículo 33, se define como monumentos artísticos los "bienes muebles e inmuebles" que registran valor estético relevante condicionado por su grado de representatividad, corriente estilística, grado de innovación, materiales y técnicas utilizadas y otras análogas. Tratándose de bienes inmuebles, podrá considerarse también su significación en el contexto urbano. Por otra parte, los monumentos históricos, se consideran los bienes vinculados con la historia de la nación. En México, los bienes muebles e inmuebles 
que tienen algún vínculo con la iglesia son de propiedad federal, por lo que dicha ley considera también los inmuebles construidos en los siglos XVI al XIX, destinados a templos, arzobispados, casas cúrales; seminarios, conventos y otros dedicados a un culto religioso. Se incluyen también los bienes muebles y obras civiles relacionados con la historia de nuestro país en México o en el extranjero.

Por otra parte, es competencia del Presidente de la República, realizar la declaratoria de Zona de Monumentos Arqueológicos, Artísticos o Históricos, en los términos de esta Ley por lo cual se considera como Zona de Monumentos Históricos a la histórica ciudad de Puebla. De esta manera, surge la Ley sobre protección y conservación de Poblaciones Típicas y Bellezas Naturales del Estado de Puebla debido a que la Ley Federal sobre Monumentos y Zonas Arqueológicas, Artísticos e Históricos de 1972, omite como ámbito de su competencia la protección de las Poblaciones Típicas y Bellezas Naturales, por lo que se debe legislar en esta materia para proteger este patrimonio cultural. Dicha ley, establece que las Poblaciones Típicas, son aquéllas de excepcional valor arquitectónico vernáculo y popular exponentes de una corriente histórica, social y cultural del arte mexicano; las poblaciones características de una región del Estado y los lugares de belleza natural que se ubiquen dentro de un municipio, o que comprendan dos o más de éstos (Gobierno, 2013).

Es importante señalar que, la diversidad conceptual de las categorías de bienes culturales se rige por una nueva cultura correspondiente que identifica los asentamientos antes y después de la conquista española. Sin embargo, la particularidad a nivel mundial consiste en reconocer los valores de identidad entre culturas, promover la conservación, protección y restauración del patrimonio histórico y cultural.

\subsection{Ciudad patrimonio y centros históricos}

En documentos internacionales, como La Haya de 1954 y la convención de 1972 se ha abordado la conservación de centros históricos, ciudad y territorio como bienes naturales. Además de aquellos como los tejidos urbanos tradicionales, el paisaje natural o agrario, por su importancia como testimonio vivo de las culturas que ahí evolucionaron. De este modo la ciudad y el territorio son lugares de máxima manifestación de la cultura ancestral, 
convivencia e intercambio cultural. Así, la ciudad, es capaz de mostrar los valores urbanísticos, valores estéticos y artísticos exhibidos en conjuntos urbanos de gran calidad ambiental debido a sus elementos arquitectónicos, estéticos y morfológicos.

Como lo menciona González Varas (2006) algunos conjuntos urbanos son resultado de la planificación proyectada mediante plazas, jardines, calles, etc., cuyo diseño no siempre se integra al conjunto de la ciudad; no obstante, también contienen valores artísticos como conjuntos urbanos no planificados. A lo anterior, hay que agregar que la integración urbanística y paisajística, dota de una singularidad potenciada por la morfología urbana que integra los valores estéticos como un conjunto histórico. Ante las diferencias encontramos también una gran variedad de características que distinguen a los conjuntos urbanos y que González Varas, clasifica en tres grupos (González \& Varas Ibañez, 2006):

- Ciudades no habitadas, de gran testimonio arqueológico, cuyo estado de conservación fácil de controlar; en México se identifican ciudades como Teotihuacán.

- Ciudades históricas habitadas, se detectan ciclos evolutivos estratificados bajo la influencia de cambios socioeconómicos y culturales con difícil actuación política para equilibrar la exigencia de conservación del patrimonio cultural y urbano; esto sucede en las ciudades con un nombramiento como patrimonio mundial.

- Ciudades y metrópolis modernas del siglo XX, en donde se percibe una organización urbana de autenticidad y al mismo tiempo de un futuro incierto a causa del desarrollo incontrolable, son ciudades que tienen como papel principal el de motor de la economía mundial, tales como Chicago, New York, Brasilia, etc. De acuerdo con su contexto y características abordan de manera específica las estrategias de conservación que cuiden la autenticidad y rescate de los valores históricos, artísticos y culturales.

No hay que olvidar que, en las ciudades históricas, permanece el significado cultural reflejado en las formas de asentamiento y utilización del espacio, en donde se cumplen acciones económicas, de servicios y de vivienda. De esta manera, conservar su patrimonio histórico resulta complicado al estar condicionada por la situación económica, por lo que se deben seleccionar los métodos de intervención que integren los avances tecnológicos al introducir nuevos elementos, así como los fenómenos de expansión urbana a que son 
sometidas. Es importante identificar que estas acciones pueden provocar un proceso de gentrificación, que al ser visible en diferentes países requiere de la atención necesaria.

En este sentido, el centro histórico es el elemento más relevante y resentido en la ciudad industrial, donde la vivienda era solo una mínima parte de las funciones desarrollaban en la ciudad preindustrial, lo que explica la riqueza reflejada en los espacios públicos y plazas, así como otros elementos morfológicos que las (González \& Varas Ibañez, 2006). Así, la relación conceptual y enfoque del patrimonio en este periodo considera al centro histórico como bien cultural, al considerarse también como un bien económico. El resultado es la integración de la problemática de los centros históricos en una perspectiva global, donde la conservación de los valores culturales se asocia a una discusión de carácter socioeconómico; la conservación y el mantenimiento de su tejido social original se plantea como una alternativa que implica decisiones políticas sobre las funciones atribuidas al centro histórico y la utilización de su patrimonio arquitectónico-residencial, es decir, prácticas de vivienda como una estrategia para la conservación de este y de sus valores culturales dentro del proceso general de expansión y transformación urbana.

\subsubsection{Centros históricos ¿לherencia del pasado o construcción del presente?}

Los instrumentos de planificación urbana en México desde 1970, manifiestan una clara necesidad por controlar un crecimiento actual y futuro de las ciudades, pero es a partir de la década de los años 80, cuando las políticas urbanas presentan un cambio significativo, al incorporar aspectos de manera particular sobre aquellas ciudades, que, por su origen novohispano, contaban con un patrimonio edificado de gran valor cultural y, por lo tanto, de un potencial turístico (Espinoza, 2005). A ciudades como Morelia, Guanajuato, Puebla, Querétaro, San Luís Potosí, Ciudad de México y Guadalajara se les denomina "ciudades coloniales", cuya característica corresponde a una estructura mono céntrica sede de los poderes político, religioso y económico (establecimientos comerciales y de servicios), además de una alta densidad de edificaciones de valor patrimonial histórico y artístico de los

siglos XVIII, XIX y XX; así como un entramado urbano que aún mantiene características formales correspondientes al momento de la fundación (Espinoza, 2005). A partir de 1980 
estas políticas comienzan a redefinir a los centros urbanos como históricos y son objeto de acciones de rehabilitación, rescate, renovación y demás términos alusivos a un interés primordial: las intervenciones sobre estos están en virtud de coincidir, en México con el centro urbano y tienen un impacto significativo sobre la estructura urbana en general (Espinoza, 2005).

\section{Origen del esquema mono céntrico}

Desde el momento de su fundación, las ciudades coloniales, muestran un mismo proceso de crecimiento y desarrollo, correspondiente a su traza con un espacio centra plaza. Posteriormente, se va dando la conformación de pueblos de indios cercanos a la ciudad, que eran necesarios para su servicio, que con el paso del tiempo propiciarían la extensión del núcleo fundacional virreinal al convertirse en barrios. Por otro lado, también surgen las “colonias" a principios del siglo XIX y la primera mitad del XX, en donde a diferencia de los barrios, estas se caracterizan por el predominante uso habitacional. Posterior a las colonias surge el desarrollo de "fraccionamientos", que, a diferencia de la etapa anterior, además de los usos habitacionales generaron áreas comerciales (Lopez E. y Ibarra, 1996, págs. 29-35).

\subsubsection{El proceso de transformación en los centros urbanos}

El proceso de segregación socio espacial, incentivado con el surgimiento de las colonias, ocasiono que algunos habitantes de los centros urbanos prefirieran cambiar su residencia hacia las nuevas colonias (Espinoza, 2005). Otra consecuencia, fue el inicio de un proceso de deterioro espacial y funcional, ya que el desplazamiento de los grupos económicamente más poderosos, hacia nuevas áreas de crecimiento, re-orienta las inversiones pública y privada fuera de la zona centro (Espinoza, 2005). Este desinterés por las zonas centrales, pese a la disponibilidad de infraestructura y equipamiento, llevó a considerarlos como nodos conflictivos para la integración funcional de la "nueva ciudad" del siglo XX; situación que se nota claramente en los planteamientos urbanísticos que consideraron libramientos viales o circuitos periféricos que garantizaban la integración de las nuevas áreas de crecimiento sin

tener que circular por los centros urbanos (Espinoza, 2005). De esta manera, el cambio en los patrones de movilidad de la población y la progresiva construcción de colonias y 
fraccionamientos demandó la conformación de nuevas de zonas comerciales y de servicios. (Espinoza, 2005).

\subsubsection{El cambio de paradigma sobre el patrimonio edificado}

En México, la conservación del patrimonio inició con un criterio temporal que privilegió la conservación del patrimonio arqueológico (Florescano, 1980) de ahí, fue evolucionando desde la inclusión de valores artísticos y monumentales, hasta llegar al interés patrimonial, en función de aquello que se identifica como testimonio de la cultura y que encuentra su concreción material más acabada en los contextos urbano-arquitectónicos denominados centros históricos, que representa la conjunción de edificaciones que datan del siglo XVII al XX (Espinoza, 2005).

Es preciso mencionar que la estructura urbano-arquitectónica en la zona centro de las ciudades coloniales, presenta innumerables adecuaciones y transformaciones producto de la demanda por albergar aquellos establecimientos como oficinas administrativas de gobierno, equipamientos de abasto, educación, salud, etc. (Espinoza, 2005)

El cambio de paradigma en el ámbito de la restauración en México enfrentó una serie de obstáculos para su materialización en los instrumentos legales; ya que, desde 1960 da inicio la preocupación por parte del Estado de conservarlos y restaurarlos (Lombrado, 1997). En consecuencia, de la reunión del ICOMOS celebrada en Gubbio, Italia, esta nueva visión, demandaba pasar de los tradicionales procesos de catalogación y declaratorias de inmuebles relevantes, a declaratorias de zonas de monumentos considerando aspectos de restauración en los instrumentos de planificación y administración urbana (Espinoza, 2005).

Hacia finales de la década de 1980, surge la necesidad de instrumentar acciones e intervenciones sobre los centros urbanos, tendientes a revalorizar el patrimonio histórico existente, dando origen a un sinnúmero de planteamiento urbanos, que eran definidos bajo connotaciones de rescate, rehabilitación, renovación, reactivación o cualquier otro calificativo referente a la conservación del patrimonio edificado, que además de manifestar propuestas conceptuales y metodológicas distintas, evidenciaban intereses diversos sobre el 
aprovechamiento del patrimonio urbano-arquitectónico (Espinoza, 2005). Sin embargo, resulta incuestionable el hecho de aceptar que los centros históricos, son, antes que nada, centros urbanos y por lo tanto se encuentran sujetos a procesos de transformación, por lo tanto, insistir en su carácter histórico se asume bajo dos vertientes distintas: como una iniciativa, que propicia un final a dicha transformación por considerar que atenta contra la conservación del patrimonio; o en su caso asumiendo su transformación, donde privilegiar la conservación del patrimonio urbano-arquitectónico sólo constituye otra acción tendiente a lograr la vigencia dentro de la estructura urbana actual, pero ahora ya no en términos comerciales o administrativos, sino turísticos y culturales (Espinoza, 2005).

\section{Los centros históricos, asentamientos humanos vivos}

Reiterando a los centros históricos, "como todos aquellos asentamientos humanos vivos, fuertemente condicionados por una estructura física proveniente del pasado" (Hardoy \& R. Dos Santos, 1983) en el caso de las ciudades mexicanas, privilegiar el carácter histórico de su estructura urbano-arquitectónica, permite identificar tres aspectos relevantes:

I. Carácter temporal, incentivado por las investigaciones históricas donde el carácter artístico sobre la historia de la ciudad presenta a los centros históricos como la culminación de un proceso. Un ejemplo, es el interés observable por recrear un ambiente de otras épocas, a través de vehículos para el recorrido turístico que simulan los tranvías utilizados en dicha época, del siglo XX (Espinoza, 2005).

II. Intensidad de uso, en el caso mexicano predomina el uso excesivo de inmuebles, que atenta contra la conservación del patrimonio edificado. Bajo este principio, se busca garantizar su conservación a partir de la reubicación de equipamientos públicos como oficinas administrativas y centrales de transporte que provocan un uso intensivo de las zonas centrales, lo cual atenta contra su esencia de centralidad, "basada por la concentración de actividades administrativas, económicas, religiosas y simbólicas” (Castells, 1974). 
Los factores anteriores, no sólo aíslan, delimitan y caracterizan a los centros urbanos bajo un enfoque histórico-patrimonial, sino que además construyen un nuevo elemento dentro de la estructura urbana de las ciudades y permiten afirmar que privilegiar su carácter histórico, demanda en principio, disgregar los factores de centralidad. En este sentido, el concepto contemporáneo de centro histórico, permite ubicarlo más como una creación del presente (Espinoza, 2005). Si se acepta este concepto, como elemento contemporáneo dentro de la estructura urbana de la ciudad novohispana, será conveniente orientar la discusión hacia sus posibles impactos e implicaciones que tiene sobre esta (Espinoza, 2005).

\subsubsection{Las políticas sobre rehabilitación de los centros históricos: hacia un nuevo modelo de ciudad}

Actualmente, Espinoza (2005) identifica las políticas de rehabilitación en los distintos niveles de gobierno como principal prioridad a las zonas históricas, imprescindibles dentro de la estructura urbana. En este contexto se destaca que:

"La dinámica turística sobre los centros históricos, es previsible que llegue a propiciar una interrelación a nivel regional e incluso internacional, con centros históricos de otras ciudades, de hecho, en las ciudades de Morelia, Guanajuato y Querétaro cada vez se presentan más acciones de promoción turística en conjunto bajo el esquema de complementariedad y no competencia como tradicionalmente se venía presentando. Sin embargo, el reto consiste en la búsqueda constante de un equilibrio "interno" de la ciudad. Conviene señalar que la generación de una nueva estructura de ciudad basada consciente, o inconscientemente en un interés por participar de la dinámica global del turismo cultural, resulta altamente riesgosa para la dinámica socioeconómica del país en general y de los centros históricos en particular” (Espinoza, 2005, págs. 2-3).

\section{Hacia un nuevo modelo de ciudad}

Es difícil atribuir a un solo factor el cambio en la estructura urbana de cualquier ciudad o conjunto de ciudades que de manera simultánea experimentan un proceso similar de 
transición, de un esquema mono céntrico, hacia uno policéntrico (Espinoza, 2005). Es preciso señalar, que además del interés por la conservación del patrimonio urbano-arquitectónico en los centros históricos, se identifican otros factores donde se destaca el acelerado crecimiento urbano en la mayoría de las ciudades medias en México durante la década de los años 80 del siglo $\mathrm{XX}$, que sin duda estimuló las tendencias de crecimiento urbano sobre suelo agrícola. El régimen de propiedad ejidal frenaba la comercialización inmobiliaria, ocasionando el replanteamiento de esquemas de planeación urbana, en busca de disminuir la tendencia expansionista, así como alternativas de redensificación en zonas que contaban con infraestructura y servicios subutilizados (Espinoza, 2005).

El deterioro en las finanzas nacionales es otro factor causante de la crisis económica acontecida a mediados de la década de 1980, obligando al gobierno y los habitantes a realizar inversiones con mayor rentabilidad, revalorizando así zonas de la ciudad que contaban con servicios, equipamientos e infraestructura y que por alguna razón se consideraban subutilizadas, como los centros históricos (Espinoza, 2005),

Durante la misma década, a nivel mundial se observó un progreso en el ámbito del turismo cultural, siendo un detonador determinante la inscripción de algunos "centros y conjuntos Históricos" en la lista del Patrimonio Mundial de la UNESCO, en donde de 24 sitios en México, más del 40\% son centros históricos y zonas de monumentos como Puebla, Morelia, Oaxaca, Zacatecas y Querétaro (Espinoza, 2005). De este modo se revalorizan y adquieren relevancia los centros históricos, como escenario de un nuevo esquema de ciudad, en términos funcionales, debido a la descentralización de actividades hacia otras zonas en el caso de los equipamientos político-administrativos o económico-financieros y demás establecimientos que parecen considerarse incompatibles con el modelo de centro histórico. En la mayoría de los centros históricos, las acciones urbanas consideraban la reubicación de estos equipamientos con la finalidad de disminuir su intensidad de uso (Espinoza, 2005).

En este sentido, los instrumentos de planeación urbana en México ilustran de forma objetiva lo anterior; los primeros Programas de Desarrollo Urbano de ciudades de origen novohispano, realizados hasta mediados de 1980, no contemplaban acciones particulares sobre los centros urbanos. Las propuestas se limitaban a considerar uno o dos sub-centros urbanos, definidos por el propio crecimiento de la ciudad dependiendo de su 
tamaño, reconociendo su papel como sustento nodal de la estructura urbana. Espinoza (2005), identificó dos modificaciones en los instrumentos de planeación sobre centros históricos: 1) una zonificación primaria que integra la propuesta de varios sub-centros urbanos (incluso de carácter metropolitano) comerciales o administrativos que se pretenden realizar o reubicar en determinadas zonas; 2) conformar un esquema de ciudad policéntrica basada en una centralidad exclusivamente histórica y simbólica del centro urbano (Espinoza, 2005).

De este modo, los aspectos anteriores conllevan a una serie de implicaciones sociales, como la reubicación, ante el interés por disminuir la intensidad habitacional del centro histórico. Esta situación daría paso a la conservación del patrimonio edificado, al promover su inclusión a la dinámica global del turismo cultural, siendo clave el factor histórico para el aprovechamiento del patrimonio cultural (Espinoza, 2005).

Sin embargo, entre las acciones de intervención, se identifica un doble discurso a partir de los posibles efectos negativos. Por un lado, está la preocupación de mantener una dinámica social característica de las zonas centrales que incluye vivienda para cualquier nivel económico; y, por otro lado, en el ámbito de la planeación se han buscado referencias, pero no existen modelos ideales específicos de vivienda dentro de la rehabilitación de los centros históricos, dado que, según Espinoza (2005), más que estrategias urbanas, su éxito radica en los procesos administrativos mediante los cuales se realizan las acciones. Entre los principales retos del nuevo proceso de descentralización, destaca la relación entre el uso y el disfrute del patrimonio cultural edificado por parte de los habitantes de la ciudad, en donde se deberá mejorar dicha relación trabajando de manera coordinada e integral la rehabilitación urbana, social y económica de los centros históricos.

1.3. El turismo cultural como factor de transformación de la ciudad histórica

\subsubsection{El turismo y su relación con el patrimonio cultural}

En la actualidad, el ocio cultural forma parte de los aspectos más importantes en las ciudades históricas, al mismo tiempo que el turismo cultural, ha ido adquiriendo jerarquía en el sector 
turístico (Blanco A. , pág. 169), mediante un incremento de visitantes a destinos culturales. En Europa, entre las décadas de 1970 a 1990 registró un aumento del 100\% (Herrero, 2011), por lo que la Organización Mundial de Turismo (OMT) reconoció la relevancia que los viajes culturales tomaron a nivel mundial. De esta manera se ven reflejadas nuevas inquietudes del turismo por la cultura como el elemento más relevante en el desarrollo de las economías. En este ámbito y como consecuencia, se hace presente el concepto de mercantilización de la cultura, como un fenómeno orientado hacia un consumo cultural, que si no está bien orientado por medio de políticas culturales puede contribuir a la degradación y perdida del patrimonio.

Así, el patrimonio cultural presenta dos principales tendencias en su utilización como recurso turístico, por un lado, se promueve su uso intentando proteger y conservar los valores de identidad de los pueblos y sus culturas; y por el otro, se entiende como una fuente de riqueza que fortalece la economía a través de los productos turísticos de las ciudades históricas. De este modo este fenómeno incentiva la modalidad del turismo cultural que los promotores turísticos han aprovechado como elemento de la oferta-demanda derivada de la curiosidad del visitante por conocer la historia de los pueblos y las distintas culturas donde la oferta se rige por los atractivos culturales de la región y el comportamiento económico de los gastos derivados. La explicación que nos da Herrero (2011) acerca de la evolución que ha tenido el turismo cultural, parte del interés por las cuestiones culturales denominado "postmodernismo cultural contemporáneo". Dicha evolución se produce a partir de la búsqueda de la autenticidad en el pasado y en consecuencia se incita la recuperación y valoración del legado patrimonial, a través de fenómenos como "la moda etnográfica y la arquitectura industrial" que impulsan una demanda que va acompañada de nuevos atractivos culturales y productos turísticos, en los que una de las principales características es que no existe una línea única de consumo turístico cultural ya que destacan mercados fraccionados y productos diversos.

En este contexto se origina también la comercialización de la cultura, donde las ofertas se realizan a través de su propia exhibición y posibilidades de atracción, lo que explica la transformación de los usos del suelo y la readaptación de edificios que pierden su funcionalidad habitacional por su capacidad de atracción y exposición, aunado al interés 
artístico del propio edificio. Por otro lado, el apogeo del turismo cultural se relaciona, según Herrero (2011), a la aparición de nuevas clases medias distinguidas por su estatus social reflejado en las actividades cotidianas como son las educativas, de ocupación y de consumo de mercancías. Otra característica del postmodernismo cultural es la valorización que alcanzan las localidades y las regiones donde se ubican los bienes patrimoniales a través de lo cual se justifica el elevado nivel de desarrollo cultural y económico. De esta forma entre los agentes que más aportan al desarrollo del turismo cultural, destacan la recuperación y puesta en valor del legado patrimonial, sin importar donde se ubique este ni a qué cultura pertenezca, al tiempo que genera estabilidad y diversidad a la economía local.

Por otro lado, si bien es cierto que el turismo cultural incrementa el interés de los promotores turísticos, -el turismo en sí mismo es un fenómeno transversal capaz de impulsar las economías-. También, con el afán de buscar el mayor aprovechamiento, en ocasiones exceden la sobreutilización de los recursos y más aún si no se cuenta con los planes, programas y políticas correspondientes o se establecen las limitantes físicas, espaciales y temporales en protección del patrimonio cultural. Por lo tanto, Herrero considera necesario racionalizar el turismo cultural, así como los atractivos turísticos, siendo un claro ejemplo Europa donde se incrementa cada vez más la afluencia turística en los principales destinos culturales que en actualidad puede representar un riesgo. No hay que olvidar el perfil de visitantes vinculados directamente al turismo cultural y que además incide en la concentración detectada hacia determinados productos culturales, en donde sobresalen los turistas "ocasionales" que solo dedican parte de su tiempo a esta categoría turística y los "específicos" que viajan con la intención de concentrar su viaje en el motivo cultural.

Es así como el turismo cultural además de ser una categoría del sector turístico también surge como una opción de consumo cultural que adquiere importancia tanto en la gestión como en la promoción y comercialización de los recursos culturales incrementando también los flujos económicos y turísticos de las regiones. Sin embargo, para lograr el total aprovechamiento del potencial que presenta el turismo cultural, es necesario acompañarle de nuevas propuestas y estrategias en las ciudades, poblados y barrios históricos con el propósito lograr un equilibrio económico, social y ambiental en beneficio de la población residente. 


\section{Principales elementos del patrimonio y turismo cultural}

Una de las principales características del turismo cultural es su presencia en grupo o individual ${ }^{7}$, lo que demanda una renovación y conservación constante de elementos como la accesibilidad, la infraestructura y el paisaje urbano. En este sentido se requiere promover, actualizar y gestionar sus productos turísticos ya sean patrimoniales o turístico-culturales. Por lo tanto, "el turismo cultural es una actividad productiva, implicada cada vez más en la economía local de las ciudades históricas"; es por ello que se considera a los valores históricos, culturales y medioambientales, como recursos estratégicos de las ciudades históricas y que a medida que pasa el tiempo van tomando más importancia por su capacidad de integración y aprovechamiento como recursos turísticos culturales (Troitiño Vinuesa, 1996, pág. 34). En este sentido, la relación cada vez más dinámica entre patrimonio y turismo cultural, se convierte en un tema complejo que implica la realización de estudios e investigaciones concretas para conocer su situación y planear su desarrollo, lo cual requiere claridad de los conceptos vinculados. Por esta razón, se han identificado los componentes del patrimonio cultural, su evolución e importante trascendencia en el ámbito internacional y nacional.

\subsubsection{Patrimonio, turismo cultural y recuperación urbana}

Es así como el patrimonio cultural uno de los recursos económicos potenciales de las ciudades históricas para los gobiernos a través del tiempo, siendo rentabilizado con este fin. Así mismo, la valoración de la identidad cultural que proyecta el patrimonio urbanoarquitectónico es uno de los recursos que ofrecen mayores acciones de restauración y consolidación-en diversas escalas-, logrando desarrollar equipamientos turísticos culturales que han tenido una importante aportación a la economía local. No obstante, no existe un control en el cambio de usos del suelo que incide negativamente en el uso habitacional. En este contexto, algunas empresas hoteleras apoyan a la conservación y restauración de

\footnotetext{
${ }^{7}$ En Europa, existe una relación estrecha entre los viajes de turismo urbano y los llamados de fin de semana o en ruta, consecuencia del precio accesible y la proximidad entre ciudades junto con la situación de que los viajes de 15 días o más son excesivamente caros para el turismo en general; por estos efectos es que se ven reducidos los viajes por motivos culturales y patrimoniales a menos de dos noches de pernoctación, salvo que surjan eventos de interés para el visitante.
} 
inmuebles históricos donde se ubican, y su valor agregado consiste en ofertar a los turistas una estancia más agradable en un entorno histórico que se convierte en un elemento de atracción. Cabe resaltar que, si bien recupera y mejora el inmueble, el contexto donde se inserta también cambia en función de las nuevas necesidades del turismo transformando tanto la imagen de la ciudad histórica como su identidad.

Con este argumento, la cultura se percibe como un factor de desarrollo para las ciudades históricas, mientras que las administraciones promueven que el inmueble produzca sus propios recursos para su sostenibilidad. Así, los bienes culturales han pasado de ser únicamente el patrimonio de las ciudades históricas a ser un recurso estratégico para el desarrollo de su economía. Por lo general los países que destacan por su patrimonio, cuentan con iniciativas generales de protección y conservación, sin embargo, corresponde a las administraciones locales elaborar estrategias e implementar de manera coordinada acciones y que atiendan problemáticas referentes al patrimonio, como tráfico vehicular, contaminación, equipamiento turístico y urbano, así como otros aspectos sociales como desempleo, inseguridad y marginación social (De la Calle Vaquero \& García Hernández, 2016).

Esta situación muestra que, nos son suficientes las iniciativas sectoriales existentes, puesto que las ciudades requieren de estrategias y políticas económicas y urbanas más coherentes respecto al impacto del turismo cultural, lo cual requiere de la participación de las diferentes instancias administrativas encargadas de planificar el desarrollo de la ciudad incluyendo los aspectos en materia de patrimonio, turismo y desarrollo urbano.

\subsubsection{El centro histórico, patrimonio tradicional y las infraestructuras modernas}

Se pueden regular los productos turísticos sin sobrepasar los límites de su capacidad, de manera que no altere el contexto donde se ubica. De este modo pueden permanecer las actividades turísticas que promuevan y fomenten la admiración y conservación del patrimonio, inculcando tanto a turistas como residentes el aprovechamiento de este, sin caer 
en su degradación. La relación turismo-ciudad tiende a ser más estrecha cuando se unen dos factores como el patrimonio y la cultura; por ello cuando nos referimos a turismo cultural es difícil concebir el uno sin el otro en las ciudades históricas, en donde quedan explicitas las características cualitativas de identidad y tradición (Marchena Gómez \& Repiso Rubio, 1999, pág. 40). De esta forma, un indicativo en las ciudades históricas, serán las tipologías turísticas y la manera en que inciden en la economía y sociedad local, por lo que, hay que contribuir por medio de estudios del desarrollo del turismo cultural y las inversiones de infraestructura urbanística y turística que basa su desarrollo en elementos culturales y patrimoniales, sin convertirlos solo en productos rentables para la economía de las ciudades históricas.

\section{El centro histórico como potente patrimonio cultural y su utilización como recurso turístico.}

Actualmente los centros históricos concentran una gran cantidad de usos, actividades y funciones que, a través del tiempo, han jugado un papel muy importante en el desarrollo de la vida urbana de la ciudad. Hoy por hoy, es el lugar donde se reúne el patrimonio arquitectónico y urbanístico que ha conducido su valoración por ser parte de su riqueza cultural acompañada de su identidad, que siendo bien aprovechados pueden dar lugar a nuevas actividades en torno a la vivienda.

No obstante, recientes acciones enfocadas al turismo muestran un alto grado de interés por parte del gobierno y del sector inmobiliario dando como resultado la preocupación de los gestores culturales, quienes realmente buscan incidir o promover políticas de protección y conservación de su patrimonio cultural material e inmaterial. En este contexto es necesario conocer la problemática actual que presentan los conjuntos históricos, que bien puede estar encaminada a la disminución o pérdida de las funciones que ahí se desarrollan. De este modo será más fácil para los tomadores de decisiones abordar y proponer acciones concretas de recuperación y revitalización de los elementos arquitectónicos y urbanísticos que remitan la tendencia hacia una ciudad sostenible (Troitiño Vinuesa, 1996, págs. 9-29). Así, habremos de recuperar los centros históricos integrándolos como un vínculo entre la cultura y sociedad, intentando proyectar una realidad equilibrada entre la antigua y nueva ciudad con relación a sus elementos y valores funcionales culturales, sociales y urbanísticos. 
Sin duda, el centro histórico no debe verse solo como un recurso económico por todo el patrimonio que cobija, sino como un símbolo cultural representativo de los valores ancestrales, ubicándolo como un recurso potente y diverso, aprovechado de forma consiente por el sector turístico. En este sentido, como ya lo indica Troitiño (1996), el patrimonio cultural tiende a ser un recurso importante que debe tomarse en cuenta en los instrumentos de planificación respetando sus características éticas y culturales y elaborando estrategias de protección y recuperación urbana.

Cabe resaltar que el turismo es una actividad que va tomando fuerza, por este motivo, se requiere de una constante actualización de políticas y estrategias económicas, culturales y sociales, para la utilización, conservación y preservación de estos recursos arquitectónicos y urbanísticos. Sin embargo, no hay que olvidar que el turismo conduce importantes cambios en las ciudades históricas, de manera que, si no se tiene la suficiente visión para dirigir y regular dichas políticas de manera responsable, estos cambios pueden generar nuevas problemáticas identificadas por Troitiño (1996) como el abandono residencial, la terciarización o crisis del comercio tradicional.

En muchas ciudades históricas, el turismo ha adquirido tal relevancia que es considerado uno de los motores de la transformación de la realidad urbanística, económica y social, es decir, de la vida urbana (Troitiño Vinuesa, 1996, pág. 18); tomando en cuenta estas consideraciones, los instrumentos creados para el desarrollo económico y social de la ciudad, deberán introducir estrategias concretas para la promoción y gestión del patrimonio cultural.

\subsubsection{El turismo cultural como factor de valoración o degradación del patrimonio}

En términos generales, podemos decir que las ciudades históricas, cuentan con un capital cultural - compuesto por su patrimonio a través del cual se han creado productos turísticosque, a través de políticas de protección y rescate del patrimonio cultural, así como de las funciones de comercialización y valoración de los productos turísticos y servicios que con él se relacionan, lo pueden convertir en una fuente de riqueza (Blanco A. ). Por lo anterior, es imprescindible la colaboración conjunta de los gestores públicos en acciones de coordinación 
y provisión, con los agentes privados que proporcionen iniciativas desde el punto de vista empresarial para el sector cultural.

En este sentido, la política cultural, pretende proteger y conservar los recursos culturales y el desarrollo turístico por su fragilidad y carácter no renovable que presentan. De este modo, se hace necesario plantear estudios de viabilidad y regulación de usos mixtos que permitan la revitalización y reutilización de inmuebles para contribuir a la captación de recursos que por un lado permitirán su autofinanciación, mantenimiento, protección y conservación, y por el otro sea utilizado como un recurso económico que aporte su contribución a la economía del lugar garantizando la habitabilidad. Finalmente, la gestión de los recursos culturales puede presentar limitantes derivados del tipo de inversión sea esta pública o mixta; de igual forma son importantes también los recursos humanos y profesionales, así como los de formación de gestores del patrimonio cultural. Por último, otra limitante es la falta de colaboración y coordinación entre los tres niveles de gobierno federal, estatal y municipal.

\section{El turismo y el patrimonio cultural y urbanístico}

El turismo cultural ha alcanzado gran importancia en las dos últimas décadas, al tomarse en cuenta como un factor más del desarrollo de las ciudades históricas por ser poseedoras de un valioso patrimonio cultural. En consecuencia, se ha ido relacionando de manera ineludible el turismo con el territorio y la cultura, por lo que actualmente son utilizados los dos últimos como recursos para su desarrollo. Este hecho característico ha ido poniendo en riesgo no solo la protección y utilización del patrimonio y uso habitacional ante una falta de control de las nuevas políticas y espacios destinados al turismo cultural.

De este modo, el patrimonio arquitectónico y urbanístico es la base de las nuevas políticas y estrategias turísticas por la diversidad de posibilidades que ofrecen, respetando los significados y valores tangibles e intangibles. Por tanto, las políticas basadas en la promoción de los recursos culturales se vinculan a los procesos productivos de la ciudad, "la creación de empleo, innovación tecnológica y la generación de riquezas", de este modo las actividades turísticas deben tomar en cuenta factores de desarrollo económico, urbanístico, 
social y medioambiental (Troitiño Vinuesa, 1996). Uno de los beneficios de la gestión del patrimonio cultural es que puede originar la afirmación de la identidad de las culturas y continuar propagando su conocimiento, al tiempo que puede contribuir a mejorar las condiciones de vida de las sociedades poseedoras de dicho patrimonio. En Europa se diferencian cinco campos de acción vinculados a la cultura: "promoción de la identidad local, valoración del patrimonio cultural, valoración de los conocimientos especializados tradicionales, creación de infraestructuras culturales permanentes, animación y difusión cultural (Troitiño Vinuesa, 1996, pág. 12).

Las principales actividades al respecto son los programas de desarrollo local, que consisten en la renovación y rehabilitación de los pueblos como en el caso de la Sierra Norte de Madrid, avanzando en la conservación y posterior asignación de funciones al patrimonio rehabilitado; asimismo, para la valoración del patrimonio arquitectónico y urbanístico, se concretan acciones en la recuperación de inmuebles, que son acondicionados para la adaptación de infraestructuras o equipamientos habitacionales con nuevas funciones (hoteles, escuelas taller, museos, centros de negocios y comerciales, etc.). A través de estas iniciativas se ha logrado la recuperación que han significado un apoyo para la economía local. Por otra parte, cabe mencionar las amplias posibilidades de reutilización de los edificios arquitectónicos como centros culturales y de interpretación del patrimonio, contemplados para la exposición histórica local y como polos de atracción turística. (Troitiño Vinuesa, 1996, pág. 14). En este sentido son amplias las posibilidades que presentan los edificios

históricos en su reutilización para nuevas funciones junto a la vivienda en otros países, no obstante, en México obedecen solo a los intereses del sector inmobiliario.

\subsubsection{De patrimonio cultural, arquitectónico y urbanístico, a recurso turístico: problemas y limitaciones}

Para complementar el estudio del patrimonio cultural, es necesario desagregarlo a su valoración como patrimonio tangible o intangible. El primero abarca los elementos materiales del valor monumental histórico o artístico -muebles o inmuebles- desarrollado a lo largo de la vida de los pueblos, son parte del acervo patrimonial en el país y en la actualidad son fácilmente inventariados y aprovechados económicamente como productos turísticos. 
Los segundos, son más difíciles de catalogar por ser valores no materiales, sin embargo, son parte del patrimonio como simbología cultural de los valores de una ciudad o conjunto histórico. Por otro lado, este patrimonio es herencia de las culturas precursoras convirtiéndose en la historia del lugar, ya sea como parte de una forma de vida a legado y herencia de un pueblo, que se ha de mantener y admirar por futuras generaciones como testimonio de la cultura y los valores históricos que ahí se desarrollaron.

\section{Impacto en el patrimonio arquitectónico y urbanístico}

Así, la cultura es reconocida como el conjunto de modos de vida, costumbres, conocimientos, desarrollo artístico, científico e industrial de un grupo social. No obstante, desde el punto de vista económico y globalizador es en sí el patrimonio que hoy en día es capaz de generar riqueza si se utiliza como recurso turístico en las ciudades históricas, capaz de proporcionar beneficios y ventajas que permitan fortalecer su economía, convirtiéndose así en un recurso estratégico que destaca su potencial como componente de los proyectos que transforman los inmuebles con un carácter funcional orientado al comercio y servicios turísticos. Por otro lado, es indiscutible la conciencia que han tomado los habitantes de las ciudades históricas, en donde surgen dificultades de adaptación del turismo cultural debido a la asignación de usos de los edificios para restaurantes, hoteles, administración pública, educación, etc. algunas veces carente de los criterios pertinentes. También se presentan situaciones de desorganización, que contribuye a la aglomeración de los visitantes en los principales atractivos de la ciudad, lo cual limita y transgrede el potencial de las ciudades históricas.

Esta inadecuada función de los edificios históricos puede limitar su utilización habitacional, pero no hay que olvidar que el valor que alcanza es consecuencia de la vida activa de la ciudad donde se ubica, sin importar si la tutela del inmueble es pública o privada (De la Calle Vaquero \& García Hernández, 2016). De esta forma se podrá ver limitado su aprovechamiento turístico, siempre y cuando no se ponga en peligro el uso habitacional y los valores sociales y culturales que lo han catalogado como parte del conjunto patrimonial.

Partiendo de que el patrimonio en su origen tuvo un uso residencial, algunos autores coinciden en que conviene su adaptación a un nuevo uso complementario a este que al mismo 
tiempo le permita colaborar en las acciones de conservación. Algo similar sucede con el potencial del conjunto turístico de una ciudad histórica -que incluye también otros elementos de tipo urbano- siendo que se podría aprovechar para fomentar actividades cotidianas por los residentes, complementando el uso de los espacios públicos para el desarrollo de otras actividades turísticas y cultura (festivales, teatro en la calle, cine, encuentros culturales, etc.).

Como hemos visto en otros apartados, sin duda, es importante la relación entre el turismo y otros factores como el medio ambiente, el patrimonio y la cultura en las ciudades históricas. Asimismo, es importante evaluar el impacto que el turismo puede causar al patrimonio urbanístico y arquitectónico, pero la responsabilidad de preservar el patrimonio, así como de promover su correcta utilización recae también en las administraciones correspondientes, propietarios y sector inmobiliario.

Por otro lado, algo similar ocurre con el patrimonio arquitectónico que es uno de los rasgos más distintivos de las ciudades históricas por su importancia auténtica, que no solo refleja la monumentalidad de la ciudad, sino que además se vuelve el principal elemento del conjunto de estilos arquitectónicos que incluyen la arquitectura popular de sus barrios indígenas.

\section{El turismo y los valores ambientales de la ciudad histórica}

Otro elemento que se han vinculado al turismo cultural es el medio ambiente en los conjuntos históricos integrado con el patrimonio arquitectónico y urbanístico. Así mismo, en los territorios existen medios naturales a los que hay que proteger y conservar contemplados en la lista de la UNESCO. En este sentido, al igual que los bienes muebles e inmuebles, los bienes ambientales son considerados como una categoría más de los bienes culturales de los que derivan los bienes paisajísticos y urbanísticos. De este modo, para el estudio del turismo cultural es necesario considerar el medio ambiente aunado a los factores sociales y funcionales relacionados con la conservación y protección del patrimonio, para y así contribuir al desarrollo de productos turísticos de calidad y respetuosos con el medio natural y construido. Por lo tanto, se hallará indispensable vigilar por la calidad del ambiente de los centros históricos. 
Los valores históricos y culturales en los conjuntos históricos representan el patrimonio heredado por nuestros ancestros, que sin duda forman parte del medio ambiente en las ciudades históricas. La conservación de estos medios naturales y materiales junto a los componentes sociales y funcionales, incorporados adecuadamente a la vida actual de la ciudad histórica, es la causa de que presenten una mayor o menor calidad ambiental, manteniendo y respetando sus valores culturales.

\subsubsection{Los efectos del turismo en los componentes del medio ambiente y en el patrimonio}

Sin duda, el entorno es fundamental para la caracterización de las ciudades históricas puesto que es parte de ellas, al igual que los elementos naturales que le ayudan a definir su esencia medioambiental incrementando su valor. Así, de esta relación, Vinuesa (1996) ha identificado una zona de contacto de la ciudad y su entorno territorial que incrementa su valoración, sin embargo, requiere de igual o más cuidados que el patrimonio edificado, solo que, de manera integral a los entornos medioambientales de las ciudades, que, además, son frágiles y más aún cuando existe una intensa sobre utilización de estos espacios.

El grado en aumento de la relación del turismo con el medio ambiente, ha logrado diversificar la oferta en función de los intereses para los distintos destinos. Las ciudades históricas a través de su medio ambiente, aportan el testimonio histórico y cultural proveniente de las realidades naturales, morfológicas, económicas y sociales que le dotan de los rasgos distintivos específicos (Brandis García \& del Río Lafuente, 1998). Es entonces, a partir del surgimiento del turismo cultural en las ciudades históricas, donde se ha logrado su consideración por la alta valoración de sus patrimonio histórico y cultural que actualmente es preciado por los turistas. Además de que también ellos mismos han aprendido a valorar y admirar los atributos del medio ambiente que se ha convertido en parte de las características peculiares de estas ciudades. Asimismo, por la implicación económica que ha tenido el turismo cultural en las ciudades, se ha utilizado este medio como un recurso que en los últimos años aparece entre las estrategias de planes y programas turísticos. 


\subsection{Gentrificación, origen y definición del concepto}

Durante el crecimiento de las ciudades, como en todos los procesos de desarrollo, las formas de vida y las ideas evolucionan con nuevas formas de organización, que sin duda son necesarias para la época actual. Berman (1982, en Duque 2010:19), considera que el crecimiento urbano junto con los movimientos sociales masivos, se reflejan como fuentes principales de la modernidad que tuvo lugar desde los inicios de la civilización. Duque (2010:19) considera que una de las principales señales de crecimiento de las ciudades, puede ser la fractura de sus límites espaciales, provocando una modificación en la relación existente entre espacio y tiempo, generando necesidades de movilidad con transportes y traslados mayores para realizarlos; evidenciando cuestiones sociales y económicas. Cabe destacar, que solo abundaremos la transformación y permanencia de los espacios, en donde la movilidad es un factor en la evolución urbana como parte de la dinámica de desplazamientos en la ciudad. Los nuevos desarrollos que van definiendo el crecimiento y cambios de la ciudad, se definen como "movilidad residencial" en mercados locales y de vivienda; y migración si se presenta un cambio de mercado local (Susino, 2000 en Duque 2010). En este sentido, para, este estudio consideraremos la movilidad residencial que se produce dentro a causa de la gentrificación.

Habitualmente los cambios de residencia eran originados por factores de atracción o repulsión, el primero, se explica por la llegada de gente a ciertas zonas de algún modo deseadas; el segundo, por factores que involuntariamente los trasladaron a otros lugares. En la modernidad, poco se habla de la vivienda como una necesidad, por el contrario, se percibe más bien como un artículo de consumo, por lo que esta posibilidad de elección se convierte en una lucha por los espacios entre grupos sociales (Duque 2010:23). Con relación a ello, Marcuse (1994 en Duque 2010:23) habla de una ciudad dividida por las crecientes desigualdades. En ese contexto, la vivienda aumenta sus funciones y cambia su carácter, convirtiéndose en objeto de consumo y de conflictos, tomando como escenario el centro urbano cargado simbólica y culturalmente. De esta manera, la gentrificación en la intersección entre lo espacial, lo temporal y lo social, es la mejor expresión de la naturaleza

de la ciudad posmoderna que "crece encima y dentro de la vieja" (Amendola, 1997:120 en Duque 2010:24). 
Durante más de cuatro décadas, hablar de gentrificación ha sido complicado a pesar de que existe una variedad de estudios desde distintas perspectivas y escenarios. Sin embargo, con el ánimo de forjar un término que pudiera arropar los distintos procesos que se viven en las ciudades históricas más importantes, se hace inevitable hablar del origen del concepto. De acuerdo a Salinas (2013), el termino fue empleado para describir un proceso de cambio social que tuvo origen en un barrio de la ciudad de Londres (2003, en Duque 2010). El termino original surge a partir de una categoría de la estructura social-rural británica llamada la "gentry", que hace referencia a la clase social que se sitúa por debajo de la nobleza (Hamnett 2003 en Duque 2010:24). El texto de Ruth Glass (1964) en Duque (2010:24) muestra una "aparente contradicción" en la identificación de una nueva clase social urbana que nace del paso de la sociedad industrial a la postindustrial, donde el proceso de recuperación de los barrios centrales de clase obrera comenzó a percibirse de manera paulatina en las principales ciudades americanas, inglesas y escandinavas a principios de los años 60 del siglo XX. Este proceso de gentrificación continua hasta que los vecinos originarios de los barrios ocupados por la clase trabajadora, son desplazados haciendo que finalmente cambie el carácter social de estos barrios o distritos (Glass, 1964: XVIII en Duque 2010:25).

Los estudios relacionados con el concepto, coinciden en que la gentrificación es un fenómeno de clases sociales, ante la polémica de su origen, ya que inevitablemente se ve alcanzada por los debates en torno a la estructura social, destacando la superioridad de las clases medias sobre las clases más bajas (Duque 2010:26). Para otros autores (Dangschat y Felde 1992, en Duque 2010), se muestra como un cambio en la estructura social, donde se revitalizan los espacios a consecuencia de la movilización selectiva de los pobladores y por inversiones efectuadas en los espacios donde se inicia el proceso. Para Duque (2010:26), los nuevos pobladores denotan perfiles de mayor cualificación económica (parejas incluso sin hijos), en este plano, los procesos de gentrificación, presumen el rescate físico y económico del "lugar" referente a edificaciones, viviendas y contexto urbano, asumiendo un estado de degradación previo que llegar incluso al abandono (Marcuse, 1986 en Duque 2010:26). Este proceso, suele iniciarse con la renovación, recuperación o transformación de ciertos espacios urbanos, la mayoría de las veces ubicados en el centro de las ciudades. Otra forma de identificarlo es con el cambio social que se da a partir del desplazamiento de la población 
originaria y la llegada de nuevos pobladores que, además de tener un estatus socioeconómico superior, suelen tener diferentes estilos de vida y prácticas urbanas, que sin duda impactan los aspectos culturales (Duque 2010:26).

En este sentido, se produce en zonas degradadas, pero también en la transformación de fábricas o almacenes en viviendas o incluso en proyectos comerciales promovidos por particulares, o incluso bajo la atención de autoridades públicas, mediante la interrelación de factores económicos, sociales y culturales (Clay 1979, en Duque 2010). En este sentido, Duque (2010:27), encuentra en Fidel (1992) diversas formas de gentrificación que relata en su estudio sobre Lincoln Park, en la ciudad de Chicago, y destaca la persistencia del estatus de algunas zonas que pasan por la ausencia de algunos de sus pobladores, pero que finalmente se recupera y, sin embargo, esto no representa una sustitución de la población original. Menciona otras situaciones en zonas de alto estatus degradadas, pero que resultan todavía interesantes, así como lugares donde existe un "excedente de gentrificación", en donde destaca que la demanda de viviendas renovadas supera la oferta, propiciando su extensión a zonas contiguas impulsadas en ocasiones por las inmobiliarias. Otra modalidad, más drástica se da cuando se produce el derribo de viviendas para la construcción de otras nuevas, provocando alteraciones al grado de no quedar nada de la comunidad anterior. Finalmente, destaca como otra situación común la recuperación de espacios que consiste en la conversión de la industria o comercio, en vivienda y espacios modernos.

Es importante mencionar que no todos los procesos de gentrificación se dan de manera simultánea, por lo que el modelo de desarrollo realizado por Clay (1979 en Duque 2010:28) muestra cuatro fases:

1. Interviene un grupo de particulares; escasa atención pública al proceso y recursos propios para la rehabilitación por la difícil obtención de hipotecas; artistas, diseñadores, etc., participan activamente en la rehabilitación de sus edificios; poco desplazamiento, se ocupan casas vacías o se adquieren según el funcionamiento del mercado (Duque 2010:28).

2. Entrada de pequeños inversores que adquieren y vigorizan edificios localizados; crece el desplazamiento de habitantes por la ausencia de viviendas vacantes, ante la demanda; el 
cambio es limitado; los primeros serán considerados habitantes antiguos (oldtimers) por los llegados en periodos posteriores (Duque 2010:28).

3. El barrio trae el interés público y mediático, iniciando la gentrificación; los pequeños renovadores continúan actuando y los precios se dispararán, accesibles solo a la clase media como una inversión a causa del aumento de la valoración de la zona; los bancos conceden dinero para invertir con mayor facilidad, con fines hipotecarios o edificatorios. Comienzan las tensiones sociales entre vecinos antiguos y nuevos (Duque 2010:28).

4. Llegan nuevos habitantes de clase media, relacionados con negocios y empresas; se va sustituyendo el capital cultural por el económico; edificios y solares, reservados para especular se ponen en el mercado; aparecen nuevos comercios. Se intenta lograr una delimitación como zona histórica que proteja las inversiones privadas de periodos anteriores. El desplazamiento afecta también a propietarios, anteriormente se centraba en los arrendatarios, más vulnerables al aumento de precios de la vivienda (Duque 2010:29).

Dentro de este modelo de desarrollo por fases, Duque (2010) destaca la interacción de actores, la aparición conflictos e involucramiento de bancos e inversión pública, sin duda, factores económicos, sociales y culturales que se interrelacionan, características que dan claridad la existencia de un proceso de gentrificación (Duque 2010:29).

\section{Posibilidades de adaptación del término}

El termino gentrificación ha trascendido en el ámbito académico de habla inglesa, siendo utilizado en ocasiones por pobladores afectados por estos procesos, tanto en Estados Unidos como en Reino Unidos. Así, en Webster's Dictionary of the Américan language (1988) y Oxford English Dictionary (1993) incluyen la definición (Duque 2010:29). En el idioma español, se utiliza incluso en un contexto fuera de lo académico, no es una traducción, sino una adaptación en su escritura, utilizado por investigadores, sin embargo, pierde su contenido, aunque conserva los matices en el contexto anglosajón. En consecuencia, en España varios autores han intentado definirlo y hacer traducciones adecuadas del término sin conseguirlo, como aristocratización, elitización residencial y aburguesamiento, el cual resulta más preciso por el protagonismo qué adquiere con él la clase media. Finalmente, investigadores franceses y españoles coinciden en emplear el termino de gentrificación, el 
cual se centra en la transformación o renovación de espacios urbanos, que requiere de la flexibilidad de las personas para adaptarse a las nuevas realidades propias del proceso (Duque 2010:30, 31).

\section{Causas y efectos sociales de la gentrificación}

El término gentrificación, conlleva factores demográficos, ecológicos, socioculturales, políticos-económicos, etcétera, derivando el debate en torno a dos posturas opuestas. De esta manera, tenemos como referencia teórica a la ecología urbana y el paradigma crítico, es decir, la sociología de base marxista; la diferencia entre ambos en cuanto a su valoración positiva o negativa se fundamenta en la visión de sus efectos sobre la ciudad (Duque 2010:36). Por un lado, estaba la renovación de la edificación y por el otro de la población en aquellos centros de población a causa de la crisis en la que se encontraban. Al crecer las ciudades bajo este esquema no es novedad que las nuevas residencias en zonas periféricas, sean habitadas por gente con mayor nivel adquisitivo y al interior por las clases medias, o por los más pobres, dejando sin uso las viviendas en peores condiciones provocando su destrucción. Duque (2010:37) desde la perspectiva del consumo, focaliza a la gentrificación como un esquema de modernidad con grandes cambios culturales y progresiva capacidad de los individuos para establecer su propia vida.

En la mayoría de los sitios gentrificados, suele haber beneficios por las mejoras, haciendo notable que las nuevas tendencias de crecimiento de las ciudades son la pauta que va marcando la nueva clase media que no solo busca adquirir una casa o vivienda, sino que también adquirir otros bienes fundados en la estética, el valor histórico y la autenticidad (Duque 2010:38). Por otra parte, su principal efecto se observa al desplazar a los habitantes originarios más pobres, por no contar con los recursos necesarios, por lo tanto, las críticas a este enfoque se relacionan al individualismo centrado en aspectos de corte cultural. Asimismo, como factores positivos se alude a la recuperación de los centros de población o mejoras en las edificaciones, olvidando consecuencias graves como es el desplazamiento de los habitantes de escasos recursos (Duque 2010:38). 
Para la teoría del consumo, existe disponibilidad de sitios para la gentrificación y asume de manera informal el "modelo de filtrado" (Duque 2010:38) como la mejor forma de hacer desarrollo. Sin embargo, en las ciudades donde predomina la fuerza del mercadeo el crecimiento no se distribuye de manera uniforme, se va dando en aquellos lugares con mejores condiciones y bajos precios del suelo. En este sentido, la gentrificación se da donde el capital regresa a las zonas céntricas de las ciudades, por lo que es la disponibilidad de espacios lo que genera la demanda (Duque 2010:39). Así, las consecuencias negativas que trae la gentrificación a los desplazados, además de que otros estudios polarizan las posturas y las alejan dificultando su entendimiento. Actualmente, las corrientes de estudio ya no se ocupan de su origen, sino de cómo funciona en los territorios donde se produce. Esto es lo que Ley (1996, en Duque 2010:39) llama la geografía de la gentrificación, que analiza y compara este concepto, sin considerarlo como un proceso generalizado en el mundo, por el contrario, profundiza en nuevos temas en torno a contextos financieros, de inmigración, minorías étnicas, políticas urbanas y en general discursos sobre la gentrificación (Less 2000, en Duque 2010:39). Finalmente, "producción y consumo" trabajan sobre la comercialización de espacios residenciales, en torno a decisiones individuales o colectivas en algunos casos bajo presiones sociales. Por ende, la gentrificación se liga a la elección y al consumo para los ricos, mientras que para los desplazados significa cohesión y restricción y ambas vertientes transcurren simultáneamente (Duque 2010:40).

\section{El desplazamiento}

Uno de los principales riesgos desde el punto de vista social generados por la gentrificación es el desplazamiento, por ello Duque refiere a la correlación abandono-desplazamientogentrificación, por lo que ha intentado precisar tres modalidades (Marcuse 1986 en Duque 2010:40). El desplazamiento directo, es el más evidente y fruto de la expulsión forzosa de los hogares; el desplazamiento en cadena se produce cuando ocurren desplazamientos sucesivos de hogares en una misma vivienda; y finalmente el desplazamiento por exclusión, que impide que algunos hogares se trasladen a determinadas zonas por estar fuera de sus posibilidades económicas. De este modo, se provoca la escasa renovación de la población 
con habitantes del mismo nivel social y económico (Davidson y Less, 2005 en Duque 2010:40).

Por otra parte, la presión que se ejerce para provocar el desplazamiento originado por los cambios en el entorno, hace que los habitantes se muevan de manera voluntaria antes de verse directamente afectados (Duque 2010:40) y las causas detonantes son el abandono y la gentrificación, de esta manera proceso de gentrificación implica un cierto grado de desplazamiento (Duque 2010:41).

En este contexto, Duque (2010), observa que el problema de la movilidad, es su trasfondo en los cambios de residencia como movilidad descendente, que en lugar de mejorar la zona o tipo de vivienda se empeora la calidad; y como la movilidad forzosa, cuando no es voluntad de los habitantes moverse a otros espacios como en las disposiciones municipales, promovidas por acciones que no pueden pagar. En otros casos por la falta de mantenimiento y ruina de las viviendas, o porque los barrios son considerados como parte de proyecto de renovación urbana (Duque 2010:41).

\subsubsection{Repercusión de la gentrificación en el ámbito social}

Existen casos donde los habitantes son obligados a retirarse a causa de las presiones (Marcuse 1986, en Duque 2010), donde los vecinos se han ido y las tradiciones se van perdiendo (Duque 2010:42). Para algunos críticos sus efectos, poco afectan a los involucrados de las zonas céntricas degradadas. No obstante, son las personas más vulnerables social y económicamente las primeras en verse afectadas de la aparente mejora urbana (Duque 2010:42). Así, la gentrificación altera los problemas, no los resuelve, por ello el estudio de los procesos de gentrificación en un barrio especifico, deben identificar el número de afectados, así como sus características.

Duque destaca que en la última etapa de los años noventa, "se produce una rápida recuperación de los procesos de gentrificación” (1999, en Duque 2010). Posterior a ello, estudios empíricos profundizan en las ciudades clásicas, pero también en occidentales e incluso en las más pobres en diferentes partes del mundo. Para entonces, las metodologías 
son más diversas, haciendo su estudio multidisciplinar. En este sentido, se ha incrementado el interés por su estudio enfocado a los colectivos y minorías, referenciando fenómenos sociales que provocan gentrificación (Duque 2010:47).

\subsubsection{El proceso de gentrificación en barrios históricos}

Algunos autores han realizado estudios de los que podemos tomar ejemplos sobre el análisis de cómo la transformación de almacenes y espacios portuarios en estudios/viviendas por parte de los artistas puede ser el motor de cambio (Zukin, 1982 en Duque 2010). Mele (2000, en Duque 2010) analiza la contracultura, primero al levantar la imagen del barrio y posteriormente al consumir por su propio éxito. Por encima de todos los demás grupos existe una auténtica tradición relacionando gentrificación y cuestiones étnicas desde un punto de vista antropológico (Maurrasse, 2006, en Duque 2010). Para Slater (2006, en Duque 2010), los recientes estudios carecen de un enfoque crítico con el fenómeno, por lo que Caulfield (1989), alude una reacción conformista encausada por la modernidad como una búsqueda de alternativas. A partir de este enfoque, surgen otros estudios que la consideran como una "solución deseable" para el rescate de los centros históricos en proceso de degradación. Slater (Duque 2010:48) considera tres motivos: el debate político e ideológico que ha impedido avanzar en la investigación; la dificultad para medir el desplazamiento que ha motivado que crezca el interés en estudiar a las clases medias y los beneficios de la gentrificación; y por último, la era neoliberal de las políticas públicas junto con las tendencias para fomentar la privatización y disolución de los núcleos de pobreza concentrada, han llevado a un proceso global y dirigido desde el estado de intervención mediante la mezcla social.

Las posturas que abrigan el ingreso de las clases medias en zonas centrales, han contado con el apoyo de las autoridades, convirtiéndose en una medida de planeación durante la aplicación de políticas urbanas y de intervención social, que podría ser promovido desde las instancias públicas. Coulomb analiza el caso de las políticas no urbanas del nuevo laborismo en Inglaterra y sus implicaciones, mostrando las inconformidades que solo aumentaron la desigualdad, centrando su discurso en la exclusión social. Inicialmente el término fue concebido con intención crítica y en la actualidad es visto como una solución 
para los problemas urbanos (Duque 2010, pág. 48). Así, en la agenda urbana del laborismo radica en "combinar dos corrientes la renovación de barrios en forma de lucha contra la exclusión social y el renacimiento urbano consistente en una regeneración estética y económica” que muchos califican de gentrificación encubierta (Duque 2010, pág. 49).

Otros autores, se inclinan por la "regeneración urbana" como un medio para lograr la "sostenibilidad social y ecológica", lo que define la participación de las instancias de gobierno en un proceso de gentrificación. Duque (2010) menciona el caso de Bromley, Tallón y Thomas (2005) que analizan la renovación de los centros de Bristol y Swansea donde hablan de los grupos sociales a los cuales "es más deseable atraer al nuevo núcleo urbano", lejos de promover la salida de los habitantes actuales o sustituirlos por los que llegan, lo que denota la poca preocupación por los desplazados comparando su situación con las ventajas que les da la "regeneración" (Duque 2010, pág. 49). Los cambios que se observan después del proceso de gentrificación, son diferentes desde la perspectiva de los implicados directamente llámense pobladores o poderes públicos, sin contar las repercusiones en la macroeconomía. Los urbanistas neoliberales, asumen que la recuperación de los centros históricos, siendo que las autoridades o principales poderes públicos quienes han frenado un gran número de iniciativas en torno a este objetivo.

Desde la década de los años 90, las autoridades de las capitales promovían la gentrificación como una forma de recolectar recursos económicos que les ayudarían a solventar problemáticas de sus competencias que cada vez se hacían mayores, y provocar este proceso para los ayuntamientos significaba recuperar los impuestos que perdían por las clases medias que abandonaban los barrios y se disponían a reubicarse en las zonas metropolitanas (Duque 2010, pág. 50). No ocurría así en los años 70 y 80, donde los habitantes y vecinos ofrecían resistencia a los procesos de gentrificación, logando detenerlos o aminorarlos; actualmente, la controversia en torno a la gentrificación es menor. 


\subsection{Exclusión social y territorio}

En estudios como el que nos ocupa, otro de los procesos sociales que no se puede desvincular del ámbito territorial es la exclusión social. (Subirats 2005, pág. 2), constata que, en estudios en España, existe la "desigual presencia de factores de exclusión”, con diferente grado de desarrollo a partir de la configuración de sus políticas de bienestar y de la labor que realizan en contra de la exclusión urbana. Sin embargo, sus características locales en relación a esta se tornan con grandes diferencias entre las comunidades.

Por tal motivo, el análisis de la exclusión social en el ámbito urbano, ha tenido gran relevancia académicamente en Europa en los últimos años. Por ello, gran cantidad de variables de análisis en torno a esta, son consideradas en ciudades europeas, donde se despierta el interés de nuevos pobladores que buscan mejores entornos laborales, para quienes se ofrecen espacios habitables deficientes ubicados en la periferia o en sus centros históricos, buscando la inclusión de personas de origen similar. Este escenario puede terminar “concentrando y densificando situaciones de carencia y exclusión” (Subirats, 2005, pág. 2). Así, los nuevos crecimientos hacia la periferia o en entornos degradados, las ciudades sin proponérselo, eliminan los vínculos comunitarios entre las personas, que, claramente derivan en realidades de exclusión social debido a las diferentes características por su origen. Esta situación puede segregar a esta parte de la población de "la gran corriente social mayoritaria", provocando una disminuida "movilidad social" y en consecuencia mayor "privación y marginalidad".

\subsubsection{Desigualdad, exclusión y segregación social}

Abordar la relación socio-espacial de las ciudades implica relacionar las desigualdades sociales, la exclusión social y los procesos de segregación o concentración de pobreza y exclusión. A partir de esto, se puede determinar la existencia, nivel y tipo de segregación social o espacial, y su interrelación (Subirats, 2005, pág. 2). Musterd (2002), destaca tres tipos: ciudades duales, donde se produce una marcada segregación social y territorial; ciudades segregadas, con una clara división territorial y altos niveles de conexión social; y finalmente, las ciudades con marcada desigualdad social y segregación territorial casi 
imperceptible. Keestelot (2003) clasifica a las ciudades topológicas como los lugares donde distintos grupos sociales ocupan áreas residenciales diferenciadas, sin algún tipo de relación social, relacionadas al modelo urbano norteamericano. Además, destaca a las ciudades dramáticas, donde existe una mezcla de grupos sociales con segregación espacial, como un modelo de la realidad de las ciudades en Europa, (ver Tabla 1) (Subirats 2005, pág. 3).

Por otra parte, Subirats (2005, pág. 3) describe tres tipologías de Beck (1998), respecto a las ciudades incluyentes, que aceptan la diferencias y convivencia de distintos proyectos y realidades sociales; las ciudades negativas, que rechazan la unificación y fraccionan diversas realidades como garantía de seguridad; y finalmente, las ciudades alternativas en donde todos han de tener oportunidades, sin mezcla de personas, realidades y territorios. A partir de estas tipologías, Subirats (2005, pág. 3) establece categorías de acuerdo al nivel de exclusión social y/o segregación territorial que muestran.

\section{Segregación territorial}

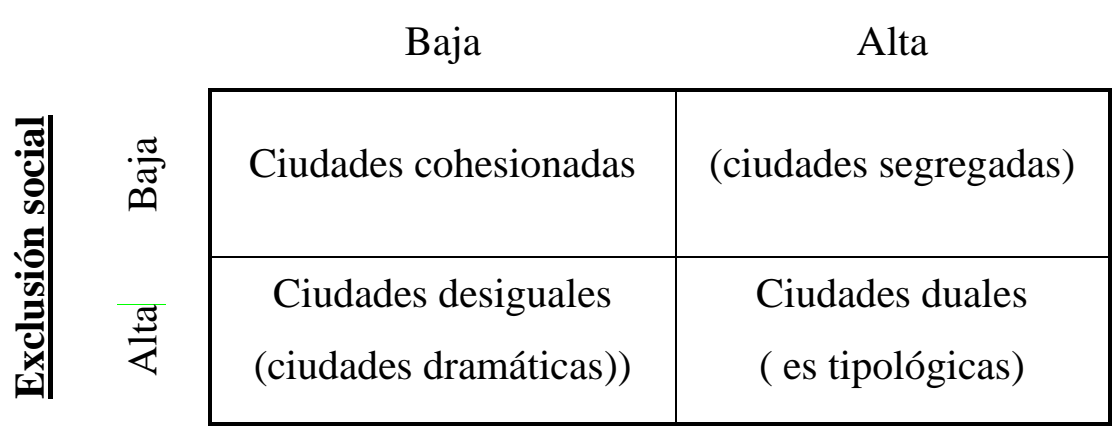

Tabla 1 EXCLUSION SOCIAL Y SEGREGACION TERRITORIAL: TIPOLOGIA DE CIUDADES. (ELABORACION I. CRESPO/J.SUBIRATS (IGOP), 2005).

\section{Características urbanas de la exclusión social}


A partir del análisis en torno a exclusión social, Subirats (2005, pág. 4), utiliza la aproximación de la exclusión social para exponer las diversas circunstancias de desigualdad, y vulnerabilidad, por lo que, a su juicio, son los principales generadores de exclusión social en Europa. Por otra parte, la fragmentación e individualización de la sociedad postindustrial -principalmente por la "diversificación étnica" es derivada de la movilidad de individuos provenientes de países pobres que no son considerados en políticas interculturales. Lo anterior conduce a una situación precaria por la falta de apoyo legal, económico, relacional y familiar. Otra vertiente se refiere a la alteración de la pirámide de edades con un aumento de la tasa de dependencia demográfica vinculada a etapas de dependencia física; las relaciones familiares muestran un aumento considerable en la "monoparentalidad en capas populares (Subirats, 2005, pág. 4).

De esta manera, encontramos que son los rasgos particulares de las ciudades las que destacan la notoriedad de grupos o personas por su nivel de contribución y participación en las redes sociales y políticas debido a su alta marginación en el ámbito territorial, colocándolas en desventaja debido a que sus problemáticas difícilmente son tomadas en cuenta por las instancias encargadas de disminuir la exclusión social de la que forman parte. Son notables las expresiones urbanas causadas por la exclusión social, que además se vinculan con los nuevos desarrollos a raíz de distintos procesos que originan que muchas personas o grupos queden sin empleo por su incapacidad de integrarse a "nuevas realidades productivas". Además del déficit de inclusividad del estado de bienestar que se deriva en la dificultad ante el intento de establecer políticas en respuesta a la desigualdad por ausencia de representantes sociales "homogéneos y estables".

A través del tejido urbano se puede identificar, en el caso europeo, la creación de nuevas políticas de bienestar con instituciones concretas que prestan servicios de salud y educación, atendiendo principalmente a comunidades que aun presentan una dinámica de cohesión y vinculación interna. En otro tiempo, la fragmentación de las políticas públicas se compensaba con la integración de las redes sociales existentes en el entorno de los individuos (Subirats, 2005, pág. 5). Actualmente, la realidad social hoy se encuentra desestructurada e individualizada, siendo más evidente la desigualdad y exclusión social que no solo afecta a los individuos, sino también a los colectivos que ya registran fuertes carencias que intentan 
ser atendidas por políticas incapaces de resolver las necesidades multidimensionales de los individuos y los colectivos enmarcados por las nuevas medidas de desarrollo en el mercado.

\subsubsection{Escenarios de exclusión social, referencias latinoamericanas reflexiones cruzadas con el caso europeo}

El estudio de los temas de pobreza y exclusión en Latinoamérica y Europa parten de sus momentos históricos y distintas realidades económicas, sociales y políticas. De esta manera se ha identificado que las condiciones de bienestar en Latinoamérica se desarrollan de forma más restringida. Al respecto Ziccardi (Subirats, 2005, pág. 6) considera que el modelo de bienestar nunca ha estado plenamente desarrollado, y concentra su reflexión en el papel de las ciudades y sus gobiernos con relación a la cuestión social. Las reformas estructurales de los años 80, con la abstención de la acción estatal, provocaron graves efectos sociales que hicieron aún más evidente la debilidad de los gobiernos locales para hacer frente a la clara expansión de la cuestión social en el continente. Estudios recientes, han logrado confirmar que la situación social de estas ciudades se agrava, siendo las diferencias más notables frente a la problemática europea el mayor crecimiento poblacional y demanda de bienes y servicios colectivos, subempleo, economía informal, menores ingresos públicos, precariedad en el trabajo y baja cualificación de las mujeres, exclusión a créditos, discriminación étnica,

mínima participación social y política, inseguridad, criminalidad, violencia urbana así como mayores índices de división territorial y segregación urbana. No obstante, estos fenómenos comienzan a hacer presencia en el ámbito europeo, siendo la diferencia la calidad y cantidad de los sucesos, al igual que distintos actores y roles de los poderes públicos, tradiciones y formas de actuación de partidos y agentes sociales (Subirats, 2005, pág. 7).

Subirats, destaca tres fenómenos singulares y dignos del debate crítico y comparativo de las situaciones de exclusión social urbana entre Latinoamérica y Europa. El primero refiere la segmentación y segregación social y urbana en Latinoamérica con espacios destinados a las elites económicas y políticas que en el caso europeo son más inusuales (Subirats, 2005, pág. 7) en la búsqueda de espacios donde predomine la homogeneidad social en medio de la degradación del tejido social. En el segundo fenómeno enfoca la escala social en Latinoamérica con experiencias que algunos estudios identifican como "sociabilidad 
forzada" (Subirats, 2005, pág. 7), primero como iniciativas de formas estrictas de subsistencia y posteriormente como alternativas estratégicas de economía social y solidaria, identificándose como fenómenos afines a situaciones de pobreza y exclusión social que no tienen comparación en el caso europeo. Por último, también (Subirats, 2005) destaca la emergencia en el aumento en temas de exclusión relacionadas a comunidades indígenas, con manifestaciones y expresiones que las insertan en conflictos urbanos y no en rurales, destacando que este fenómeno no podría medirse con alguno similar en Europa, sin embargo, sería interesante contrastar con escenarios de inclusión - exclusión de las poblaciones indígenas en Latinoamérica con el fenómeno relativamente similar al de los inmigrantes en Europa.

\subsection{La vulnerabilidad urbana}

\section{El Departamento de Asuntos Económicos y Sociales de las Naciones Unidas ofrece la} siguiente definición del concepto «vulnerabilidad»:

«(...) puede definirse como un estado de elevada exposición a determinados riesgos e incertidumbres, combinado con una capacidad disminuida para protegerse o defenderse de ellos y hacer frente a sus consecuencias negativas. La vulnerabilidad existe en todos los niveles y dimensiones de la sociedad y es parte integrante de la condición humana, por lo que afecta tanto a cada persona como a la sociedad en su totalidad». (Naciones Unidas 2003: 8)

De acuerdo a Robert Castel, la vulnerabilidad como concepto que puede tener variantes, coincidiendo siempre en los distintos entornos sociales y contraponiéndose a la opinión de Leinor quien refiere a la exclusión, no como un proceso, sino como un estado de las condiciones de las personas, por lo que Castel propone una "zona social intermedia" entre la condición de excluido y la "zona de integración” de la exclusión social (Gutiérrez, 2013, pág. 76). Esta zona de vulnerabilidad, Robert Castell la identifica como una zona intermedia que además de ser inconsistente, se muestra también frágil en su relaciones sociales y escases de trabajo, condiciones que se reflejan en los territorios (Gutiérrez, 2013), colocando a los 
individuos en situaciones de riesgo como antesala de la zona de exclusión social.

La vulnerabilidad, también se muestra en el ámbito urbano en tal forma que la seguridad y la "potencialidad" de un espacio urbano se ve afectado por diversas causas que lo colocan en situación crítica, donde se materializa la exclusión (Gutiérrez, 2013).En este contexto, se puede originar la segregación espacial dentro del sistema urbano por ser vulnerable al quedar fuera de las medidas preventivas que le impidan a los espacios urbanos entrar en crisis induciéndolos a una degradación funcional y social que finalmente se conviertan en zonas marginadas (Hernández Aja 2007: 5, en Gutiérrez, 2013). Por otra parte, la vulnerabilidad urbana es vista como el proceso de malestar en las ciudades derivado de múltiples desventajas, en donde una mayor movilidad se contempla como la única esperanza de superar su condición social de exclusión, sin embargo, este riesgo se torna como una condición difícil de alcanzar (Gutiérrez, 2013, pág. 77). Se consideran dos aspectos, el primero es el incremento de las amenazas y los riesgos que afectan a las personas/sociedades/grupos sociales/estados; y el segundo refiere a la debilidad de los mecanismos para afrontar dichos riesgos y amenazas. De este modo, una forma de contrarrestar esta debilidad necesita de la apropiación de la sociedad con el fin de satisfacer las necesidades culturales, materiales y relaciones dentro de la misma sociedad.

Podemos decir entonces que los dos principales detonantes de la vulnerabilidad urbana tienen su origen en la exclusión residencial y laboral que, interactuando entre sí, liberan factores que resultan inhibidores de carácter político, cultural, social, personal..." (Gutiérrez, 2013, pág. 78). Cuando en un espacio se conjugan situaciones en torno a un medio social, económico y urbano decaído, es inevitable mezclar "factores objetivos y subjetivos" en donde todas las desventajas sociales y estructurales desfavorecen el desarrollo de proyectos importantes bajo contextos de seguridad. También es importante destacar que en el "entorno psicosocial" son los pobladores los que ven afectada su percepción del espacio que habitan y sus propias condiciones sociales. 


\subsubsection{Clasificación de la vulnerabilidad}

En su investigación, Gutiérrez (2013) clasifica a la vulnerabilidad, destacando en primera instancia la vulnerabilidad socio-demográfica la cual se deriva de los procesos demográficos que también tienen implicaciones sociales, por lo que sus necesidades se muestran como múltiples demandas que deben ser atendidas por los poderes públicos de forma prioritaria. Es importante sumar otros factores relacionados con los servicios médicos, el propio detrimento de las viviendas y espacios en renta, que los llevan a ser calificados como población vulnerable. En el caso de la vulnerabilidad socio-económica, esta depende de la capacidad de cada hogar de procurarse su bienestar y estabilidad material y emocional, y para ello se debe contar con un empleo. En consecuencia, la estabilidad económica, se relaciona también con los niveles de formación de la población para colocarse en los diferentes escalafones laborales.

La vulnerabilidad residencial tiene que ver con los niveles de satisfacción de las necesidades de la población y su hábitat, por lo que es importante satisfacer el desarrollo de la vida cotidiana y su dimensión relacional, por lo que un hábitat degradado afecta no solo a las viviendas, sin o también el entorno vecinal que conjuntamente provocan efectos de vulnerabilidad. Finalmente, la vulnerabilidad subjetiva, se basa en las percepciones de los pobladores en relación a su entorno urbano y social, lo cual refleja la calidad de su medio ambiente residencial que se define por factores relacionados con los ruidos, contaminantes, malas comunicaciones, escasas zonas verdes y el grado de delincuencia de su entorno.

Hemos visto ya la necesidad de identificar la vulnerabilidad de los espacios urbanos como en nuestro caso de estudio, sin embargo, además de los indicadores que nos ayudan a definir esta condición, es también importante saber y conocer de acuerdo a la categorización que realizan Calderón Calderón, B., \& García Cuesta, J. L. (2018), pág. 301, si la vulnerabilidad es de origen o adquirida. Por lo que al barrio de Analco se refiere, presenta no una, sino por lo menos dos singularidades, a partir de las cuales podemos definir que esta condición ha tenido dos etapas relevantes en su historia, siendo la primera basada en su origen como barrio indígena desde la fundación de la ciudad, quedando segregado social y espacialmente, marcado tanto por una barrera física y natural que constituía el antiguo río San Francisco cómo por la planeación de la ciudad novohispana dónde los barrios que daban 
servicio a la nobleza estaban excluidos de este primer cuadro de la traza urbana en damero, por lo que esta situación define al barrio como vulnerable, aunado a que en si misma era una población indígena con características propias y dificultades de acceso a servicios similares a los de las familias nobles de aquel tiempo. Otra singularidad, es el proceso actual de degradación social y urbano en el que se encuentra inmerso el barrio de Analco, situación que ha sido aprovechada por el sector inmobiliario a través de la adquisición de inmuebles de valor patrimonial, dando inicio a un proceso de gentrificación que se sustenta en valores de vulnerabilidad distintos a los de su origen, por lo que bien podríamos categorizar esta segunda etapa de vulnerabilidad como adquirida - por las problemáticas surgidas con el paso del tiempo-, además de la falta de inversión en el rescate del patrimonio urbanoarquitectónico que promueva su conservación, preservación y salvaguarda. 


\section{CAPITULO II.}

ANTECEDENTES

HISTORICOS, FUNDACIÓN Y NOMBRAMIENTO DE LA CIUDAD PATRIMONIO 


\section{ANTECEDENTES HISTORICOS, FUNDACIÓN Y NOMBRAMIENTO DE LA CIUDAD PATRIMONIO}

2.1. Centro histórico de la ciudad de Puebla y la conformación de barrios

\subsubsection{Puebla, patrimonio cultural}

PROGRABA PARCIAL DE DESARROLLO URBANO SUSTENTABLE DEL CENTRO HISTORICO DEL MUNICIPIO DE PUEQLA
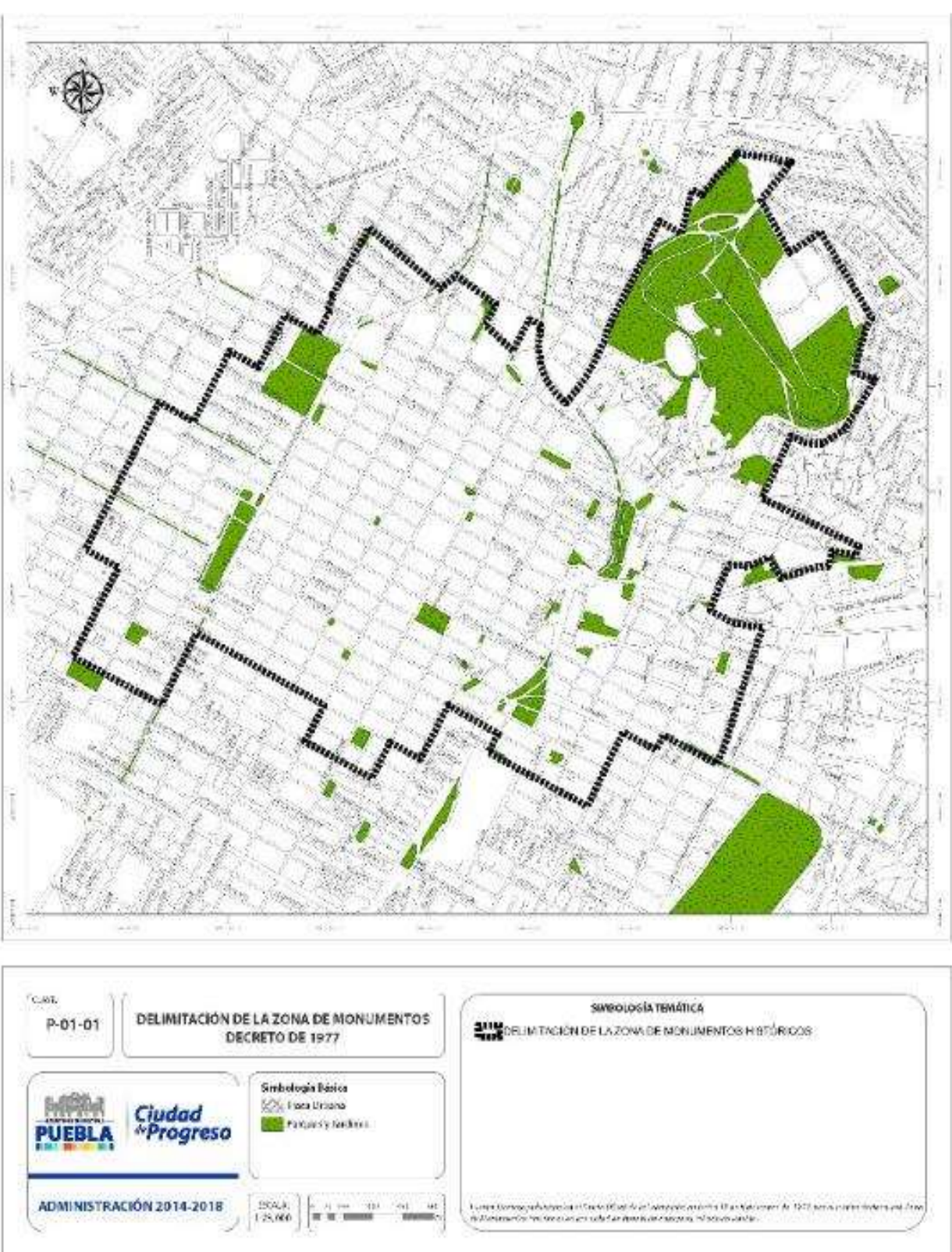

Figura 3 Delimitación de la Zona de Monumentos, Decreto del año 1977. Fuente: Plano tomado del (Gobierno del Estado, 2015) 
La ciudad de Puebla desde su fundación, alberga una diversidad de estilos arquitectónicos y peculiaridad artística que han caracterizado a su centro histórico como uno de los más reconocidos a nivel nacional e internacional, dando origen a su nombramiento como Patrimonio Cultural de la Humanidad por parte de la UNESCO en el año 1987, siendo una de las 10 ciudades del país. Su centro histórico pertenece a la 4a Zona Metropolitana más importante del territorio mexicano, considerada como una zona estratégica de desarrollo por sus atractivos artísticos, históricos y culturales (GOBIERNO M. d., 2014), donde su espacios y estructura urbana son testimonio del excepcional valor histórico, social, político y cultural.

Fue decretado “Zona de Monumentos Históricos en la Ciudad de Puebla de Zaragoza” en el año 1977 (ver Fig. 3). Posteriormente y como dato más reciente el 31 de enero de 2005 es declarado como “Zona Típica Monumental” (GOBIERNO DEL ESTADO, 2005).

\subsubsection{Antecedentes históricos de la ciudad de Puebla}

La ciudad se fundó en el año 1531 destinada para los españoles con el fin de propiciar la inmigración, arraigar las culturas y saberes europeos, paliar el abuso sobre los indios y asegurar un enclave en la ruta entre los estados de México y Veracruz. De esta manera, la ciudad, desde su fundación hace 489 años, muestra una traza simétrica en sus calles alineadas al norte; que en su origen recibió el nombre de Puebla de los Ángeles. Para el comienzo del siglo XVII, estaba conformada por 310 calles, que podrían aparecer ya en el plano de 1754 elaborado por Don José Medina (ver Fig. 4). Actualmente su centro histórico se integra por aproximadamente 100 cuadras en la zona central de la ciudad. 


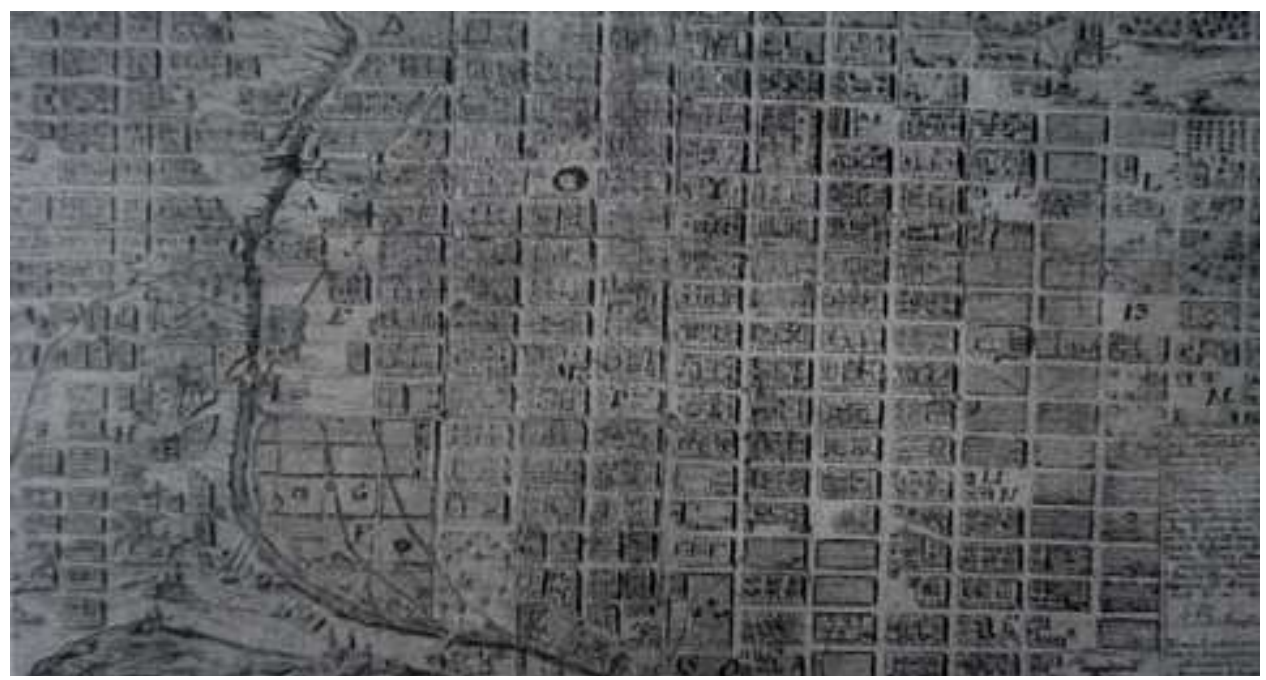

Figura 4 Plano de la ciudad de los Ángeles por (Medina, 1754).

Muy pronto en la ciudad se desarrolla la industria textil y la cerámica, dando como testimonio de su auge el aumento de población, que pasó de los 50 fundadores a 70,000 pobladores a finales del siglo XVII. Paralelamente, aumento la influencia de la iglesia, y antes del triunfo liberal el clero poseía la mitad de las construcciones de la ciudad. Así, la conquista española dejó sentir su influencia al fundar la ciudad barroca que hoy es una joya arquitectónica y cultural del país.

En la actualidad, Puebla ha sabido preservar y armonizar la riqueza que crearon arquitectos, artistas y artesanos, por ello hoy su centro histórico es Patrimonio de la Humanidad que contiene iglesias, conventos, fachadas, portones etc., creadas desde su fundación.

\subsubsection{Declaratoria como Patrimonio Cultural de la Humanidad}

Asumimos como antecedente en el ámbito mundial, la Carta de Atenas de 1931, que contiene principios generales y teorías de protección de monumentos, inspiradas en evitar y disminuir la degradación y riesgos causados por agentes externos, mediante la protección, conservación y restauración, fundadas en leyes promulgadas para cada sitio de interés histórico, artístico y 
científico. Destaca también la contribución de arquitectos y antropólogos junto con las instituciones y organizaciones públicas y/o privadas que guardan una estrecha relación con el patrimonio y la Convención sobre la protección del Patrimonio Mundial, Cultural y Natural, consumada en Paris del 17 de octubre al 21 de noviembre de 1972 en conferencia general de la UNESCO, en la que consta el deterioro del patrimonio causado por la evolución social y económica de los pueblos, y considera que su protección es insuficiente a raíz de la magnitud de medios económicos y técnicos que demandan, sin embargo, es importante para los pueblos conservar sus bienes únicos e irremplazables, sin importar a que país pertenezcan y que tanto la amplitud y gravedad del riesgo es de colectividad internacional, como la protección de manera organizada y permanente según los métodos científicos y modernos.

Estos documentos, consideran la protección del Patrimonio Cultural y Natural, y las obligaciones de los estados firmantes de la Convención, cuyas tareas son identificar, proteger, conservar, rehabilitar y transmitir el patrimonio a las futuras generaciones, y también los faculta para considerar el patrimonio en la legislación jurídica, científica, técnica, administrativa, etc., así como en estudios de investigación de la misma índole que permitan hacer frente a los peligros que amenazan su patrimonio. Otro objetivo de la Convención, es hacer conciencia del valor del patrimonio y sus amenazas, por lo que, es obligación de los Estados Parte, presentar y elaborar un inventario de los bienes situados en su territorio, a partir de los cuales el Comité del Patrimonio Mundial, publica la "Lista de Patrimonio Cultural", así como también especifica las disposiciones legislativas, reglamentarias y las medidas tomadas que aplicara la Convención.

En 1986, el Honorable Congreso del Estado de Puebla crea la "Ley sobre protección y Conservación de Poblaciones Típicas y Bellezas Naturales del Estado de Puebla”, cuya última revisión fue el 24 de marzo de 1995; esta ley considera características y peculiaridades de los lugares y paisajes del territorio poblano, así como los elementos primordiales para su desarrollo económico, social y turístico. Incluso considera medidas para la protección del entorno Ecológico, del Patrimonio Cultural y Natural, del Medio Ambiente, de las Zonas Típicas que han desarrollado una serie de valores históricos, arquitectónicos, artísticos, etc., mismos que no eran abordadas en la Ley Federal sobre Monumentos. 
La ciudad desde su fundación ha tenido un desarrollo privilegiado en los aspectos económicos y urbanísticos, por el legado cultural de los indígenas que la habitaron y que más tarde dio lugar al mestizaje cultural que aportó una extraordinaria arquitectura civil y religiosa, dando paso al conjunto urbano que constituye una parte importante del Patrimonio Cultural Mexicano. En este sentido, para su declaratoria como zona de monumentos fue considerando el importante lugar que ocupó en los acontecimientos Históricos de Independencia y Soberanía Nacional, junto con la Batalla del 5 de mayo de 1862 frente a la invasión francesa, y el inicio de la Lucha Armada que culminó con la Revolución Mexicana en 1910. Por lo tanto, por estas características formales respecto a su estructura urbana y el valor incalculable para la historia, social, política y artística en México es que el 11 de diciembre de 1987, el Comité del Patrimonio Mundial de la UNESCO, concede la inscripción del Centro Histórico de la Ciudad de Puebla a la "Lista del Patrimonio Mundial, que debe ser protegido para el beneficio de la humanidad y principalmente de las generaciones venideras.

2.2. Historia urbano-arquitectónica del barrio de Analco a partir del nombramiento de ciudad Patrimonio Cultural de la Humanidad

\section{Vivienda}

En 1625 la ciudad concedió dos manzanas del barrio de Analco a algunos naturales de Tlaxcala, donde se avecindaron varias familias españolas y se construyó el Puente de Analco (1626). Para hablar de la historia urbano-Arquitectónica es necesario saber que el uso de suelo predominante fue habitacional, donde la mayoría eran vecindades y viviendas en hilera por lo que se pueden clasificar en multifamiliares y unifamiliares. Las viviendas multifamiliares presentan mayor deterioro parcial o total que las unifamiliares donde se observa más cuidado de parte de los propietarios. Ambas conservan la estructura original según la apreciación externa, algunas de uso mixto con comercio y talleres donde se hacían trabajos como la alfarería (Sánchez, 2000). En el año 1902 se registraron 58 hornos para pan, 42 de ellos en Analco con 3 hornos para cemita (Leicht, 1986).

\section{La plaza principal}


La plaza principal y su arbolado le dan una barrera natural al barrio que contrasta con la contaminación auditiva y visual de su entorno, fortaleciendo la imagen urbana en este punto junto al templo dando relevancia a la presencia casi nula de elementos arquitectónicos como desagües de cantera; encaramientos con dinteles y escudos al nivel de clave; y elementos de enmarcamiento como elementos de transición de un espacio a otro caracterizados por tener arcos de medio punto, rebajados y en ocasiones mixtilíneos en algunos casos. En la mayoría predominan enmarcamientos, molduras u otros elementos decorativos que puedan definir algún estilo característico del barrio con materiales específicos (ver Fig. 5) (Sánchez, 2000).

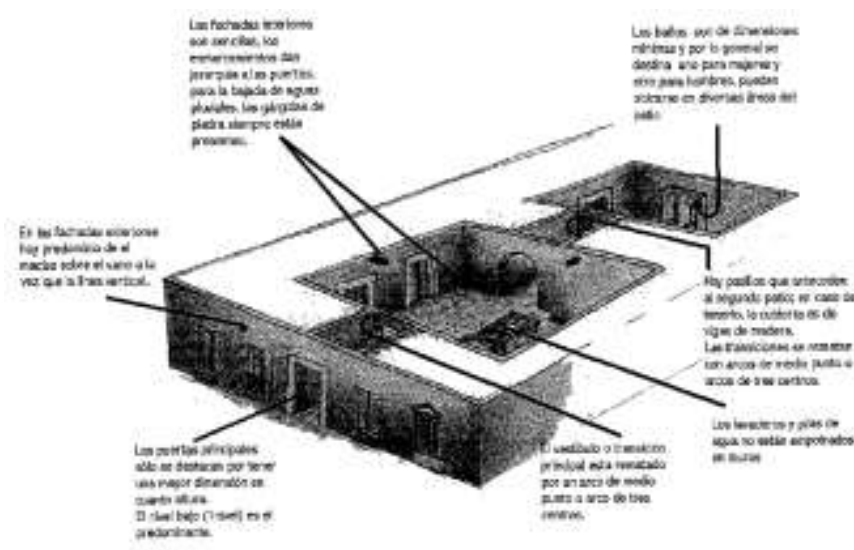

Figura 5 Descripción esquemática de la vivienda en barrios tradicionales, Imagen tomada de. (Sánchez, 2000)

Los materiales más utilizados para la construcción de patios en viviendas del barrio, son la piedra bola y piedra laja; en sus techos, aún se conserva la estructura original, fabricada a base de vigas de madera y en muros hay más diversidad de materiales como: xalnene, adobe, piedra y tabique. (Sánchez, 2000)

\section{Proporción y escala}

La dimensión de la vivienda en el Barrio es predominantemente de un solo nivel, debido a las proporciones, se crea un sentido de orden, aunque también hay variedad de elementos y diversidad de tamaños. (Sánchez, 2000). La conservación de la imagen urbana del barrio, en torno a la parroquia se mantiene a pesar de haber introducido viviendas modernas y 
materiales fuera de las características tipológicas, sin embargo, la diferencia es imperceptible desde la calle y las fachadas originales aún se preservan.

\subsubsection{Transformación en la primera década del siglo XXI: el origen de la gentrificación en el barrio de Analco.}

Desde la última década del siglo XX, debido al impacto que causo el proyecto "Paseo de San Francisco", se generó un proceso de cambio de uso del suelo en el barrio de Analco, que se ha venido acelerando en las primeras dos décadas del siglo XXI. El barrio no es el único que ha sufrido las consecuencias por la implementación de este tipo de proyectos, se suman los barrios de el Alto y Xanenetla, aunque se han preservado sus principales características, por lo que no es tan evidente el cambio físico a falta de las condiciones de conservación y características físicas que presentan, no obstante, se hace más evidente la problemática social que viven.

Debido al desarrollo de comercio y servicios, en el barrio de Analco se hace más notable la transformación de la zona. La etapa de modernización empieza aproximadamente en la última década del siglo XX y se extiende hasta la actualidad, ya que, su transformación tiene objetivos a largo plazo que consisten en el desarrollo de proyectos de rehabilitación de vialidades como la avenida 3 oriente, que presenta mejoras de movilidad además presentar

el mayor número de cambios en el uso de suelo, (ver Fig. 6), lo que ha permitido detonar un cambio radical al interior del barrio, trayendo consigo la especulación del suelo aunado al abandono y deterioró de algunas zonas, pero también el rescate de inmuebles en desuso para educación, comercio y el turismo (ver Fig. 7). 


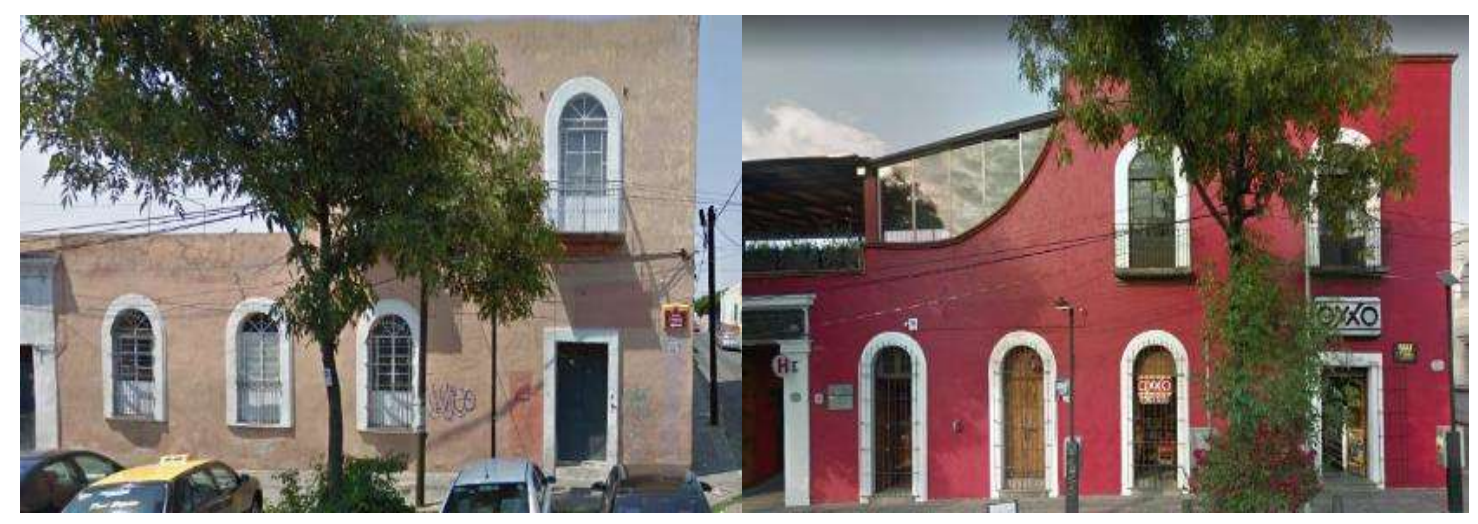

Figura 6. Cambio de uso de suelo a servicio turístico, avenida 3 oriente entre 14 y 16 sur, barrio de Analco

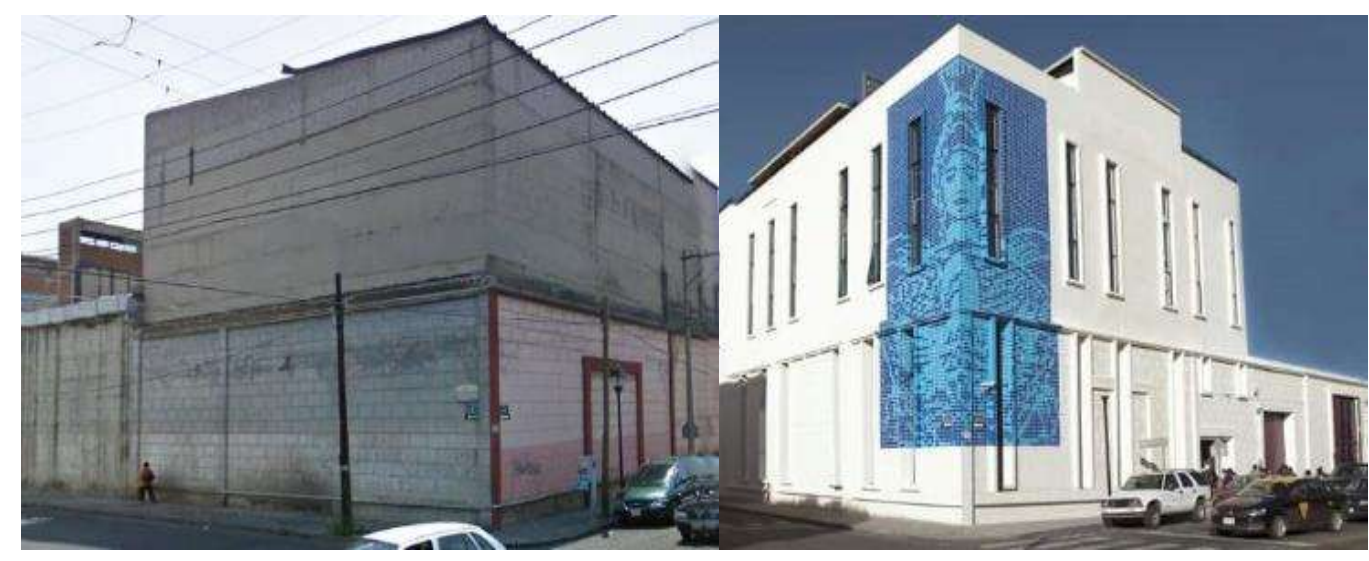

Figura 7. Cambio de uso de suelo a equipamiento educación superior, Facultad de psicología de la BUAP, avenida 3 oriente esquina con 16 sur. Barrio de Analco.

Esta transformación no es espontanea, es más bien inducida, ya que, si bien existen normativas que contemplan al turismo como una fuente de desarrollo económico, (ver Fig. 8), que impulsa la práctica de actividades orientadas a la salvaguarda y conservación del patrimonio en la zona de monumentos de la ciudad, también existe una mala aplicación de la ley, dando paso a proyectos ilícitos en el barrio de Analco poniendo en riesgo su peculiaridad. 


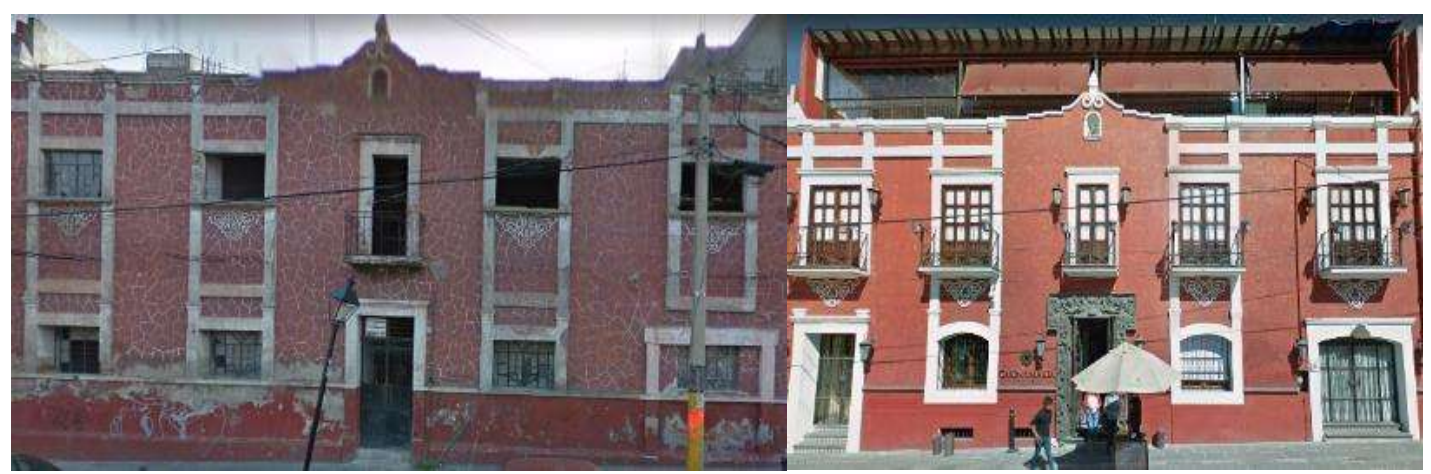

Figura 8. Cambio de uso de suelo a comercial, avenida 3 oriente esquina con 12 sur, barrio de Analco.

También el barrio del Alto posee importantes tesoros arquitectónicos y espacios con una carga histórica y simbólica para la ciudad; aún conserva gran parte de su patrimonio cultural tangible con arquitectura popular e intangible, con saberes y celebraciones. Además de los cambios físicos en el barrio, existen problemas sociales (inseguridad, gentrificación...) que de no ser tratados podrían generar afectaciones irreversibles. Por ello, es necesaria la implementación y cumplimiento de normativas y lineamientos que permitan la conservación integral de la zona, de lo contrario, podría seguirse incrementando la transformación de uso del suelo (ver Fig. 9).

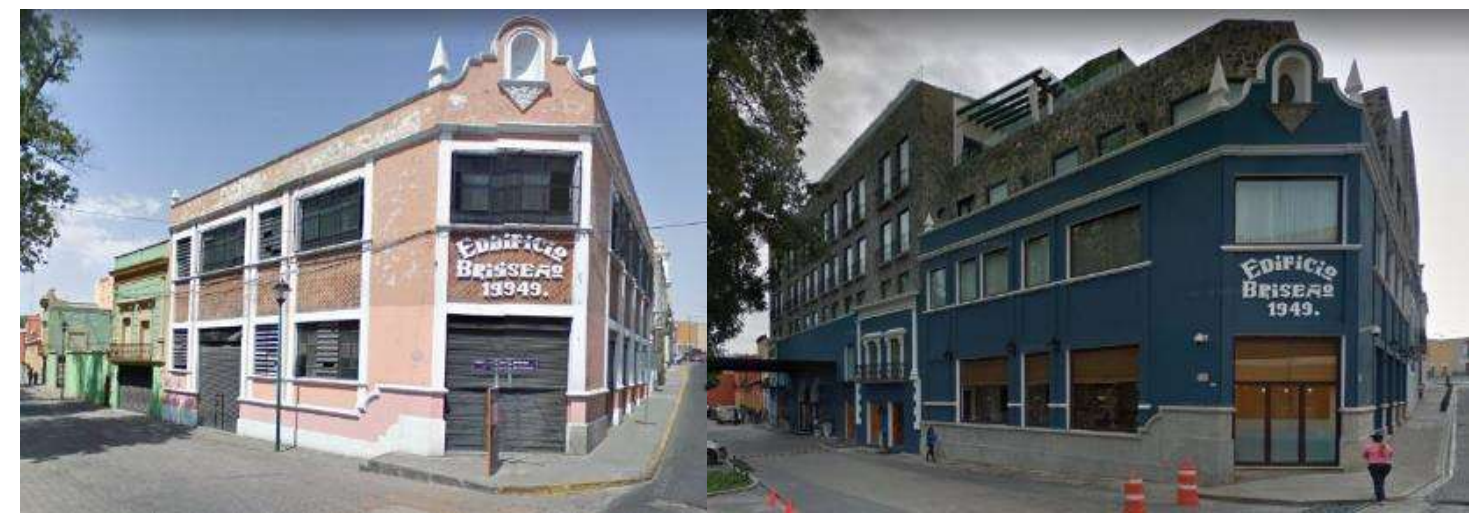

Figura 9. Cambio de uso de suelo a servicio turístico (hotel), avenida 14 oriente esquina con 10 norte, barrio del Alto. 
De igual forma, el Barrio de Xanenetla considerado también de gran valor histórico es parte de la zona de monumentos, el cual ha mantenido su uso de suelo y mayoría de la población. Sin embargo, al estar más alejado del centro histórico, tiene otra problemática de orden social originada por la inseguridad, provocando que sea considerado uno de los más peligrosos de la ciudad de Puebla. No obstante, esta situación ha permitido que dentro del barrio se desarrollen proyectos artísticos en busca de la participación comunitaria mediante la creación de murales que expresan la historia de cada familia, así como su identidad en espacios comunes (ver Fig. 10). De este modo, la implementación de este tipo de acciones ha coadyuvado a mitigar la degradación de la zona parcialmente.

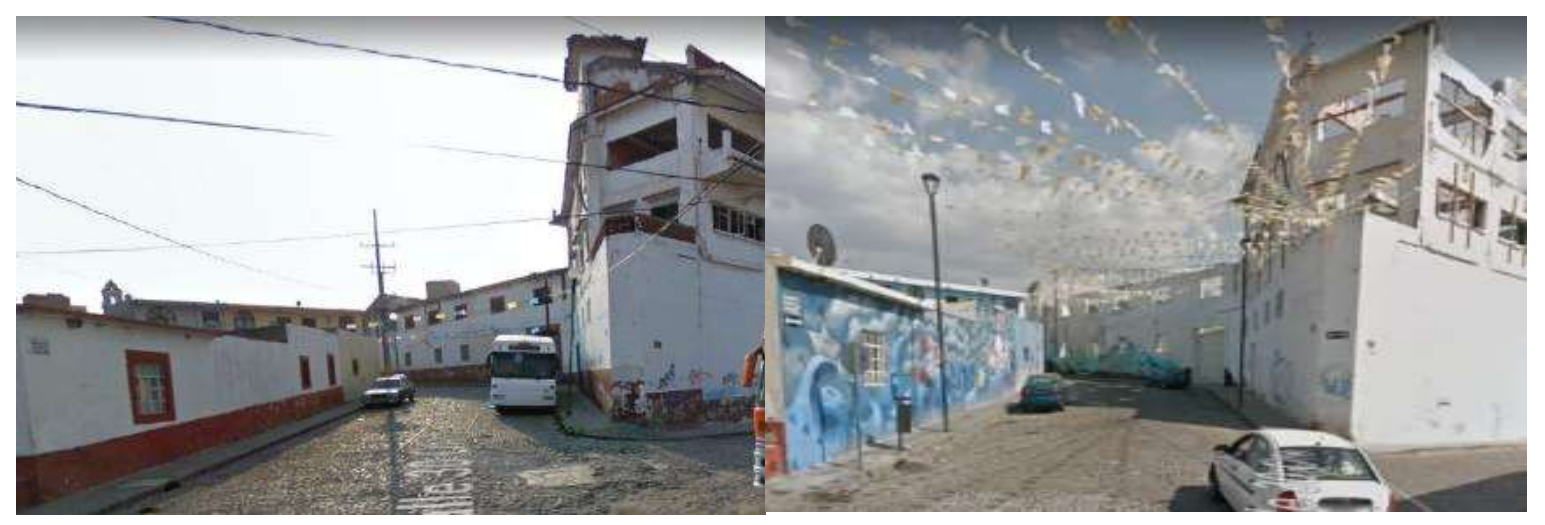

Figura 10. Proyecto "Ciudad Mural", rescate del patrimonio, barrio de Xanenetla. Calle 4 norte esquina con 30 oriente

\section{El origen de la gentrificación en el barrio de Analco}

Derivado de los procesos de transformación en la ciudad de Puebla, se inició la gentrificación de manera casi imperceptible al interior del barrio como consecuencia de proyectos de gran impacto en zonas cercanas a este, logrando identificar ampliamente este proceso a través del análisis de los cambios de uso del uso del suelo y la migración de sus habitantes. En consecuencia, observamos estos fenómenos no solo el barrio de Analco, sino en todos los barrios históricos de Puebla, los cuales han sufrido este impacto en los últimos veinte años, cada uno desde diversos contextos según sus características.

En el caso de Analco, desde el punto de vista urbano, ha sido notable el cambio del uso del suelo como una estrategia del gobierno para rescatar, revitalizar y reutilizar los 
espacios a través de la "dotación” de equipamiento, comercio y servicios, en algunas zonas e inmuebles degradados. También es cierto que con estas acciones se propicia la intervención de agentes ajenos al barrio que sin duda buscan los espacios históricos para desarrollar o emprender negocios que poco benefician a la población local y en nada ayudan a conservar sus rasgos distintivos. Claro ejemplo ha sido el mercado de artesanías del barrio, que, a pesar de tener gran afluencia durante los fines de semana, poco es el beneficio que deja a sus habitantes, pues en este caso la mayoría de los comerciantes son foráneos.

En la siguiente gráfica, mostramos el comportamiento de la actividad inmobiliaria durante los años 2013, 2015 y 2020 dentro del periodo de estudio (ver Tabla 2), observando no solo los datos duros del incremento de los precios en los valores unitarios del suelo en los barrios históricos de Puebla, sino también podemos identificar el origen de estos cambios en el uso del suelo a causa de factores principalmente económicos que conllevan a un proceso de gentrificación que aún se encuentra en vías de desarrollo.

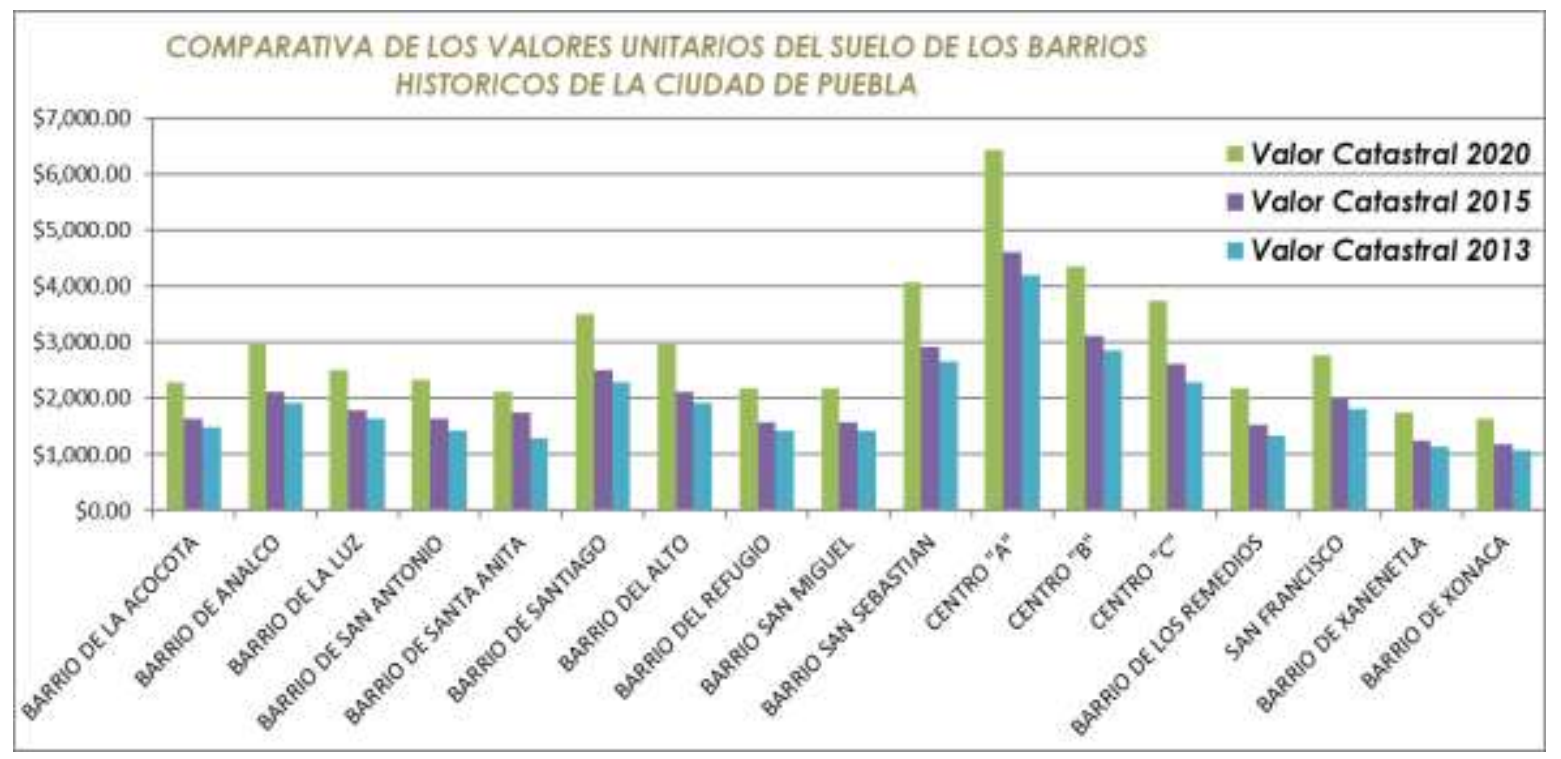

Tabla 2. Comparativa de los valores unitarios del suelo de los barrios históricos de la ciudad de Puebla. (Elaboración propia con información Catastral 2013,2015 y 2020).

Podemos observar que los barrios de Analco, Santiago, El Alto, San Sebastián, San Francisco que por su cercanía con la zona centro conservan los valores unitarios más altos 
del suelo elevando las expectativas de los especuladores beneficiados por el turismo cultural que atrae la zona centro. En el barrio de Analco no se identifican proyectos de gran impacto como en el de San Francisco, sin embargo, sufre lentamente los cambios del uso del suelo y la especulación que van ganando terreno frente a la pérdida del uso habitacional que detona más inseguridad y a la vez lo transforman haciendo más difícil conservar los edificios que forman parte del patrimonio cultural, aunado a la perdida de la riqueza cultural intangible y en consecuencia, dando paso inevitable al proceso de gentrificación en el barrio.

Estos cambios se perciben en el entorno urbano-arquitectónico del barrio de Analco durante los primeros veinte años del siglo XXI, a pesar de que existen diversos actores a favor de la conservación, desafortunadamente ha sido inevitable el deterioro del patrimonio cultural a causa de la especulación, afectando la memoria histórica cada vez menos conocido por los nuevos habitantes que forman parte de esta gentrificación. Derivado de la reactivación del centro histórico, en el barrio de Analco han coexistido una serie de transformaciones desde los ámbitos social, urbano, arquitectónico y económico, que de manera conjunta debido a la especulación repercuten en la perdida de la identidad cultural.

Por otra parte, el uso turístico en las proximidades de la iglesia repercute en la transformación del patrimonio con el desarrollo de nuevos espacios de acuerdo a los intereses y necesidades de particulares, como son hoteles y espacios de esparcimiento que refuerzan el proceso de gentrificación y exclusión social detonado posiblemente de manera inconsciente por la población local migrante que finalmente rompe con la integración urbanaarquitectónica que caracterizó a los barrios desde su fundación. 


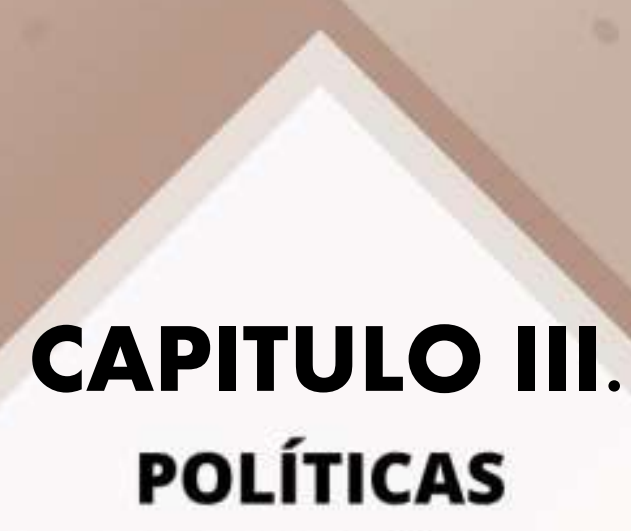

DE INTERVENCIÓN PARA EL RESCATE DEL PATRIMONIO CULTURAL POBLANO 


\section{POLÍTICAS DE INTERVENCIÓN PARA EL RESCATE DEL PATRIMONIO CULTURAL POBLANO}

En este apartado se hace una revisión de la legislación en forma general respecto al desarrollo de políticas de intervención para el rescate, protección y conservación del patrimonio cultural y de la actividad turística en el ámbito internacional y en los 3 niveles de gobierno durante los últimos 30 años. De esta manera, la exploración realizada a los instrumentos de planeación muestra las acciones específicas vinculadas directamente con el turismo y patrimonio cultural en el centro histórico de la Ciudad de Puebla, así como el impacto de las estrategias implementadas directamente en el barrio de Analco.

Comenzamos por destacar que, después de la conquista española y la imposición de su cultura, para garantizar la salvaguarda de la cultura nativa que logro preservarse surgieron leyes y organismos enfocados a la protección del patrimonio cultural de México. No obstante, los primeros instrumentos que se crearon buscaban la forma de impulsar la protección de zonas arqueológicas, de manera muy ambigua. De esta manera, durante el siglo XX, se observa un mayor número de instrumentos destinados al cuidado exclusivo de sitios arqueológicos y paisajes naturales, que fortalecerían el interés nacional para llevar un mejor control de los monumentos de forma aislada, siendo a partir de la publicación de la Ley federal sobre monumentos y zonas arqueológicas, artísticas e históricas en el año 1972 donde se amplía en México la protección, conservación, restauración y recuperación de no solo los monumentos arqueológicos, sino además los artísticos e históricos en estas zonas.

Actualmente la normativa de México, está enfocada en mayor medida a la preservación del patrimonio tangible, sin embargo, cada vez son más las organizaciones que fomentan la importancia de la cultura intangible, a pesar de que las nuevas prácticas en las ciudades históricas muestran poco interés por seguir promoviendo la preservación de la gran riqueza cultural hacia las futuras generaciones. Por lo anterior, es importante conocer la legislación actual, así como las políticas públicas vigentes que nos ayudaran con esta importante tarea entre la sociedad. 


\subsection{Legislación Internacional del Patrimonio Cultural y Desarrollo Urbano}

En la siguiente tabla, se muestran los principales documentos creados en el ámbito internacional para temas afines a esta investigación como son el patrimonio cultural y desarrollo urbano, de los cuales solo describimos los que consideramos más relevantes, (ver Tabla 3). Sin duda, los instrumentos a nivel internacional son un importante referente, puesto que han marcado la pauta normativa en este ámbito, a fin de buscar la preservación del patrimonio de todos los países, permitiendo que la esencia cultural, material e inmaterial de cada lugar permanezca para júbilo y conocimiento de futuras generaciones.

\begin{tabular}{|c|c|c|}
\hline \multicolumn{3}{|r|}{ Legislación internacional. } \\
\hline Tema & Año & Ley / Reglamento /Norma \\
\hline \multirow{11}{*}{$\begin{array}{c}\text { Patrimonio } \\
\text { Cultural }\end{array}$} & 1931 & Conferencia Internacional de Atenas, 1931; "Carta de Atenas" \\
\hline & 1964 & $\begin{array}{l}\text { Carta (de Venecia) Internacional sobre la Conservación y la Restauración de } \\
\text { Monumentos y de Conjuntos Histórico-Artísticos; II Congreso Internacional de } \\
\text { Arquitectos y Técnicos de Monumentos Históricos-Venecia 1964. Aprobada por } \\
\text { Icomos en } 1965 \text {. }\end{array}$ \\
\hline & 1967 & $\begin{array}{l}\text { Informe Final de la reunión sobre Conservación y Utilización de Monumentos y } \\
\text { lugares de interés Histórico y Artístico. (ICOMOS Normas de Quito) }\end{array}$ \\
\hline & 1972 & $\begin{array}{l}\text { Carta del restauro 1972, Anexo D, Instrucciones para la tutela de los "Centros } \\
\text { Históricos" }\end{array}$ \\
\hline & 1972 & Convención para la Protección del Patrimonio Mundial, Cultural y Natural, 1972 \\
\hline & 1976 & $\begin{array}{l}\text { Declaración de Nairobi. Recomendación Relativa a la Salvaguardia de los } \\
\text { Conjuntos Históricos y su Función en la Vida Contemporánea", } 1976\end{array}$ \\
\hline & 1977 & Decreto de la Zona de Monumentos Históricos (Ciudad de Puebla) \\
\hline & 1987 & $\begin{array}{l}\text { Carta internacional para la conservación de ciudades históricas y áreas urbanas } \\
\text { históricas (Carta de Washington) }\end{array}$ \\
\hline & 1987 & Declaratoria de Puebla como Patrimonio Cultural de la Humanidad" (Unesco, 1987) \\
\hline & 1994 & $\begin{array}{l}\text { Conferencia de Nara, Japón (Convención del Patrimonio Mundial) Documento de } \\
\text { Nara. }\end{array}$ \\
\hline & 2002 & $\begin{array}{l}\text { Convención para la Protección del Patrimonio Mundial Cultural y Natural, Año } \\
\text { 2002, Convención Internacional ONU }\end{array}$ \\
\hline $\begin{array}{l}\text { Desarrollo } \\
\text { Urbano }\end{array}$ & 2016 & Agenda 21 HABITAT III Quito. \\
\hline
\end{tabular}

Tabla 3. Legislación Internacional, elaboración propia.

\section{Conferencia Internacional de Atenas, 1931; "Carta de Atenas"}


Considera que, a partir de las condiciones de la vida moderna, los monumentos se ven amenazados por "agentes externos", aunado a la falta de reglas generales que regularan la actuación, por lo que recomienda "el respeto al carácter y la fisonomía de la ciudad al construir edificios, principalmente en la cercanía de monumentos antiguos, donde el ambiente debe ser objeto de un cuidado especial". Además, considera que la aplicación de estilos pasados en construcciones nuevas en un entorno de zonas históricas, no es favorable y no debe ser permitido, puesto que las obra pasadas surgen a partir de un conjunto de elementos estéticos y técnicos propios de cada generación y por ello la mezcla de estilos puede desembocar en una recomposición carente de los testimonios auténticos que tanto se desea preservar (Unesco, 1931a). En conclusión, se propone, con el fin de proteger los inmuebles, mantener en uso los espacios y en su caso, intervenciones que respeten el carácter histórico y artístico de los inmuebles; para la inclusión de edificios nuevos en contextos históricos, instruye el respeto de la imagen urbana de la zona. (Ramírez, 2014, pág. 199).

\section{Carta (Venecia) Internacional sobre la Conservación y la Restauración de Monumentos y de Conjuntos Histórico-Artísticos; II Congreso Internacional de Arquitectos y Técnicos de Monumentos Históricos-Venecia 1964. Aprobada por Icomos en 1965.}

"Las obras monumentales de los pueblos continúan siendo el testimonio vivo de tradiciones" la humanidad toma conciencia de estos valores y los considera "patrimonio común", por lo que se sabe responsable de la salvaguarda y transmisión con toda su autenticidad. En la carta, se define que cada nación deberá asegurar la conservación y restauración de sus monumentos en el marco de su propia cultura y tradiciones; en el artículo $1^{\circ}$, define que un monumento es "la creación arquitectónica aislada o el conjunto urbano o rural que da testimonio de una civilización, de una evolución significativa o de un acontecimiento histórico", sean obras modestas o monumentales con gran significado cultural. En el artículo $7^{\circ}$ referente a la conservación, establece que un monumento es testigo inseparable de la historia y lugar donde se ubica, por lo que resultaría inconcebible el desplazamiento de una parte o todo, excepto cuando existan razones que así lo justifiquen; en el artículo 9, indica la restauración de monumentos con el fin de conservar valores estéticos e históricos con base en su esencia antigua; el artículo $11^{\circ}$, expresa el respeto a las valiosas aportaciones en distintas épocas y 
estilos de construcción de los monumentos, justificando su desaparición solo bajo la condición de que ningún elemento sea de interés; en caso de restauración, el artículo $12^{\circ}$ indica que los elementos que reemplace a los inexistentes, deberán integrarse de manera armónica al conjunto, quedando perfectamente identificadas para eliminar la posibilidad de falsificación del monumento histórico. (Ramírez, 2014, págs. 201-202).

\section{Informe final de la reunión sobre Conservación y Utilización de Monumentos y lugares de interés Histórico y Artístico. ICOMOS Normas de Quito, 1967}

Las Normas de Quito mencionan la necesidad de conservar y utilizar el patrimonio cultural para impulsar el desarrollo del lugar donde los bienes culturales se consideren de valor económico, susceptibles de erigirse en instrumentos de progreso. La riqueza cultural de cada lugar, dependerá de la adecuada conservación y utilización de sus monumentos y lugares con valor histórico, ya que su inoportuno manejo podría desencadenar en su perdida. Entre los puntos tratados, se menciona que en diversas ciudades de Iberoamérica con un amplio patrimonio como "templos, plazas, fuentes y callejas" sufrieron degradaciones al punto de ser irreconocibles. En este sentido, la riqueza destruida por irresponsables actos de devastación urbanística, afecta la economía nacional que deriva en las mejoras de infraestructura, cuando en realidad estas acciones degradan el paisaje tradicional del sitio. (ICOMOS, 2005).

\section{Carta del restauro 1972, Anexo D, Instrucciones para la tutela de los "Centros Históricos"}

En el intento de contar con criterios uniformes para la conservación (entendida como salvaguarda y preservación) del patrimonio artístico se han reelaborado -considerando la antes existente Carta del Restauro de 1932, la cual refería la salvaguarda y restauración de monumentos- unas normas sobre restauración bajo la opinión del consejo superior de

antigüedades y bellas artes, incluyendo de este modo todo el patrimonio artístico. Tales 
normas referidas como la "carta del restauro 1972", , son normas técnico-jurídicas integradas por un informe y seguido por la carta dividida en artículos que describen el concepto de obra de arte, así como las definiciones, prohibiciones, estudio y uso de las operaciones de salvaguarda y restauración; en ella se describe la metodología para el reconocimiento e intervención en el campo de la restauración. Los anexos que forman parte de la carta, son considerados instrucciones para la salvaguarda y restauración de antigüedades, como es el caso del anexo A; el anexo B, refiere instrucciones para la ejecución de restauraciones arquitectónicas; el anexo C, señala instrucciones para la ejecución de restauración de pinturas y escultura, y finalmente el anexo D, que menciona instrucciones para la tutela de los centros históricos. (S/F, 1972).

\section{Convención para la Protección del Patrimonio Mundial, Cultural y Natural, 1972}

Actualmente el patrimonio cultural y natural, está siendo amenazado por constantes cambios en la vida de la población, evolución de la economía e implementación de tecnologías alternativas que facilitan las actividades diarias de la sociedad. La importancia de proteger el patrimonio, por ser único e irremplazable, obliga a identificar, proteger, conservar y transmitir a las generaciones futuras el patrimonio cultural y natural situado en su territorio actuando por su propio esfuerzo y hasta el máximo de los recursos de que disponga, beneficiado por la asistencia y la cooperación internacional en los aspectos financiero, artístico, científico y técnico (Convención, ONU 1972, art.4). A fin de garantizar la preservación del patrimonio cultural y natural, se creará el "Fondo del Patrimonio Mundial", como fondo fiduciario, de conformidad con las disposiciones pertinentes del Reglamento Financiero de la ONU (Convención, ONU 1972, art. 15.2). Además, los estados parte, están obligados a promover el respeto y la importancia de la protección del patrimonio cultural y natural, considerando en los programas de planificación general, las medidas jurídicas, científicas, técnicas, administrativas y financieras, adecuadas, así como la creación de centros nacionales o regionales, y estimulación de la investigación científica en este campo (Convención, ONU 1972, art. 5. d, e). (Ramírez, 2014, pág. 204).

\footnotetext{
${ }^{8}$ La "Carta del Restauro 1972" fue redactada por Cesare Brandi con la colaboración de Guglielmo De Angelis D’Ossat.
} 


\section{Declaración de Nairobi. Recomendación Relativa a la Salvaguardia de los Conjuntos Históricos y su Función en la Vida Contemporánea", 1976}

Con el fin de evitar la especulación, esta declaración establece recomendaciones de vigilancia permanente en apego a los criterios de salvaguardia del patrimonio cultural en todas las operaciones de reparación urbana o de rehabilitación. Considera la reglamentación y control de nuevas construcciones buscando la armonía en su arquitectura y protegiendo la imagen urbana de los conjuntos históricos a través de las operaciones de rehabilitación recomendadas tales como las instalaciones subterráneas, control de publicidad comercial, acceso a estacionamientos, mobiliario urbano y revestimientos del suelo. También se prevén medidas contra los desperfectos originados por la "explotación turística” y el exceso de vehículos, por lo que considera establecer redes de transporte que faciliten la circulación peatonal y de transporte. (Ramírez, 2014, pág. 208).

\section{Decreto de la Zona de Monumentos Históricos, 1977}

Se considerará zona de monumentos aquella que posee características ricas en cultura, como la representación de notables esfuerzos humanos desde el origen de su ciudad, este debe reflejar su tradición cultural y, conservar en gran parte, restos de sus construcciones prehispánicas con carácter monumental, elementos de su antiguo trazo, y que su historia haya sido trascendental para la historia mundial. Para el caso del centro histórico de puebla, se tomaron en cuenta variables como su valor, carácter, su estado de conservación, transformación, época de origen de los inmuebles y los usos del suelo. Para preservar el legado histórico, cualquier acción que se realice sobre éste, se sujete a las condiciones establecidas en las disposiciones legales aplicables, así como cualquier obra de construcción, restauración o conservación en zona de monumentos históricos, procurando evitar que dichas acciones lleguen a alterar la armonía urbana de la zona. Corresponde a la autoridad competente autorizar y otorgar el permiso para la realización de cualquier obra dentro del perímetro de la zona de monumentos históricos. (Ramírez, 2014, pág. 217). 
Carta internacional para la conservación de ciudades históricas y áreas urbanas históricas (Carta de Washington)

Dicha carta es creada con el objetivo de la conservación de todos los conjuntos urbanos del mundo, ya que como lo establece esta son resultados de los procesos graduales de desarrollo, y por ende son la expresión material de la diversidad de las sociedades a lo largo de la historia. Esta tiene inferencia en todo tipo de poblaciones, pero concretamente, los cascos, centros, barrios, barriadas, arrabales, u otras zonas que posean dicho carácter.

Frente a la amenaza para la conservación de ciudades históricas, el Consejo Internacional de Monumentos y Sitios Históricos (ICOMOS), ha juzgado necesario redactar dicha carta, donde se definen los principios, objetivos, métodos e instrumentos de actuación apropiados para conservar la calidad de las poblaciones y áreas urbanas históricas y favorecer la armonía entre la vida individual y colectiva, permitiendo así la construcción de la memoria de la humanidad.

Mediante la participación y el compromiso ciudadano, el cual es imprescindible para conseguir la conservación de la población o área urbana histórica. Por lo que es necesario que exista una planificación para conservación de las poblaciones y áreas urbanas históricas esta debe ser precedida por estudios multidisciplinares. Debe existir un plan de conservación que comprenda desde un análisis de datos, particularmente arqueológicos, históricos, arquitectónicos, técnicos, hasta análisis de datos, sociológicos y económicos. Para que el plan de conservación logre una relación armónica entre el área urbana histórica y el conjunto de la población. (ICOMOS, 2017).

\section{Declaratoria de Puebla como Patrimonio Cultural de la Humanidad" (Unesco, 1987)}

El 11 de diciembre de 1987, el Comité del Patrimonio Mundial de la UNESCO, inscribe al Centro Histórico de la Ciudad de Puebla en la "Lista del Patrimonio Mundial" debido a su legado histórico y cultural, el cual se considera único y un testimonio vivo de la cultura para las generaciones venideras. Los elementos que han sido considerados por la UNESCO para su nombramiento son: 
- Valor Universal por su valor universal excepcional fundada ex nihilo en 1531.

- Es una ciudad colonial llena de riquezas naturales y culturales; rodeado por majestuosos volcanes -Popocatépetl, Iztaccíhuatl y Citlaltépetl.

- Su ubicación estratégica entre el puerto de Veracruz y la Ciudad de México la convierte en un importante corredor de transporte permitió la exportación de su estilo regional de arquitectura barroca, una fusión de estilos europeos e indígena, después del siglo XVI.

- El centro histórico de Puebla integrado por importantes edificios religiosos como la Catedral, las iglesias de Santo Domingo, San Francisco, la Iglesia de los Jesuitas y el antiguo palacio arzobispal.

- Integridad en la conservación de su integridad principalmente a través de su estructura original del Renacimiento, establecido a mediados del siglo XVI.

- La autenticidad de la ciudad, la cual, a pesar de haber sufrido innumerables cambios, todavía contiene muchos edificios religiosos (Cruz de los Ángeles, Pérez Paredes, Torralba Flores, Bonilla Gasca, 2017).

\section{Conferencia de Nara, Japón (Convención del Patrimonio Mundial) Documento de Nara.}

Con el fin de buscar nuevos horizontes para la preservación y respeto hacia la diversidad cultural y patrimonial, el Comité del Patrimonio Mundial concede un respeto pleno a los valores sociales y culturales de todas las sociedades, al examinar el valor universal de los bienes culturales propuestos para que formen parte de la Lista del Patrimonio Mundial. Dicho documento sobre la Autenticidad con base en la Carta de Venecia de 1964, se fundamenta en él y lo extiende en respuesta a intereses del mundo contemporáneo. Este documento hace énfasis en la protección y conservación de la diversidad cultural y patrimonial en el mundo, la cual se debe divulgar de manera activa, esencialmente para el desarrollo humano de manera que se conozcan todas las culturas, formas y medios particulares de expresión tangibles e intangibles que constituyen su patrimonio. Tiene como objetivo fomentar la responsabilidad con el patrimonio cultural y su comunidad, además, busca el comprender su significado, para valorar todos los aspectos de su autenticidad como un papel fundamental en todos los estudios científicos del patrimonio cultural, así como en los planes de restauración y preservación del mismo, así como en los procedimientos de inscripción e inventarios 
utilizados por la Convención del Patrimonio Mundial con una visión más inclusiva de la diversidad cultural. (INAH, 2018).

\section{Convención para la Protección del Patrimonio Mundial Cultural y Natural, Convención Internacional ONU (2002)}

A pesar del interés general por la preservación del patrimonio y de la conciencia existente sobre su pérdida, son mínimas las acciones llevadas a cabo para la salvaguardia de este. Se menciona su importancia y varios son los instrumentos que se han implementado para la preservación del patrimonio material, pero ¿qué pasa con el patrimonio inmaterial? Se deja de lado a pesar de que comparten la misma importancia y prueba de ello es que actualmente no se cuenta con instrumentos legales suficientes destinados exclusivamente a la preservación y salvaguardia del patrimonio inmaterial. En consecuencia, surge la necesidad de fomentar la importancia del patrimonio cultural inmaterial y de su salvaguardia, entre la sociedad y especialmente las generaciones recientes.

Para suscitar un mayor nivel de conciencia en la humanidad, la UNESCO en su $32^{\circ}$ reunión, convoco a la Convención para la Salvaguardia del Patrimonio Cultural Inmaterial (Paris, 2003), donde los Estados parte consideraron pertinente la integración de recomendaciones y resoluciones internacionales existentes mediante nuevas disposiciones inherentes al patrimonio cultural inmaterial, con base en la valiosa función que cumple como componente de unión, intercambio y entendimiento entre la sociedad. La Convención para la Salvaguardia del Patrimonio Cultural Inmaterial, se realizó a fin de trabajar en (Paris, 2003), ART. 1:

a) la salvaguardia del patrimonio cultural inmaterial;

b) el respeto del patrimonio cultural inmaterial de las comunidades, grupos e individuos de que se trate;

c) la sensibilización en el plano local, nacional e internacional a la importancia del patrimonio cultural inmaterial y de su reconocimiento recíproco;

d) la cooperación y asistencia internacionales.

\section{Agenda 21 HABITAT III Quito.}


Dicho documento trata temas sobre vivienda y el Desarrollo Urbano Sostenible los objetivos de la conferencia son asegurar un compromiso político renovado para el desarrollo urbano sostenible, evaluar los logros hasta la fecha, identificar la pobreza y abordar desafíos nuevos. Por lo que el documento tiene una visión de futuro, orientado a la acción. Para la investigación se analizó el apartado 4 - cultura urbana y patrimonio, en dicho apartado se analiza y establece la función histórica de las ciudades y la cultura reconocida como un recurso clave y activo para el desarrollo urbano sostenible. La cultura, se vuelve una fuerza impulsora del desarrollo urbano ya que, como parte de los procesos sociales, es lo que nos lleva al patrimonio urbano el cual refleja identidades, expectativas y visiones de las sociedades a través del tiempo. Por lo anterior, la agenda busca incluir los Objetivos de Desarrollo Sostenible (ODS), dedicado a la cultura en "ciudades sostenibles", lo que permitirá firmemente el reconocimiento internacional de la cultura dentro de la planificación urbana estratégica, disminuyendo las amenazas contra esta y el patrimonio urbano, mediante políticas de conservación. Al hablar de cultura y patrimonio, inevitablemente se habla de turismo por ser controversial, sin embargo, en la agenda se establece que, potencialmente puede dañar la capacidad de las comunidades en salvaguardar y transmisión de su patrimonio e identidad cultural. En consecuencia, se vuelve indispensable crear, implementar y promover estrategias urbanas culturalmente sensibles que permitan construir ciudades resilientes e incluyentes. Lo que nos llevara a la mejora de la cultura local y el reconocimiento de la diversidad cultural permitiéndonos mitigar diferentes amenazas urbanas. (UNESCO, Agenda 21, 2016)

\subsection{Legislación Nacional Mexicana de Patrimonio Cultural y Desarrollo Urbano}

Dentro del marco legal mexicano que gestiona las actividades turísticas relacionadas a la cultura, existe un número considerable de leyes y dependencias gubernamentales encargadas de regular y promover dicha actividad en México, desde la Constitución política pasando por el plan nacional de desarrollo y la ley federal de turismo. Estas leyes contemplan al turismo como una fuente de desarrollo económico que impulsa la práctica de actividades con fines recreativos, deportivos, educativos y culturales en condiciones adecuadas de economía, seguridad y comodidad, a manera de promover el turismo social, así como fortalecer el 
patrimonio histórico y cultural de cada región del país, (ver Tabla 4). Con respecto al sector social y privado, estos, en conjunto con los gobiernos locales y municipales, tienen la obligación de ejecutar y elaborar de manera coordinada programas destinados a fomentar el turismo social. Además, con el apoyo de dependencias y entidades se deben promover convenios con prestadores de servicios para la propagación del conocimiento en beneficio de la actividad turística, de manera que no se deje de lado la importancia del respeto y la conservación del patrimonio.

\begin{tabular}{|c|c|c|}
\hline \multicolumn{3}{|c|}{ Legislación Nacional Mexicana. } \\
\hline Tema & Año & Ley / Reglamento /Norma \\
\hline \multirow{4}{*}{ Patrimonio Cultural } & 2015 & $\begin{array}{l}\text { Ley orgánica del Instituto Nacional de Antropología e } \\
\text { Historia. }\end{array}$ \\
\hline & $2007-2012$ & El proyecto nacional de catálogo, CONACULTA \\
\hline & 2018 & $\begin{array}{l}\text { Ley Federal Sobre Monumentos Y Zonas Arqueológicas, } \\
\text { Artísticas e Históricas. (Última Reforma DOF 16-02-2018) }\end{array}$ \\
\hline & 2020 & $\begin{array}{l}\text { Constitución Política De Los Estados Unidos Mexicanos. } \\
\text { (Última reforma publicada DOF 08-05-2020) }\end{array}$ \\
\hline \multirow{3}{*}{ Desarrollo Urbano } & 2015 & Legislación mexicana de Turismo Cultural \\
\hline & 2019 & $\begin{array}{l}\text { Ley General De Asentamientos Humanos, Ordenamiento } \\
\text { Territorial Y Desarrollo Urbano. }\end{array}$ \\
\hline & $2019-2024$ & Plan Nacional de Desarrollo \\
\hline
\end{tabular}

\section{Ley orgánica del Instituto Nacional de Antropología e Historia INAH (2015).}

En ella se establecen los objetivos generales en relación con la población del país y con la protección, conservación, restauración y recuperación del patrimonio cultural, arqueológico, histórico y paleontológico; así como la promoción y difusión de actividades y funciones que son de su competencia:

I. Deberá aplicar leyes, reglamentos, decretos y acuerdos en materia de su competencia.

II. Efectuar investigaciones científicas que interesen a la Arqueología, Antropología, Etnografía e Historia de México.

III. El otorgar los permisos y dirigir las labores de restauración y conservación de los monumentos arqueológicos e históricos. 
Además de estas funciones esta la aplicación y creación de instrumentos de conservación y restauración, sin embargo, también será capaz de adquirir y administrar bienes que formarán su patrimonio, trabajar en el rescate y difusión del patrimonio cultural inmaterial y sobre todo el llevar el registro público de las zonas y monumentos arqueológicos e históricos permitiendo así su salvaguarda. (LEY ORGÁNICA DEL INSTITUTO NACIONAL DE ANTROPOLOGÍA E HISTORIA, 2015)

\section{El proyecto nacional de catálogo, CONACULTA. (2007 - 2012)}

El INAH, ha realizado e integrado los catálogos en cada una de las Entidades Federativas de México, en un trabajo complejo que se sigue actualizando y promoviendo en alianza con las autoridades locales y delegacionales. Estos catálogos monumentales solo hacen el seguimiento evolutivo del inmueble, basado en información de los hallazgos de investigaciones. Además, contienen los bienes nacionales en un instrumento flexible que se enriquece y actualiza constantemente con el manejo de la información cambiante que la Coordinación Nacional de Monumentos Históricos ha trasladado a un soporte magnético, integrado por fichas (con un número clave de identificación, nombre, uso original y el actual, época de construcción entre otras características). Esta información es de disposición pública para la óptima gestión y salvaguarda del patrimonio por parte de autoridades, especialistas y sociedad en general, así como con fines aplicados a estudios de investigación. (INAH, 2012)

\section{Ley federal sobre monumentos y zonas arqueológicas, artísticas e históricas (2018)}

Esta ley fue publicada en el Diario Oficial de la Federación en el año 1972 y declara en el artículo 2 "de utilidad pública, la investigación, protección, conservación, restauración y recuperación de los monumentos arqueológicos, artísticos e históricos y de las zonas de monumentos"9. -Además, añade que concierne a las autoridades de los diferentes niveles gubernamentales realizar campañas permanentes para fomentar su conocimiento y respeto (Gobierno Federal, 1972). En el artículo 21 declara que "se crea el Registro Público de

\footnotetext{
${ }^{9}$ Última reforma publicada. DOF, 13 de enero de 1986.
} 
Monumentos y Zonas Arqueológicas e Históricos, dependientes del INAH y el Registro Público de Monumentos y Zonas Artísticas, dependientes del Instituto Nacional de Bellas Artes y Literatura, para la inscripción de monumentos arqueológicos, históricos o artísticos y las declaratorias de zonas respectivas" (Gobierno Federal, 1972).

Considera monumentos arqueológicos a los bienes muebles e inmuebles anteriores a la cultura hispánica; monumentos artísticos a aquellos bienes que revistan valor estético relevante como la representatividad, la inserción en una corriente estilística, los grados de innovación, los materiales y técnicas utilizadas. Con base en esta ley, en el año de 1977 el centro histórico de la ciudad de Puebla fue por decreto federal declarada Zona de Monumentos Históricos en la Ciudad de Puebla de Zaragoza.

\section{Constitución Política de los Estados Unidos Mexicanos (2020)}

Establece en su artículo 115, fracción V, entre sus diversos e importantes incisos que los municipios están facultados para "formular, aprobar y administrar la zonificación y planes de desarrollo urbano municipal", así como también, deberán participar en la creación y administración de reservas territoriales, en planes y programas de desarrollo regional alineados a los de nivel federal, si los hubiera.

Entre las facultades de mayor importancia en materia de desarrollo urbano, los municipios deberán regular el uso del suelo en sus jurisdicciones territoriales y de tenencia de la tierra y participar en la administración de zonas de reservas ecológicas y en la creación y aplicación de programas de ordenamiento en la materia. (Gobierno Federal, 1917) ${ }^{10}$.

\section{Legislación Mexicana de Turismo Cultural (2015)}

Esta Ley es de orden público e interés social, de observancia general en toda la República en materia turística, correspondiendo su aplicación en forma concurrente al Ejecutivo Federal, por conducto de la Secretaría de Turismo, y en el ámbito de sus respectivas competencias a

\footnotetext{
${ }^{10}$ Última reforma publicada. DOF, 10 de julio de 2015.
} 
las Dependencias y Entidades de la Administración Pública Federal, así como a los Estados, Municipios y el Distrito Federal.

\section{Ley General de Asentamientos Humanos, Ordenamiento Territorial y Desarrollo urbano (2019)}

La presente ley es de orden público y tiene como objetivo fijar normas básicas e instrumentos de gestión, para la planeación, ordenamiento y regulación del territorio y los asentamientos humanos en el país. Define criterios en el ámbito de sus respectivas competencias para que exista congruencia, coordinación y participación entre la Federación y sus entidades, municipios y demarcaciones territoriales para la planeación de la fundación, crecimiento, mejoramiento, consolidación y conservación de los centros de población, la protección y el acceso equitativo a los espacios públicos. Además, propicia mecanismos de participación ciudadana, en particular con mujeres, jóvenes y personas en situación de vulnerabilidad, en los procesos de planeación y gestión del territorio con base en el acceso a información (UNIÓN, 2019).

\section{Plan Nacional de Desarrollo PND (2019-2024)}

El PND estipula políticas de desarrollo enfocadas a tres principales temáticas como son política y gobierno, política social y economía, entre las cuales se pretende crear un modelo de desarrollo económico, ordenamiento político y convivencia entre los sectores sociales, en apego a los principios rectores definidos en esta propuesta. (Gobierno Federal, 2019)

\subsection{Legislación Estatal de Patrimonio Cultural y Desarrollo Urbano en Puebla}

En este apartado, se describe a través de los planes y programas estatales cómo ha sido la evolución de las políticas de acción en temas de cultura y patrimonio (ver Tabla 5), así como aquellos que directa o indirectamente inciden en el desarrollo de la actividad turística. En esta exploración se muestra la principal problemática que existe entre el turismo cultural y patrimonio en el centro histórico de la ciudad de Puebla. También nos referimos a los 
objetivos, estrategias y líneas de acción creadas en torno al Programa de Desarrollo Angelópolis, al Plan para la Recuperación de la Zona de Monumentos del Centro Histórico de la Ciudad de Puebla (2000) y algunos Planes y Programas de Desarrollo elaborados para la ciudad, el municipio y el estado de Puebla. Destaca, dentro del Programa de desarrollo Regional Angelópolis, una breve descripción de las acciones específicas para el Rescate del Centro Histórico de la Ciudad de Puebla (Paseo del Río de San Francisco), dentro del cual se han realizado diversas actividades de restauración y adaptación de funciones; en él se integran una diversidad de estrategias con el fin de elevar el potencial económico de Puebla.

\begin{tabular}{|c|c|l|}
\hline \multicolumn{2}{|c|}{ Legislación Estatal en Puebla. } \\
\hline \multirow{2}{*}{ Tema } & Año & \multicolumn{1}{c|}{ Ley / Reglamento /Norma } \\
\hline \multirow{3}{*}{ Patrimonio Cultural } & 1977 & $\begin{array}{l}\text { Decreto por el que se declara una Zona de Monumentos } \\
\text { Históricos en la Ciudad de Puebla de Zaragoza. }\end{array}$ \\
\cline { 2 - 3 } & 2000 & $\begin{array}{l}\text { Plan para la Recuperación de la Zona de Monumentos } \\
\text { del Centro Histórico de la Ciudad de Puebla. }\end{array}$ \\
\cline { 2 - 3 } & 2005 & $\begin{array}{l}\text { Decreto del ejecutivo del Estado que declara “Zona } \\
\text { típica Monumental” parte de la ciudad de Puebla, } \\
\text { Municipio del mismo nombre del Estado de Puebla. }\end{array}$ \\
\cline { 2 - 4 } Desarrollo urbano & 2011 & $\begin{array}{l}\text { Ley de Fomento a la Cultura del Estado Libre y } \\
\text { Soberano de Puebla }\end{array}$ \\
\hline & $2011-2017$ & $\begin{array}{l}\text { Ley sobre protección y conservación de poblaciones } \\
\text { típicas y bellezas Naturales en el Estado de Puebla. }\end{array}$ \\
\cline { 2 - 4 } & 2005 & $\begin{array}{l}\text { Plan Estatal de Desarrollo. } \\
\text { Puebla. }\end{array}$ \\
\hline
\end{tabular}

Tabla 5 Legislación Estatal Puebla, elaboración propia.

\section{Decreto por el que se declara una Zona de Monumentos Históricos en la Ciudad de Puebla de Zaragoza (1977).}

El 18 de noviembre de 1977 se publicó el decreto por el cual se declara Zona de Monumentos Históricos en la Ciudad de Puebla de Zaragoza, con una superficie de 6.9 km2. Las características formales de edificación de la ciudad de Puebla, la relación de espacios y su estructura urbana, son testimonio del "excepcional valor" para la historia social, política y del arte en México. Esta zona, es parte importante del patrimonio cultural 
a nivel nacional, por ser la expresión cultural prehispánica y mestiza que logró gran originalidad en las manifestaciones estéticas, principalmente su arquitectura civil y religiosa, que integradas conforman un extraordinario conjunto urbano. Por ello, este decreto se emitió para atender convenientemente la preservación del legado histórico de la zona e incorporarla al régimen previsto por la Ley Federal sobre Monumentos y Zonas Arqueológicas, Artísticos e Históricos y su Reglamento, así como para protección, conservación, restauración y recuperación de los elementos que la integran. (Gobierno de Mexico, 2016)

Plan para la Recuperación de la Zona de Monumentos del Centro Histórico de la Ciudad de Puebla (2000).

Este Plan manifiesta una de las tendencias para considerar al patrimonio histórico-cultural como un elemento dinamizador de la economía de las ciudades históricas que lo poseen, donde el patrimonio es considerado como un capital a través del cual se apuesta a favor del desarrollo y la mejora de la calidad de vida de los habitantes, ya que por su gran diversidad de bienes muebles e inmuebles, que además de ofrecer su historia, leyenda o tradición, acervos documentales, etc., también deben servir como recursos turísticos y elementos a considerar en nuevas estrategias de desarrollo turístico-culturales. Anteriormente, las estrategias planteadas eran superficiales, por ello, este plan propone hacer un análisis a fondo que permita la recuperación del Centro Histórico de la ciudad de Puebla, desarrollado en un marco de políticas de conservación, revitalización, reutilización, mejoramiento y consolidación. El plan propone 12 acciones entre la que destacan las de conservación y restauración de inmuebles y patrimonio cultural, las cuales a su vez consideran 21 proyectos estratégicos, dirigidos al mejoramiento de la imagen urbana y vivienda entre otros temas, sin embargo, cada una de estas propuestas se han pensado a largo plazo con el fin de que cada una otorgue beneficios para el centro histórico de la ciudad de Puebla.

Decreto del ejecutivo del Estado que declara "Zona típica Monumental" parte de la ciudad de Puebla, Municipio del mismo nombre del Estado de Puebla (2005).

Decreto creado considerando: 
- Que las Zonas Típicas Monumentales son áreas peculiares creadas por el hombre, que, con el tiempo, han adquirido valores ambientales, etnográficos, históricos, arquitectónicos, artísticos y de diversa índole, justificando así su protección y mejoramiento, para el caso particular de la ciudad de Puebla. (GOBIERNO DEL ESTADO, 2005)

- Que la preservación del entorno ecológico y la cultura que de él se deriva, debe ser impostergable para conservar el patrimonio cultural, no solo de los poblanos y mexicanos, sino de la humanidad entera. (GOBIERNO DEL ESTADO, 2005)

- Que, la zona de monumentos de la ciudad de Puebla, obra del hombre en su más elevado sentido, va configurando el patrimonio cultural de un grupo social, plasmado en el idioma, costumbres, creación artística y demás rasgos sobresalientes. (GOBIERNO DEL ESTADO, 2005)

\section{Ley de Fomento a la Cultura del Estado Libre y Soberano de Puebla (2011).}

\section{Disposiciones Generales}

Artículo 10.- Las disposiciones de esta Ley son de orden público y de observancia general en el territorio del Estado de Puebla.

Artículo 2o.- Esta Ley tiene por objeto:

I.- Garantizar en el Estado de Puebla el disfrute, preservación, promoción, difusión y recreación de la cultura que, como derecho en la vida cultural, todo habitante tiene;

II.- Regular estructura y funcionamiento de Autoridades e Instituciones Públicas encargadas de la preservación, difusión, promoción e investigación de la actividad cultural;

III.- Promover la participación de individuos, grupos y organizaciones privadas en la preservación, promoción, fomento, difusión e investigación de la cultura;

IV.- Fomentar mecanismos de coordinación con órganos federales, estatales, municipales e instituciones privadas para la difusión, promoción e investigación de la actividad cultural en el Estado; 
V.- Establecer las bases para que las actividades culturales en el Estado lleguen a todos los sectores de la población. (Congreso de Puebla, 2011)

\section{Ley sobre protección y conservación de poblaciones típicas y bellezas Naturales en el Estado de Puebla (2017).}

El artículo 3 declara, de utilidad pública la protección, conservación y restauración de las áreas de belleza natural ubicadas dentro del territorio estatal; de las poblaciones o parte de ellas; de edificaciones o conjuntos dignos de ser protegidas, por su valor arquitectónico, cultural o típico que sea característico del Estado o de una región del mismo... El artículo 41, menciona que, el Ayuntamiento de una población o parte de ella, o áreas de belleza natural declaradas 'Zona Típica Monumental', procurarán su conservación, haciendo lo necesario dentro de sus posibilidades presupuestales... (Gobierno de Puebla, 2017)

\section{Plan Estatal de Desarrollo 2011 - 2017.}

Puebla es un estado con diversos atractivos turísticos naturales, culturales, gastronómicos y artesanales, por lo que, este plan de desarrollo, considera acciones estratégicas con intención de crear empleos que contribuyan a transformar el estado. Por ello, se identificó la necesidad de atraer mayor número de turistas mediante un plan de mercadotecnia que promueva las riquezas del estado en el ámbito nacional e internacional. (Gobierno del Estado de Puebla, 2017). También se busca detonar el impulso de municipios y rutas turísticas enfocadas al disfrute y aprovechamiento del turismo natural, rural, de aventura, cinegético, cultural y religioso del estado, para lo cual se considera importante la promoción de inversionistas del sector público y privado para el desarrollo de proyectos viables que satisfagan la demanda turística.

\section{Ley de Planeación para el desarrollo del Estado de Puebla (2005).}

Las disposiciones de esta ley, son de orden público e interés social y establecen normas y principios fundamentales de acuerdo a los cuales se llevará a cabo la planeación del desarrollo económico, social, político y cultural en el estado, mediante la creación de lineamientos que integran y operan el Sistema Estatal de Planeación Democrática. Además, 
establecen las bases para que el Ejecutivo Estatal coordine actividades de planeación con los Municipios de la Entidad de acuerdo a la legislación aplicable, así como las bases para promover y garantizar la participación demócrata de diversos grupos sociales, a través de su representación organizada para la elaboración de planes y programas.

Este instrumento, promueve la planeación en la búsqueda de un desarrollo económico, social, político y cultural que beneficie a las mayorías, con el fin de que su proceso, sirva a los intereses de la sociedad, a través de acciones que adopten enfoques globales y transformar la dinámica del proceso económico y social, con la participación de la sociedad en su conjunto. Por otra parte, establece que toda acción que se realice, debe ser congruente con los objetivos de desarrollo económico y social, asegurando la atención de las necesidades básicas de la población y la mejora, en todos los aspectos de la calidad de vida, logrando así una sociedad más igualitaria. (Gobierno del Estado, 2015)

\subsection{Legislación Municipal del Patrimonio Cultural y Desarrollo Urbano en Puebla.}

Consideramos importantes los instrumentos que hemos descrito con anterioridad por que en ellos se definen lineamientos generales que marcan la pauta a seguir en relación al patrimonio cultural y desarrollo urbano en los diferentes niveles de gobierno, sin embargo, sabemos que no son menos importantes los instrumentos locales o municipales, puesto que en ellos destaca la particularidad de acciones específicas para los temas que nos ocupan, por lo que en este apartado destacamos las más importantes en torno al tema (ver Tabla 6).

\begin{tabular}{|c|c|l|}
\hline \multicolumn{2}{|c|}{ Legislación Municipal en Puebla. } \\
\hline Tema & Año & \multicolumn{1}{|c|}{ Ley / Reglamento /Norma } \\
\hline \multirow{3}{*}{ Patrimonio Cultural } & 1999 & $\begin{array}{l}\text { Plan para la Recuperación de la Zona de Monumentos } \\
\text { en la Ciudad de Puebla }\end{array}$ \\
\cline { 2 - 3 } & 2015 & $\begin{array}{l}\text { Plan de Manejo del Programa Parcial del Centro } \\
\text { Histórico. }\end{array}$ \\
\hline
\end{tabular}




\begin{tabular}{|c|c|l|}
\hline \multirow{5}{*}{2015} & $\begin{array}{l}\text { Programa Parcial de Desarrollo Urbano Sustentable del } \\
\text { Centro Histórico del Municipio de Puebla. }\end{array}$ \\
\cline { 2 - 3 } & 2018 & $\begin{array}{l}\text { Código Reglamentario Para El Municipio De Puebla, } \\
\text { COREMUN }\end{array}$ \\
\hline \multirow{5}{*}{ Desarrollo Urbano } & 1994 & Creación del Fideicomiso del Paseo del San Francisco. \\
\hline $1993-2002$ & $\begin{array}{l}\text { El Programa de Desarrollo Regional Angelópolis y el } \\
\text { Municipio de Puebla. Rescate del Centro Histórico de } \\
\text { La Ciudad de Puebla (Paseo del Río de San Francisco) }\end{array}$ \\
\hline $2011-2017$ & $\begin{array}{l}\text { Actualización del Programa Regional de Desarrollo. } \\
\text { Región Angelópolis. }\end{array}$ \\
\hline $2014-2018$ & Programa de Desarrollo Urbano de la Ciudad de Puebla. \\
\hline & $2018-2021$ & Plan Municipal de Desarrollo Urbano. \\
\hline & Tabla 6. Legis/ación Municipal en Puebla, elaboración propia.
\end{tabular}

\section{Plan para la Recuperación de la Zona de Monumentos en la Ciudad de Puebla (1999)}

El Plan registra 2,619 construcciones consideradas monumentos históricos, divididas en 5 categorías en los 4 cuadrantes de la zona. (ver Fig. 11). De igual forma, se han identificado el número de inmuebles por cada cuadrante en cada una de las 5 categorías (ver Tabla. 7), donde se aprecia el vasto patrimonio arquitectónico de Puebla, ubicado en la Zona de Desarrollo Turístico Prioritario junto con su variedad de estilos, épocas de construcción, usos, etc. Entre los monumentos más representativos, se encuentra la Basílica de la Catedral, la Iglesia de la Compañía de Jesús, el templo barroco de San Cristóbal, el Templo de Santo Domingo donde destaca en su interior la Capilla de la Virgen del Rosario. 
Entre la gran riqueza arquitectónica de Puebla, se distinguen el edificio Carolino, de estilo clásico renacentista y el Palacio Municipal de estilo neoclásico, cuyos portales le dan un realce como ciudad española desde su fundación. ( H. Ayuntamiento del Municipio de Puebla, 2008).

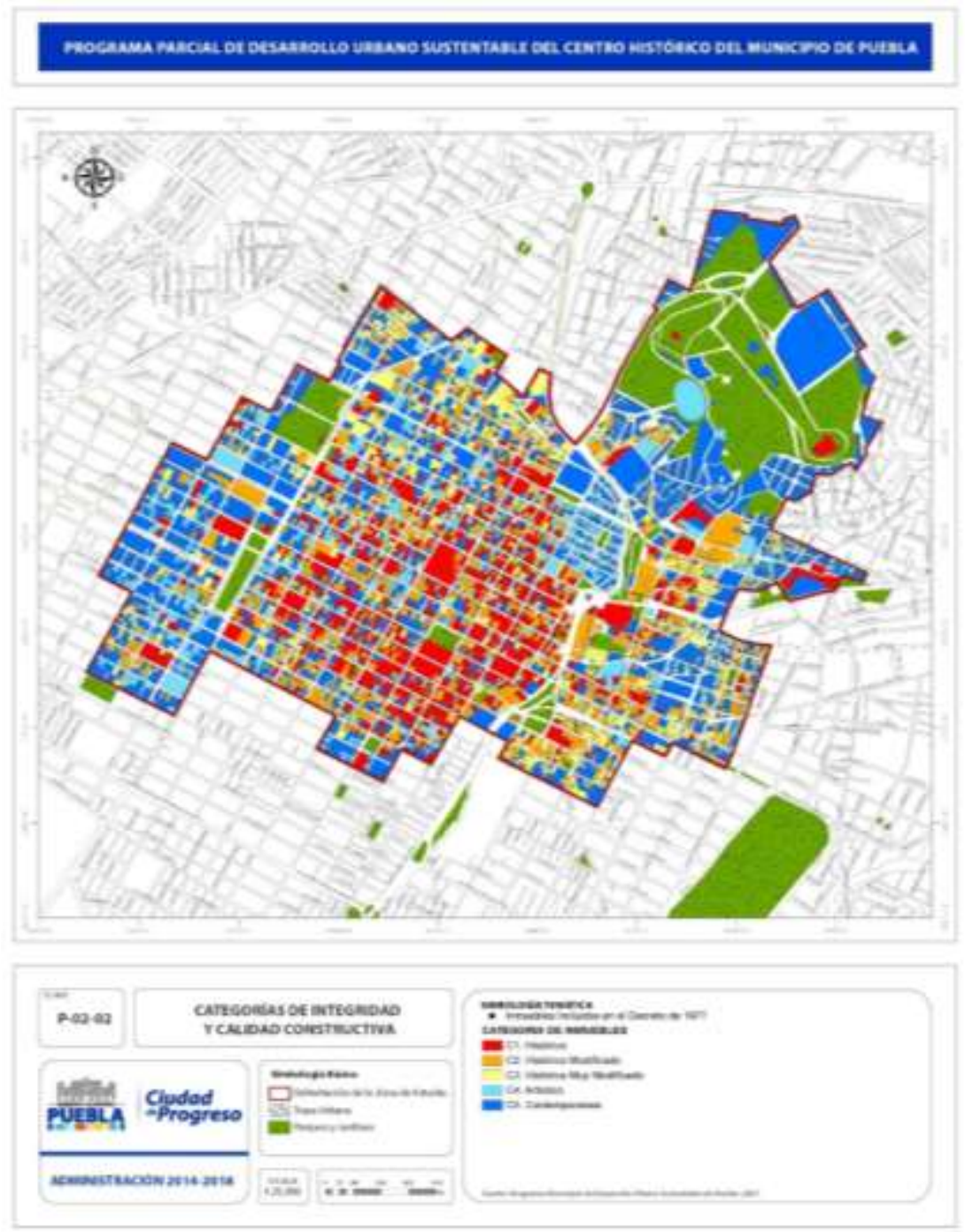

Figura 11. Categorías de integridad y calidad constructiva, plano tomado de (Gobierno del Estado, 2015).

Patrimonio Arquitectónico de la Zona de Monumentos por Categoría

\begin{tabular}{|l|c|}
\hline Categoría & N. ${ }^{\circ}$ Inmuebles \\
\hline 1. Histórico & 703 \\
\hline 2. Histórico Modificado & 1.365 \\
\hline 3. Histórico Muy Modificado & 1.423 \\
\hline 4. Artístico & 849 \\
\hline
\end{tabular}




5. Arquitectura Contemporánea
Tabla 7. Plan para la Recuperación de la Zona de Monumentos en la Ciudad de Puebla.

\section{Plan de Manejo del Programa Parcial del Centro Histórico (2015).}

Este instrumento, ha sido recientemente adoptado por la UNESCO como un requisito conducente para países que aspiren a que sus sitios o ciudades sean considerados Patrimonio de la Humanidad, por lo que es importante destacar que este documento fue elaborado a partir de la Guía Metodológica para Formulación, Seguimiento y Evaluación de Planes de Manejo para las Ciudades Mexicanas Patrimonio de la Humanidad y los Centros Históricos y Patrimoniales, elaborada por la Secretaría de Desarrollo Social (SEDESOL), así como en los términos de referencia proporcionados por el Instituto Municipal de Planeación Puebla (IMPLAN), siendo concebido como Plan de Manejo para el Programa Parcial de Desarrollo Urbano Sustentable del Centro Histórico del Municipio de Puebla.

\section{Programa Parcial de Desarrollo Urbano Sustentable del Centro Histórico del Municipio de Puebla. (2015).}

El fin del Programa Parcial, es actualizar las estrategias, políticas y normas para el desarrollo urbano de la zona, que además de ser estratégica, es de las más importantes del centro urbano metropolitano. En un ámbito territorial de estas características, es necesario contar con un instrumento vigente, que atienda nuevas situaciones y permita ordenar y regular los aprovechamientos territoriales con visión sustentable a largo plazo, además de proporcionar certidumbre a las inversiones pública, privada y social. Este nuevo Programa Parcial, cumple con lo establecido en el artículo 45, párrafo segundo, fracciones I, II, III y IV de la Ley de Desarrollo Urbano Sustentable del Estado de Puebla. 
El Centro Histórico del Municipio de Puebla fue decretado como Zona de Monumentos Históricos en 1977, sin embargo, su límite original fue generado a partir de una estructura urbana que se ha modificado con el paso de los años. En este sentido, el presente Programa Parcial ha retomado el trabajo de campo realizado en ejercicios de planeación anteriores, además de la realización de nuevos recorridos de campo y actualización cartográfica para definir la zona de estudio que corresponde a la Zona de Monumentos como área importante para la conservación de su patrimonio arquitectónico y cultural. (ver Fig. 12) (Gobierno del Estado, 2015).

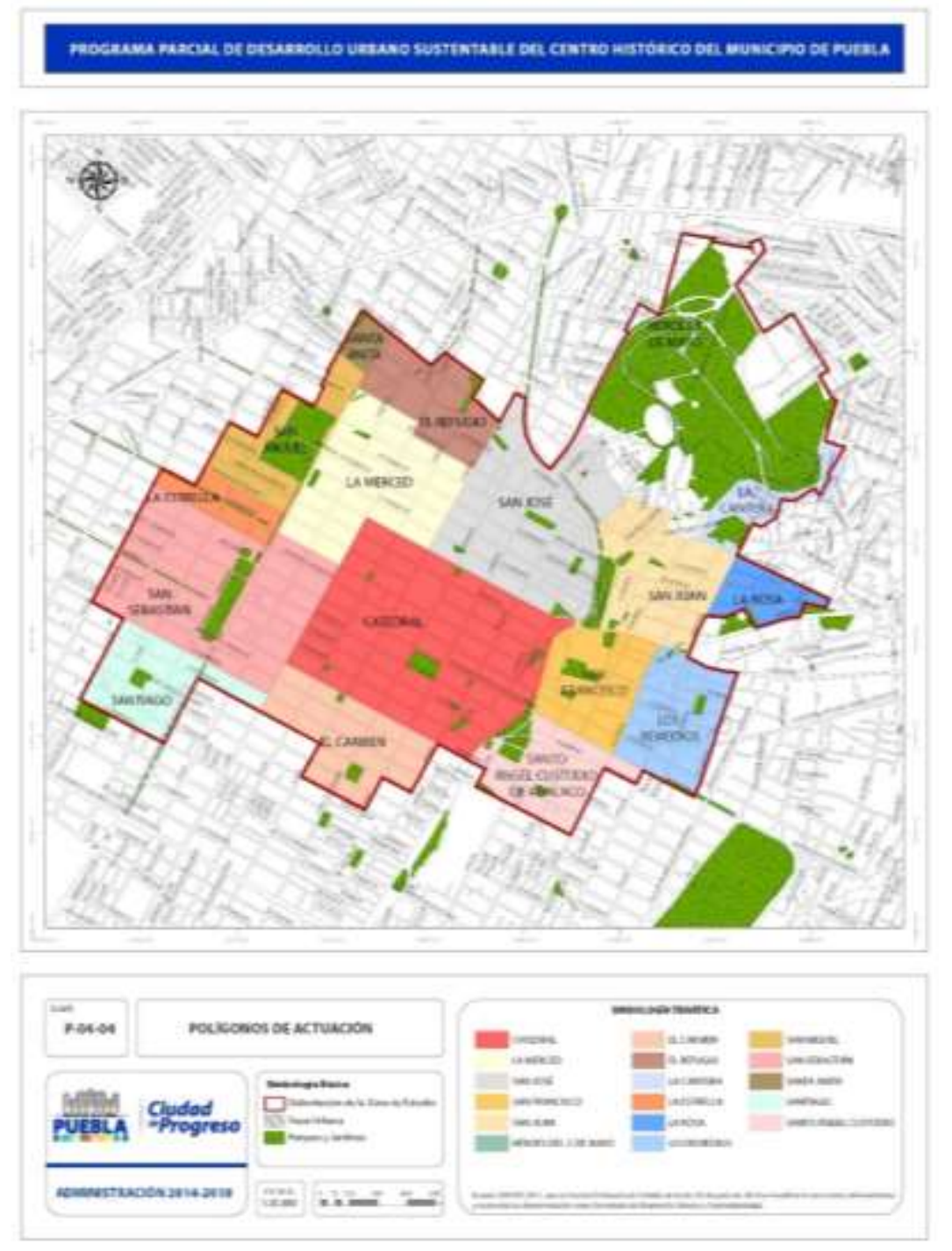

Figura 12. Polígonos de Actuación, plano tomado de (Gobierno del Estado, 2015).

Código reglamentario para el municipio de Puebla, COREMUN (2018) 
El presente Código, tiene por objeto desarrollar las bases para la organización y el funcionamiento del gobierno municipal; proveer la exacta observancia de las leyes administrativas del Estado en los ámbitos de su competencia, así como regular las actividades privadas y los servicios públicos que al Ayuntamiento le corresponda reglamentar o proporcionar. Para efectos de la disposición anterior, en este ordenamiento se codifican todos los preceptos reglamentarios de carácter municipal, bajo los principios de simplificación, unificación, desregulación y mejora regulatoria, con el propósito de que todas las disposiciones presentes y futuras relativas a la estructura, organización y adecuado funcionamiento del Municipio de Puebla, así como a los derechos y obligaciones en las materias de su competencia, contenidas en un solo Código y de esta manera, a los servidores públicos del Ayuntamiento y habitantes, les resulten claros sus objetivos y funciones, así como el acceso al marco normativo municipal, el conocimiento práctico y aplicación de sus preceptos. (H. Ayuntamiento del Municipio de Puebla, 2018).

\section{Creación del Fideicomiso del Paseo de San Francisco (1994).}

Este fideicomiso es creado conforme a lo dispuesto en la Ley Orgánica de la Administración Pública del Estado Libre y Soberano de Puebla, Ley General de Títulos y Operaciones de Crédito y demás aplicables. El fideicomiso tiene como fin, la preparación y realización de las acciones señaladas en el Programa Parcial de Desarrollo Urbano, Mejoramiento, Conservación e Integración del Paseo del Río de San Francisco. El patrimonio del "Fideicomiso del Paseo de San Francisco", será constituido con recursos económicos y bienes transferidos en propiedad y demás requisitos de carácter legal. Dicho fideicomiso se deberá formalizar mediante la celebración del contrato respectivo a través de un Fiduciario y los Fideicomisarios, que serán representados por el Gobierno del Estado y el H. Ayuntamiento del Municipio de Puebla. Las instancias de la Administración Pública Estatal, coadyuvaran a la realización de las acciones que, en el ámbito de su competencia, sean necesarias para su ejecución, y se establece que la Secretaría de la Contraloría General del Estado, designará al Comisario del Fideicomiso. (Gobierno del Estado, 1994). 


\section{El Programa de Desarrollo Regional Angelópolis y el Municipio de Puebla. Rescate del Centro Histórico de La Ciudad de Puebla (Paseo del Río de San Francisco) (1993-2002).}

A partir del nombramiento de la ciudad de Puebla como Patrimonio Cultural de la Humanidad, se ha trabajado en su protección y conservación a través de la producción de políticas nacionales e internacionales en la materia, concentradas en planes y programas que hicieran frente a la problemática particular del centro histórico ${ }^{11}$.

Se llama "Rescate del Centro Histórico de la Ciudad de Puebla”, ya que, en la segunda mitad del siglo XX, se vio fraccionado por el entubamiento del Río de San Francisco (actualmente Boulevard Héroes del 5 de mayo), incrementando su deterioro con edificios expropiados y mutilados para su creación. Además, la instalación de actividades terciarias originó la degradación de la infraestructura y mobiliario urbano, la pérdida de patrimonio edificado y con ello la calidad de vida de los habitantes originarios.

Estas condiciones del centro histórico de la ciudad de Puebla, determinaron la participación del Gobierno Estatal a través de este Plan de Rescate (ver Fig. 13), con el fin de mejorar la calidad de vida y la economía de la ciudad, para ello se requirió de la inversión pública y privada a través de la promoción turística, aunada a su gran valor patrimonial arquitectónico y cultural que la catalogan como una de las ciudades novohispanas más bellas en América Latina.

Por lo anterior, se describen cronológicamente (ver Tabla 8), las principales acciones realizadas para el centro histórico durante la primera década a partir de su nombramiento en 1987, destacando su proceso de conservación y revitalización hasta 1997, incluyendo la intervención de la UNESCO y el ICOMOS, instituciones que tuvieron una participación destacada en la elaboración de las políticas de intervención.

\footnotetext{
${ }^{11}$ El centro histórico de la ciudad de Puebla antes de ser contemplado en forma particular en planes y programas, había alcanzado un deterioro considerable provocado por el cambio de uso del suelo y la emigración de las familias a la periferia que daba paso a la degradación de inmuebles y a la reducción de valor económico de la zona.
} 


\begin{tabular}{|c|c|c|}
\hline FECHA & ACCIONES & OBSERVACIONES \\
\hline 1987 & $\begin{array}{l}\text { Declaración del Centro histórico de Puebla } \\
\text { como Patrimonio Cultural de la Humanidad } \\
\text { (UNESCO) }\end{array}$ & Protegido adicionalmente por Decreto Oficial de la federación \\
\hline 1991 & $\begin{array}{l}\text { Creación del Consejo del Centro Histórico } \\
\text { de la Ciudad de Puebla }\end{array}$ & $\begin{array}{l}\text { Responsable de proteger, preservar, custodiar y mejorar la } \\
\text { zona histórica y los monumentos de la ciudad }\end{array}$ \\
\hline 1992 & $\begin{array}{l}\text { Programa Operativo para la Reutilización y } \\
\text { Revitalización del Centro Histórico }\end{array}$ & $\begin{array}{l}\text { Primer intento de la sociedad poblana por establecer } \\
\text { lineamientos para el rescate y la conservación del Centro } \\
\text { Histórico }\end{array}$ \\
\hline \multirow[t]{5}{*}{1993} & $\begin{array}{l}\text { Programa de Desarrollo Urbano de la } \\
\text { Ciudad de Puebla }\end{array}$ & $\begin{array}{l}\text { Elaborado por el municipio de la ciudad de Puebla que } \\
\text { establece el marco legal para el Programa Parcial } \\
\text { subsiguiente }\end{array}$ \\
\hline & Megaproyecto Puebla Plus & $\begin{array}{l}\text { Elaborado por HKS Architects asociación con Sasaki } \\
\text { Associates Inc. y por arquitectos y urbanistas poblanos cuya } \\
\text { conceptualización arquitectónica se determinó era necesario } \\
\text { reexaminar }\end{array}$ \\
\hline & $\begin{array}{l}\text { Programa Parcial de Desarrollo Urbano, } \\
\text { Mejoramiento, Conservación e Integración } \\
\text { del paseo del Río de San Francisco }\end{array}$ & $\begin{array}{l}\text { Aprobado por el Cabildo del Ayuntamiento del Municipio, } \\
\text { abarca } 22 \text { has. para uso cultural y turístico, según la } \\
\text { convocatoria de usos del suelo }\end{array}$ \\
\hline & $\begin{array}{l}\text { Declaratoria de Utilidad Pública del } \\
\text { Programa Parcial }\end{array}$ & $\begin{array}{l}\text { Vialidad del Programa Parcial y, por tanto, de las } \\
\text { adquisiciones y expropiaciones requeridas }\end{array}$ \\
\hline & $\begin{array}{l}\text { Estudio sobre el Programa Parcial "Paseo } \\
\text { del Río de San Francisco" }\end{array}$ & $\begin{array}{l}\text { Plan de Conservación de la Zona solicitado por el Gobierno del } \\
\text { Estado a la SEDUEEP para definir los criterios generales de } \\
\text { restauración de la zona, así como la normativa para el } \\
\text { desarrollo del proyecto }\end{array}$ \\
\hline \multirow[t]{3}{*}{1994} & $\begin{array}{l}\text { Programa de Restauración y Revitalización } \\
\text { del Centro Histórico }\end{array}$ & $\begin{array}{l}\text { Propuesta independiente de un grupo de arquitectos } \\
\text { poblanos para la revitalización de cuatro áreas del Centro } \\
\text { Histórico }\end{array}$ \\
\hline & $\begin{array}{l}\text { Creación del Fideicomiso del Paseo de San } \\
\text { Francisco }\end{array}$ & $\begin{array}{l}\text { Constituido para agilizar la ejecución del Programa Parcial de } \\
\text { Desarrollo Urbano, Mejoramiento, Conservación e } \\
\text { Integración del paseo del Río de San Francisco y garantizar la } \\
\text { transparencia en la compra y usos de los predios }\end{array}$ \\
\hline & Primer Anteproyecto del Plan Maestro & Elaborado por el Arq. Sergio Zepeda Trigo \\
\hline \multirow[t]{2}{*}{1995} & Anteproyecto del Plan Maestro & $\begin{array}{l}\text { Colaboración del Arq. Giorgio Lombardi, nombrado por la } \\
\text { UNESCO para la elaboración del Megaproyecto }\end{array}$ \\
\hline & $\begin{array}{l}\text { Programa Parcial de Desarrollo Urbano y } \\
\text { Conservación del Centro Histórico de la } \\
\text { Ciudad de Puebla }\end{array}$ & $\begin{array}{l}\text { Comprendía la zona de monumental de la ciudad de Puebla } \\
\text { según el decreto presidencial de } 1997\end{array}$ \\
\hline \multirow[t]{2}{*}{1996} & $\begin{array}{l}\text { Plan de Conservación y Ordenamiento } \\
\text { Urbano Arquitectónico del Paseo del Río de } \\
\text { San Francisco }\end{array}$ & $\begin{array}{l}\text { Elaborado por el INAH Puebla, consta de seis proyectos: } \\
\text { historio, arquitectónico, urbano, arqueológico, tipológico y } \\
\text { jurídico }\end{array}$ \\
\hline & $\begin{array}{l}\text { Plan Maestro del Paseo del Río de San } \\
\text { Francisco }\end{array}$ & $\begin{array}{l}\text { Realizado por el despacho Sordo Madaleno con el apoyo del } \\
\text { INAH Puebla, el Consejo del Centro Histórico de la Ciudad de } \\
\text { Puebla, la Comisión del Patrimonio Edificado de Puebla y un } \\
\text { grupo de especialistas }\end{array}$ \\
\hline
\end{tabular}

Tabla 8. Tabla cronológica de las principales acciones para el Rescate del Centro Histórico de la Ciudad de Puebla

(Ayuntamiento Municipal, 2002). 


\section{Manzanas para el proyecto del Rio de San Francisco}
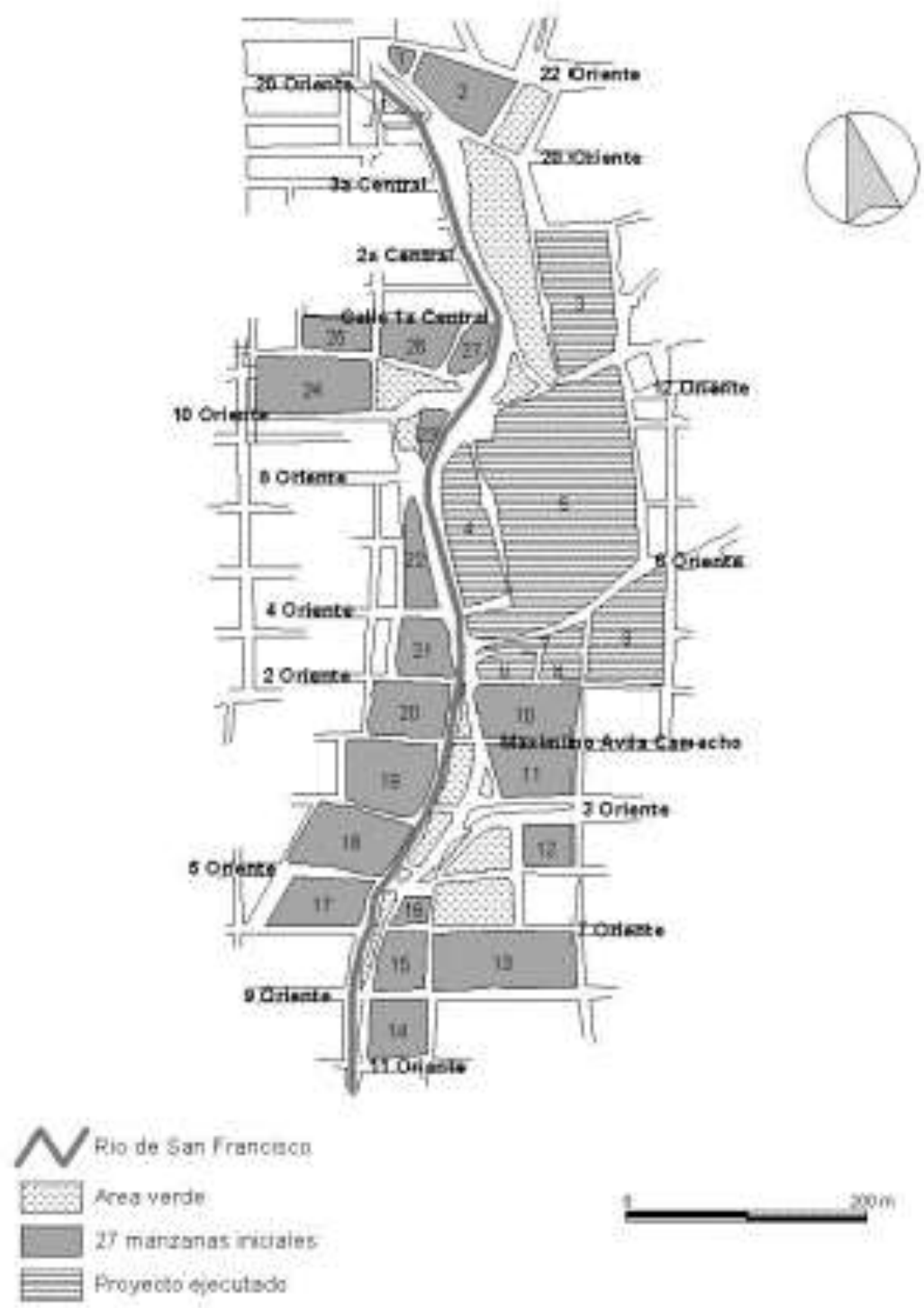

Figura 13. Programa del Paseo del Río, consistente en crear un complejo turístico, cultural y comercial sobre los barrios antiguos del oriente de la ciudad de Puebla. Retomado de (Ávila, 2001).

En la figura 14, se aprecia el desarrollo turístico más relevante en la revitalización del centro histórico, que integra áreas comerciales, zonas de esparcimiento y un centro de convenciones que sin duda ha sido sede de diversos eventos gastronómicos, artísticos, culturales y educativos, coloquios, convenciones y eventos internacionales, por lo que, en conjunto, han servido a Puebla como detonador económico y social en los últimos años. 


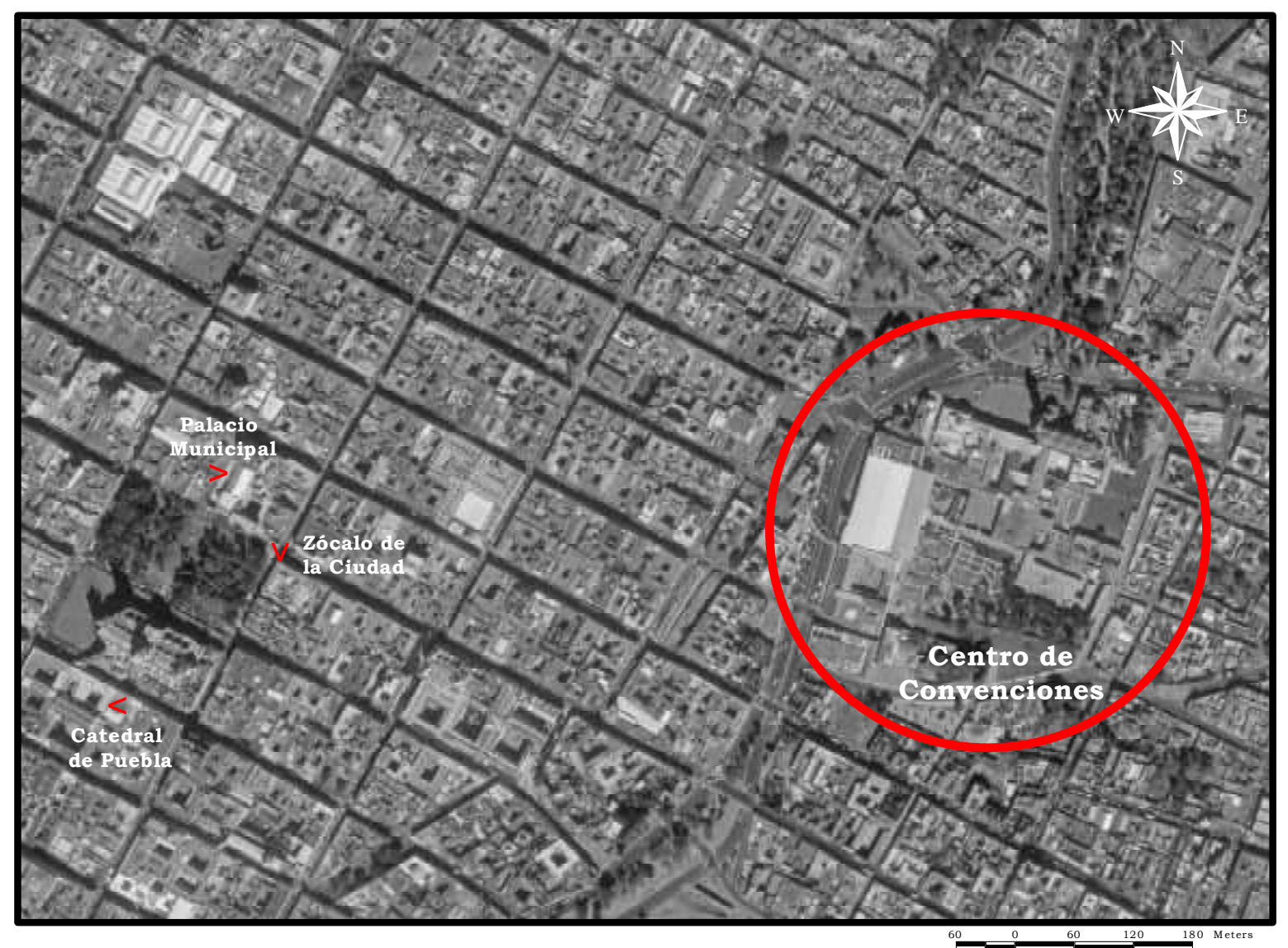

Figura 14. Ubicación del Centro de Convenciones en la Zona de Monumentos Históricos de la Ciudad de Puebla y su cercanía con el Palacio Municipal, el Zócalo y la Catedral de Puebla, elaboración propia.

\section{El Programa de Desarrollo Urbano Angelópolis (1993)}

Este programa abarca 14 municipios del Estado de Puebla ${ }^{12}$, mismos que integran la Región Angelópolis ${ }^{13}$ (ver Fig. 15). Desde su origen (1993), el programa fue elaborado para impulsar el desarrollo económico de la zona en una visión a largo plazo, apoyado en recursos federales, estatales y municipales, siempre con el objetivo de proveer bienestar y mejora de la calidad de vida de la población.

12 Amozoc, Cuautinchán, Cuautlancingo, Coronango, Domingo Arenas, Huejotzingo, Juan C. Bonilla, Ocoyucan, Puebla, San Andrés y San Pedro Cholula, San Martín Texmelucan, San Miguel Xoxtla y Tlaltenango.

${ }^{13}$ Para su mejor estudio y desarrollo, el Estado de Puebla está divido en 7 Regiones Económicas: Región Sierra Norte, Región Sierra Nororiental, Región Serdán, Región Angelópolis, Región Valle de Atlixco y Matamoros, Región Tehuacán y Sierra Negra y Región Mixteca. 


\section{Regionalización Economica del Estado de Puebla}

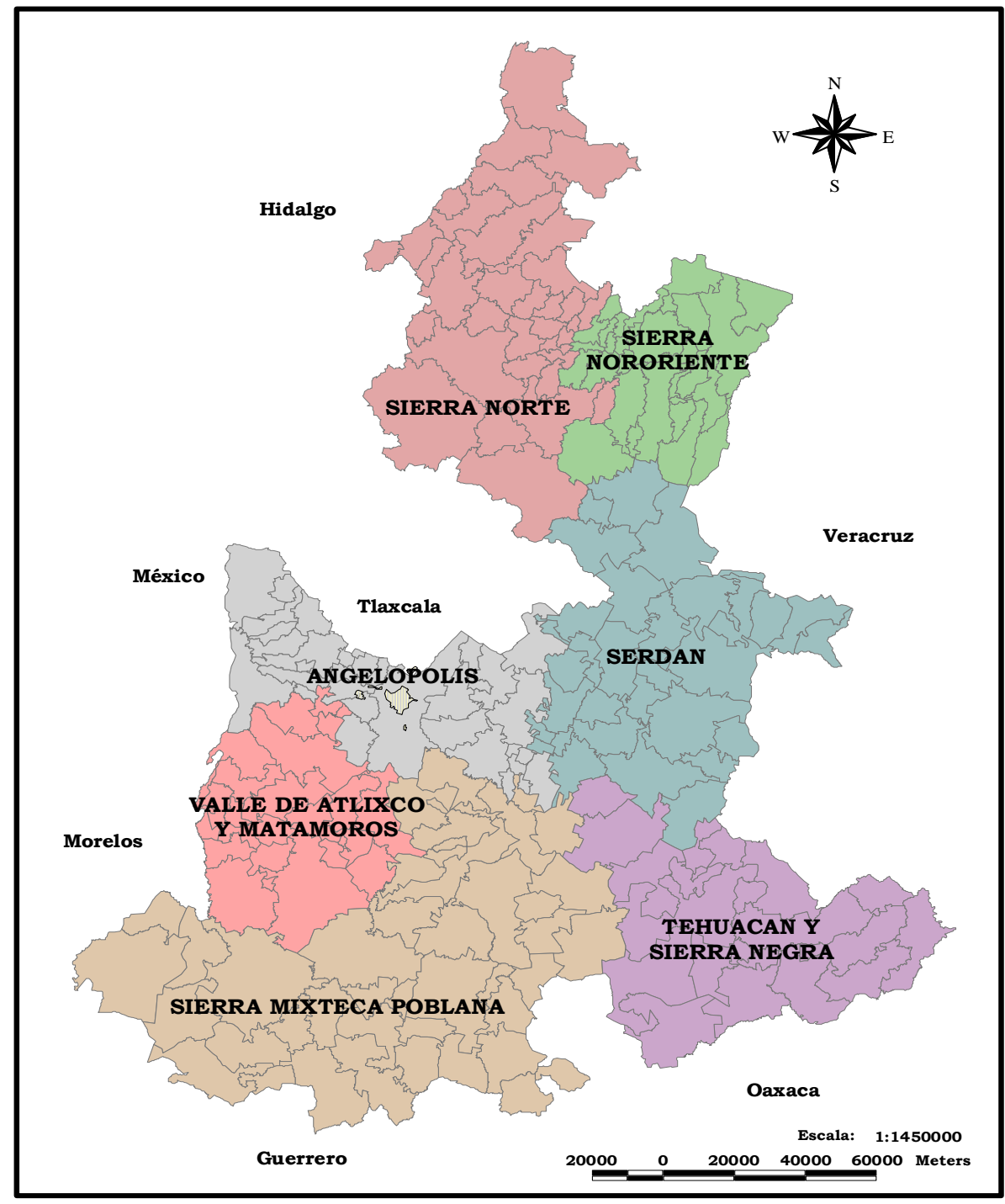

Figura 15. Región Angelópolis.

Entre sus principales objetivos, destaca la atención a infraestructura y servicios, con el fin de dinamizar la economía de la región; es también un tema importante para el desarrollo urbano, además para otros rubros como el industrial, turístico, etc., sin embargo, en 1994, se vio interrumpido por la crisis económica de este año ${ }^{14}$, dando paso a una revisión de metas y ajustes que fueron contemplados para reiniciar su ejecución al año siguiente. A este plan, se sumaron nuevos programas regionales y planes maestros detonadores de desarrollo, entre los que destaca el Programa de Desarrollo Regional Centro-Poniente, enfocado en el desarrollo

\footnotetext{
${ }^{14}$ Esta crisis tuvo lugar justo en el cambio de la administración a nivel nacional al terminar el periodo del entonces presidente Carlos Salinas de Gortari.
} 
urbano integral de un centro industrial y turístico, consideraba la modernización de vial y de transporte, entre otras acciones.

El Plan Maestro de Vialidades y Transporte realizado en 1993, sumo esfuerzos, identificando y atendiendo la principal problemática del sistema de transporte existente en la región y las malas condiciones carreteras; hasta el año 2000, fue notable la mejora en este rubro y más aún el desarrollo de la red carretera de la región.

\section{Actualización del Programa Regional de Desarrollo. Región Angelópolis.}

La actualización de este programa regional, contempla diferentes ámbitos sin embargo en materia de ordenamiento territorial y medio ambiente, destaca la atención a las entidades federativas que conforman zonas metropolitanas y la megalópolis del centro, en donde el principal objeto consiste en ordenar y regular los usos y destinos del suelo, así como establecer las bases que coadyuven al mejoramiento, conservación y sustentabilidad de los centros de población y mejorar la competitividad de las ciudades apoyados en instrumentos de planeación y normativos. Para un desarrollo económico y social optimo, se consideró necesario sumar inversiones dentro y fuera del país, así como el fomento para el disfrute de los atractivos turísticos existentes. (Gobierno de Puebla, 2014)

\section{Programa de Desarrollo Urbano de la Ciudad de Puebla (2014-2018).}

Este programa cuenta con un diagnóstico previo con el fin de conocer las deficiencias dentro de las actividades económicas, sociales, la estructura urbana, vialidad, transporte, vivienda, equipamiento urbano e infraestructura, así como también lo referente al patrimonio arquitectónico, en donde particularmente se detecta la problemática del desplazamiento habitacional que en un principio se mezclaba con otras actividades como el comercio y los servicios. Se hace énfasis en la magnitud del patrimonio y la riqueza cultural que alberga el centro histórico, por ello, se plantea la idea de mantener a Puebla a la vanguardia en investigaciones en la materia, con el objetivo de incorporar instrumentos para el buen funcionamiento entre las formas de vida, costumbres y tradiciones que sean compatibles con las nuevas tendencias y que marca el ritmo de vida actual. (Gobierno del Estado, 2015). 


\section{Plan Municipal de Desarrollo Urbano (2018-2021).}

Este instrumento busca el mejorar la calidad de vida de los ciudadanos creando ciudades incluyentes y sostenibles pero sobre todo resilientes, mediante la vinculación con distintos organismos de gobierno que generen estrategias alineadas a la normativa municipal en estos rubros con las metas y criterios de sustentabilidad que establece la agenda 2030, por ello, el programa del plan municipal, destaca la línea de acción enfocada a "dar seguimiento a los programas de obra pública en materia de conservación y restauración del centro histórico.

Como parte de los Ejes estratégicos que integran este plan, en el eje Ciudad incluyente centrada en las personas y la cultura, tiene como objetivo el mejoramiento de servicios básicos y espacios en la vivienda. En su Estrategia general, considera instituir una política de bienestar, alineada a la estrategia federal, con acciones en materia de salud, educación, culturales, entre otras, a fin de contribuir con la reconstrucción del tejido social. Un aspecto importante de dicho documento, es un apartado que busca impulsar acciones para preservar los bienes culturales tangibles e intangibles, así como manifestaciones artístico-culturales, con la finalidad de incrementar el bienestar de la población, por lo que su estrategia, consiste en gestionar programas y proyectos de manera transversal e integral, que propicien, de forma simultánea, el desarrollo de la cultura y de las artes. (IMPLAN, 2018) 



\section{ANTECEDENTES DEL PATRIMONIO Y TURISMO CULTURAL EN PUEBLA}

4.1. Patrimonio y turismo cultural en México

En este capítulo describiremos el contexto nacional en el que se encuentra inmersa la ciudad histórica de Puebla, la cual comparte algunas características referidas al patrimonio cultural con las ciudades españolas, como el nombramiento de "Patrimonio de la Humanidad" y que pertenezca a la Lista del Patrimonio Mundial de la UNESCO. Sin embargo, son diferentes las acciones, estrategias, así como el contexto económico y social con que cada una cuenta, sin olvidar las leyes, reglamentos y normativas propias.

México cuenta con una gran diversidad de patrimonio cultural, comenzando por las seis eco-regiones entre desiertos, bosques templados, selvas secas, selvas húmedas, humedales y mares; también existe una biodiversidad variable y vasta, debido a que concentra una de cada diez de las especies vegetales y animales que viven en el mundo, siendo el cuarto lugar con mayor número de especies que no habitan en otras regiones (CONACULTA, 2010, pág. 42). En cuanto a las Áreas Naturales protegidas, existen porciones terrestres y acuáticas en diversos ecosistemas en las que el medio ambiente original aún no ha sido modificado, obteniendo de ellas beneficios ecológicos cada vez más respetados y valorados. Por tanto, la Ley General de Equilibrio Ecológico y Protección al Medio Ambiente, incluye estatutos especiales de protección, conservación, restauración y desarrollo. En este ámbito, la Comisión Nacional de Áreas Naturales Protegidas (CONANP) controla las 148 áreas existentes en el territorio mexicano que suman un área de 17,303,133 hectáreas distribuidas en seis categorías: Reservas de la Biosfera, Parques Nacionales, Monumentos Naturales, Áreas de Protección de los Recursos Naturales, Áreas de Protección de Flora y Fauna y Santuarios.

Por otra parte, el patrimonio que conforma la "Lista del Patrimonio Mundial" o de la Humanidad de la UNESCO, se integra por una serie de bienes culturales o naturales de valor inigualable, que además de enriquecer la vida del ser humano, nos da la posibilidad de conocer nuestros orígenes culturales y étnicos; derivando la iniciativa de promover la 
conservación para el conocimiento y disfrute de nuevas generaciones. Actualmente, son poco más de 172 países los que han firmado la Convención Sobre la Protección del Patrimonio Mundial Cultural y Natural de 1972, entre los cuales se encuentran distribuidos un total de 832 bienes: 582 culturales, 206 naturales y 35 mixtos. De este total, México cuenta con 34 bienes inscritos y 9 de estos bienes son Ciudades Históricas -entre las que destaca la ciudad de Puebla, cuya declaratoria data del año 1987-, 8 Sitios Arqueológicos, 2 de ellos son Bienes Naturales, 2 son Conjuntos Arquitectónicos, 1 Monumento Arquitectónico y 1 de arte Rupestre. Respecto a la lista indicativa, son 21 sitios, entre culturales y naturales propuestos por México, con el fin de ampliar la visión del patrimonio.

Además, el inventario-catálogo de Zonas Arqueológicas, lo integran más de 33,000 sitios representativos de los primeros pobladores y grandes civilizaciones que desarrollaron una amplia diversidad de culturas dejando testimonio de su existencia en miles de sitios, así como también por las manifestaciones indígenas como elementos de identidad. Cabe señalar que 173 zonas Arqueológicas están abiertas al público bajo custodia del Instituto Nacional de Antropología e Historia (INAH) siendo 47 las que están protegidas por decreto del ejecutivo federal y cuentan con una declaratoria como Zonas de Monumentos (CONACULTA, 2010, págs. 53-61).

Por otra parte, México cuenta con una gran variedad de monumentos históricos, acumulados a partir de la conquista española, como fuertes y fortalezas, iglesias, conventos, hospitales, escuelas y grandes catedrales. En los últimos años se han catalogado aproximadamente el 60\% de los Monumentos Históricos que suman 67,080 inmuebles del total estimado en 110,424 (CONACULTA, 2010, pág. 53); de ellos, se encuentran bajo custodia del INAH 79, abiertos al público y en su mayoría solo funcionan como museos. Cabe resaltar que las Zonas de Monumentos Históricos localizadas en México, están protegidas por decreto nacional, para lo cual, el INAH, junto con la Coordinación Nacional de Monumentos Históricos, han desarrollado estrategias específicas para su protección. Así, de las 56 Zonas de Monumentos Históricos, decretadas por el ejecutivo federal, destacan el centro histórico de las ciudades de México, Oaxaca y Puebla, Patrimonio Mundial de la Humanidad (CONACULTA, 2010, pág. 53). 
Respecto de los Monumentos Artísticos, es el Instituto Nacional de Bellas Artes (INBA) el organismo encargado de su conservación, documentación, restauración y divulgación; con un registro de 11,952 inmuebles catalogados, perteneciendo el $6.42 \%$ de ellos a la Capital Poblana, entre los que destacan el archivo general del estado, el Archivo Histórico de la BUAP, la Fototeca Antica, la Fototeca Lorenzo Becerril del Centro Integral de Fotografía y el Museo Nacional de los Ferrocarriles Mexicanos (CONACULTA, 2010, págs. 70-18). Los centros especializados resguardan archivos municipales, estatales y privados y estos forman parte del acervo de fototecas, bibliotecas, centros culturales, centro de documentación e información, cinetecas, filmotecas, colegios o escuelas, universidades, institutos y centros de investigación, museos y galerías entre otros.

Para conocer el comportamiento del turismo en México, fue necesario retomar el resumen ejecutivo del Estudio Estratégico de Viabilidad del Turismo Cultural en México, realizado por la Secretaría de Turismo (SECTUR), el cual se refleja un amplio panorama del mercado nacional e internacional, así como la oferta y demanda de los recursos y servicios turísticos, la participación de empresas e instituciones con estrategias encaminadas a elevar su nivel de competitividad. Por otra parte, se definieron cuatro Regiones para analizar la distribución del turismo cultural en México a partir de las características geográficas, económicas, sociales y turísticas similares, perteneciendo Puebla a la región central.

Es importante saber que gran parte de los turistas en México, reconocen estar interesados por el patrimonio cultural, aunque su viaje no se haya planeado con estos motivos. En dicho estudio, se identificaron dos corrientes: en la primera, el turista busca el acercamiento al patrimonio cultural del destino; y en la segunda los turistas son ocasionales, disfrutan del turismo cultural, sin embargo, pertenecen a otros segmentos turísticos ocio, negocios, playa, etc. A partir de esta información, es posible establecer estrategias de desarrollo, promoción y gestión orientada al turismo cultural, aunque en este ámbito son escasos los estudios especializados en la materia.

Las características arquitectónicas o culturales de las ciudades reconocidas como patrimonio de la humanidad suelen ser un factor decisivo para el turismo cultural nacional e internacional, ya que, como en el caso de México, lo distinguen como un país competitivo y 
con atributos y características de mayor interés para los turistas extranjeros, tanto por su cultura viva intangible como por otros elementos tangibles y naturales.

\section{Características de la oferta de destinos turísticos culturales en México}

Para analizar el potencial de los recursos y oferta turística en México, se requiere conocer la riqueza y diversidad de su patrimonio cultural, artístico y natural. Por ello, el Centro de Estudios Superiores en Turismo (CESTUR), integra tres elementos fundamentales: el patrimonio cultural tangible o intangible, la infraestructura- servicios y las actividades que se desarrollan in situ. De este modo, se pueden identificar localidades aptas para el desarrollo del turismo-cultural, clasificándolas en cuatro categorías que permiten la generación de lineamientos estandarizados, bajo los criterios de:

- La función que desempeñan en el sistema turístico

- Las principales características del patrimonio cultural con que cuentan

- Las condiciones de infraestructura y servicios para su aprovechamiento turístico

- Las características de la población total

Sin embargo, la dimensión y competitividad de la oferta turístico-cultural no puede evaluarse solo por la diversidad de los recursos turísticos del lugar, también es importante la su ubicación geografía y otros elementos como el clima, patrimonio asociado y su accesibilidad.

Por lo tanto, entre las estrategias y retos planteados en este sector en el entorno gubernamental a nivel nacional, se percibe la intención de hacer del turismo una prioridad, enfatizando la importancia de su economía mediante el impulso de empresas turísticas más competitivas a través de la diversificación de la oferta y flujos turísticos. En este sentido, debido a que la actividad turística ha sido relevante y prioritaria en nuestro país, este rubro ha sido considerado en el Plan Nacional de Desarrollo 2013-2018 y 2019-2024, fortalecido 
mediante el Programa Sectorial de Turismo 2013-2018, como uno de los cuatro ejes principales con el fin de procurar destinos sustentables y empresas competitivas que impacten en el desarrollo económico y social del país, por lo que es importante reconocer el papel estratégico de la actividad turística.

Además, la Ley General de Turismo, promueve el trabajo coordinado entre los niveles de gobierno, incluyendo lineamientos interinstitucionales en políticas de turismo, infraestructura y equipamiento, sin embargo, el crecimiento de la actividad se ha visto limitada por diversos factores, entre los que destacan la inestabilidad económica a nivel mundial y la inseguridad en el ámbito local.

No obstante, y con el fin elevar el nivel de México como destino turístico, el gobierno federal ha canalizado a través de la SECTUR15 y el Consejo de Promoción Turística de México (CPTM), estrategias de promoción sobre destinos, servicios y productos turísticos, desarrollando campañas de difusión en México, Norteamérica, Europa y Latinoamérica. Es importante mencionar que en noviembre del año 2002 se presentó la Agenda 21 para el turismo mexicano, para analizar el turismo en algunos destinos turísticos mediante un estudio llamado "Desarrollo de un Sistema de Indicadores de Sustentabilidad". También se realizaron diversos proyectos entre los que destacan desarrollos turísticos e inmobiliarios, mega desarrollos, construcción y remodelación de hoteles, campos de golf, parques temáticos, miradores turísticos, etc.

De esta manera, el programa de modernización de las micro, pequeñas y medianas empresas turísticas (MPYMES), apoya a 280 empresas de 14 destinos turísticos para que operen con altos estándares de calidad y eficiencia y de este modo impulsar su desarrollo, mejoramiento, innovación y actualización económica. No menos importante ha sido para los tres niveles de gobierno impulsar el desarrollo de productos turísticos alternativos de alto impacto social, con acciones como la construcción de infraestructura en áreas naturales protegidas.

\footnotetext{
${ }^{15}$ Secretaría de Turismo
} 
En este sentido, destaca la participación de la Asociación Nacional de Ciudades Mexicanas del Patrimonio Mundial en la mejora de la imagen urbana y mobiliario urbano turístico y con la intervención del INAH en Zonas Arqueológicas y Rutas Culturales por regiones; para el turismo de salud congresos nacionales y talleres; para el turismo de negocios seminarios, convenciones, ferias y exposiciones; para el turismo de segmentos especializados, se ha impulsado un turismo accesible e incluyente para personas con discapacidad.

Además de otros sobre competitividad y desarrollo de productos turísticos, así como de "Planeación y Gestión para el desarrollo turístico Municipal". A este respecto, se ha pretendido contar con una infraestructura institucional que mejore los procesos de eficiencia, innovación y calidad a través de la norma ISO 9001-2000, el diseño del Programa de difusión para la instrumentación del código de conducta en el sector turismo, promoviendo el combate a la corrupción y fomento a la transparencia y desarrollo administrativo (2001-2006).

Por lo tanto, para posicionar la actividad turística como una actividad estratégica para el desarrollo económico y social del país, se requiere implementar la Agenda 21 en diez destinos turísticos, alineados a programas y al Plan Nacional; impulsar convenios para la mejora del sector hotelero y continuar con la revisión jurídica en los destinos para dictaminar el cumplimiento de las disposiciones de la Ley Federal de Turismo, reglamento y normas oficiales mexicanas vigentes en la materia.

\subsection{Servicios e infraestructura turística en Puebla}

La ciudad de Puebla está ubicada a 120 Km. de la Ciudad de México; con vías de acceso que la comunican con las principales ciudades del país, además de un Aeropuerto Internacional, ubicado en el municipio de Huejotzingo, el cual permite descentralizar parte de la actividad del Aeropuerto Internacional de la Ciudad de México. Por otra parte, cuenta con una central de autobuses locales y foráneos a cualquier punto del país. Su ubicación en la región central del país, el asentamiento de importantes culturas por la geografía del lugar, su pasado indígena, así como el movimiento revolucionario y expresiones modernas de arte y cultura, son algunas de las razones por las que la ciudad de Puebla es considerada una joya 
de la arquitectura colonial al conservar su identidad, tradición e historia reflejada en múltiples atractivos turísticos y culturales.

Cabe resaltar que la fabricación de talavera (influencia española de Talavera de la Reina) fue de las primeras industrias que se establecieron. En sus edificios, está plasmado un estilo arquitectónico propio del barroco poblano, representativo de la extensa arquitectura mexicana, destacando su monumental Catedral (1649), la Capilla del Rosario, la Casa de Alfeñique, la Biblioteca Palafoxiana y la Casa de los Muñecos. Lo anterior aunado a su traza en tablero de ajedrez conformada por calles, templos y edificios, que hoy en día caracteriza al centro histórico de la ciudad.

Su centro histórico contiene una gran variedad de sitios como bazares de antigüedades, talleres y tiendas de artesanías, reflejo de la vida cultural de la ciudad, además, de sitios específicos de cine, teatro y exposiciones, que aún mantienen vivos los lugares que conformaron la ciudad desde su fundación, los cuales fueron escenario histórico para el desarrollo de la ciudad.

\subsubsection{Perfil del visitante e indicadores de la actividad turística en Puebla}

En los últimos años se ha realizado una intensa promoción y difusión de los atractivos turísticos del Estado de Puebla con el fin de atraer un mayor número de turistas, resultado de ello fue el crecimiento de $7.86 \%$ en la afluencia de visitantes en relación con el año 2015 al registrarse 14, 127,252 de personas (Gobierno del Estado de Puebla, 2016). Es importante mencionar que la Catedral de Puebla es el principal atractivo, a pesar de que la estrella de Puebla ha incrementado considerablemente su afluencia en los últimos años. (ver Tabla. 9). 


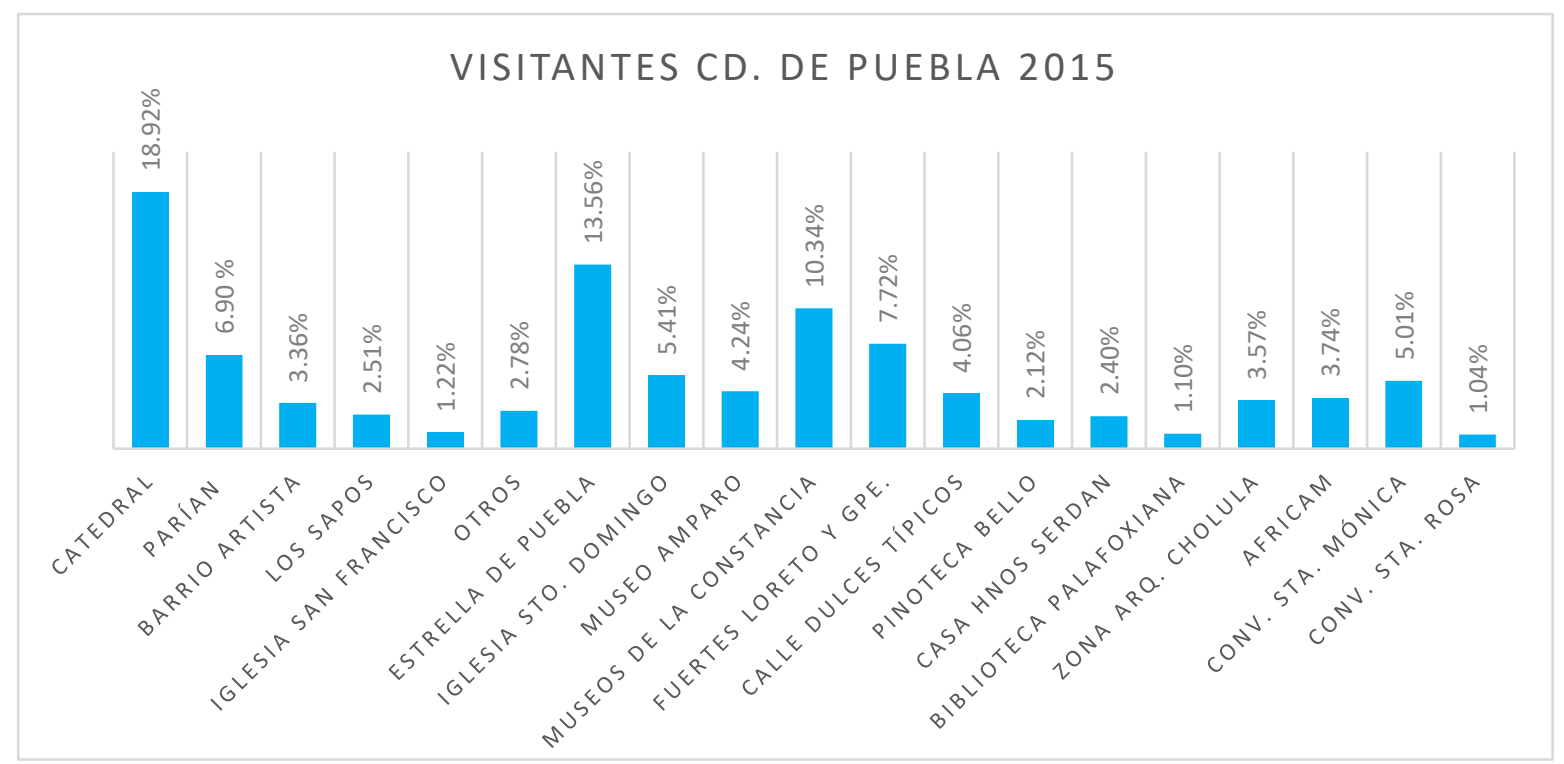

Tabla 9. El porcentaje de visitantes por punto de interés en la ciudad de Puebla. Elaboración propia en base a (Turismo, 2015).

\section{Indicadores básicos de la actividad turística en la ciudad de Puebla año 2016}

Posteriormente, en el periodo del 1 de agosto al 31 de octubre del año 2019, el crecimiento fue del $5.44 \%$ en la afluencia de visitantes, dando un registro de 3,900,000 de personas en solo tres meses (Gobierno del Estado de Puebla, 2019). En consecuencia, la derrama económica tuvo un incremento de $5.71 \%$ respecto al 2018 , alcanzando los $\$ 3,890,000,000.00$ de pesos (S/F, 2019).

De acuerdo con el Sistema Nacional de Información Estadística del Sector Turismo de México (DATATUR), en el estado de Puebla en el fin de semana largo del 14 al 16 de septiembre la ocupación hotelera se incrementó en un $26.9 \%$ con respecto a la misma fecha del año anterior (2018) (ver Fig. 16). 


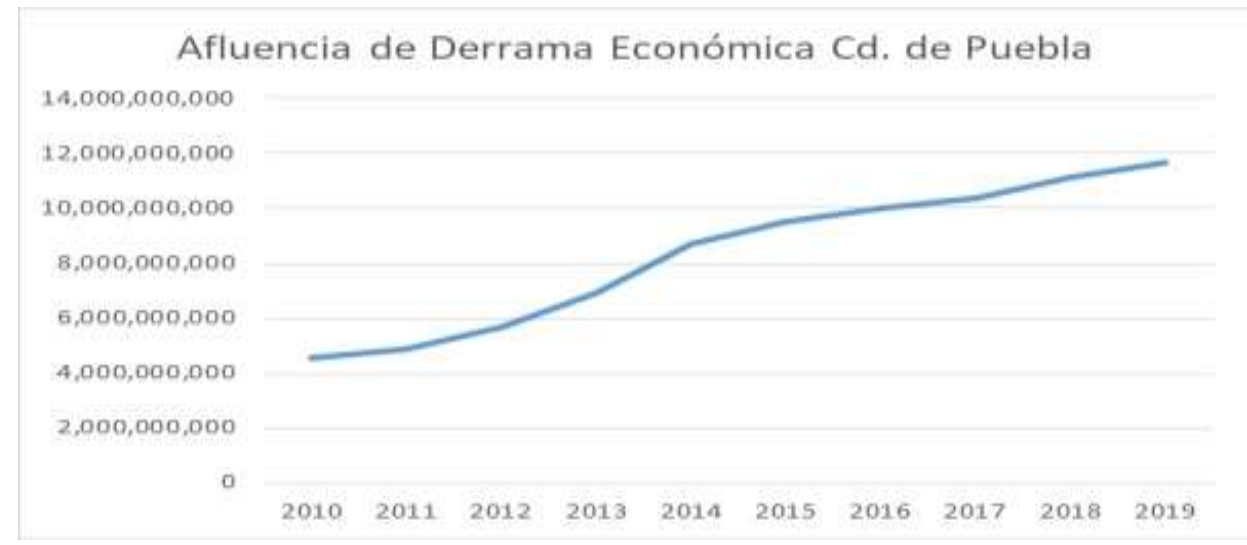

Figura 16. Afluencia de Derrama Económica Cd. de Puebla del 2010 al 2019. Fuente: Elaboración propia en base a los Indicadores Básicos de la Actividad Turística en Puebla (GOBIERNO d. E., Indicadores Básicos de la Actividad Turística en Puebla, 2010 - 2016).

Durante esta década, la ciudad de Puebla se había mostrado como uno de los principales destinos turísticos no solo a nivel nacional, sino también internacional favorecido por la gran variedad de recursos culturales y la seguridad que la ciudad brindaba a sus visitantes hasta aproximadamente el año 2018 (ver Fig. 17).

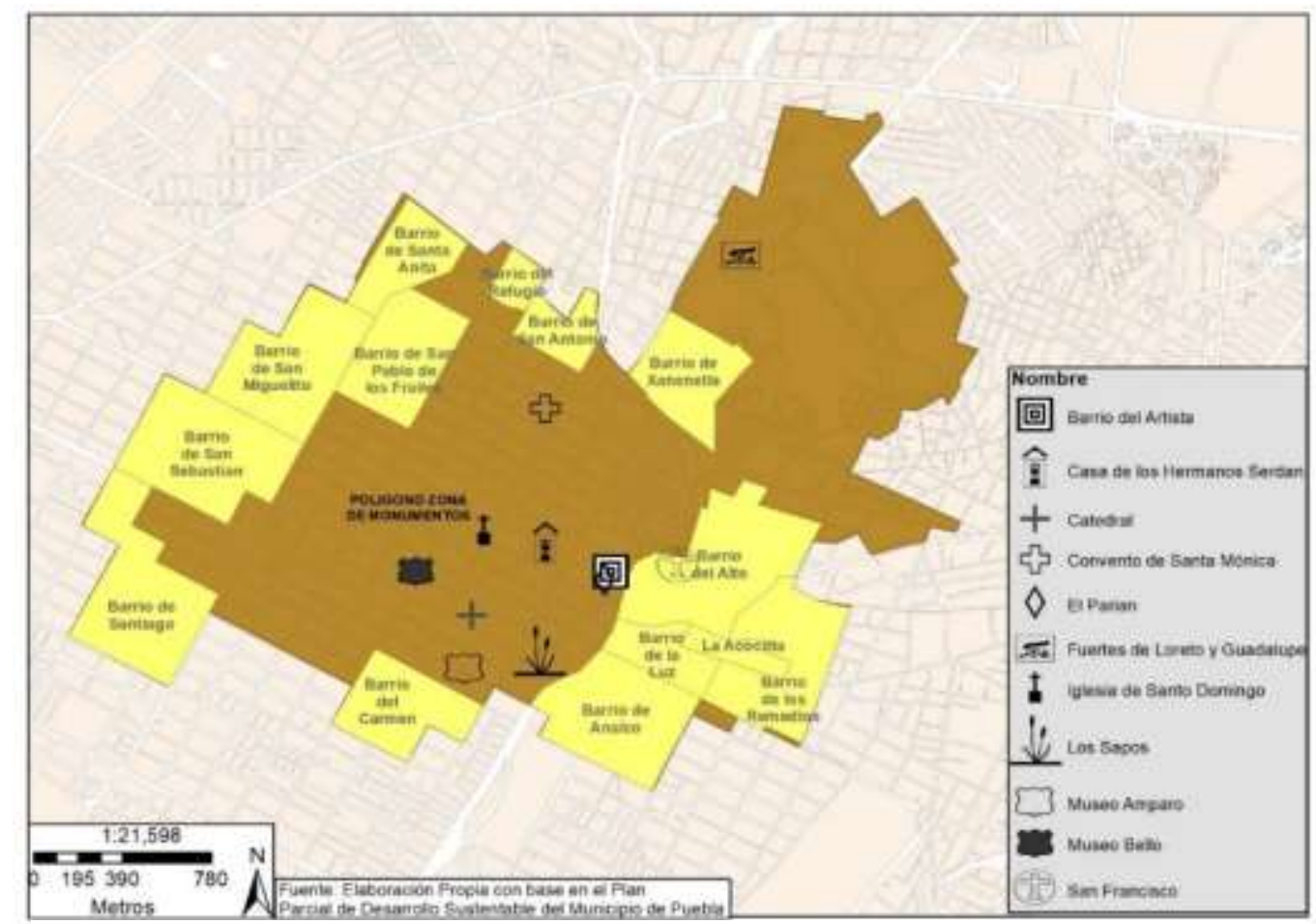

Figura 17. Barrios históricos y actividad turística de la zona de monumentos. Fuente: Elaboración propia a partir del Programa Parcial de Desarrollo Urbano Sustentable del Centro Histórico Municipio de Puebla, 2015. 
Así, los indicadores básicos de la actividad turística en Puebla de los años 2010 al 2019, nos muestran que la afluencia se incrementó considerablemente, pasando de 4,405,863 a 10,179,093 visitantes. Esto se ve reflejado también en la derrama económica que paso de 4,531,401,383 de pesos durante el año 2010 a 11,143,397,925 de pesos obtenidos en el año 2019, aumentando en más de un 50\% en este periodo (Gobierno del Estado de Puebla, 2019).

En la siguiente tabla podemos observar los datos de la ocupación hotelera que registro un aumento del 14\%, pasando del 52.97\% durante el año 2010 a $61.34 \%$ durante el año 2019 (ver Figs. 18,19). Aunque es notable el incremento en la afluencia de visitantes y la derrama económica, es probable que la caída que registra la ocupación hotelera se deba a los nuevos formatos de hospedaje (p/e: Airbnb) más flexible y de menor costo.

\begin{tabular}{cccc}
\hline \multicolumn{3}{c}{ Indicadores Estadísticos Cd. de Puebla } \\
\hline Año & $\begin{array}{c}\text { Afluencia de } \\
\text { Visitantes }\end{array}$ & $\begin{array}{c}\text { Derrama } \\
\text { Económica }\end{array}$ & $\begin{array}{c}\text { Ocupación } \\
\text { Hotelera }\end{array}$ \\
\hline 2010 & $4,405,863$ & $4,531,401,383$ & $52.97 \%$ \\
\hline 2011 & $4,699,405$ & $4,872,823,746$ & $54.99 \%$ \\
\hline 2012 & $5,559,040$ & $5,662,437,103$ & $57.88 \%$ \\
\hline 2013 & $6,968,070$ & $6,927,919,771$ & $64.57 \%$ \\
\hline 2014 & $8,519,568$ & $8,694,584,787$ & $65.70 \%$ \\
\hline 2015 & $9,139,441$ & $9,487,918,906$ & $66.48 \%$ \\
\hline 2016 & $9,431,784$ & $9,999,542,058$ & $66.99 \%$ \\
\hline $2017 *$ & $9,643,300$ & $10,358,462,534$ & $65.52 \%$ \\
\hline $2018 *$ & $9,901,420$ & $11,143,397,925$ & $62.34 \%$ \\
\hline $2019 *$ & $10,179,093$ & $11,655,494,474$ & $61.34 \%$ \\
\hline
\end{tabular}

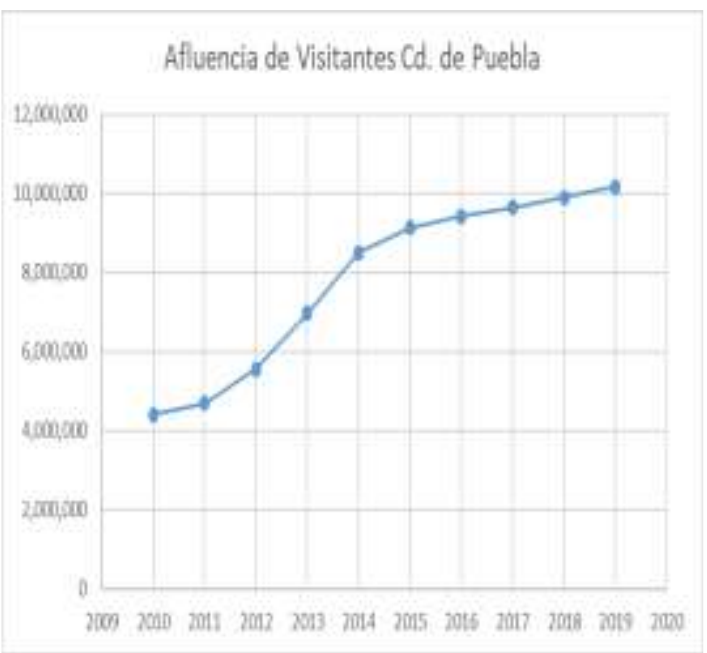

Figura 18. Afluencia de visitantes en la ciudad de Puebla del 2010 al 2019. Fuente: Elaboración propia en base a (GOBIERNO d. E., Indicadores Básicos de la Actividad Turística en Puebla, 2010 - 2016) *Obtenido de (GOBIERNO d. E., Datos Abiertos, 2017 - 2019)

\begin{tabular}{ccc}
\hline \multicolumn{3}{c}{ Actividad Hotelera Cd. de Puebla } \\
\hline Año & Hoteles & Cuartos \\
\hline 2010 & 173 & 7,792 \\
\hline 2011 & 178 & 8,035 \\
\hline 2012 & 196 & 8,607 \\
\hline 2013 & 204 & 8,931 \\
\hline 2014 & 213 & 9,737 \\
\hline 2015 & 226 & 10,203 \\
\hline 2016 & 233 & 10,575 \\
\hline 2018 & 301 & 12,736 \\
\hline
\end{tabular}

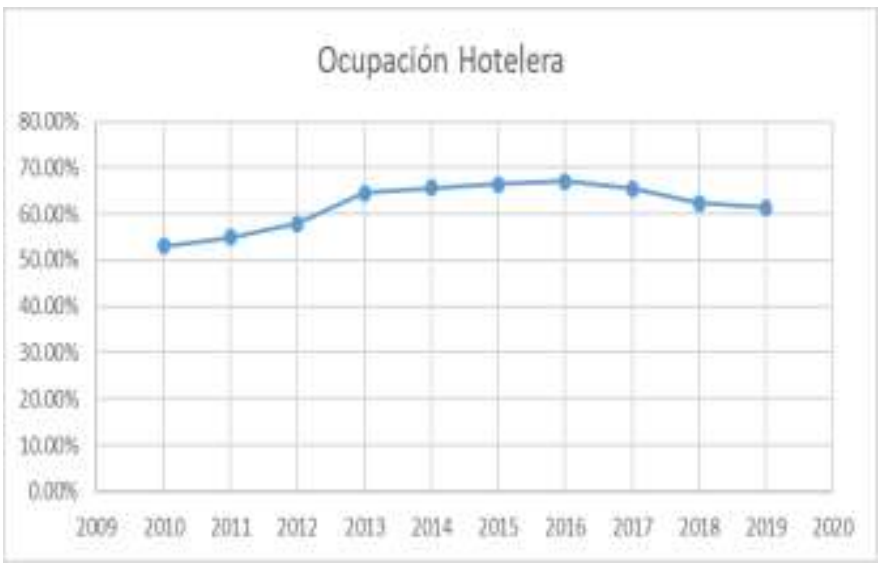

Figura 19. Ocupación hotelera de la ciudad del Puebla, del año 2010 al 2019. Fuente: Elaboración propia en base a (GOBIERNO d. E., Indicadores Básicos de la Actividad Turística en Puebla, 2010 - 2016). *Datos 2017 y 2018 obtenidos de

(GOBIERNO d. E., Datos Abiertos, 2017 - 2019) 
Algunos estudios demuestran que el turismo cultural ha ido adquiriendo jerarquía en el sector turístico ${ }^{16}$ en las ciudades patrimonio, por tanto, es importante mencionar que la motivación turística cobra gran importancia, por el deseo de conocer culturas distintas a las de su lugar de origen (VERA, 2018, pág. 67). Por lo tanto, un turista sensible al valor del patrimonio de una nación toma mayor conciencia en relación a la conservación del patrimonio, tanto tangible como intangible, comprendiendo que esta herencia distingue a la ciudad y le otorga una característica única y competitiva en relación con otros destinos turísticos (VERA, 2018).

\section{El perfil del visitante en Puebla}

Actualmente, es más fácil identificar el perfil del turista que llega a cualquier destino, ya que, a través de la Secretaría de Turismo, las Unidades Administrativas que la conforman en coordinación con organismos del Sector Turismo, se realiza la encuesta denominada "Perfil del Visitante en el Estado de Puebla" en periodos determinados. También se complementa con la estimación basada en un cuestionario obtenido en una muestra de los establecimientos, realizada por la Secretaría de Turismo del Estado de Puebla (SECTUREP) y el Instituto Nacional de Estadística, Geografía e Informática (INEGI).

Concretamente, a través de estas encuestas se obtiene información para fines de planeación y promoción, que además pueda ser útil a organismos gubernamentales, consultores privados, inversionistas y todo aquel que esté interesado en el sector turismo, respecto a características y comportamiento de los visitantes, origen de la demanda nacional o extranjera a diferentes destinos de la entidad en un periodo determinado, así como su opinión e imagen acerca de los servicios públicos y turísticos de la región.

Estos resultados, permiten evaluar el desarrollo de esta actividad, para poder implementar propuestas estratégicas que faciliten la mejora de infraestructura, servicios públicos y turísticos en el Estado, así como programas de promoción y comercialización dirigidos a los mercados nacional y extranjero. De este modo, podemos destacar un registro en la ciudad de Puebla en el año 2010 4,405,863 visitantes, de los cuales 84,31\% fueron

\footnotetext{
16 Por ejemplo, los realizados por ATLAS (Association for tourism and leisure education), citado en L. C. Herrero, "El turismo cultural en Castilla y León: un sector estratégico”, en Agustín, B. (editor), “Castilla y León presente y futuro del turismo", Estudios de la Fundación Encuentro, Pág. 169
} 
nacionales y 15,69\% extranjeros y teniendo un aproximando de 14 visitantes por día durante todo el año. De origen nacional la mayor parte provino del Distrito Federal, Veracruz y Jalisco y del extranjero de países como: Estados Unidos de Norteamérica, Alemania, Francia, España y Canadá, entre otros. Para el año 2018, hubo un total de 14, 988,319 visitantes de los cuales $93.29 \%$ fueron nacionales y $6.71 \%$ extranjeros, teniendo un aproximando de 41,063 visitantes por día durante este año. De origen nacional la mayor parte provino del Distrito Federal, y del extranjero de países como: Estados Unidos de Norteamérica. Teniendo un incremento de casi el triple entre los de año 2010 al 2018.

Podemos destacar que la mayoría realiza su viaje por descanso o placer, seguido de los que llegan por cuestiones académicas o de negocios. Otra característica, es que su desplazamiento lo realizan por tierra, siendo el autobús el medio de transporte más utilizado mientras los automovilistas particulares en su mayoría, son de procedencia nacional, y la segunda forma de desplazamiento es la aérea, utilizada por los extranjeros. Así, el turismo cultural incrementa el interés de los gestores y promotores en el sector turístico, por ser un fenómeno transversal capaz de impulsar la economía. Sin embargo, algunos agentes, con el afán obtener mayor aprovechamiento económico, en ocasiones exceden la sobreutilización de los recursos, siendo más vulnerables aquellos que no cuentan con los planes y programas para su preservación y salvaguarda.

Por lo anterior, Herrero considera necesario marcar ciertas limitaciones con el fin de racionalizar el turismo cultural y los atractivos turísticos que lo integran, debido a su incremento. No hay que olvidar el tipo de visitantes y sus características en donde sobresalen los turistas "ocasionales" o de paso, es decir, que solo dedican parte de su tiempo a esta categoría turística y los "específicos" que viajan decididamente con la intención de concentrar su viaje en el motivo cultural.17 Al respecto, otros autores como Cohen (1988), destacan que para estudiar los impactos desde esta perspectiva se deben analizar los comportamientos y el tipo de relación tanto de visitantes como de residentes. Es así como el turismo cultural pasa de ser una categoría del sector turístico a una opción de consumo cultural de gran importancia en la promoción, gestión y comercialización de los recursos

\footnotetext{
${ }^{17}$ Un claro ejemplo es la exposición "Las Edades del Hombre" que hace rotativo el lugar de exposición, lo que beneficia a las diferentes ciudades anfitrionas.
} 
culturales aumentando como se demostrado una derrama económica y turística de las ciudades, pero también pone en riesgos su permanencia ante fenómenos socioeconómicos como es el caso de la gentrificación.

\subsection{Equipamiento turístico su impacto económico y sociocultural}

Para comprender el impacto del turismo en la cultura debemos retomar la definición de este concepto, respecto a la intención de preservar la identidad de una sociedad, siendo imprescindible su implicación en nuestra vida, la cual nace de la crisis de pertenecer a un lugar o un grupo, es decir, la vinculación y apropiación a algo (BAUMAN, 2003). La construcción de dicha identidad colectiva supone la transmisión de ciertos rasgos culturales de un grupo, sin embargo, esta es subjetiva ya que sus integrantes tienden a seleccionar las compilaciones culturales que den respuesta a sus intereses y aspiraciones personales de manera relativa y cambiante.

De esta manera, una de las primeras intervenciones del gobierno del Estado que inciden directamente en el patrimonio cultural, se llevó a cabo en la primera década del siglo XXI con el derribo de la casa del torno para la construcción del teleférico que buscaba conectar el centro histórico de Puebla con la zona de los fuertes al oriente de la ciudad. Esta casa formaba parte del catálogo de inmuebles protegidos por el Instituto Nacional de Antropología e Historia (INAH), lo cual puso en riesgo el nombramiento de Puebla como ciudad patrimonio obligando al gobierno a reconstruir la casa.

Posteriormente se intentó dar un impulso al turismo con la inauguración del Centro Expositor en el año 2011 y la remodelación de la zona de los Fuertes de Loreto y Guadalupe donde se llevó acabo la histórica batalla del 5 de mayo, así como con la creación del proyecto denominado "Secretos de Puebla" en el año 2016, que consistió en la adaptación de túneles utilizados en la época antigua.

También durante la mitad de la segunda década del siglo XXI se llevaron a cabo proyectos controversiales como la Estrella itinerante de Puebla, la más grande de Latinoamérica; un tren turístico que comunica el centro histórico de la ciudad con la zona 
arqueológica de Cholula; así como el Museo Internacional Barroco, contribuyendo a que la revista Forbes catalogara a la ciudad de Puebla como la ciudad más "cool" para visitar en 2018, debido a su historia, patrimonio edificado, tradición cultural y culinaria (ver Fig. 20). Sin embargo, a partir del año 2019 es importante analizar al impacto negativo en la afluencia turística provocado por el incremento de la inseguridad en la ciudad.

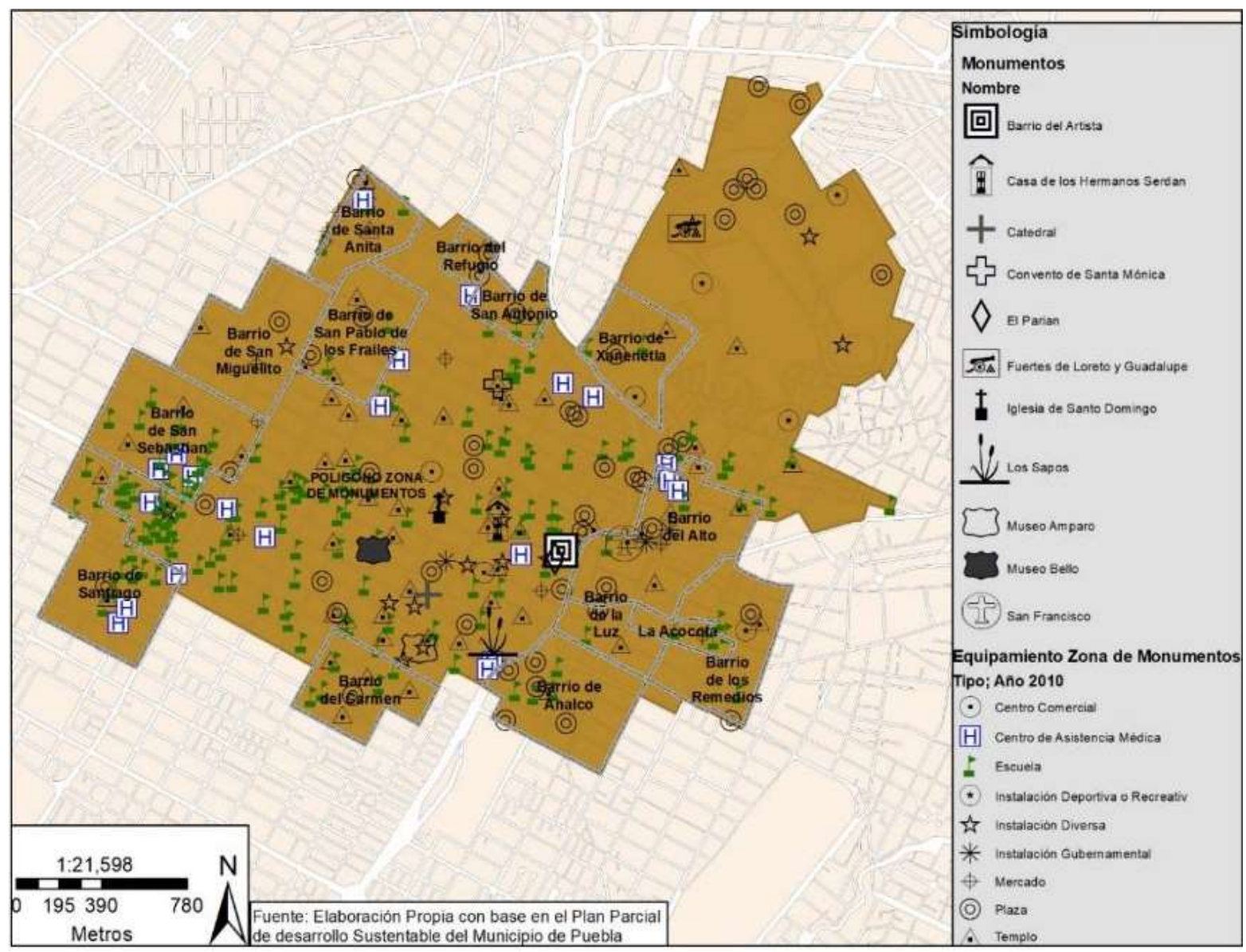

Figura 20. Equipamiento en la zona de monumentos de la Cd. de Puebla. Elaboración propia en base a (GOBIERNO d. E., Plan Parcial de Desarrollo Urbano Sustentable del Centro Histórico del Municipio de Puebla, 2015)

Considerando que la conservación se desarrolla a partir de la preservación como una extensión lógica, al integrar las políticas de preservación a las de manejo de uso de suelo factible de preservar, mientras que la conservación admite el cambio, mediante un proceso para la adaptación de las necesidades sociales (LEZAMA, 2008). No obstante, el turismo mal orientado en países en desarrollo como es el caso de México, puede provocar una 
desculturización en la comunidad, debido a que las autoridades locales priorizan las necesidades de consumo turístico, induciendo la adaptación y mezcla de costumbres occidentales a culturas indígenas, las cuales pierden su autenticidad (ver Fig. 21).

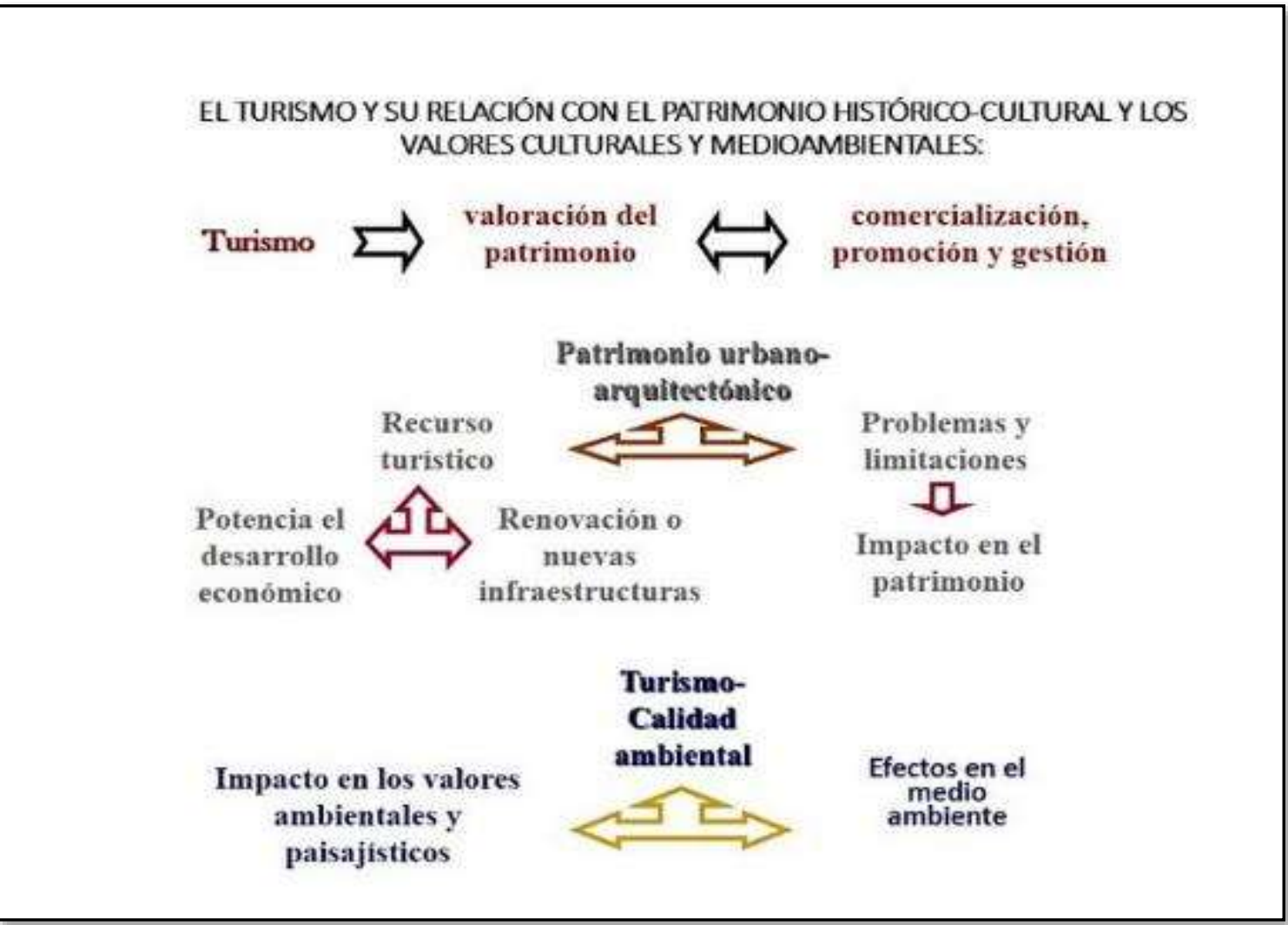

Figura 21. El turismo y su relación con el patrimonio histórico-cultural y los valores culturales y medioambientales. Fuente: Elaboración propia a partir de Brandis, D. y Río, I. (1998).

De esta forma, surge "la mercantilización extrema de las tradiciones locales, despojándolas de su verdadero significado, el cual puede fomentar un proceso de desculturización, que a la vez puede acabar destruyendo los atractivos que en su día iniciaron el flujo de visitantes" (SANCHO, 1998). También surge otra modalidad que corresponde al "turismo de masas", que no permite el intercambio cultural, favoreciendo la intrusión de estereotipos sobre la cultura local autóctona. Esta es una problemática actual de las ciudades, centros y barrios históricos principalmente en Latinoamérica. 
En este contexto, se origina también la comercialización de la cultura, a través de su propia exhibición y posibilidades de atracción, lo que explica la transformación de los usos del suelo y la readaptación de edificios que pierden su funcionalidad. Por otro lado, el apogeo del turismo cultural se relaciona a la aparición de nuevas clases medias distinguidas, cuyas actividades cotidianas de ocupación y de consumo mantienen una estrecha relación con el sector cultural (Herrero, 2011).

Una característica del postmodernismo cultural es la valorización de las localidades que alojan el legado patrimonial, por lo que su recuperación y puesta en valor justifica el elevado nivel de desarrollo turístico y económico sustentado en la venta de su cultura. Esta situación, aunque genera estabilidad y diversidad a la economía local, vulnera la autenticidad del patrimonio arquitectónico asociado a la identidad de una cultura viva.

En este sentido, el turismo incrementa el interés de los promotores culturales, por ser un fenómeno transversal capaz de impulsar la economía al obtener mayor aprovechamiento por la sobreutilización de los recursos culturales, haciendo más vulnerables a las ciudades que no cuentan con los planes y programas para su preservación y salvaguarda. Por lo tanto, al racionalizar el turismo cultural y los atractivos turísticos ante el incremento en la afluencia de turistas (Herrero, 2011). Al respecto, algunos autores destacan que, para estudiar su impacto, además se debe analizar el comportamiento y tipo de relación tanto de visitantes como de residentes (COHEN, 1988).

Por lo tanto, el turismo cultural en Puebla ha pasado de ser una categoría del sector turístico a una opción de consumo cultural de gran importancia en la promoción, gestión y comercialización de los recursos culturales. Si bien ha aumentado la derrama económica de las ciudades, también pone en riesgo el uso habitacional existente, dando paso a fenómenos socioeconómicos como la gentrificación. 


\subsection{Analogías}

\subsubsection{Barrio de Santiago, Puebla, México}

El barrio de Santiago surge poco después de la fundación de la ciudad de Puebla, siendo uno de los primeros durante el siglo XVI (ver Fig. 22). Sus habitantes al igual que en los otros barrios indígenas fueron los que ayudaron en la construcción de esta ciudad novohispana, radicando en esta zona y agrupados de acuerdo a su origen y procedencia en franjas aledañas a la antigua ciudad, siendo un límite natural el rio de San Francisco. De esta manera, se formaron los diversos barrios que hoy en día existen (El Alto, Analco, San Antonio, Santa Anita, Santiago, San Sebastián, San Pablo de los Naturales, Xanenetla, y Xonacatepec), diferenciados por la actividad a la que se dedicaban.

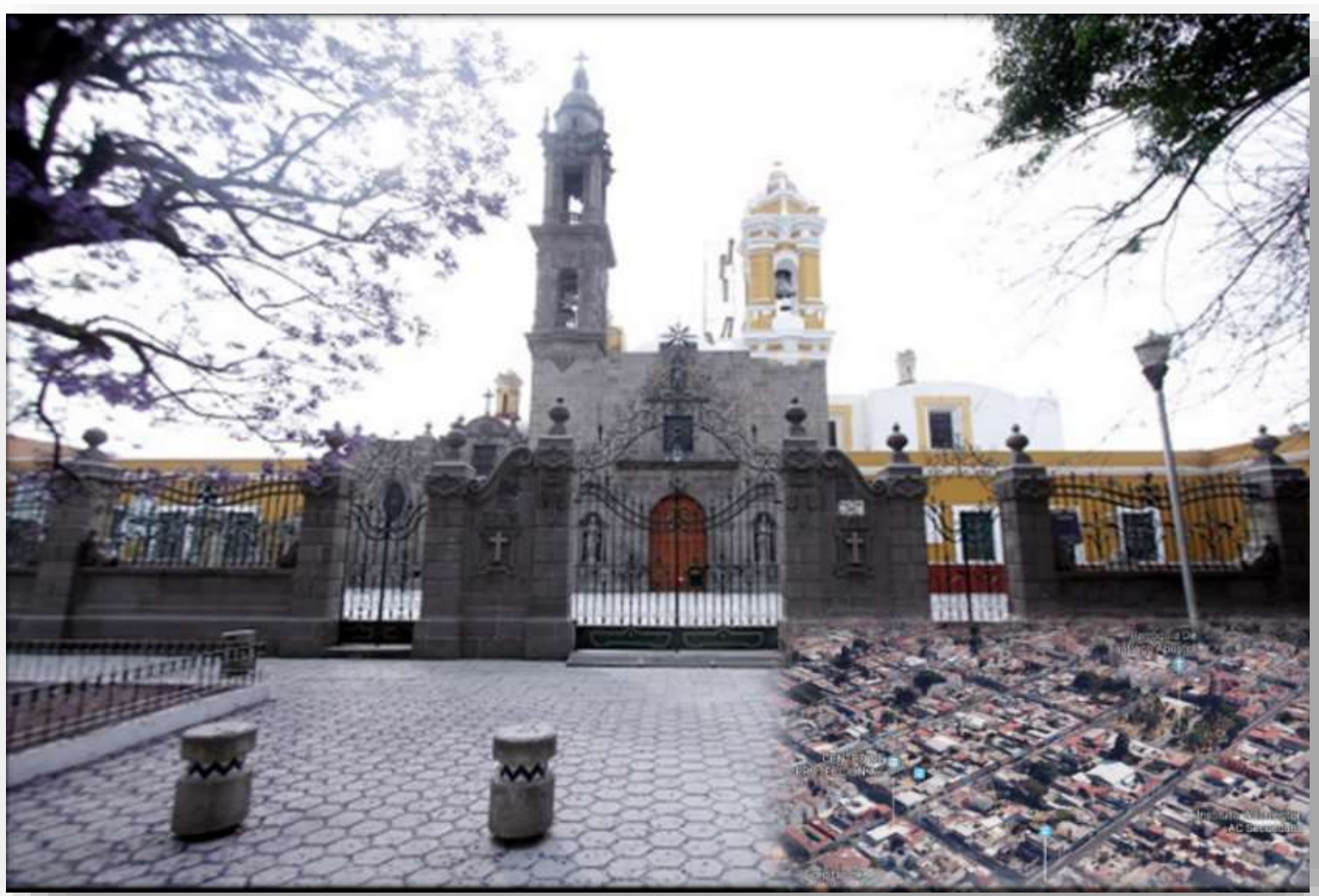

Figura 22. Barrio de Santiago. (Mauleón, 2019) 
Es importante resaltar que, a partir del año de 1973, es cuando el barrio de Santiago sufre un drástico crecimiento y cambio poblacional con la llegada de la Universidad Popular Autónoma del Estado de Puebla (UPAEP). Debido a esto, los locatarios comienzan a abandonar sus vecindades a causa del encarecimiento de rentas y escases de servicios, transformándolo en un lugar de residencia para estudiantes, con el cambio de su uso de suelo que da paso a un tipo de gentrificación: la estudiantificación," la cual según Lees, Slater y Wily sucede cuando los barrios son ocupados por estudiantes de clase media por la cercanía a su universidad" Duque (2010:33). Dentro del barrio predomina el uso de suelo de tipo comercial, servicios-comercio, siendo menos del $45 \%$ de los lotes los que fungen con uso habitacional, mostrándose en decadencia debido al aumento de estos servicios y equipamientos que los residentes temporales de esta zona demandan.

Sin embargo, no solo se vislumbra un proceso de estudiantificación, sino que también se genera una turistificación, la cual se refiere a la transformación de los barrios en enclaves destinados fundamental o exclusivamente para turistas, lo cual causa el desplazamiento de sus habitantes; Cabrera Montiel (IBERO Puebla) y Hernández Sánchez (BUAP) señalan que la gentrificación en el centro histórico de Puebla corresponde al tipo de turistificación, ya que los espacios son adaptados para complacer a los visitantes, siendo estos quienes consumen la cultura y ocupan mayormente el territorio, de manera que se deja de lado el uso habitacional como sucede en la mayoría de los centros históricos, incluido el de la Ciudad de México. De esta manera, Hernández Sánchez advirtió que el desplazamiento de los habitantes originarios del centro conllevará la pérdida de tradiciones e identidad, que es parte de la plusvalía que inicialmente tiene la Zona Monumental para el turismo (Páez). 


\subsubsection{San Miguel de Allende Guanajuato, México}

En 1542, en el estado de Guanajuato fue fundada la ciudad de San Miguel de Allende como villa, bajo el nombre de San Miguel el Grande por Fray Juan de San Miguel, posteriormente en 1826, recibiría el título de ciudad con él nombre que actualmente se le conoce (ver Fig. 23). Durante la década de 1900, San Miguel de Allende estuvo en riesgo de ser un pueblo fantasma, ya que en 1926 el gobierno mexicano decidió declararla como Monumento histórico, restringiendo el desarrollo en dicho distrito con el fin de conservar el carácter colonial que representaba.

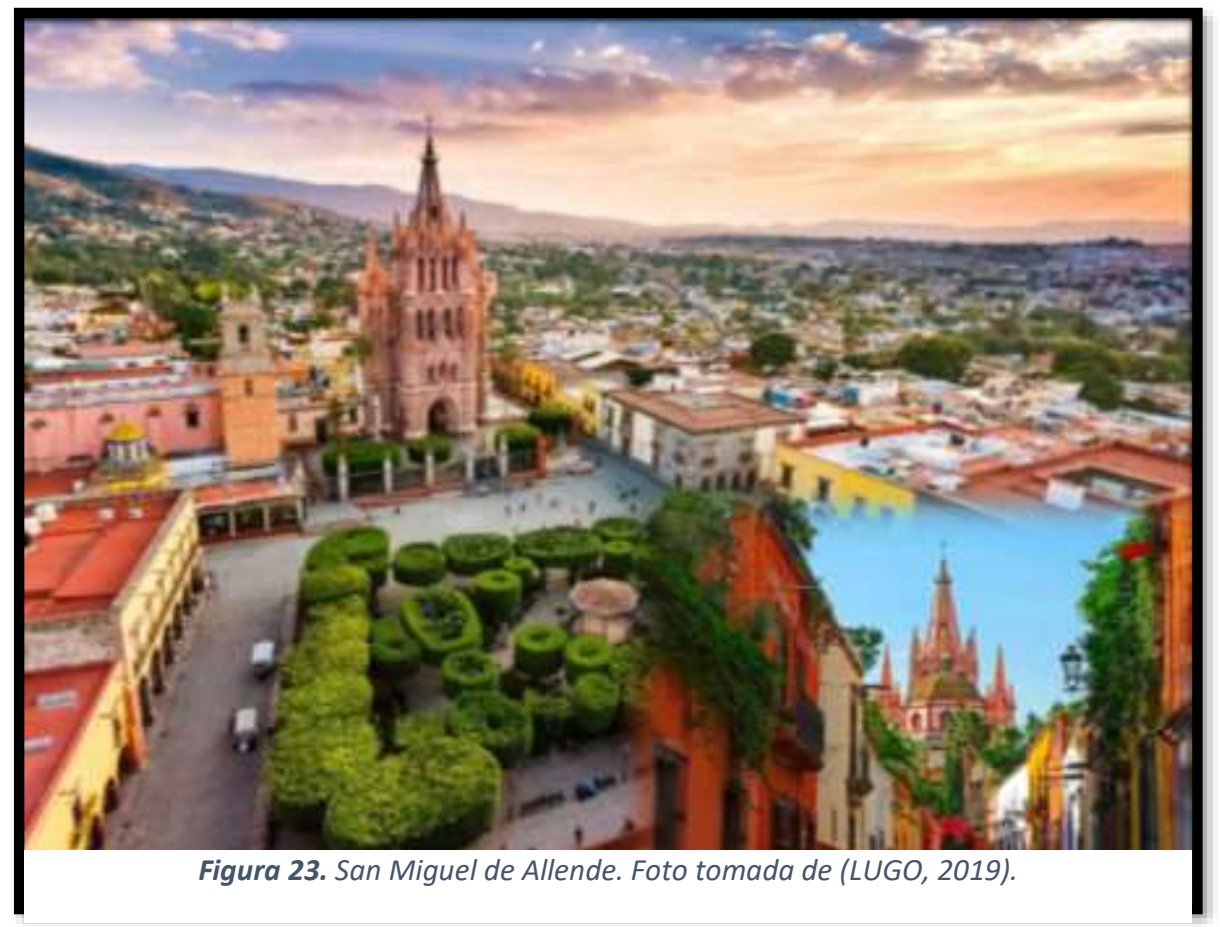

En 2002, fue nombrada "Pueblo Mágico" (CONACULTA, 2019) debido a sus atributos simbólicos, rasgos históricos y culturales, entre otros aspectos, sin embargo, más tarde le fue retirado ese título, debido a su gran riqueza cultural, artesanal e importancia que tuvo durante la Independencia de México y su distinguida arquitectura colonial de tipo barroco mexicano, por lo que en 2008 fue declarada Patrimonio Cultural de la Humanidad por la UNESCO (ToSeeMexico, 2019). Cabe mencionar, que esta ciudad cuenta con una 
gran población expatriada de nacionalidad norteamericana, canadiense, europea y de otras nacionalidades, (Unión Guanajuato, 2017).

Debido al título de ciudad turística colonial con que actualmente se le conoce, la economía de San Miguel de Allende se ha vuelto cada vez más dependiente del turismo siendo su centro histórico donde se concentra el mayor desarrollo de actividades y eventos dirigidos al consumo, recreación y entretenimiento para las diversas elites, así como la intensa vida nocturna que se vive con fines de ocio para visitantes nacionales y extranjeros. De esta forma, con la creciente llegada de migrantes foráneos (nacionales y extranjeros) con intención de residir en la ciudad y la constante interacción con los locatarios, se han hecho visibles fenómenos como la discriminación y segregación socio-espacial, provocando modificaciones en el tejido social original, además de impactar de diversas formas en las condiciones de vida de la localidad.

Desde la década de los años 80, el número de residentes extranjeros ha ido aumentando, principalmente jubilados y empresarios estadounidenses que adquirieron y rehabilitaron inmuebles céntricos para invertir en restaurantes, hoteles, gimnasios, bienes raíces, y venta de muebles y artesanías, dando inicio al proceso de cambio sobre la población originaria y residentes en la periferia. Dichos hechos dieron paso a su gentrificación acentuando la discriminación y desigualdad entre los diferentes estratos sociales, ya que la población local se desplazó hacia la periferia, mientras que las zonas más desarrolladas y el centro de la ciudad fueron ocupados por extranjeros y migrantes nacionales, provocando la especulación del uso de suelo y el encarecimiento de los costos de vida (Flores \& Guerra, 2016).

\subsubsection{Salamanca, España}

La ciudad de Salamanca tuvo su origen durante la Edad de Hierro a partir de una aldea ubicada en el cerro de San Vicente, sobre el río Tormes y habitada por población celta. Posteriormente después de diversos imperios y el paso de diversas poblaciones, Raimundo de Borgoña llevo a cabo la repoblación que sentó las bases de la ciudad con mayor tradición, cultura y esplendor monumental de Europa. Por esta razón, a finales del siglo XI, comienza a levantarse la catedral románica y se reconstruye la antigua muralla celtibérica y romana 
(ver Fig. 24). Durante el reinado de Alfonso X de Castilla y León en el siglo XIII se funda una de las universidades más antiguas de Europa: "Universidad de Salamanca, primera universidad en los tres reinos de Galicia, León y Castilla y una de las primeras de Europa después de Oxford en Inglaterra” (Morales, 2017).

Debido a los innumerables edificios históricos (palacios, casonas, conventos, colegios, escuelas) de estilo arquitectónico plateresco, barroco, gótico, entre otros que tiene la ciudad histórica de Salamanca y a su tradicional artesanía, fue reconocida como Ciudad Patrimonio de la Humanidad en 1988 por la UNESCO, principalmente por la relevancia que tiene la Universidad de Salamanca, ya que esta fue la que atrajo miles de estudiantes de distintas procedencias en busca de amparo intelectual y humanista, ayudando así al repoblamiento de la ciudad, que anteriormente pasaba por un declive poblacional debido a las sucesivas invasiones de los pueblos germánicos (Ayuntamiento de Salamanca, 2019).

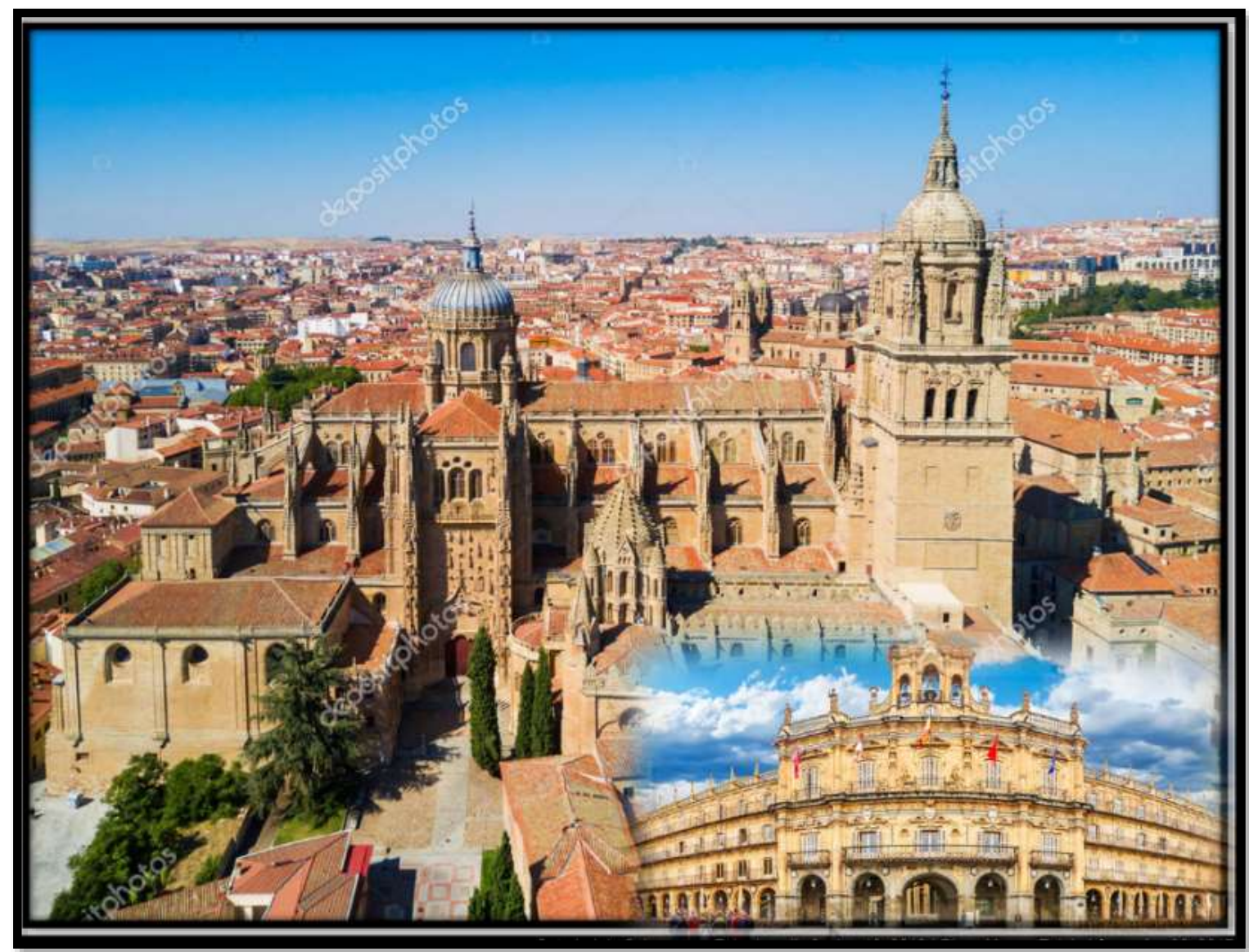

Figura 24. Catedral de Salamanca, foto de (Saiko3p, 2018). Plaza Mayor, foto de (jakobradlgruber, 2017) 
Salamanca presenta un proceso de gentrificación, originado por su vocación estudiantil, no obstante, la afluencia de turismo no tiene por qué ser negativa ya que conlleva la rehabilitación de los barrios, así como su puesta en valor, siendo su principal desventaja la expulsión de los vecinos de menor poder adquisitivo y dando como resultado que estos barrios se han hecho inhabitables para las clases trabajadoras y las de elite, ya que cuando se da en forma de turistificación, la convivencia se hace difícil cuando muchos de los visitantes "viven el día como una fiesta continua" (EFE, 2019). En consecuencia, en Salamanca se crea un Plan Especial el cual tiene como objetivo la preservación de los habitantes autóctonos, sin embargo, el arrendamiento en los barrios comienza a ser un problema para ellos y es cuando la población genuina va siendo reemplazada por población estudiantil e inicia la renta de apartamentos, despachos profesionales, comercio de turismo y hostelería, siguiendo un proceso mixto entre tercerización y “gentrificación” (Senabre, 2003).

\section{Patrimonio cultural como recurso turístico, problemas y limitaciones}

Para el mejor análisis y estudio del patrimonio cultural, se han desarrollado definiciones respecto al "patrimonio tangible o intangible" de valor monumental histórico o artístico muebles o inmuebles- que han sido desarrollados a lo largo de la vida de los pueblos y que conforman parte del acervo patrimonial en el país. En la actualidad dicho patrimonio es fácilmente inventariado y aprovechado económicamente como producto turístico. No obstante, el patrimonio intangible, es más difícil de catalogar por ser valores no materiales, y que son parte del patrimonio como simbología cultural de los valores de una ciudad o conjunto histórico. Por otro lado, este patrimonio ha sido la herencia de las culturas precursoras instaladas en los sitios y que han variado en el tiempo convirtiéndose en la historia del lugar, por lo que el patrimonio ha sido sujeto a diversas transformaciones, primero como parte de una forma de vida a legado y herencia de un pueblo de valor tangible o intangible a producto turístico, conservado como riqueza cultural de las ciudades que se han de mantener y admirar por futuras generaciones como testimonio de la cultura y los valores históricos que ahí se desarrollaron. 
Hasta este momento, hemos incluido conceptos o definiciones con el fin de conocer la diversidad cultural que nos representa en el mundo, la forma de vida de nuestros antepasados y la evolución histórica de los pueblos sin perder la identidad que los caracteriza, así como el patrimonio que en las últimas décadas adquiere tal relevancia por la representación tan amplia de nuestras creencias, costumbres y formas de vida.

Observamos que el patrimonio cultural tangible o intangible es protegido, admirado y cuando es necesario rescatado, por ser considerado como un bien al que debemos conservar y salvaguardar como símbolo de la cultura que nos representa, concepto que ha sido aceptado y reconocido por instancias internacionales que trabajan en pro de la humanidad. Esta situación, que no ha sido un proceso fácil y que ha involucrado convenciones y comisiones internacionales, en donde se ha puesto como principal objetivo la valoración y categorización del patrimonio histórico como testimonio de la civilización mundial. En lo particular, corresponde a los representantes de cada nación identificar, preservar y declarar los bienes culturales que tengan valor como patrimonio histórico, así como legislar para su protección.

Indudablemente, la ciudad patrimonio y los centros históricos principalmente, forman parte de estas categorías del patrimonio cultural, debido a que han sido testigos ancestrales de intercambio cultural, por lo que también sus valores urbanísticos, paisajísticos, estéticos y arquitectónicos, son considerados sin importar si fueron diseñadas en apego a un plano o no y exhibidos como parte del patrimonio de la humanidad. 


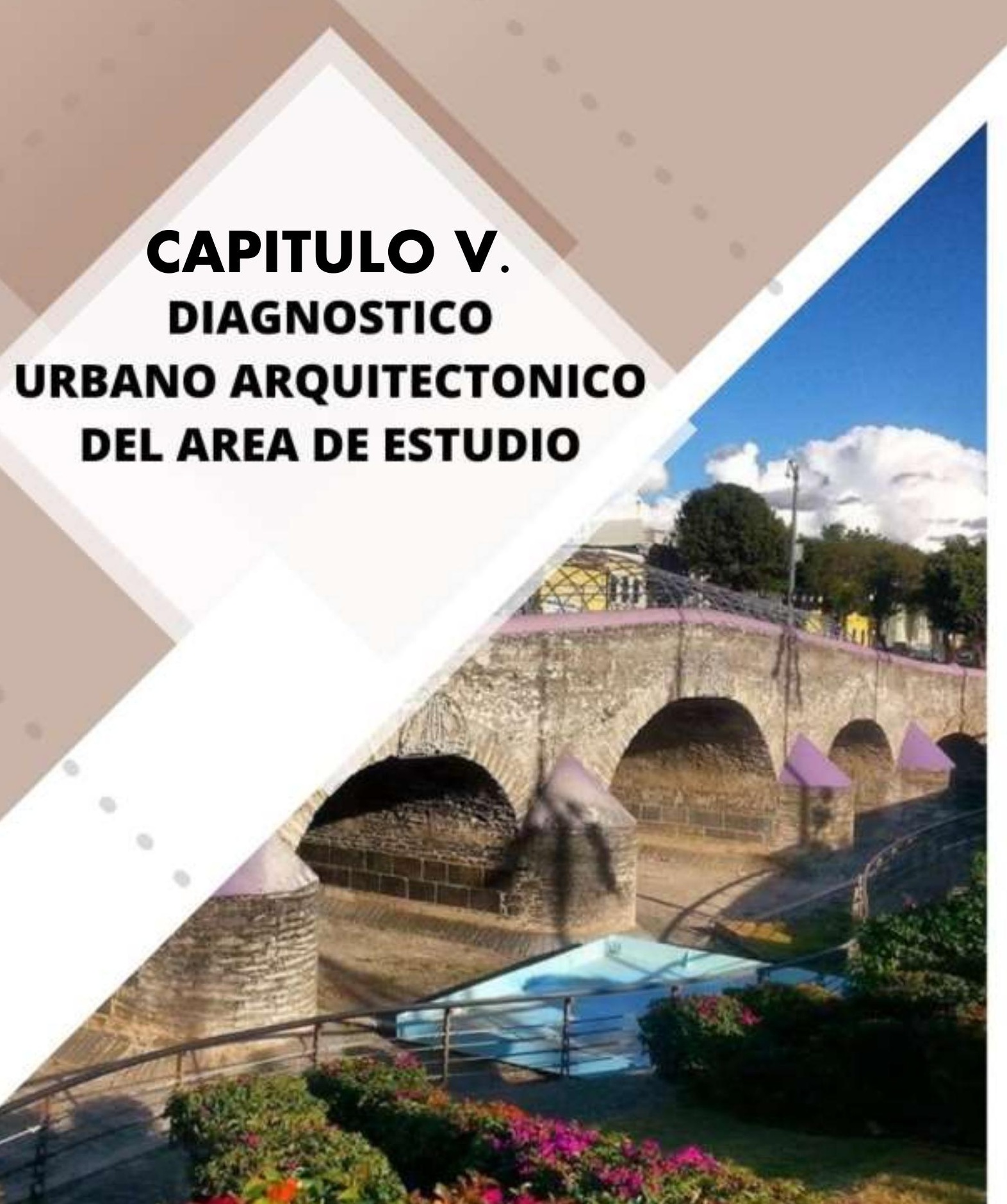




\section{DIAGNOSTICO URBANO ARQUITECTONICO DEL AREA DE ESTUDIO}

En este capítulo, realizamos una delimitación de la zona de monumentos históricos y del barrio de Analco, así como un diagnostico urbano arquitectónico del área de estudio, con la finalidad de conocer y analizar su tipología, características y condiciones, así como los componentes que nos permitirán realizar este diagnóstico e identificar las transformaciones del espacio histórico, así como la movilidad y accesibilidad que sin duda forman parte los cambios.

Resulta necesario conocer, a través del censo de población y vivienda, aspectos económicos y socioculturales del barrio que nos permitan hacer un análisis y comparación más precisa con el centro histórico de Puebla. Por otro lado, hemos realizado una encuesta en el Barrio de Analco que nos permitirá conocer sus principales cambios y permanencias desde el punto de vista de los habitantes y actores clave que se ven involucrados en el día a día.

\subsection{Delimitación del área de estudio}

El área de estudio se delimita por las 18 manzanas que conforman el Barrio de Analco, el cual forma parte de la zona de monumentos históricos de la ciudad de Puebla, por lo que a continuación, se realiza la descripción de la Zona de Monumentos y de dicho barrio.

\subsubsection{Delimitación de la Zona de Monumentos Históricos}

La necesidad de preservar, estudiar y difundir el patrimonio histórico de la nación, expresada por el gobierno federal de Lázaro Cárdenas, originó la creación del Instituto Nacional de Antropología e Historia (INAH)el 3 de febrero de 1939. Una de sus principales funciones encomendadas, fue la vigilancia, conservación y restauración de los monumentos arqueológicos, históricos y artísticos de la República, así como de los objetos que en ellos se encuentren. Para tal efecto fue creado el Departamento de Monumentos Coloniales que se dividió en dos partes, la Dirección de Monumentos Prehispánicos y la de Monumentos Coloniales. Hacia 1973 dicho departamento se incorporó a la recién creada Dirección de 
Monumentos Históricos, y seis años después desapareció del esquema y en 1989, se convirtió en la Coordinación Nacional de Monumentos Históricos que tiene como tareas específicas la conservación, restauración, protección, catalogación, investigación y difusión del patrimonio histórico edificado de la nación. Para llevarlas a cabo, cuenta con áreas como la Coordinación Nacional de Monumentos Históricos, Dirección de Apoyo Técnico, Dirección de Licencias, Inspecciones y Registro, Subdirección Administrativa, Subdirección de Catálogo y Zonas, Subdirección de Investigación, Subdirección de Proyectos y Obras y la Unidad de Informática.

Para el mejor desarrollo y aprovechamiento de los elementos patrimoniales existentes en la localidad o región, el INAH junto con la Coordinación Nacional de Monumentos Históricos, ha realizado estudios para delimitar zonas de monumentos históricos con el fin de establecer estrategias y programas especiales para su protección, conservación y restauración. Entre las 56 Zonas que desde entonces se han delimitado, destaca el centro histórico de la ciudad de Puebla, que las administraciones correspondientes promovieron en el decreto por el que se declara la Zona de Monumentos Históricos de la Ciudad de Puebla con fecha del 18 de noviembre de 1977 y que hoy es reconocido por la UNESCO como Patrimonio de la Humanidad ${ }^{18}$.

Con posterioridad a la delimitación de la Zona de Monumentos Históricos, se ha hecho una Declaratoria de la "Zona de Desarrollo Turístico Prioritario de la Ciudad de Puebla de Zaragoza". Esta ha sido promovida por los Secretarios de Desarrollo Social, el de Educación Pública y el de Turismo Cultural, Carlos R. Gutiérrez, Fernando Solana Morales y Jesús Silva Herzog respectivamente, en la declaratoria del 28 de febrero de 1994 (ver Fig. 25). Esta gestión se realizó sobre la base de la consideración que hacia el Plan Nacional de Desarrollo 1989-1994, donde establecía la necesidad de que el sector turismo participara aportando elementos para el desarrollo de la economía nacional y el equilibrio regional, a través de la mejora de la infraestructura turística y el incremento del turismo nacional y extranjero. Con la intención de promover y fomentar el desarrollo turístico integral, el Gobierno del Estado de Puebla solicito esta declaratoria ya que la ciudad capital reunía las

\footnotetext{
${ }^{18}$ Fuente: Instituto Nacional de Antropología e Historia (INAH) http://www.inah.gob.mx
} 
características necesarias en términos de la Ley Federal de Turismo, por la magnificencia de sus monumentos y la importancia de sus acontecimientos históricos en la vida nacional.

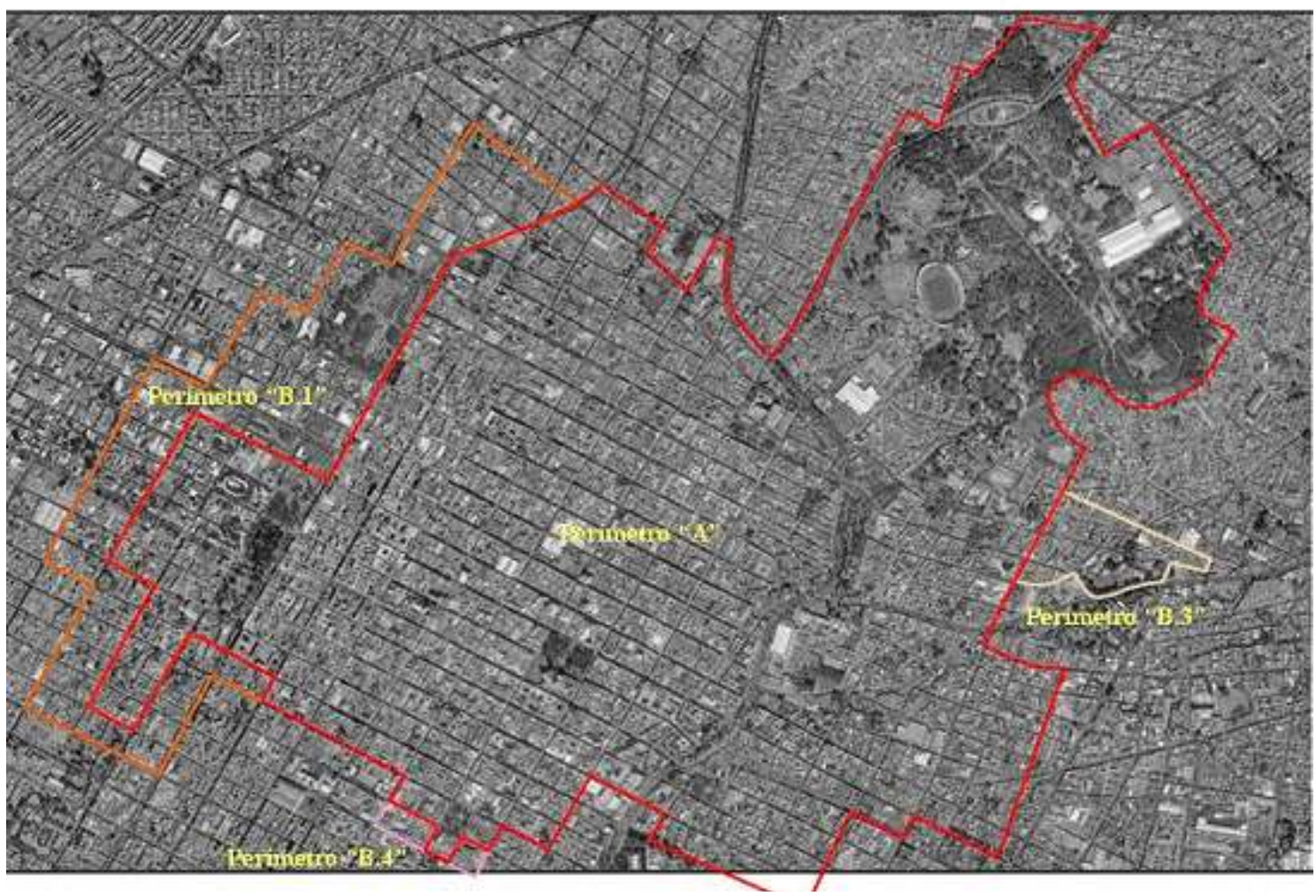

Figura 25. Delimitación del Centro histórico de la ciudad de Puebla realizada a partir de la información del (Gobierno del Estado, 2015)

La Zona de Desarrollo Turístico Prioritario de la Zona de Monumentos Históricos de la Ciudad de Puebla comprende un área de 6,9 $\mathrm{Km}^{2}, 5$ perímetros, 436 manzanas y 7,439 predios que conforman el legado de monumentos históricos originales del siglo XVI al XX. Para el sustento y buen funcionamiento de dicha zona, se adjudicó la responsabilidad a la Secretaría de Turismo para el apoyo basado en la creación de empresas turísticas que, junto con las dependencias y entidades administrativas correspondientes, buscaran financiamiento para los proyectos y servicios turísticos de la zona. Se han previsto también otros factores como la regulación del uso del suelo, buscando la compatibilidad con el desarrollo turístico y los referentes a la debida protección y fortalecimiento del patrimonio histórico y cultural que se ubique dentro de esta zona. 


\subsubsection{Delimitación del Barrio de Analco}

El barrio de Analco se localiza en el centro de la ciudad de Puebla al oriente, cruzando el boulevard 5 de mayo, colinda al norte con el Barrio de la Luz y la avenida Don Juan de Palafox y Mendoza; al sur con la avenida 11 oriente y el Centro Escolar Niños Héroes; al poniente con el bulevar 5 de mayo y al oriente con la calle 16 sur, (ver Fig. 26).

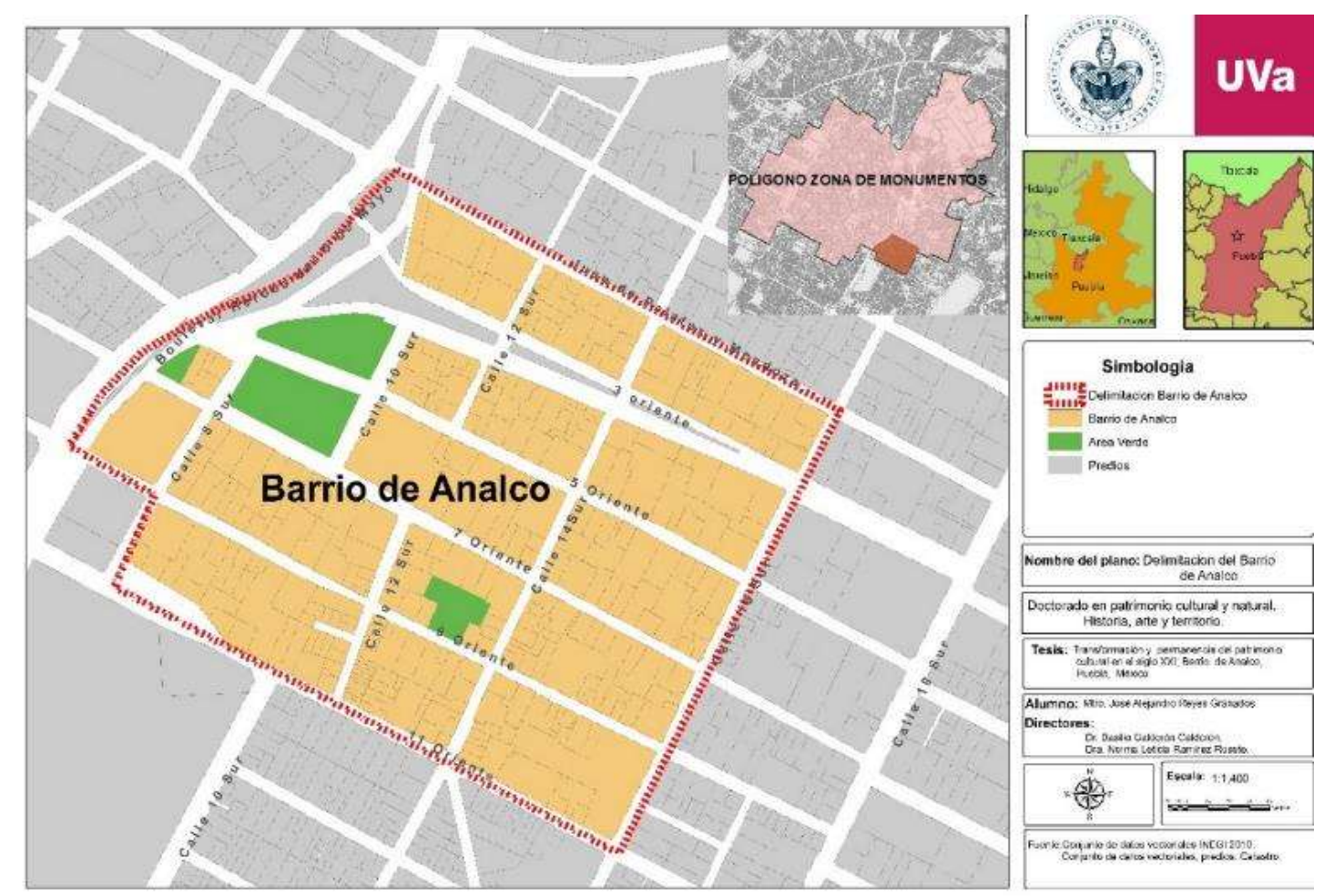

Figura 26. Plano de delimitación del Barrio de Analco, Elaboración propia en base a (INEGI, 2010).

5.2.Análisis de los componentes urbano - arquitectónicos

\subsubsection{Uso del suelo}

Para analizar los cambios del uso de suelo en el barrio de Analco, es necesario conocer su contexto, por ello identificamos la Zona de Monumentos en la carta urbana del municipio de Puebla, contenida en el Programa Parcial de Desarrollo Urbano Sustentable del Centro Histórico del Municipio de Puebla (2015). De esta manera, se muestra una densidad de vivienda que va de 51 a 120 viv./ha. perteneciendo a la categoría de primera zona de densidad selectiva, (ver Fig. 27). 

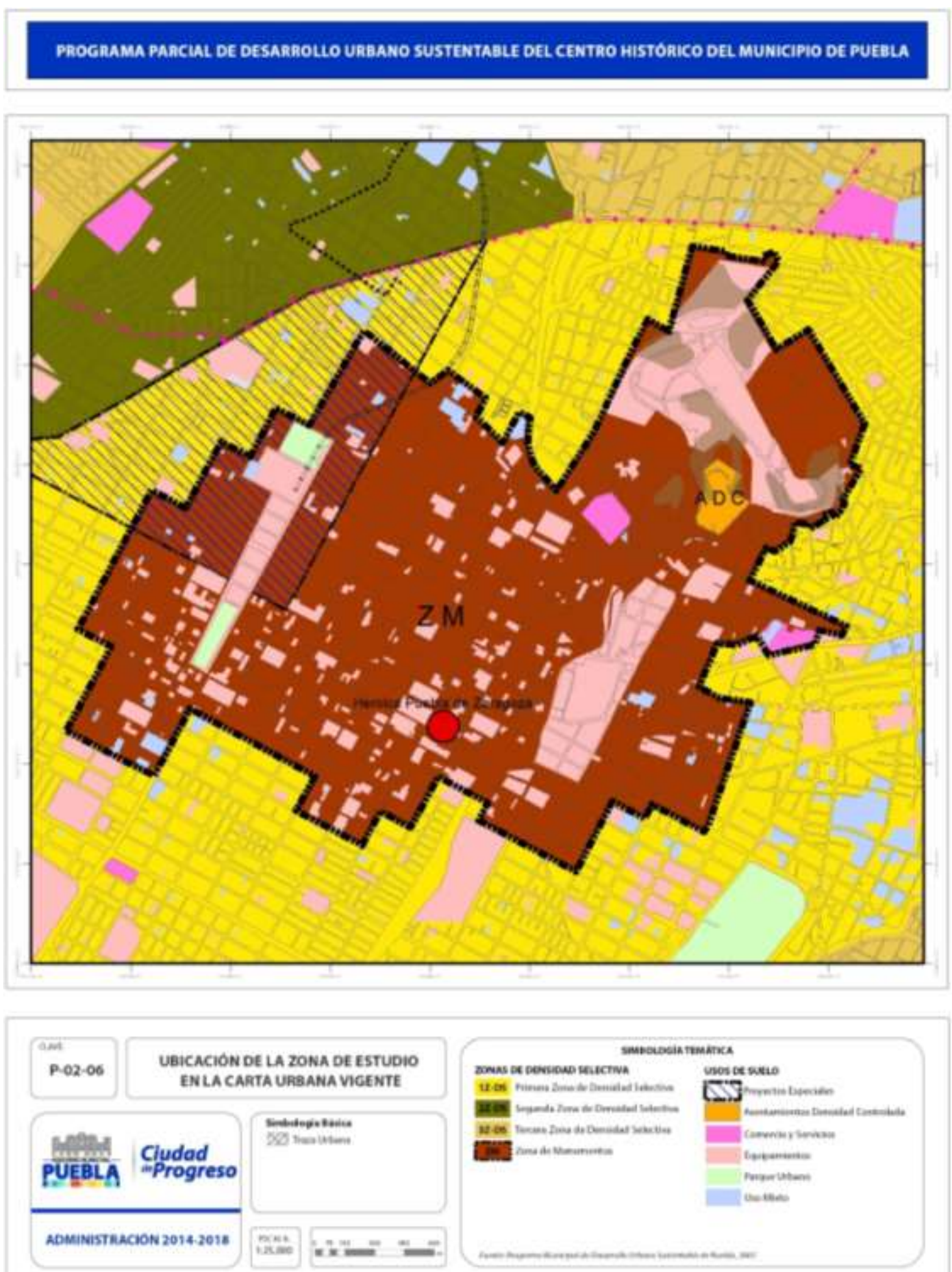

Fig. 27 Plano de ubicación de la zona de estudio en la carta urbana vigente. Fuente: anexos cartográficos de (GOBIERNO d. E., Plan Parcial de Desarrollo Urbano Sustentable del Centro Histórico del Municipio de Puebla, 2015) 
En este polígono, se clasifica el uso de suelo en 10 categorías; vivienda, vivienda y uso mixto, comercio, comercio y servicios turísticos, servicios, equipamiento cultural y religioso, espacios abiertos (plazas y parques) y la industria. Así, se observa una diversificación del uso que se desglosa en el programa parcial respecto a los que establece la carta urbana, ya que existen factores implicados en la transformación continua a causa de la especulación inmobiliaria en torno a la Zona de Monumentos Históricos, (ver Fig. 28).

PROGRAMA PARCIAL DE DESARROLLO URBANO SUSTENTABLE DEL CENTRO HISTORICO DEL MUNICIPIO DE PUEBLA
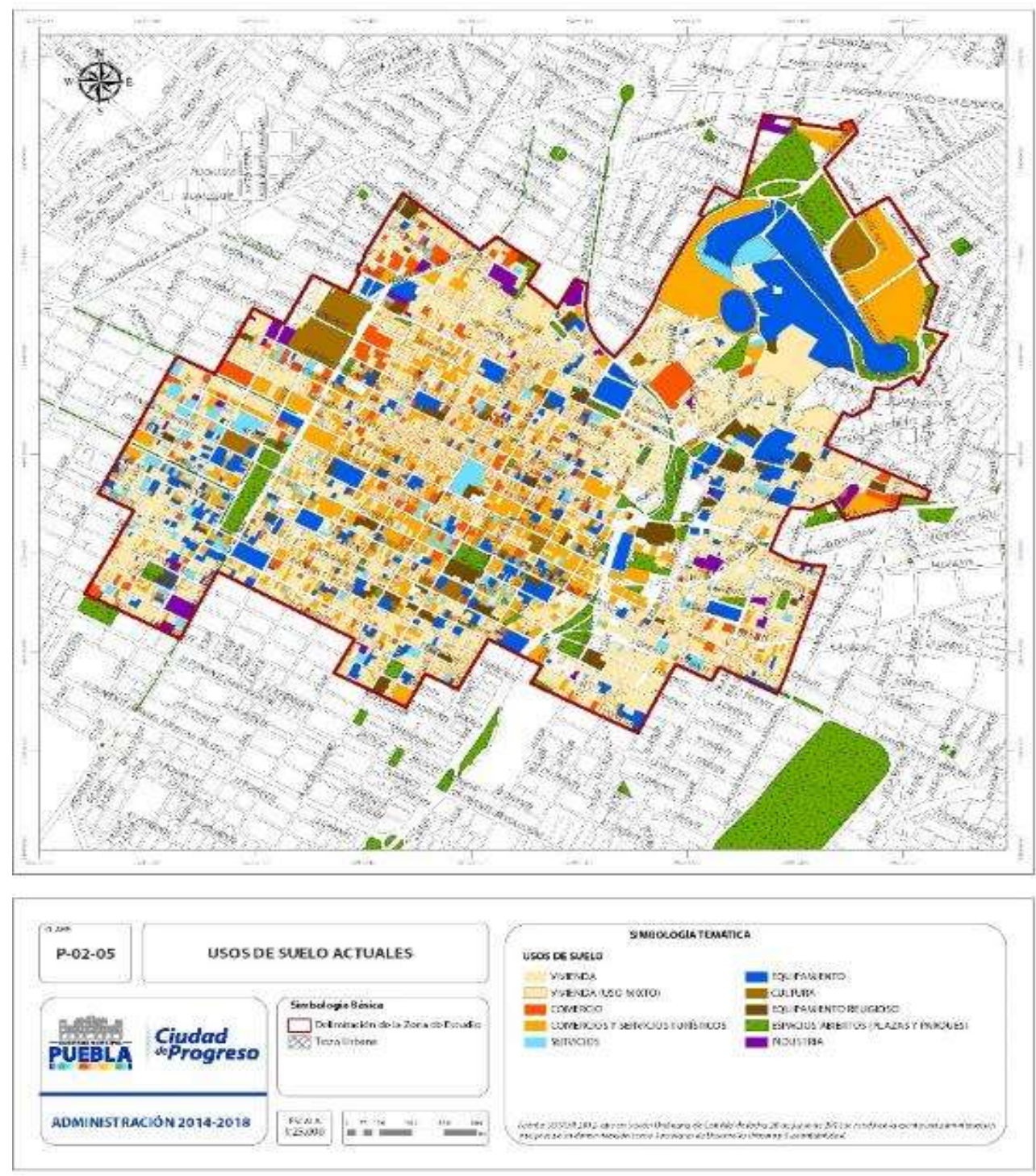

Figura 27. Plano de uso de suelo. Fuente: anexos cartográficos de (GOBIERNO d. E., Plan Parcial de Desarrollo Urbano Sustentable del Centro Histórico del Municipio de Puebla, 2015) 
Es importante conocer los cambios y transiciones en el uso del suelo que han contribuido a la pérdida del patrimonio material en el barrio de Analco. Para esto, se ha tomado como referencia el Programa Parcial del Centro Histórico de Puebla (2015) (ver Fig. 29) y un plano con información de campo obtenida en julio de 2019 (ver Fig. 30), podemos notar el aumento de inmuebles abandonados y modificados, siendo las calles 3 y 11 oriente en donde se concentra el uso del suelo mixto con la mayor transformación a uso comercial y de servicios.
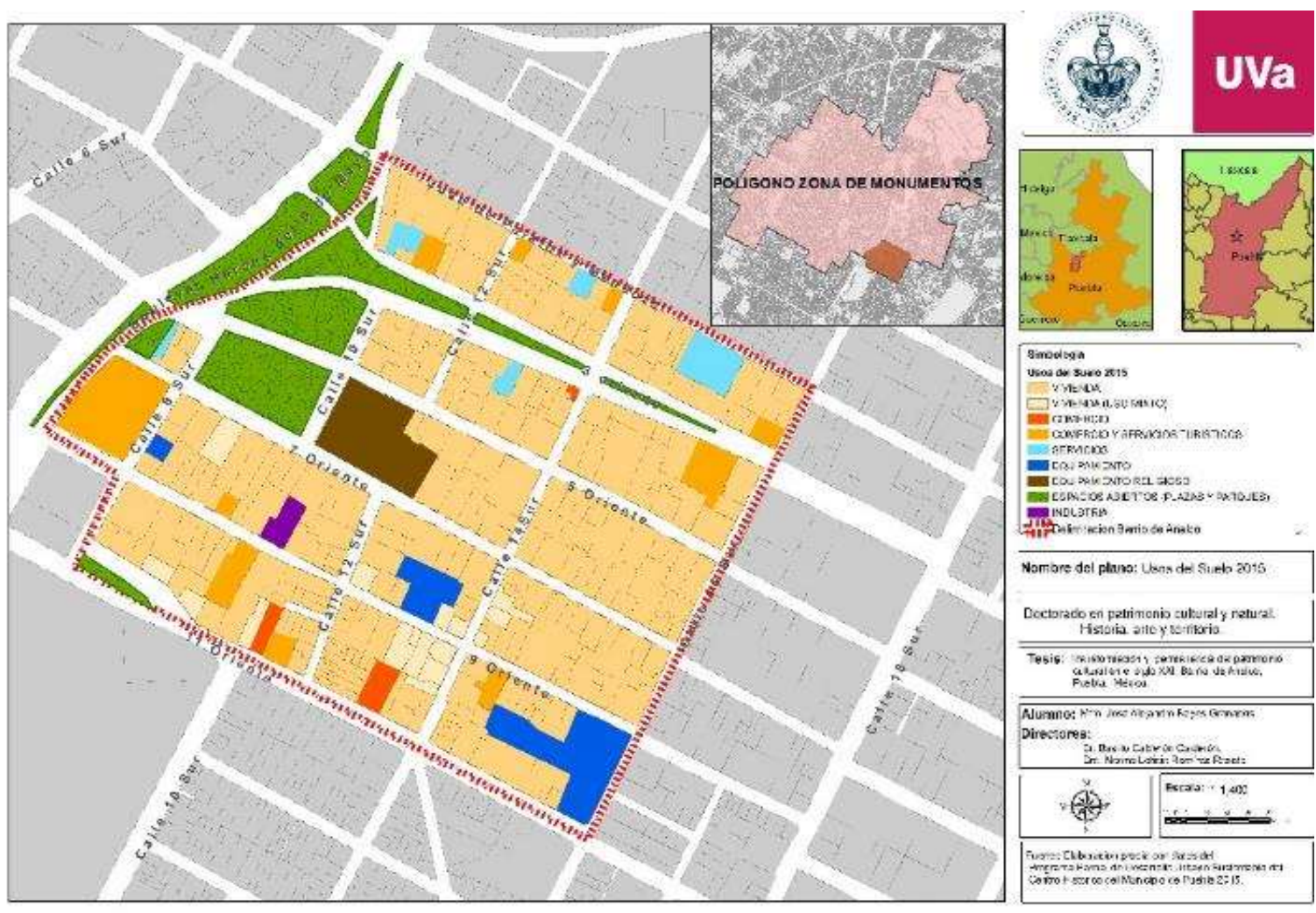

Figura 28. Uso del suelo del barrio del año 2015, Elaboración propia en base a datos de (Gobierno del Estado, 2015) 

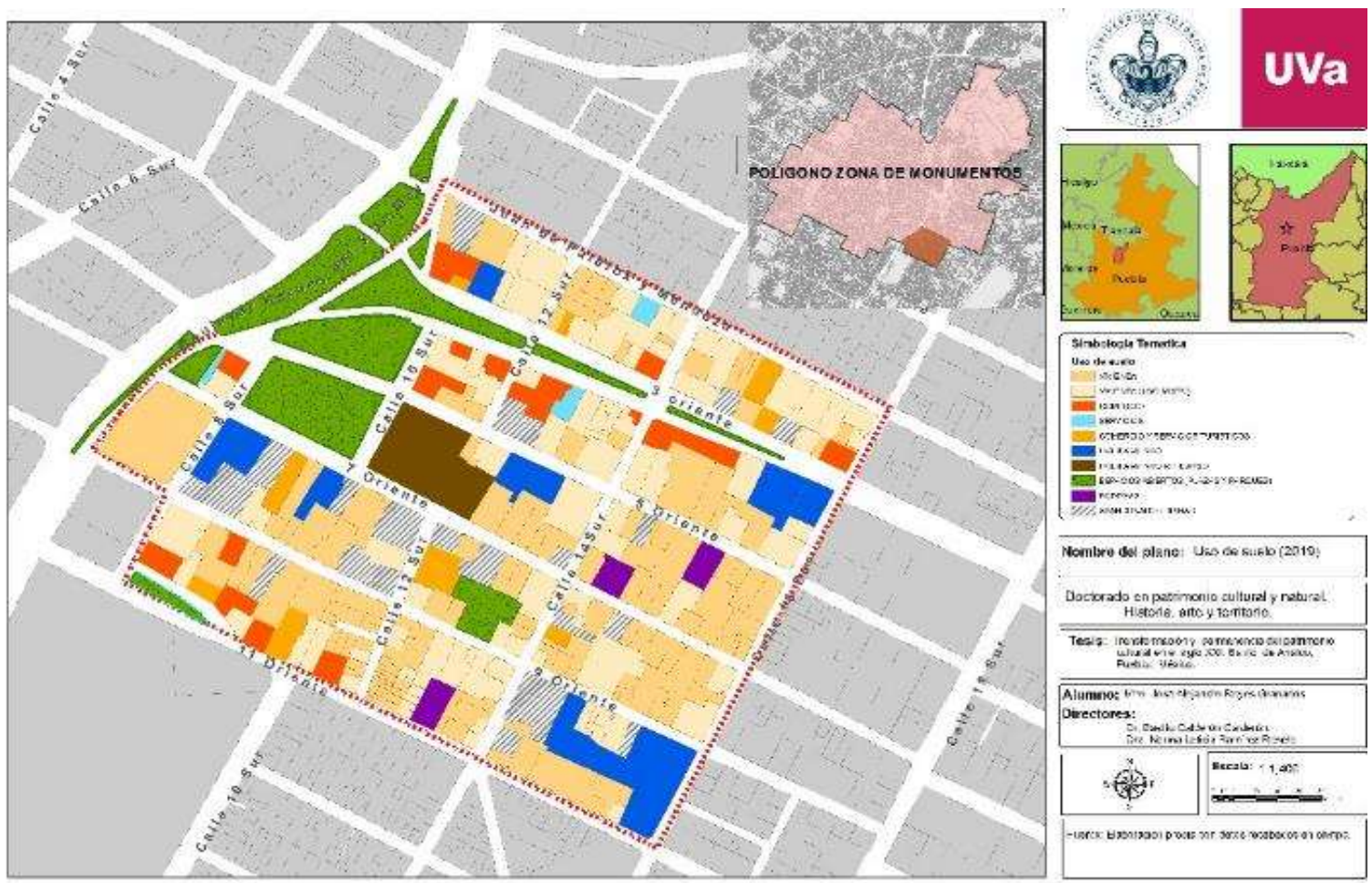

Figura 29. Uso de suelo del barrio de Analco del año 2019, Elaboración propia en base a datos obtenidos en campo

De esta manera, identificamos los usos actuales del barrio, estado de conservación y ocupación de inmuebles, así como de bodegas comerciales. Esta información, aunada al análisis fotográfico que posteriormente se presenta, corrobora que la imagen urbana del barrio ha cambiado. Por otra parte, aún se conservan oficios tradicionales, como la elaboración de pan con hornos de piedra y la alfarería de barro negro (fabricación de incensarios y de cazuelas de barro). También encontramos otros oficios como carpintería, confección de prendas, herrería y algunas industrias manufactureras como la antigua fábrica de vidrio La Luz. (ver Fig. 31). 


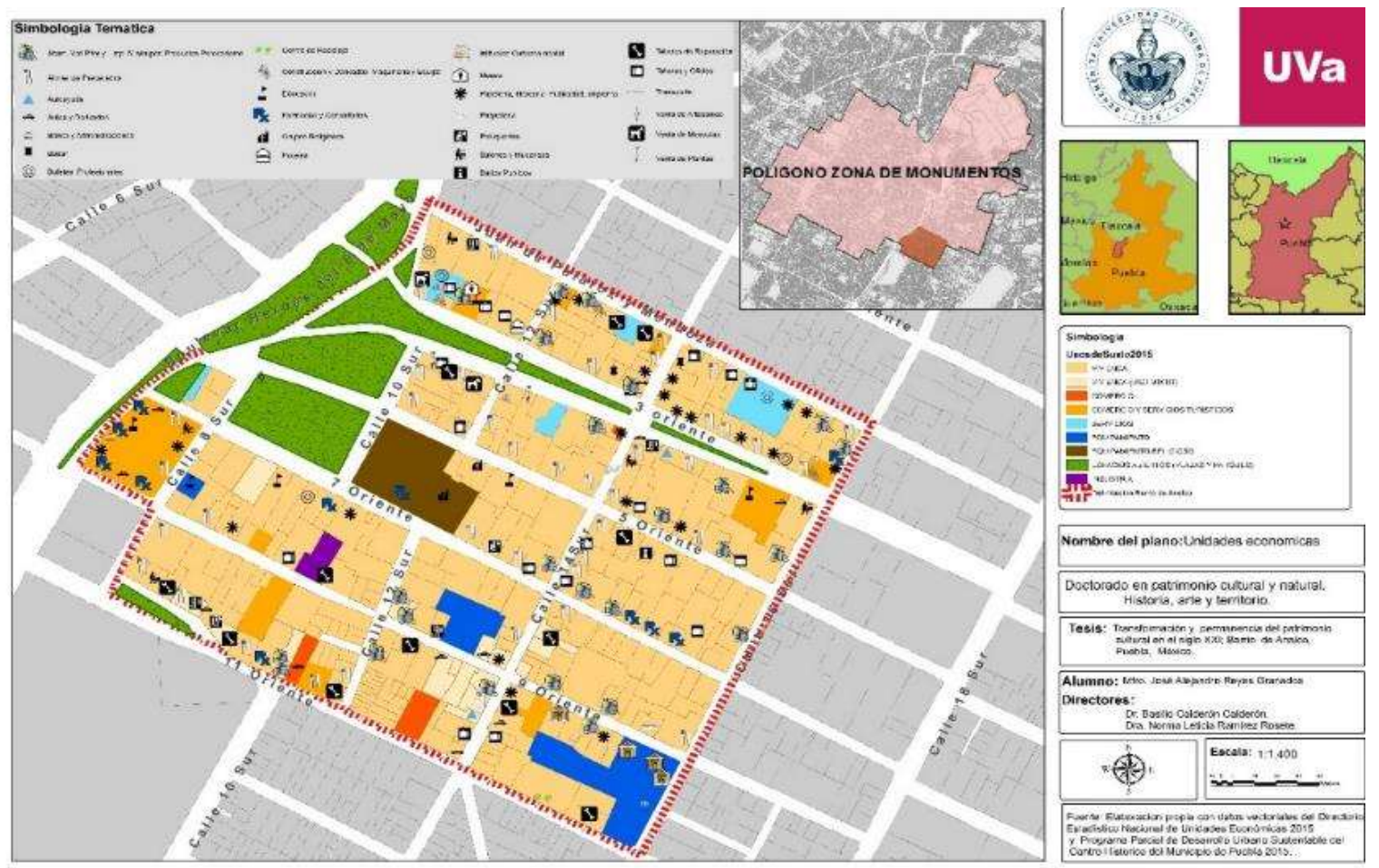

Figura 30. Plano unidades económicas del barrio de Analco, Elaboración propia en base a datos vectoriales de (Gobierno Federal, 2015)

Los establecimientos que se ubican principalmente en vialidades secundarias del barrio, son misceláneas y tiendas de abarrotes; en la calle 3 oriente se ubican en su mayoría papelerías, imprentas y mercerías debido al establecimiento de escuelas de educación superior en esta zona, además de ser la vialidad con mayor flujo vehicular que interconecta al barrio de Analco con el boulevard 5 de mayo (ver Fig. 32). 

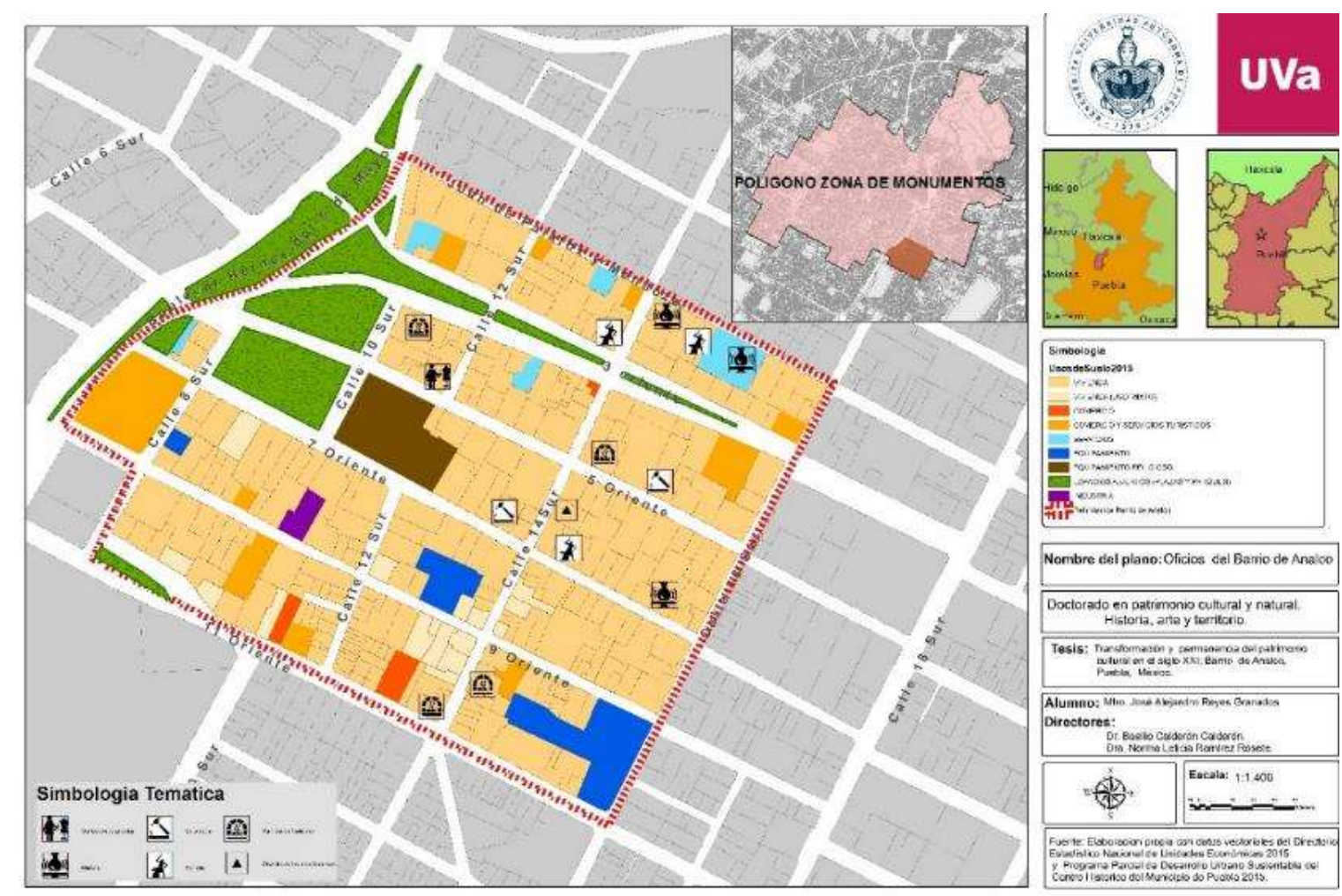

Figura 31. Plano oficios del Barrio de Analco, Elaboración propia en base a datos vectoriales de (Gobierno Federal, 2015)

\subsubsection{Morfología urbana}

En los últimos años, ha tenido lugar una transformación del uso del suelo en el barrio de Analco, provocando graves afectaciones en su morfología con nuevas edificaciones y alteraciones a las ya existentes, provocando el abandono de la población originaria y con ello un foco de atracción a nuevas oportunidades de construcción en la zona.

La traza del barrio es continua a la de la ciudad de Puebla (traza reticular), a pesar de que tuvo origen y creció en los límites de la Puebla antigua, cuenta con 18 manzanas irregulares y está integrado por 137 lotes aproximadamente, estos no tienen una forma regular por las transformaciones que ha sufrido a lo largo del tiempo por el cambio de usos o de actividades. Actualmente este barrio cuenta con un área aproximada de 270, $286.28 \mathrm{~m} 2$, y en el año 2004 esta superficie se distribuía como se muestra en la siguiente figura. (ver Fig. 33). 


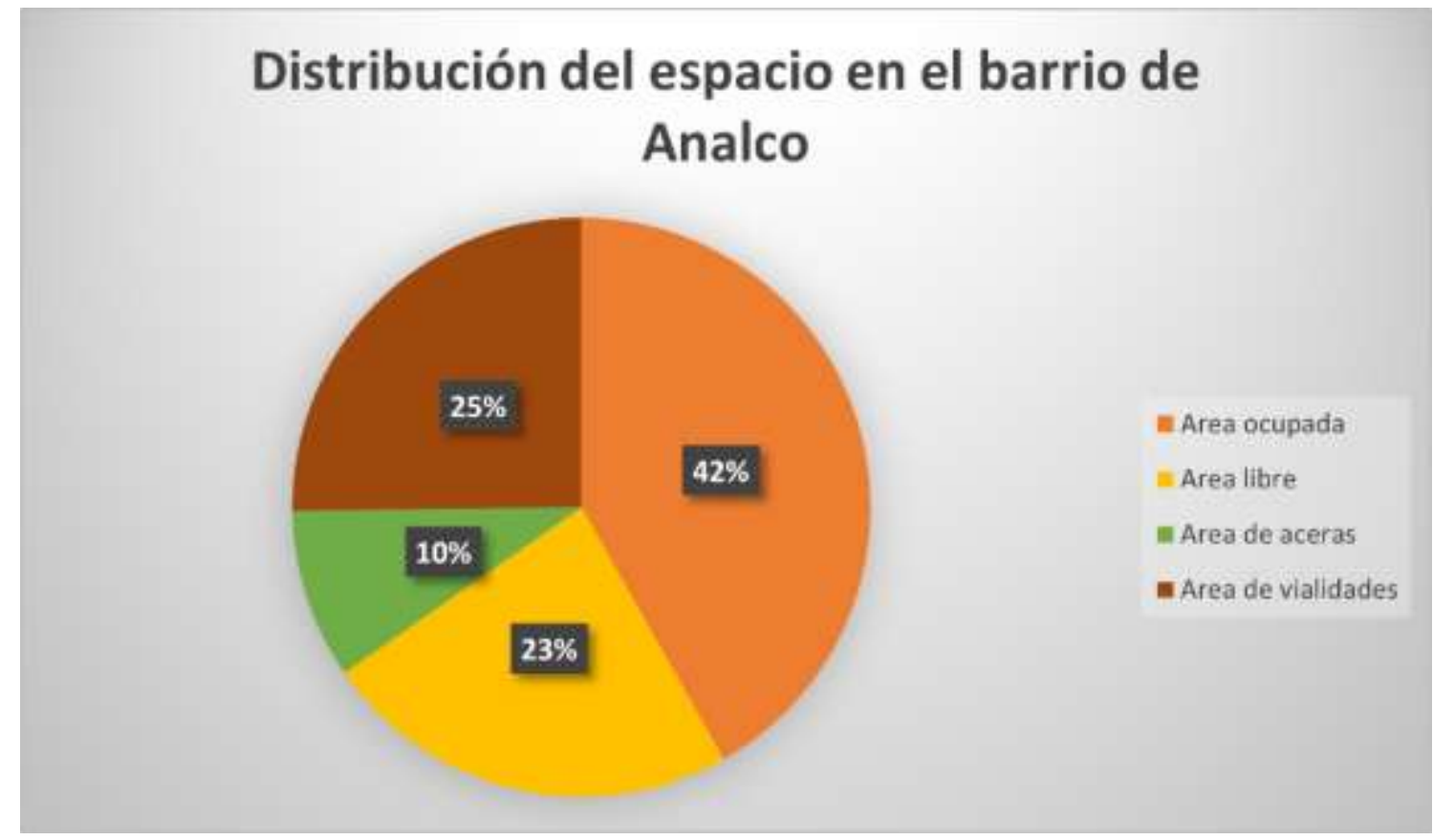

Figura 32. Distribución del espacio del barrio de Analco, Elaboración propia en base a datos obtenidos de (Gobierno del Estado, 2015)

Analco aún conserva su imagen barrial a pesar de las transformaciones que ha sufrido, sin embargo, solo unas cuantas edificaciones con valor cultural e histórico, aún conservan su estilo arquitectónico original y mientras el barrio y sus usos del suelo se transforman, los habitantes deben adaptarse a estas nuevas condiciones de vida. La reutilización de los inmuebles para su conservación es adaptada en función de las necesidades del sector inmobiliario, a pesar de que esta práctica también puede llegar desgastar el estado estructural original del inmueble, así como su significado cultural y patrimonial.

Entre las calles principales del barrio de Analco, está la 3 oriente que conecta con el boulevard 5 de mayo, además de ser una de las más transitadas; la calle 7 oriente es importante por la diversidad de leyendas como la del callejón del muerto o la piedra encantada que se ubica específicamente en la esquina de la 7 oriente y 14 sur y en la misma avenida se desarrollan actividades para la celebración de fiestas propias del barrio, así como 
para los recorridos religiosos como el viacrucis; la calle 11 oriente es más transitada por el transporte público además de ser la zona donde el flujo de peatones se incrementa debido a que, en su cruce con el boulevard 5 de mayo, se encuentra uno de los accesos al Centro Escolar Niños Héroes de Chapultepec (CENHCH), lo que genera un alto nivel de tráfico en horas pico, siendo así los nodos conflictivos más importantes junto con los de la 16 sur y la esquina con la 3 y 11 oriente, tanto por las circulación de rutas de transporte, como por los servicios que se establecen ahí; otros nodos, se crean por la falta de señalética, lo que provoca frecuentes conflictos vehiculares.

El barrio de Analco es uno de los más antiguos de la ciudad de Puebla, por lo que aún se pueden observar algunos edificios y fachadas que conservan su estilo arquitectónico al igual que sus materiales y técnicas de construcción. Por medio de datos obtenidos del Gobierno Municipal (2015) y del Instituto Catastral y Registral del Estado de Puebla (2011) se realizaron fichas de categorización arquitectónica del barrio de Analco, que se presentarán más adelante, en las cuales se distinguirán las categorías y materiales constructivos por cada calle (ver Tabla 10).

\begin{tabular}{|c|c|c|c|c|}
\hline CALLE & CATEGORÍA & MATERIAL & ESTILO & SIGLO \\
\hline 16 sur & $3,5,2$ & $\begin{array}{l}\text { Aplanado de cal y arena, aplanado de } \\
\text { concreto, aparente metal y piedra }\end{array}$ & $\begin{array}{c}\text { popular, contemporáneo, colonial, } \\
\text { nacionalista y eclético }\end{array}$ & XVIII-XXI \\
\hline 14 sur & 2,3 & $\begin{array}{l}\text { Aplanado de cal y arena y aplanado } \\
\text { concreto. }\end{array}$ & popular, colonial, neoclásico y art-deco & XVII-XX \\
\hline 12 sur & $2,3,4$ & $\begin{array}{l}\text { Aplanado de cal y arena, aplanado } \\
\text { concreto. }\end{array}$ & nacionalista, popular y neoclásico & XVII-XX \\
\hline 10 sur & $1,2,3$ & $\begin{array}{l}\text { Aplanado de concreto cal y arena, aplanado } \\
\text { concreto y piedra }\end{array}$ & Colonial y neoclásico. & XVI-XX \\
\hline 8 sur & $3,2,5$ & Aplanado de cal y arena, concreto & contemporáneo, popular y nacionalista & XVIII-XXI \\
\hline $\begin{array}{c}\text { Juan de Palafox y } \\
\text { Mendoza }\end{array}$ & $0,1,2,3,4$ & $\begin{array}{l}\text { Aplanado de cal y arena, aplanado de } \\
\text { concreto }\end{array}$ & popular, moderno, art-deco y eclético & XIX \\
\hline 3 oriente & $2,3,4,5$ & $\begin{array}{l}\text { Aplanado de concreto cal y arena, aplanado } \\
\text { concreto y piedra }\end{array}$ & $\begin{array}{c}\text { Popular, moderno, art-deco, } \\
\text { nacionalista, colonial y neoclásico }\end{array}$ & XVIII-XX \\
\hline 5 oriente & $1,2,3,5$ & $\begin{array}{l}\text { Aplanado de cal y arena, aplanado } \\
\text { concreto. }\end{array}$ & $\begin{array}{c}\text { popular, moderno, neoclásico, colonial, } \\
\text { industrial y art-deco }\end{array}$ & XVII-XX \\
\hline 7 oriente & $1,2,3,5$ & $\begin{array}{l}\text { Aplanado de cal y arena, aplanado } \\
\text { concreto, aparente piedra }\end{array}$ & popular, colonial, nacional y neoclásico & XVII-XX \\
\hline 11 oriente & $0,1,5$ & Aplanado cal y arena, aplanado concreto & colonia, contemporáneo y moderno & XVIII-XXI \\
\hline
\end{tabular}

Tabla 10. Calles del barrio de Analco por categoría arquitectónica, material, estilo y siglos de construcción, Elaboración propia en base a datos obtenidos de (Gobierno del Estado, 2015) y de (Gobierno del Estado, 2011). 
En el barrio y su contexto existen varios elementos que con el paso de los años han adquirido un valor cultural por parte de sus habitantes, ya sea por su utilización como punto de reunión o por su importancia religiosa, recreativa, histórica e incluso como partes de leyendas representativas del barrio.

Entre los elementos más representativos se encuentran: el puente de Ovando (ver Fig. 34) que en la antigüedad era usado como uno de los accesos de Analco al primer cuadro de la ciudad de Puebla, en la actualidad es un hito histórico; el monumento del Ángel custodio, una obra de Enrique Carbajal, ubicado sobre el boulevard 5 de mayo; otro de los hitos es la fuente y jardín de Analco, el cual es utilizado para reuniones y actividades turísticas por medio de un tianguis cada fin de semana; la parroquia del Santo Ángel Custodio, es el hito más importante de índole religiosa; y finalmente, el parque Jerusalén que es un lugar de reunión para jóvenes, sin embargo, también es un lugar donde existe un alto nivel de delincuencia, aunque en los últimos años se ha buscado el rescate de este espacio, con diferentes actividades artísticas e iniciativas de diverso grupos y colectivos.

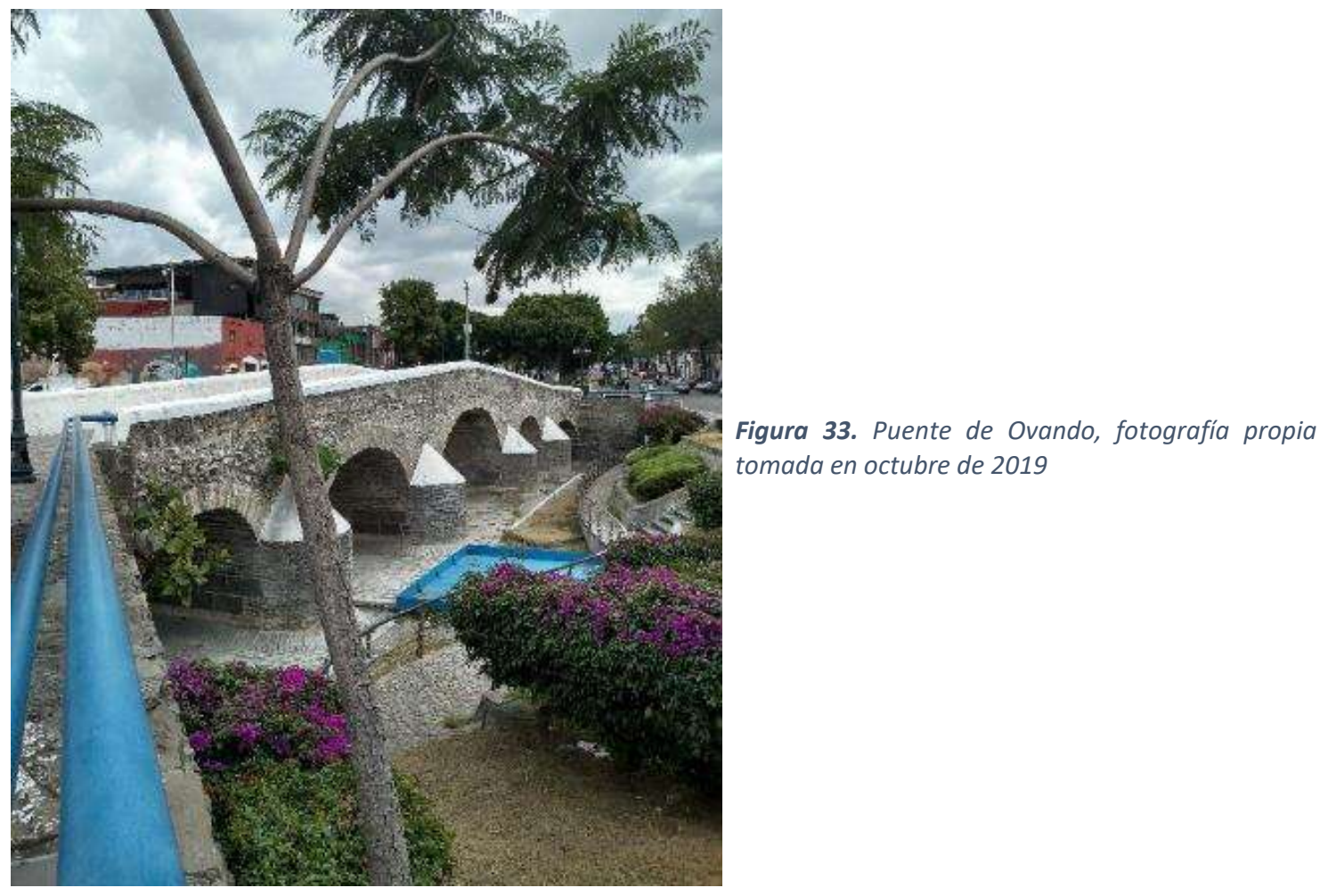




\subsubsection{Imagen urbana}

La Zona de Monumentos presenta tres polígonos que definen 3 niveles de deterioro de la imagen urbana a través de sus inmuebles: degradados, en proceso de degradación y en buen estado (Gobierno del Estado, 2015). No obstante, a pesar de que el barrio de Analco se encuentra dentro del polígono "en buen estado", los elementos urbano-arquitectónicos no son del todo homogéneos y algunos están en mal estado como se observa en la figura 35.

PAOGRAMA PARCIAL DE DESARROLLO URBANO SUSTENTABLE DEL CENTRO HISTORICO DEL MUNICIPIO DE PUEBLA
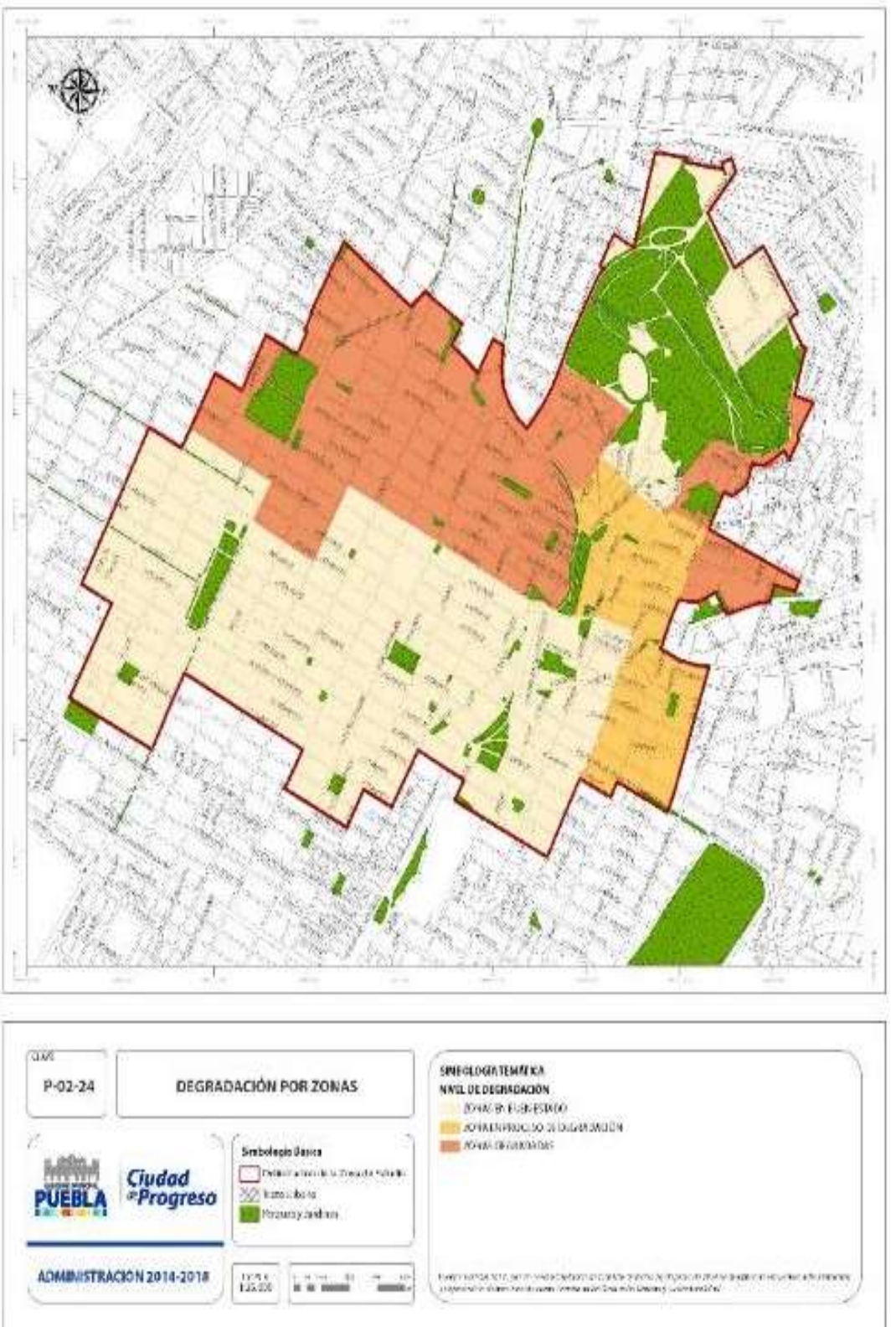

Fiqura 34. Plano de dearadación por zonas, extraído de los anexos 
Por otra parte, los servicios y equipamiento, aunque son considerados suficientes, no logran abarcar las necesidades de la población. La zona en donde se puede observar mayor cantidad de inmuebles en ruinas es en la manzana sobre la calle 7 oriente, entre la calle 12 y 14 sur, que colinda con las oficinas de la parroquia del Santo Ángel Custodio. Por otro lado, las calles 3 y 11 oriente conservan la mayoría de sus inmuebles en buenas condiciones (ver Fig. $36)$.
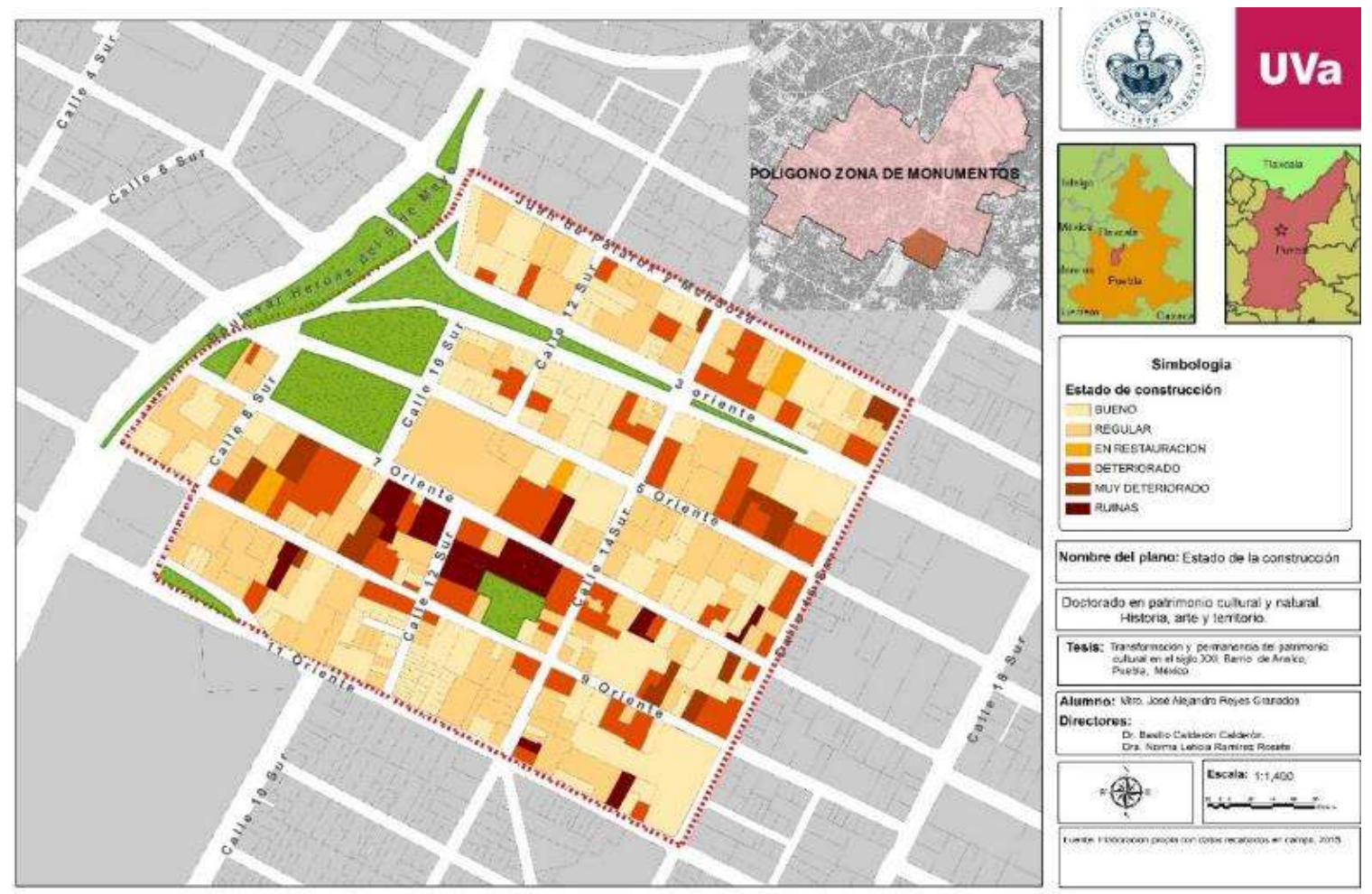

Figura 35. Estado de construcción de los inmuebles del barrio de Analco. Elaboración propia en base a datos obtenidos en campo en 2017.

En cuanto a estado de ocupación de estos inmuebles, se puede identificar al menos 30 en ruinas y/o abandonados, con base a la información obtenida en campo en el año 2019, esta información se comparó con el estado de ocupación del año 2015 y el resultado fue que aproximadamente 18 inmuebles cambiaron su estado de ocupado a abandonado o en ruinas. De igual manera la manzana en donde se ubican la mayoría de estos edificios está ubicada entre la calle 8 y 12 sur, sobre la 7 oriente (ver Figura 37). 


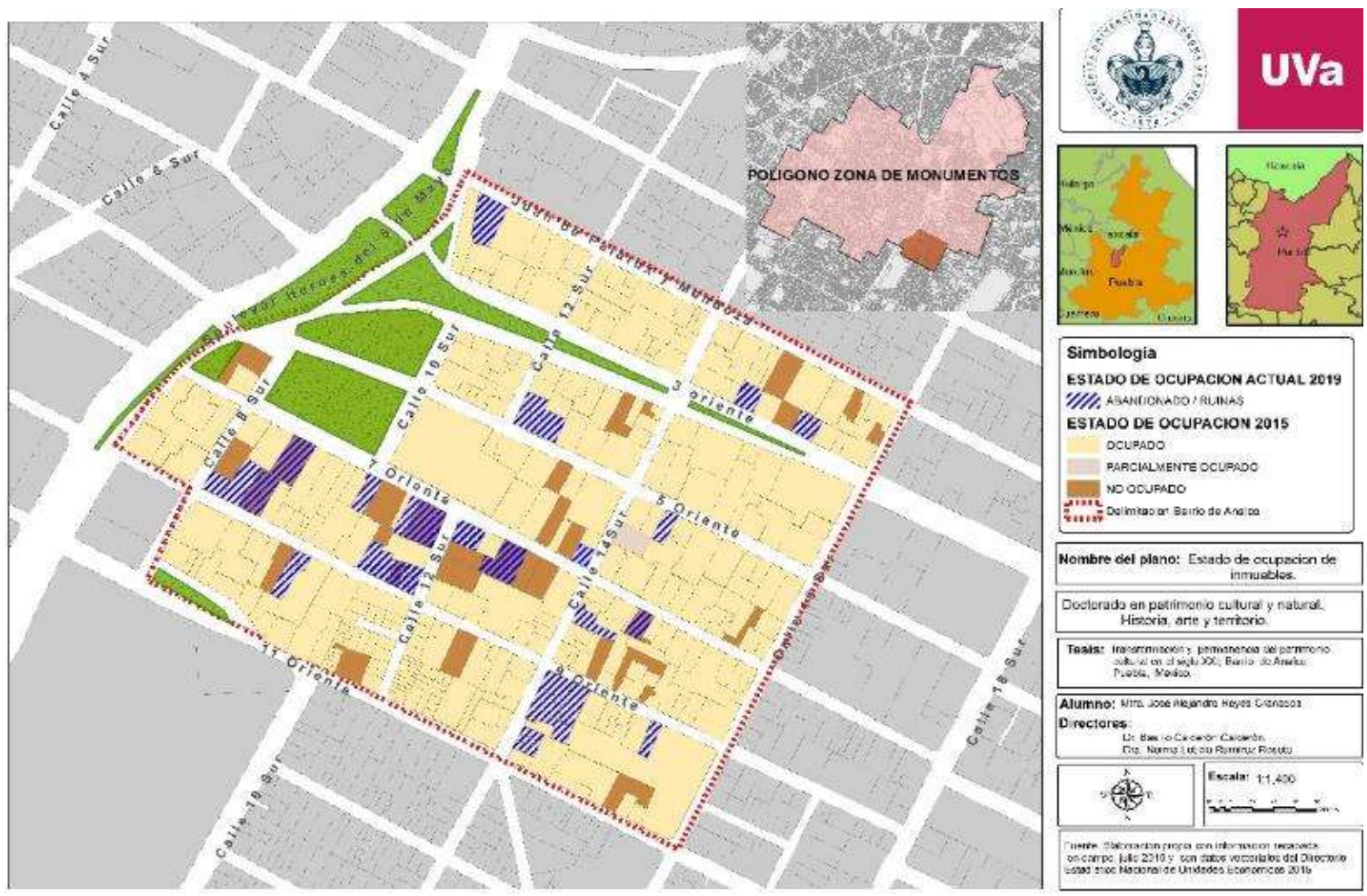

Figura 36. Plano de estado de ocupación de los inmuebles del barrio de Analco, Elaboración propia en base a información recabada en campo de julio del año 2019 y (Gobierno Federal, 2015)

\subsubsection{Espacios Públicos}

Los espacios públicos de la Zona de Monumentos del centro histórico de Puebla tienen una superficie total de 956, $615.04 \mathrm{~m} 2$, cuenta con 87 espacios públicos, que se dividen en 27 parques, 20 reservas ecológicas, 10 calles peatonales, 16 jardines, 9 plazuelas, 4 explanadas y 1 plaza. El barrio de Analco cuenta con 2 jardines y el parque Jerusalén, que juntos suman una superficie aproximada de 14,673.77 m2 (ver Fig. 38 y 39).

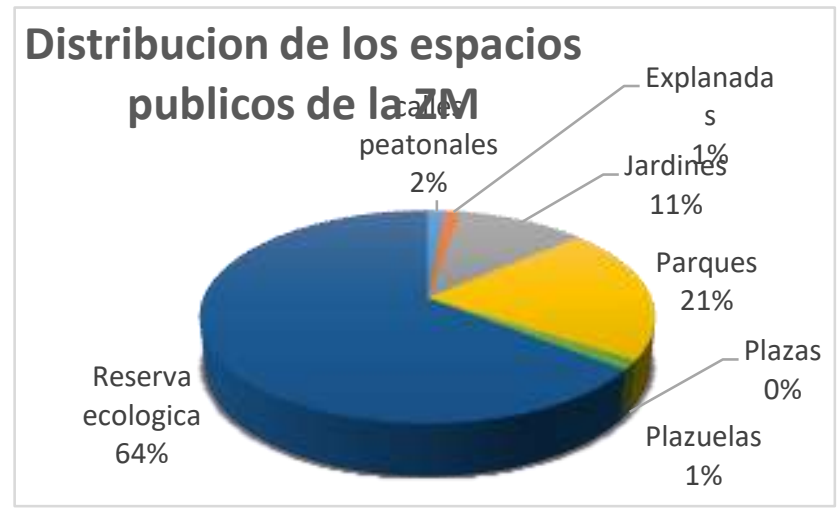

Figura 37 Distribución por porcentajes de los espacios de públicos de la Zona de Monumentos, Elaboración propia con base a información extraída de (Gobierno del Estado, 2015). 

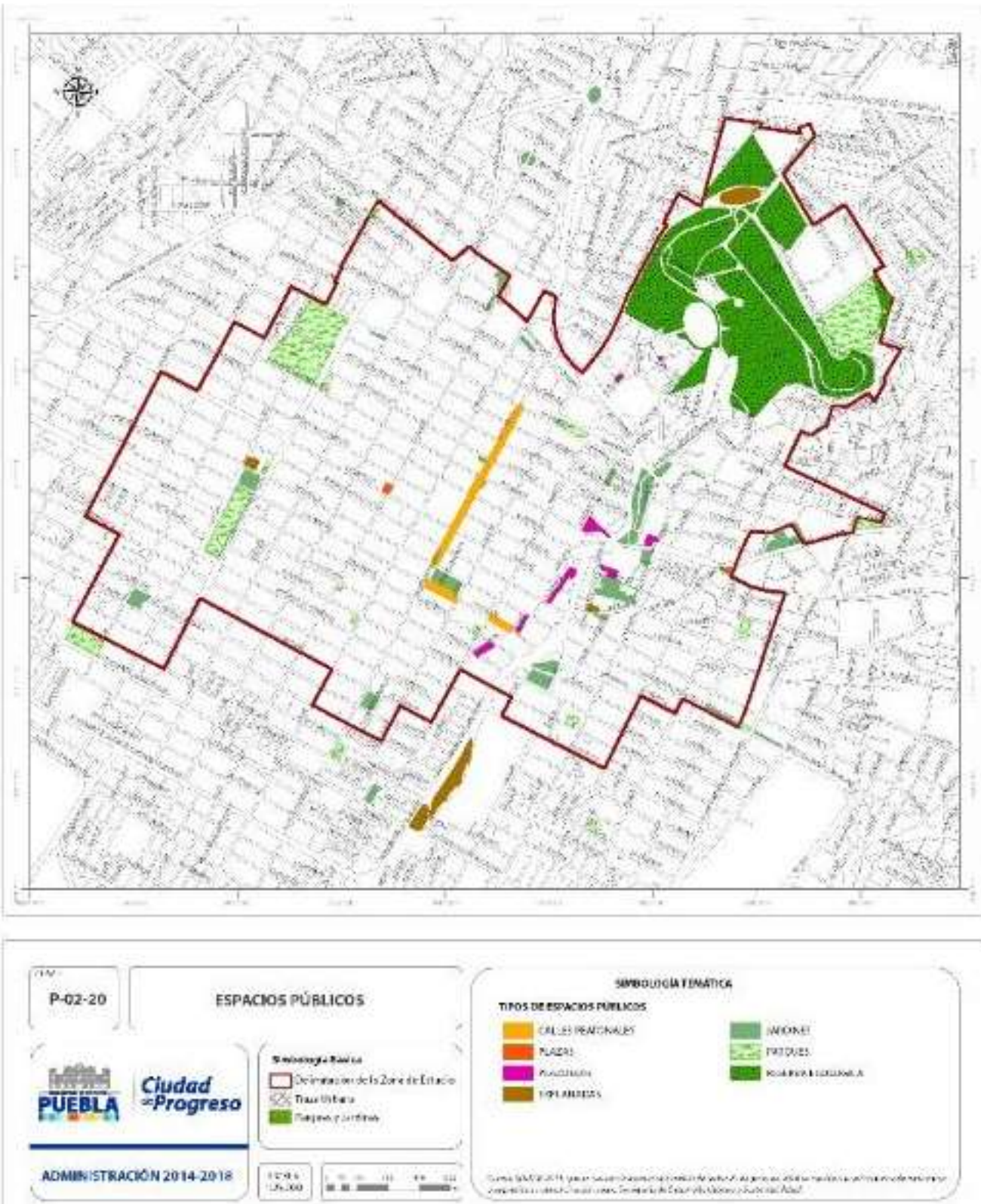

Figura 38. Plano de espacios públicos, extraído de los anexos cartográficos de (Gobierno del Estado, 2015)

Algunos de los puntos focales históricamente más representativos que podemos encontrar en la zona de monumentos son los Fuertes de Loreto y Guadalupe, mientras que los bordes que colindan con el barrio como elementos urbanos lineales percibidos como límites 
infranqueables, ya sean naturales o artificiales, son el boulevard 5 de mayo, la avenida 11 Norte-Sur y el cerro de los fuertes de Loreto y Guadalupe (ver Fig. 40).

PROGRAMA PARCIAL DE DESARROLLO URBANO SUSTENTABLE DEL CENTRO HISTORICO DEL MUNICIPIO DE PUEBLA
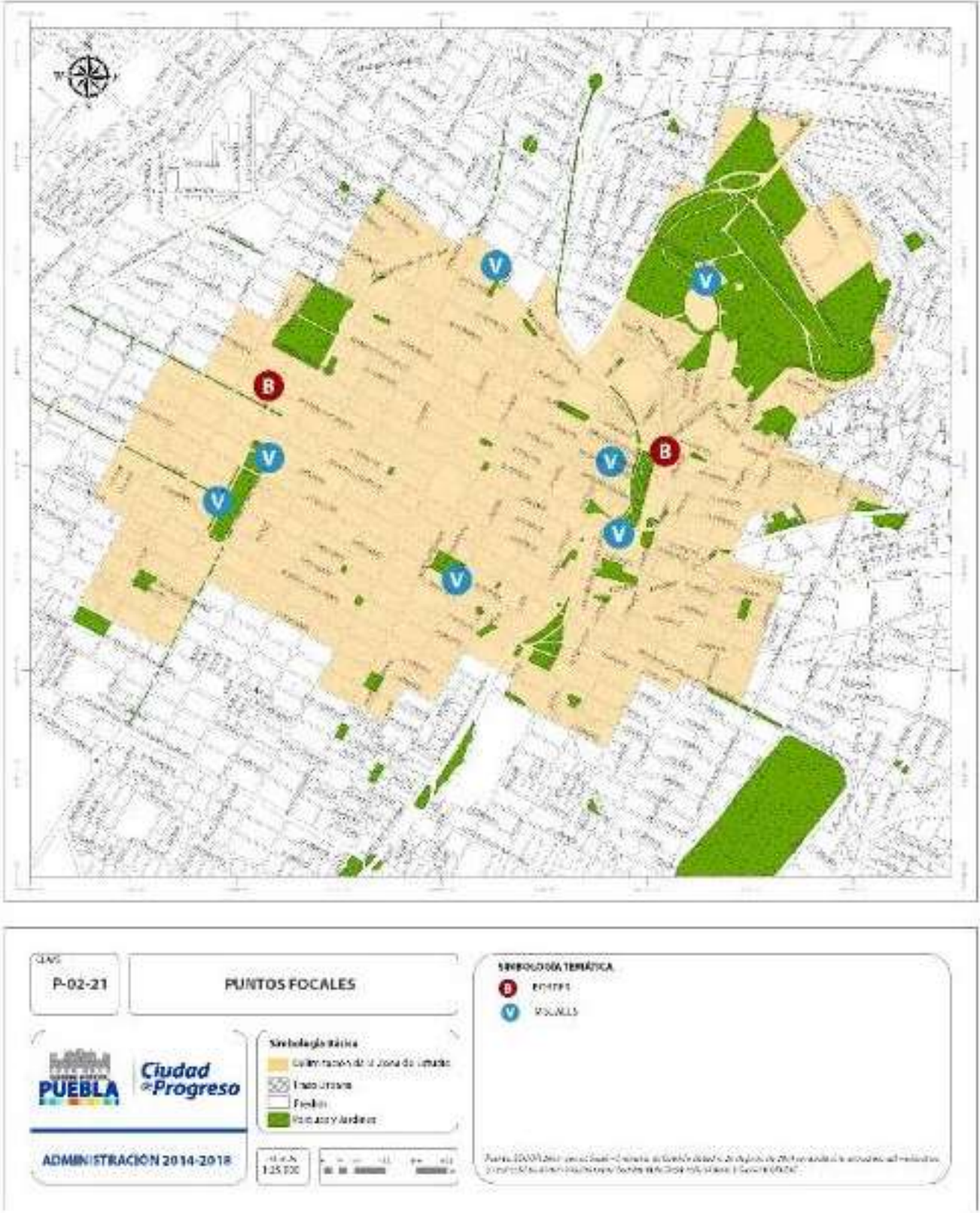

Figura 39. Plano de puntos focales, extraído de los anexos cartográficos de (Gobierno del Estado, 2015). 


\subsubsection{Equipamiento urbano}

La vocación del suelo son las características de un sector y presenta una proyección con visión a una mejora económica (ver figura 41), mostrando las vocaciones detectadas en el polígono de la zona de monumentos. Mientras que en el barrio de Analco podemos encontrar una vocación habitacional y de turismo el cual pretende potenciar las áreas en donde se encuentra la mayor concentración del patrimonio edificado, generando circuitos de visita turística.

PROGRAMA PARCIAL DE DESARROLLO URBANO SUSTENTARLE DEL CENTRO HISTORICO DEL MUNICIPIO DEPUEBLA
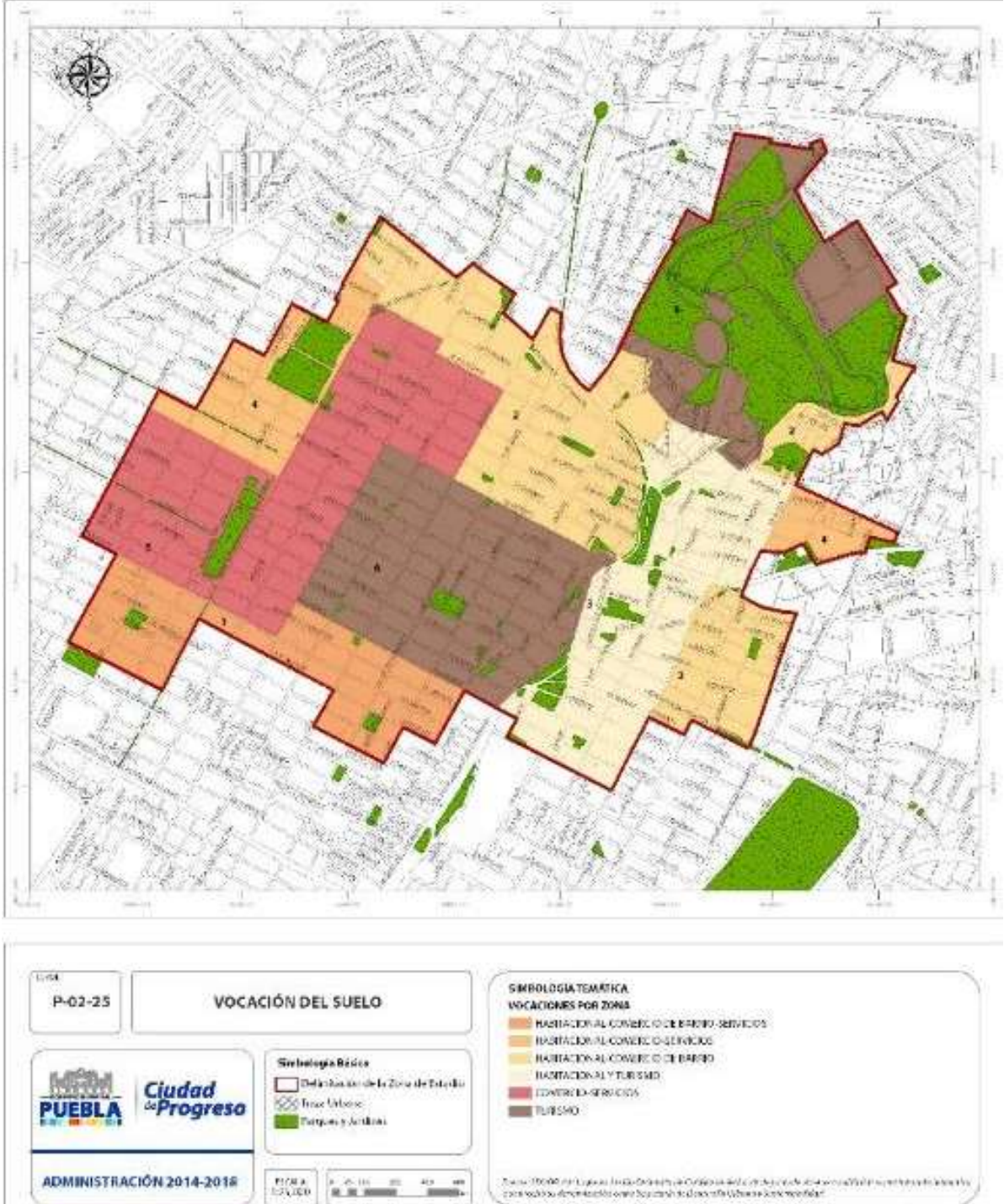

Figura 40. Plano de Vocación del suelo, extraído de los anexos cartográficos de (Gobierno del Estado, 2015) 
La zona de monumentos cuenta con servicios de educación y cultura, salud y asistencia social, comercio y abasto, entre otras (ver Fig. 42).
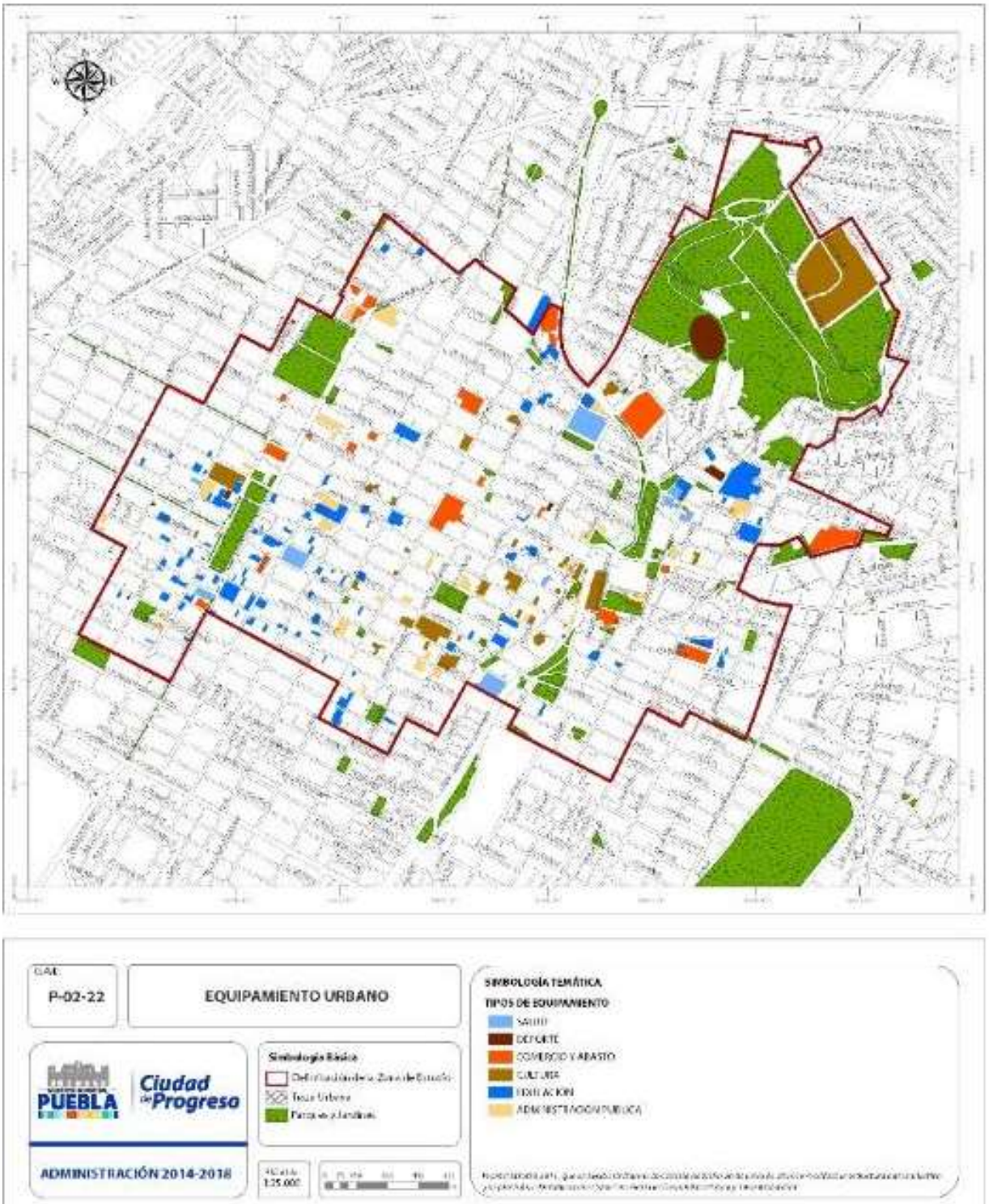

Figura 41. Plano de equipamiento de la Zona de Monumentos, extraído de los anexos cartográficos de (Gobierno del Estado, 2015). 
El equipamiento que podemos encontrar en el barrio de Analco son 4 escuelas que van desde educación básica a superior, la mayoría de estas son escuelas particulares, también cuenta con el Templo del Santo Ángel Custodio de Analco, un museo a la memoria universitaria perteneciente a la Benemérita Universidad Autónoma de Puebla y tres establecimientos de servicios gubernamentales como la dirección general de la policía Estatal Preventiva (ver Fig. 43).
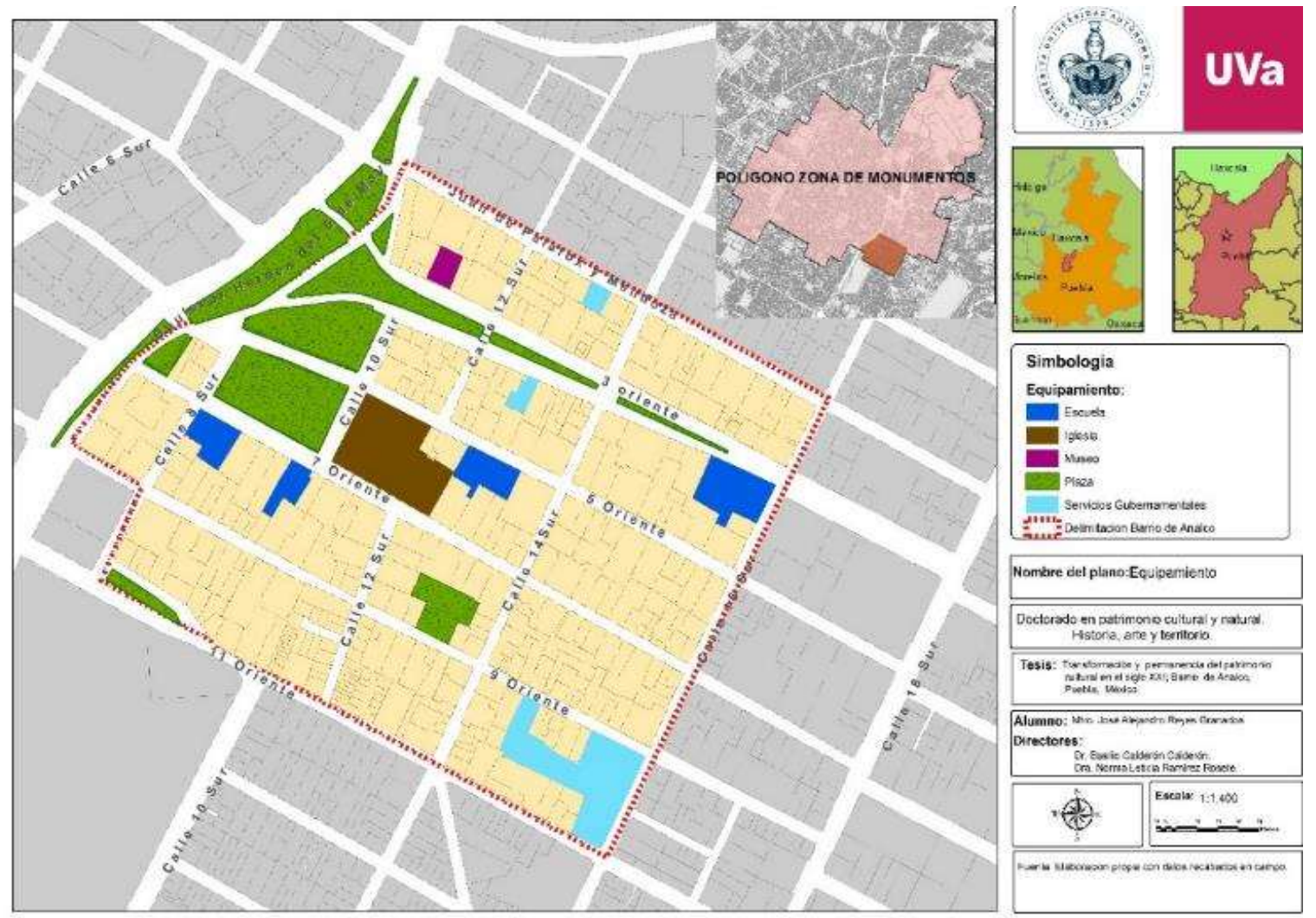

Figura 42. Equipamiento del barrio de Analco, Elaboración propia en base a datos recabados en campo, 2019.

\subsubsection{Tipología urbano-arquitectónica}

En la zona de monumentos podemos encontrar edificios desde el siglo XVI al XX, los más abundantes son los catalogados del siglo XVII, XIX y XX. En Analco la época constructiva que se puede apreciar mayormente es del siglo XIX-XX, además se identifican al menos 5 inmuebles del siglo XVII-XX. (ver Fig. 44). Sin embargo, muchos de estos inmuebles han sufrido un alto nivel de deterioro o han sido parte de proyectos inmobiliarios, por lo que la 
calidad de arquitectura tradicional en el barrio es casi nula, en consecuencia, se detecta la necesidad de contar con reformas que resguarden el patrimonio en riesgo.

PROGRAMA PARCIAL DE DESARROLLO URBANO SUSTENTABLE DEL CENTRO HISTORICO DEL MUNICIPIO DE PUEBLA
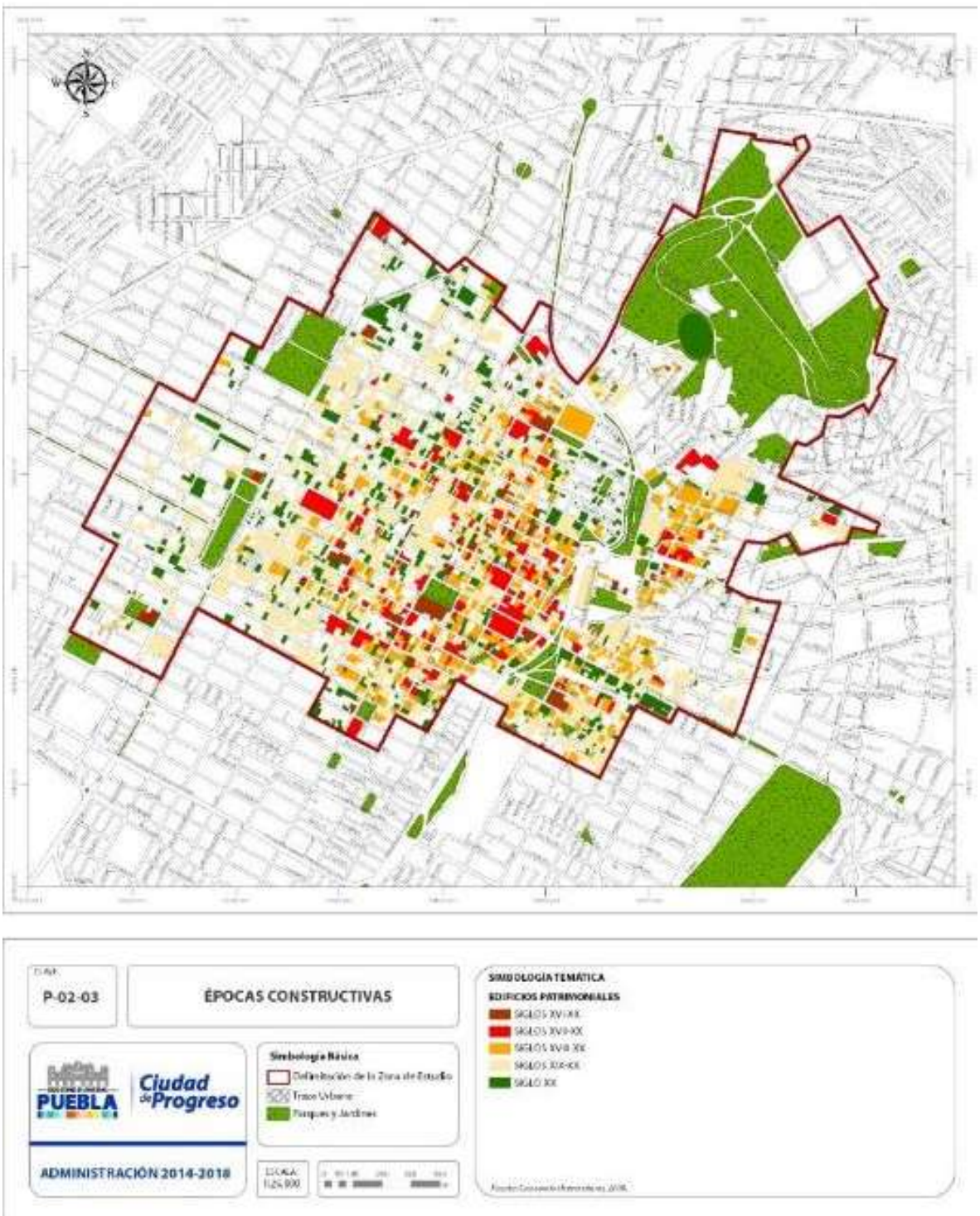

Figura 43. Plano de épocas constructivas, extraído de los anexos cartográficos de (Gobierno del Estado, 2015) 
De acuerdo con los datos recabados del Gobierno Municipal de Puebla (2015) y al Instituto Registral y Catastral del Estado de Puebla (2011), se realizaron fichas de categorización arquitectónica por largueros, en donde se muestra información relevante para el análisis de los inmuebles como es el estilo arquitectónico, siglo de construcción, uso de suelo y su estado de conservación. Esta información se presenta a continuación, en la figura 45, que muestra el larguero de la calle 5 oriente, con la fachada lateral de la iglesia del estilo arquitectónico Neoclásico, categorizado como histórico, además se encuentra el Instituto Universitario Carl Rogers y el Monasterio "Dominicas De Santa Catalina", que tiene categoría 3 y 2 respectivamente y tienen un estilo arquitectónico colonial.

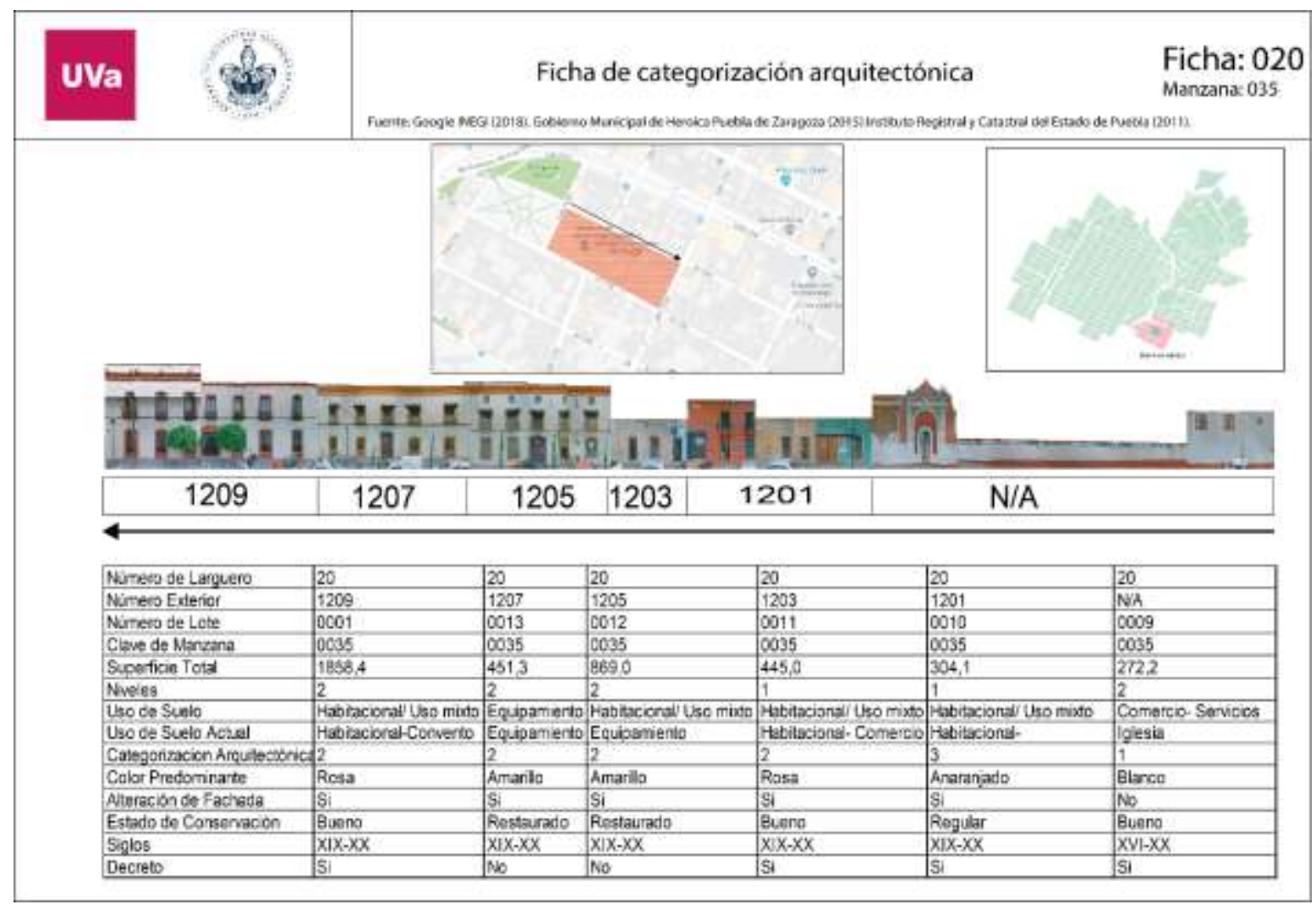

Figura 44. Ficha de categorización arquitectónica n. 020, elaboración propia en base a datos obtenidos de (Google INEGI, 2018), (Gobierno del Estado, 2015) y (Gobierno del Estado, 2011).

En la figura 46, se muestra la fachada principal del templo del santo Ángel custodio, ubicado en la calle 10 sur entre las calles 5 y 7 oriente mismo que pertenece al estilo 
arquitectónico Neoclásico, del siglo XVI-XX y que cuenta con la categoría arquitectónica de Histórico.

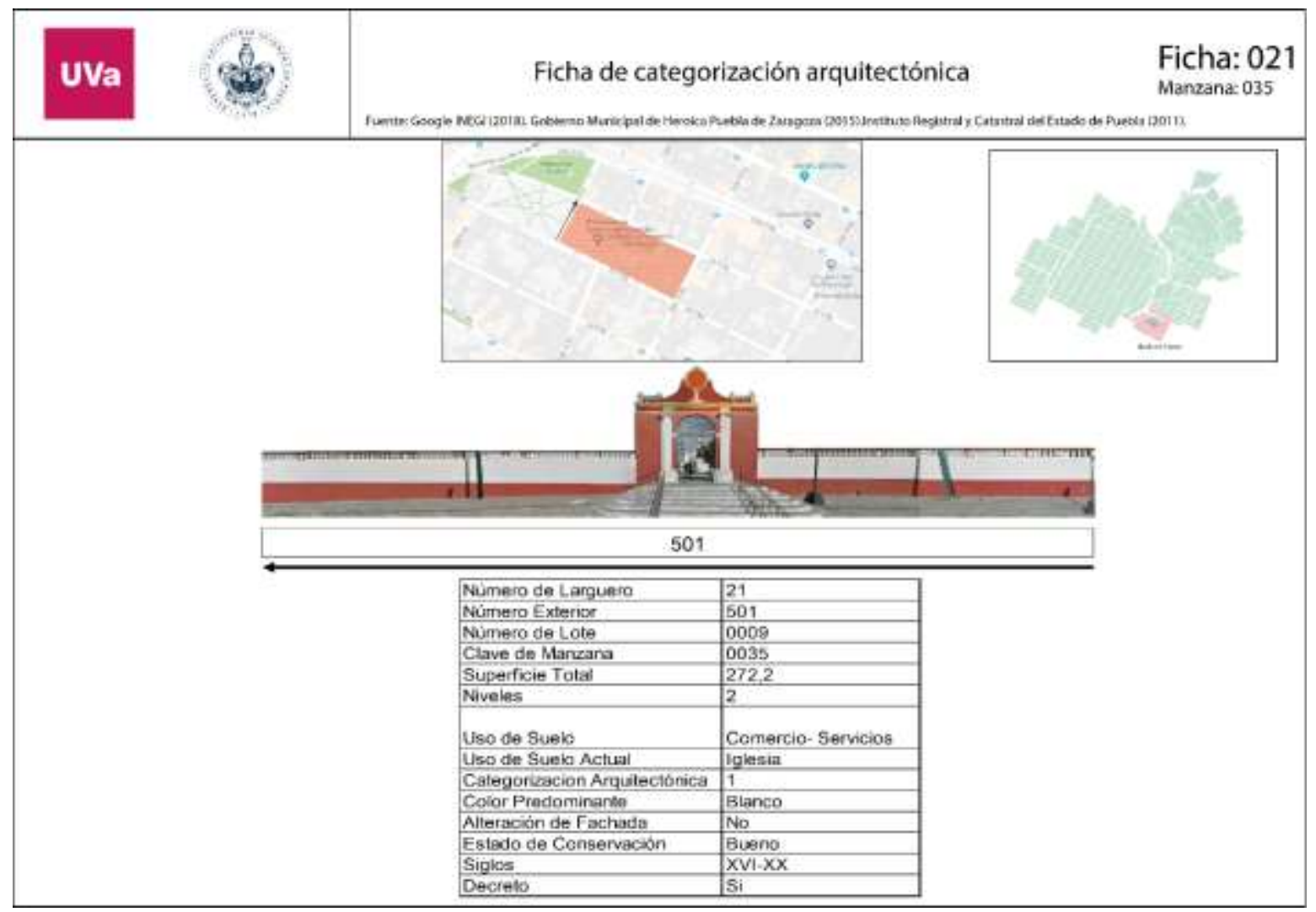

Figura 45. Ficha de categorización arquitectónica n. 021, elaboración propia en base a datos obtenidos de (Google INEGI, 2018), (Gobierno del Estado, 2015) y (Gobierno del Estado, 2011).

En la figura 47, se muestra la fachada lateral del Monasterio "Dominicas De Santa Catalina" y de dos casonas más, ubicadas en la calle 14 sur entre las calles 5 y 7 oriente. La que colinda con el monasterio es de uso mixto, una parte se renta para vivienda y la otra se utiliza como consultorio médico; por último, la fachada con el número 507, actualmente es una construcción deteriorada, sin embargo, en este inmueble se desarrolla un proyecto dirigido por la FA-BUAP, el cual busca rescatar y preservar la identidad del Barrio de Analco mediante la construcción de un museo comunitario, en el que se podrán realizar actividades de gestión participativa. Este inmueble es de categoría 3, que es histórico muy modificado perteneciente al siglo XVIII-XX de estilo arquitectónico popular. 


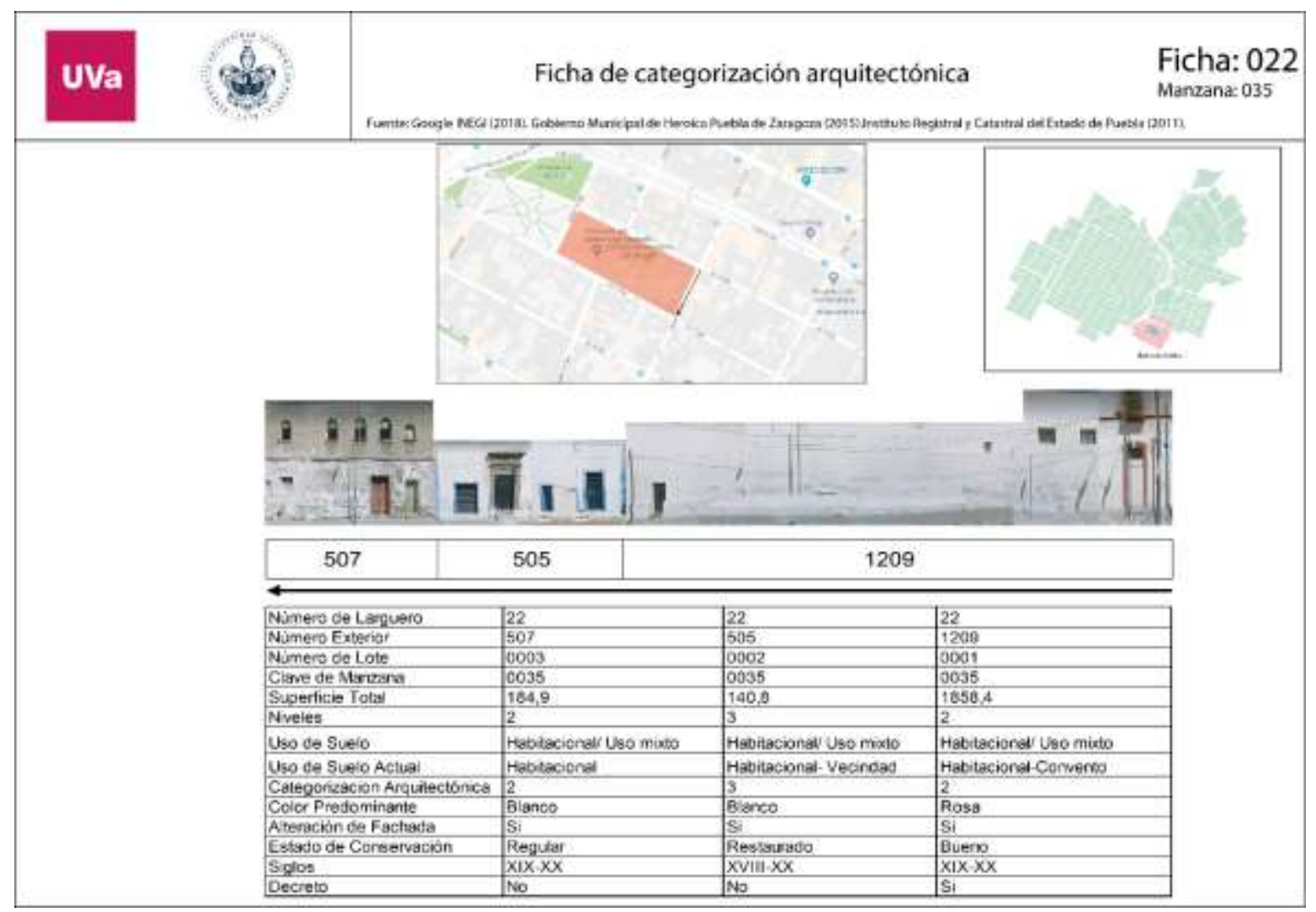

Figura 46. Ficha de categorización arquitectónica n. 022, elaboración propia en base a datos obtenidos de (Google INEGI, 2018), (Gobierno del Estado, 2015) y (Gobierno del Estado, 2011)

La figura 48, se muestra la ficha de la avenida 9 oriente entre las calles 12 y 14 sur, donde se encuentra el parque Jerusalén con la fachada número 1206, lugar que, a causa del mal estado en el que se encontró durante varios años, se volvió peligroso por la presencia de personas dedicadas a realizar actos delictivos. Sin embargo, en el año 2018 el colectivo Tomate desarrollo un proyecto de restauración del parque, el cual consistió en pintar murales y mantenimiento a la vegetación. tambien podemos observar que exsiten murales coloridos que contrastan con las demas fachadas de la imagen del barrio. 


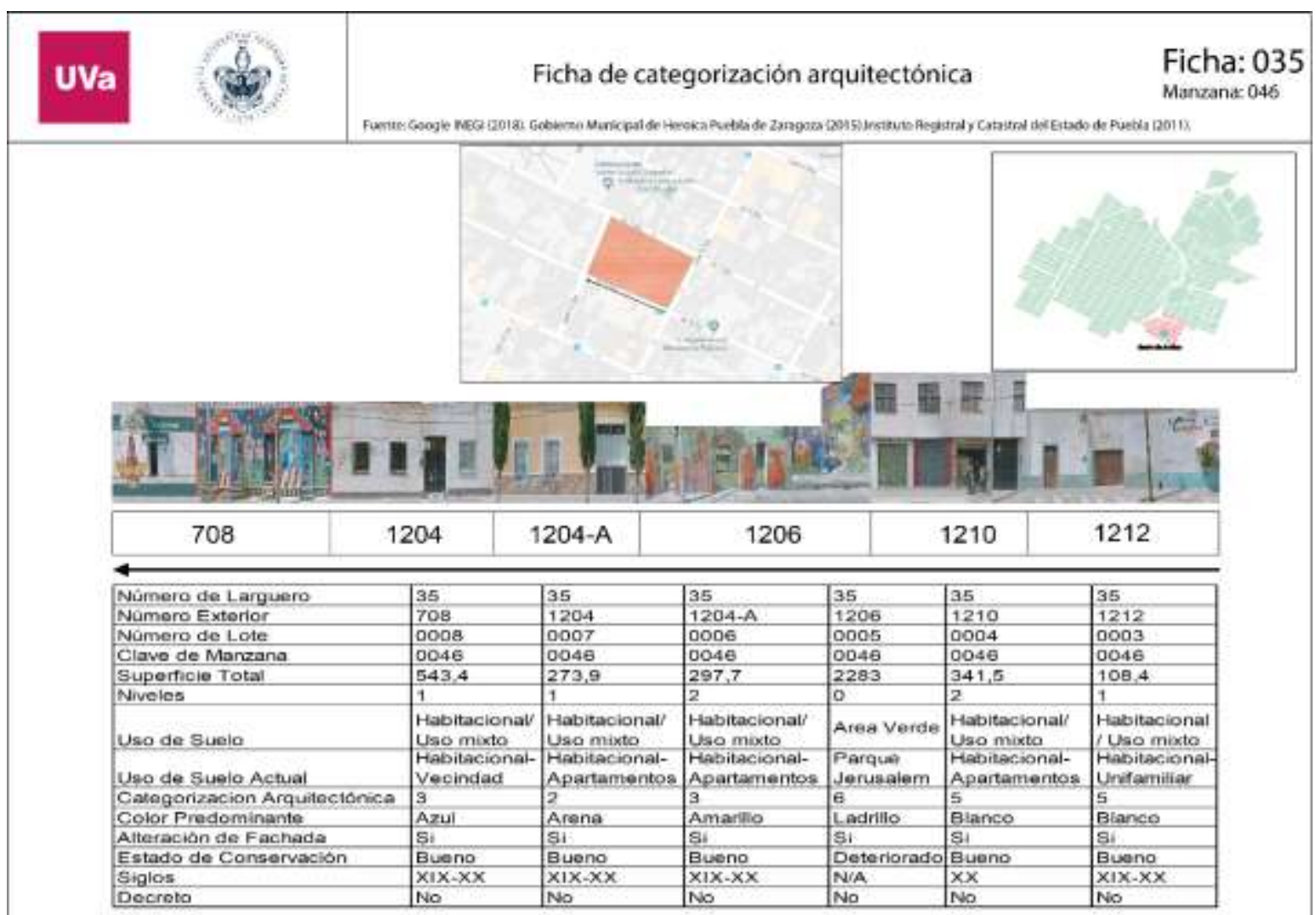

Figura 47. Ficha de categorización arquitectónica n. 035, elaboración propia en base a datos obtenidos de (Google INEGI, 2018), (Gobierno del Estado, 2015) y (Gobierno del Estado, 2011).

La figura 49, muestra la avenida 9 oriente entre las calles 14 y 16 sur, donde se encuentra la fachada con el número 1419, que corresponde a la Dirección General de la Policía Estatal Preventiva (el antiguo rastro municipal) y la estación central de la policía estatal; la fachada contigua, corresponde a la Agencia del Ministerio Público con el número 1403. 


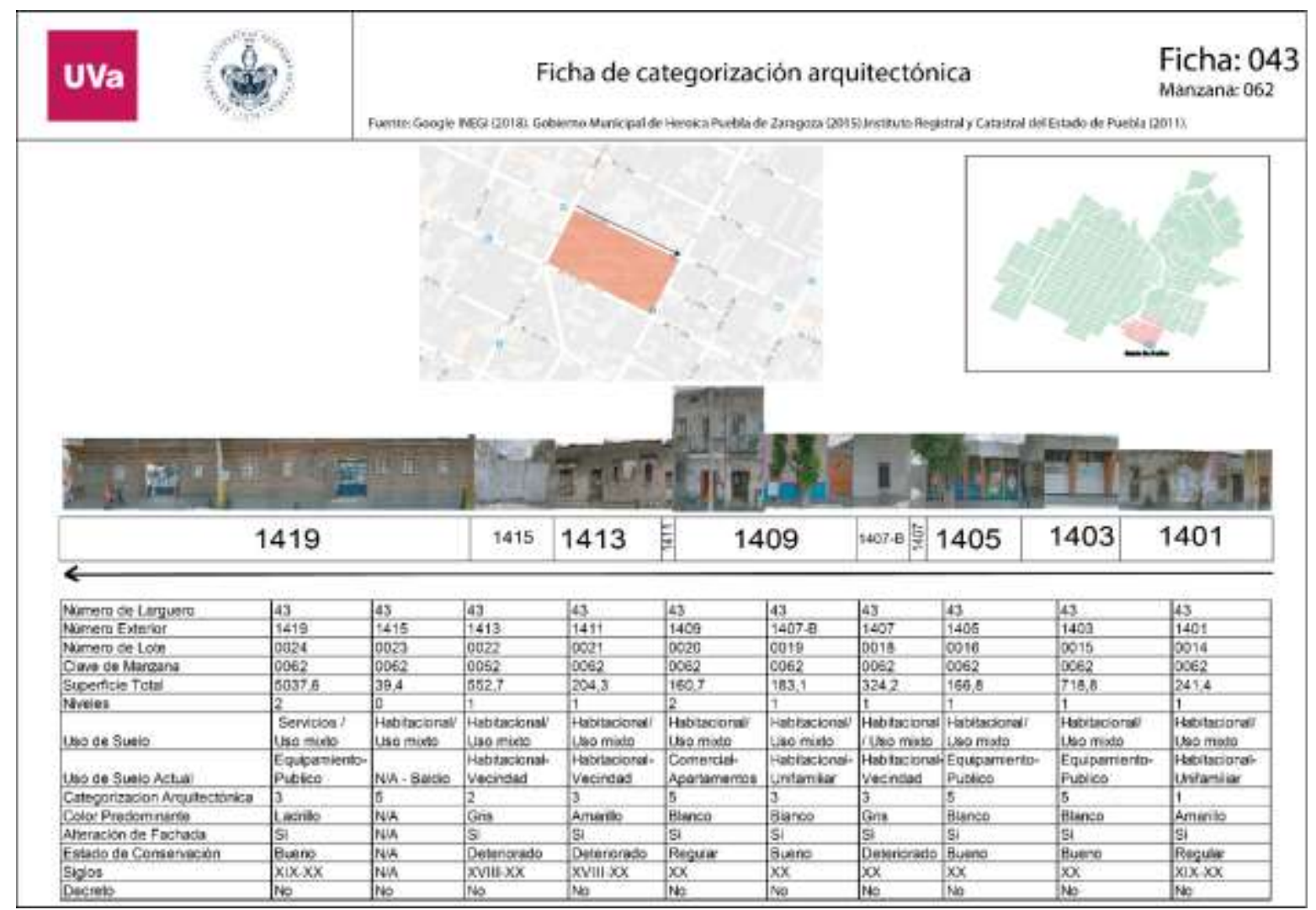

Figura 48.. Ficha de categorización arquitectónica n. 043, elaboración propia en base a datos obtenidos de (Google INEGI, 2018), (Gobierno del Estado, 2015) y (Gobierno del Estado, 2011)

La figura 50, corresponde a uno de los largueros más importantes, ya que las dos fachadas por las que está compuesta son de uso habitacional y en especial la que tiene el número 801/902; el 904, es la fachada de un edificio que anteriormente era una casona, vecindad y ahora un edificio de departamentos con dos niveles pertenece al siglo XVIII-XX y de estilo popular y neoclásico. 


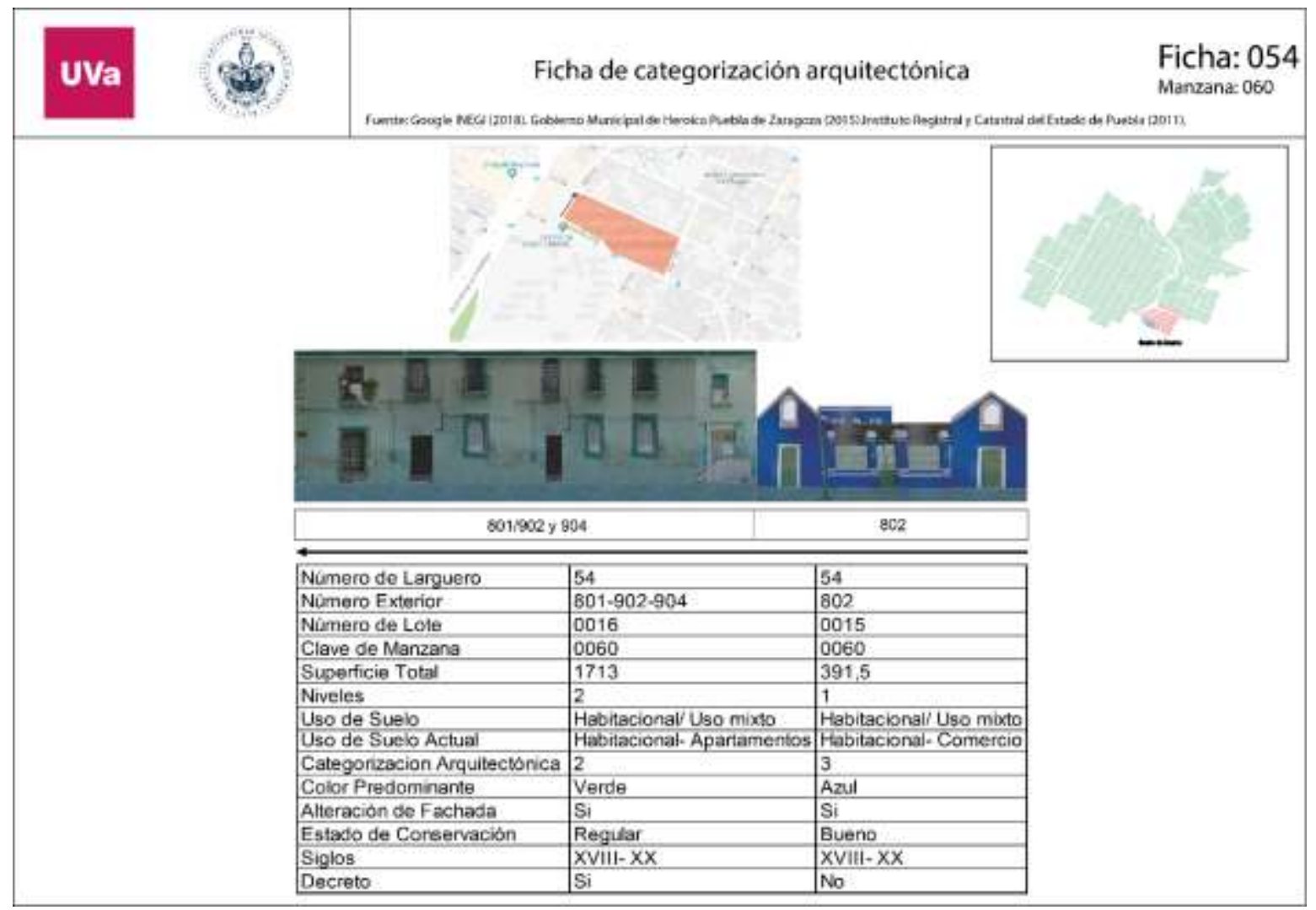

Figura 49. Ficha de categorización arquitectónica n. 054, elaboración propia en base a datos obtenidos de (Google INEGI, 2018), (Gobierno del Estado, 2015) y (Gobierno del Estado, 2011).

La figura 51, se ubica en la avenida 3 oriente entre las calles 12 y 14 sur, siendo esta una de las calles que más ha sufrido cambios de uso de suelo a lo largo del tiempo; la mayor parte de los inmuebles pertenecen a la época constructiva del siglo XIX-XX y estilo arquitectónico Popular, además de que la mayoría de estos edificios son categorizados como arquitectura contemporánea. Este larguero está compuesto por fachadas comerciales entre los que se encuentran cafés como el número 1204-A y restaurantes como la fachada 1206. 


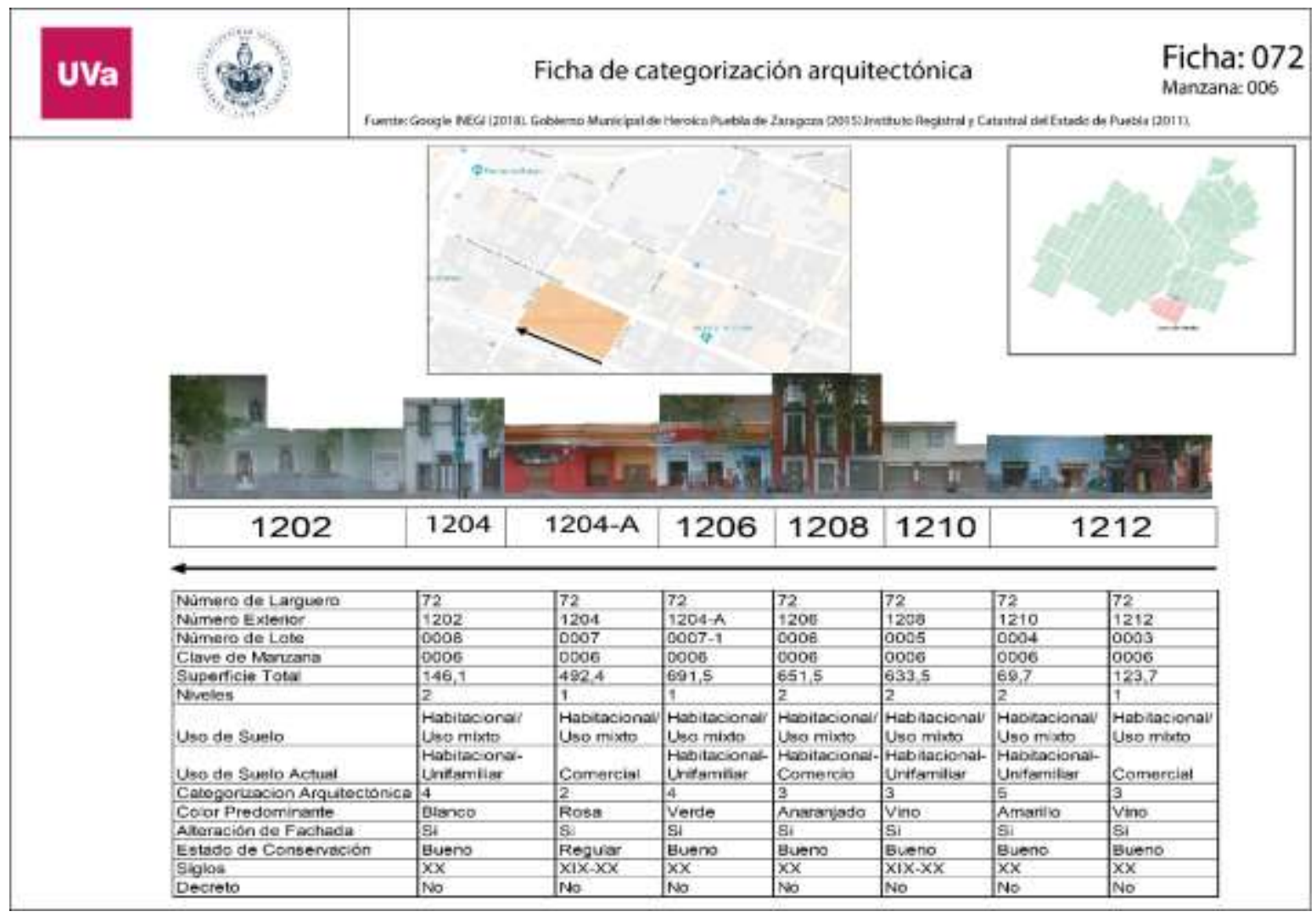

Figura 50. Ficha de categorización arquitectónica n. 072, elaboración propia en base a datos obtenidos de (Google INEGI, 2018), (Gobierno del Estado, 2015) y (Gobierno del Estado, 2011)

La figura 52, también se ubica en la avenida 3 oriente, entre las calles 12 y 14 sur, donde predominan los inmuebles de arquitectura popular y otros estilos de los siglos XVIII$\mathrm{XX}$, los cuales son categorizados como históricos muy modificados, de igual forma, hay fachadas comerciales que van desde florerías, restaurantes y bares, entre otros. 


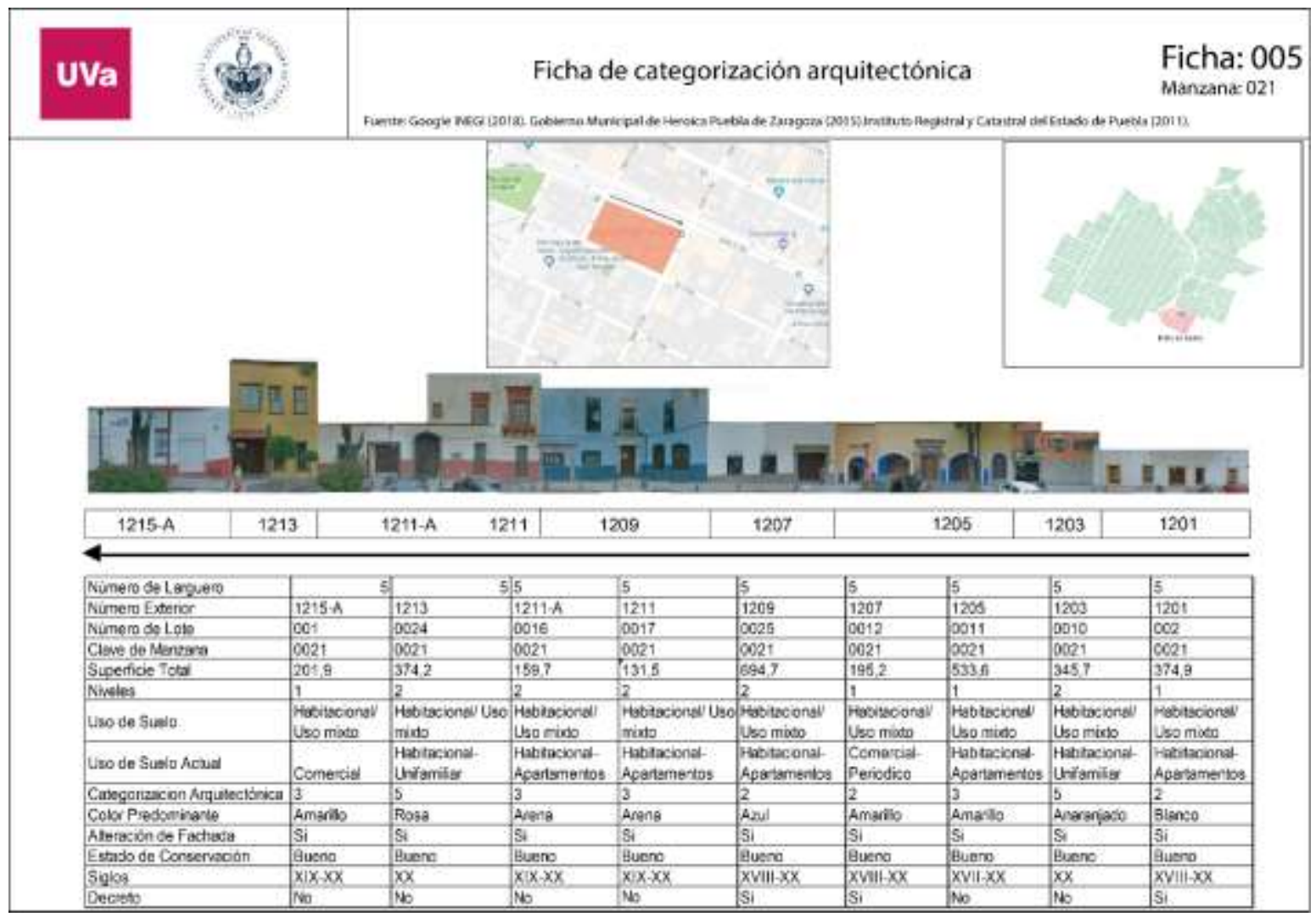

Figura 51. Ficha de categorización arquitectónica n. 005, elaboración propia en base a datos obtenidos de (Google INEGI, 2018), (Gobierno del Estado, 2015) y (Gobierno del Estado, 2011).

La figura 53 nos muestra el larguero que está ubicado en la avenida 3 oriente entre la 14 y 16 sur, estas son fachadas comerciales y de servicios, en dicho larguero existen fachadas como la 1404 que es un café y la 1414 la cual es un hotel llamado "Casona María”. Este último, es uno de los inmuebles que más ha cambiado en los últimos 10 años ya que anteriormente era vecindad, para pasar a ser una bodega y convertirse en lo que actualmente es un hotel boutique, este inmueble es categorizado como artístico, y aún conserva el estilo neoclásico. 


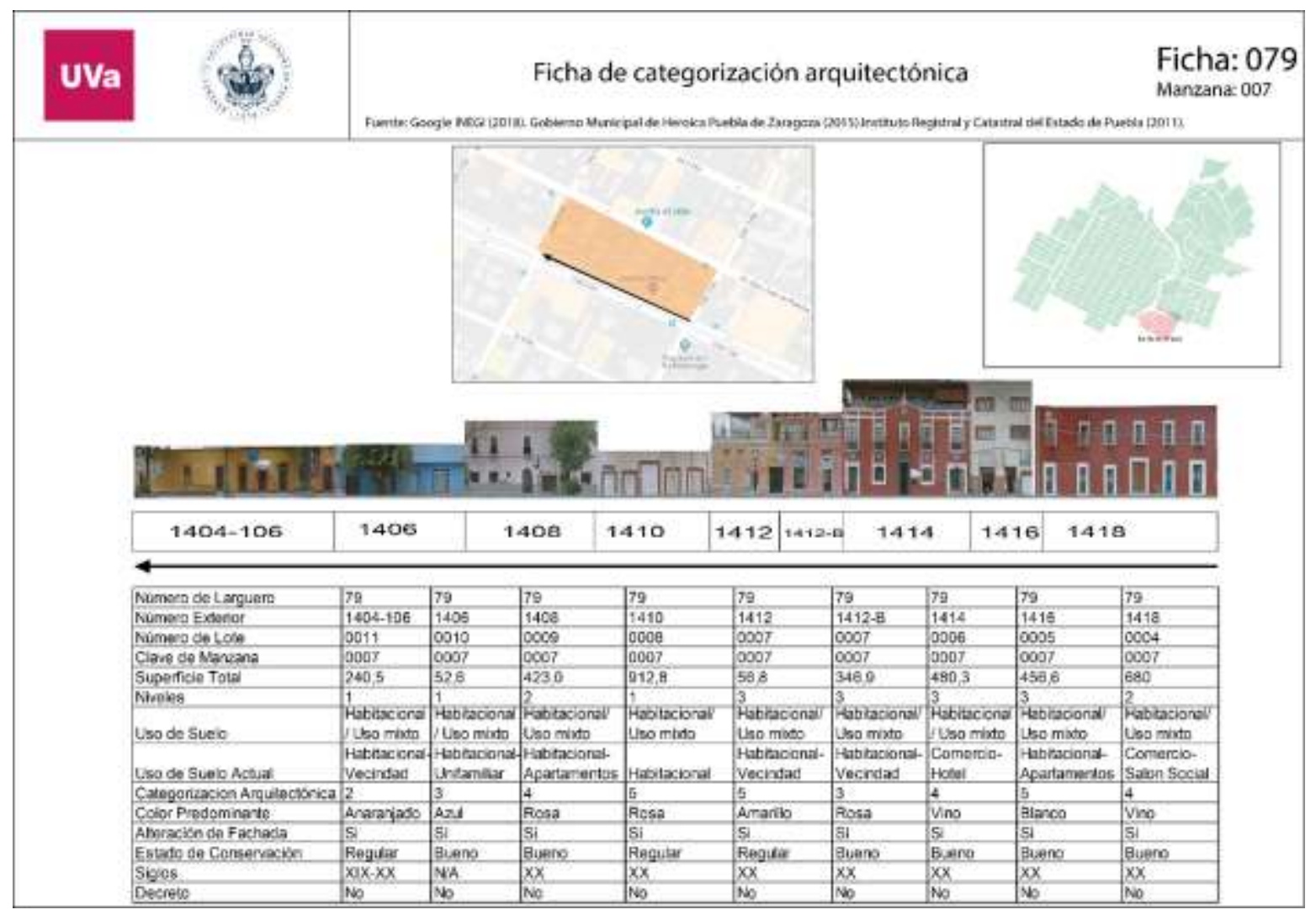

Figura 52. Ficha de categorización arquitectónica n. 079, elaboración propia en base a datos obtenidos de (Google INEGI, 2018), (Gobierno del Estado, 2015) y (Gobierno del Estado, 2011).

La figura 54, está ubicada en la avenida 3 oriente entre la 14 y 16 sur, este larguero es especialmente importante por la fachada 1413 en donde se encuentra la facultad de psicología de la BUAP. En el año 2009, fue bodega de materiales de construcción, en 2010 un estacionamiento general, y en el año 2011 aproximadamente fue una escuela de educación superior de negocios, en su fachada se pude observar se agregó de un piso de construcción que rompe la continuidad de la imagen y el perfil urbano de esa calle del barrio. 


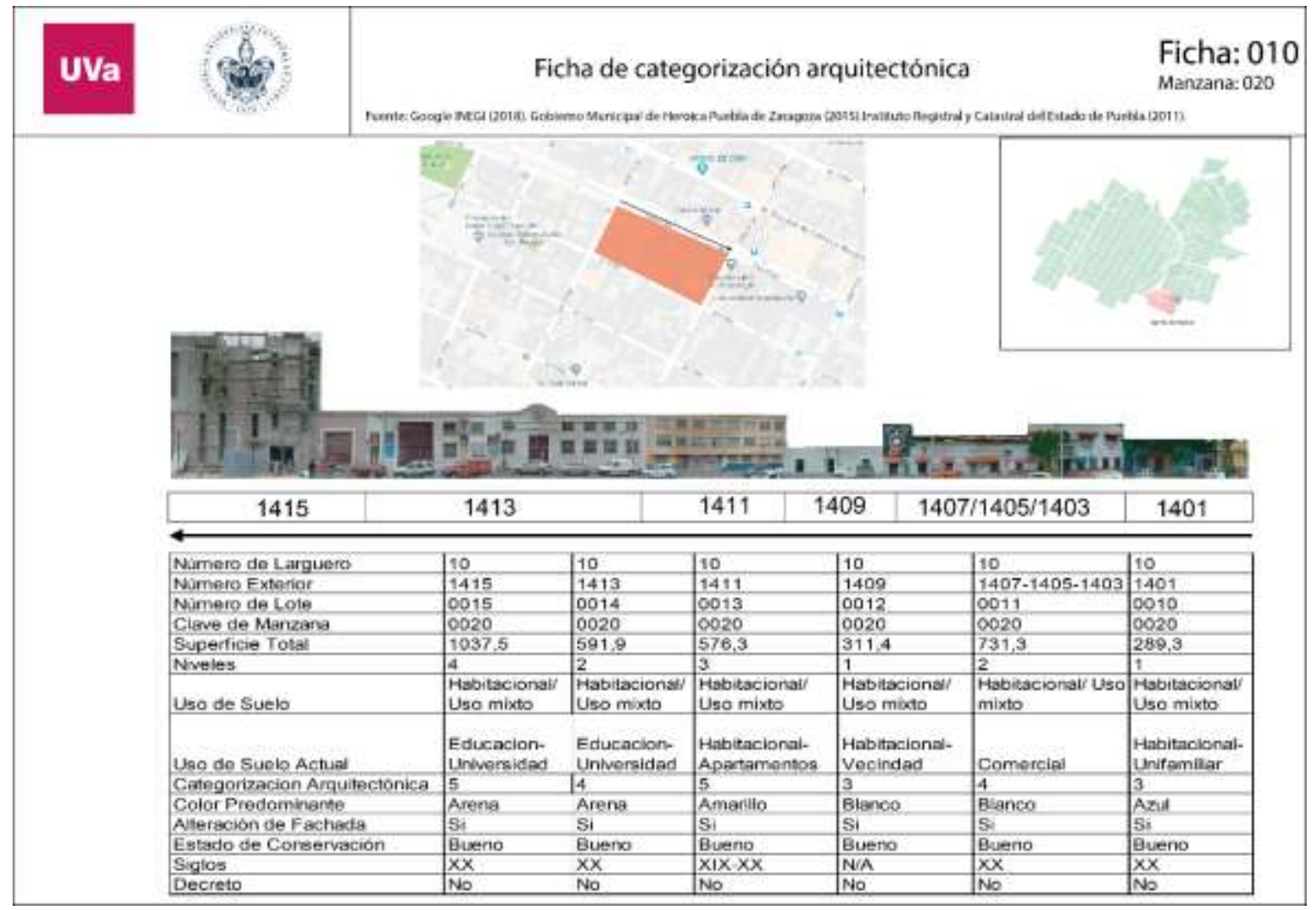

Figura 53. Ficha de categorización arquitectónica n. 010 elaboración propia en base a datos obtenidos de (Google INEGI, 2018), (Gobierno del Estado, 2015) y (Gobierno del Estado, 2011).

La figura 55, refiere la avenida 7 oriente entre la 8 y 10 sur, de este larguero destaca la fachada 1007, antes del año 2017 esta fachada permanencia en pie, sin embargo, después del sismo de septiembre del 2017, esta se derrumbó casi en su totalidad, el abandono de este inmueble ha sido aprovechado por grupos que se dedican a delinquir en la zona. 


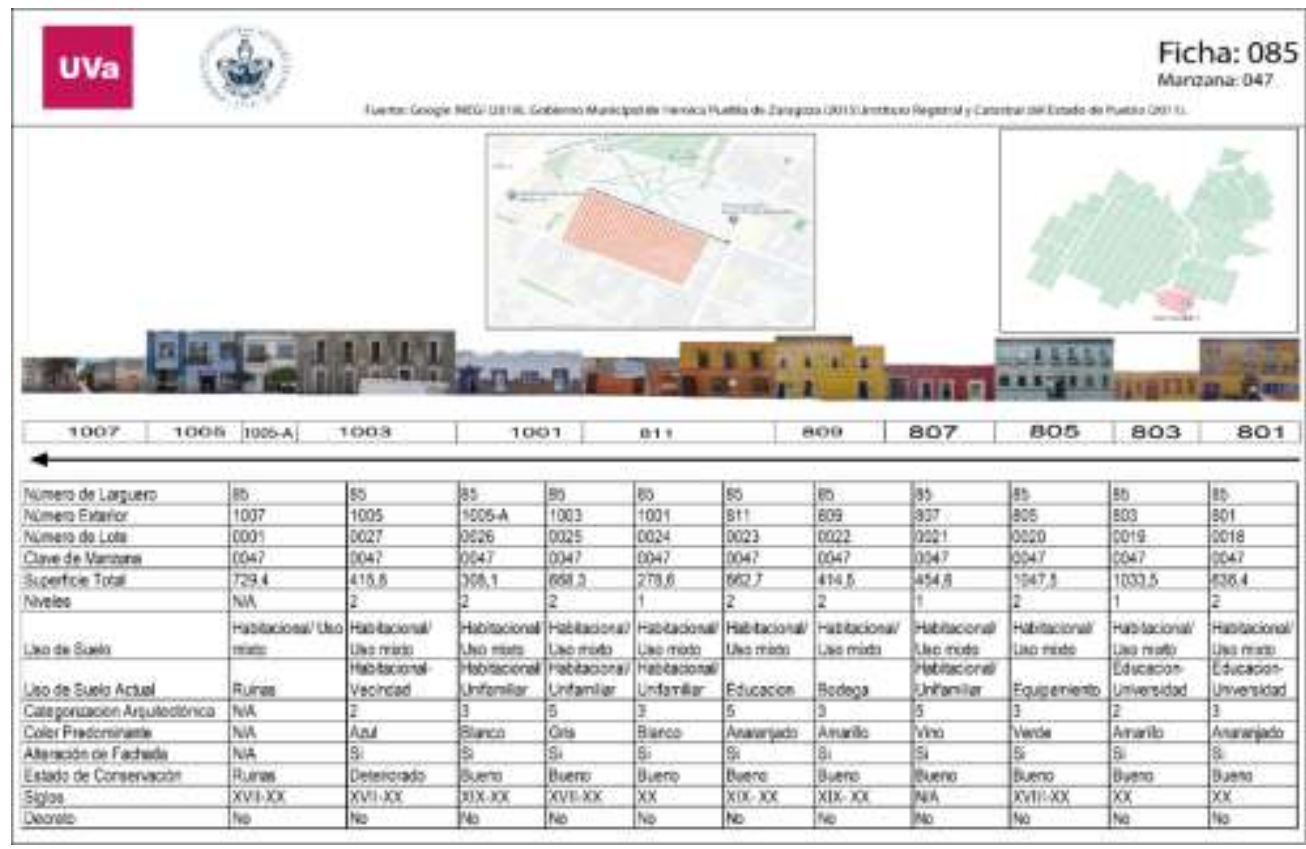

Figura 55 Ficha de categorización arquitectónica n. 085 elaboración propia en base a datos obtenidos de (Google INEGI, 2018), (Gobierno del Estado, 2015) y (Gobierno del Estado, 2011).

De la figura 56, es importante mencionar la fachada con el numero exterior 502, actualmente está cumple su uso comercial abajo y arriba el uso habitacional, este larguero se ubica en la calle 12 sur entre la avenida 7 y 5 oriente.

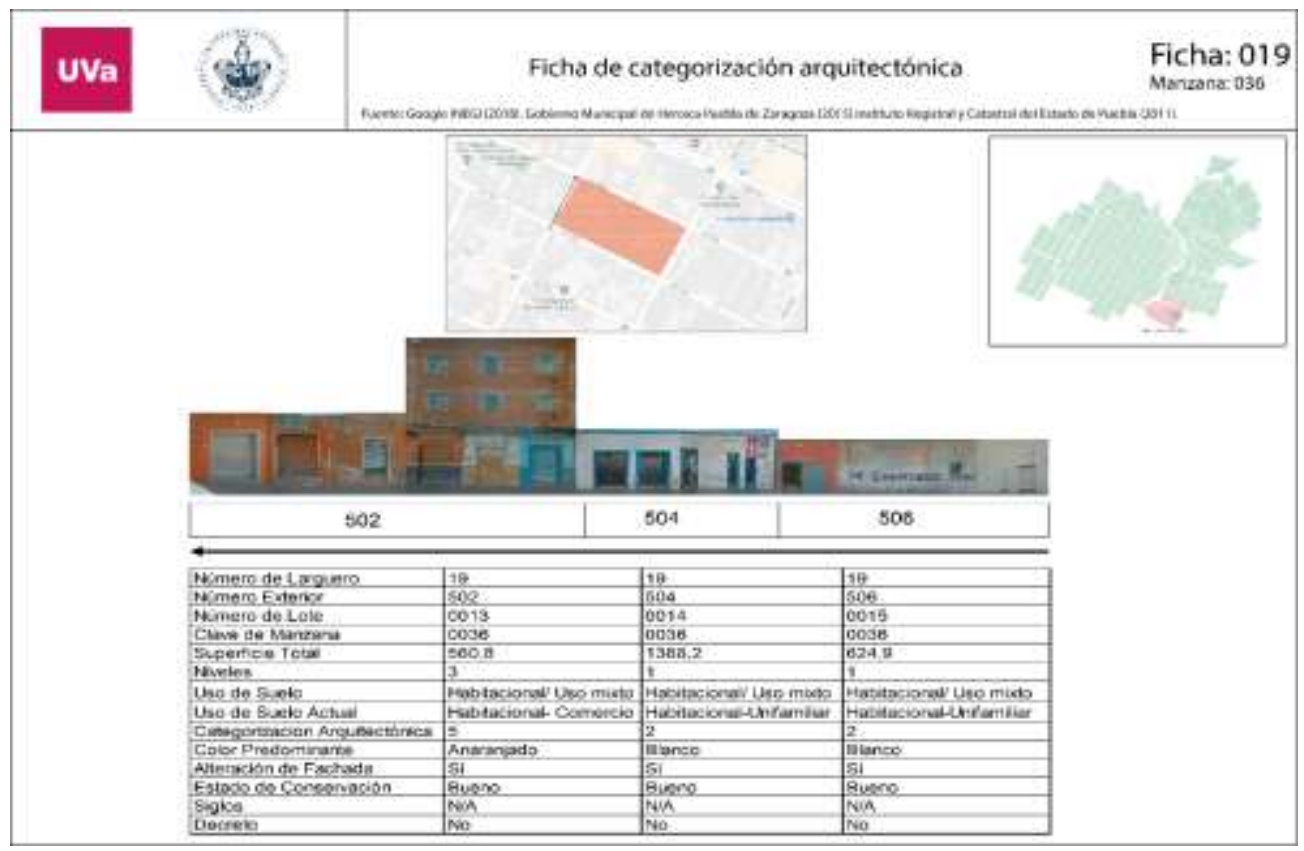

Figura 56 Ficha de categorización arquitectónica n. 019 elaboración propia en base a datos obtenidos de (Google INEGI, 2018), (Gobierno del Estado, 2015) y (Gobierno del Estado, 2011). 
En la figura 57 se puede observar que la fachada con el numero exterior 1204/501 corresponde a las oficinas del templo del Santo Ángel Custodio, la cual tiene decreto y esta categorizada arquitectónicamente con el número 1.

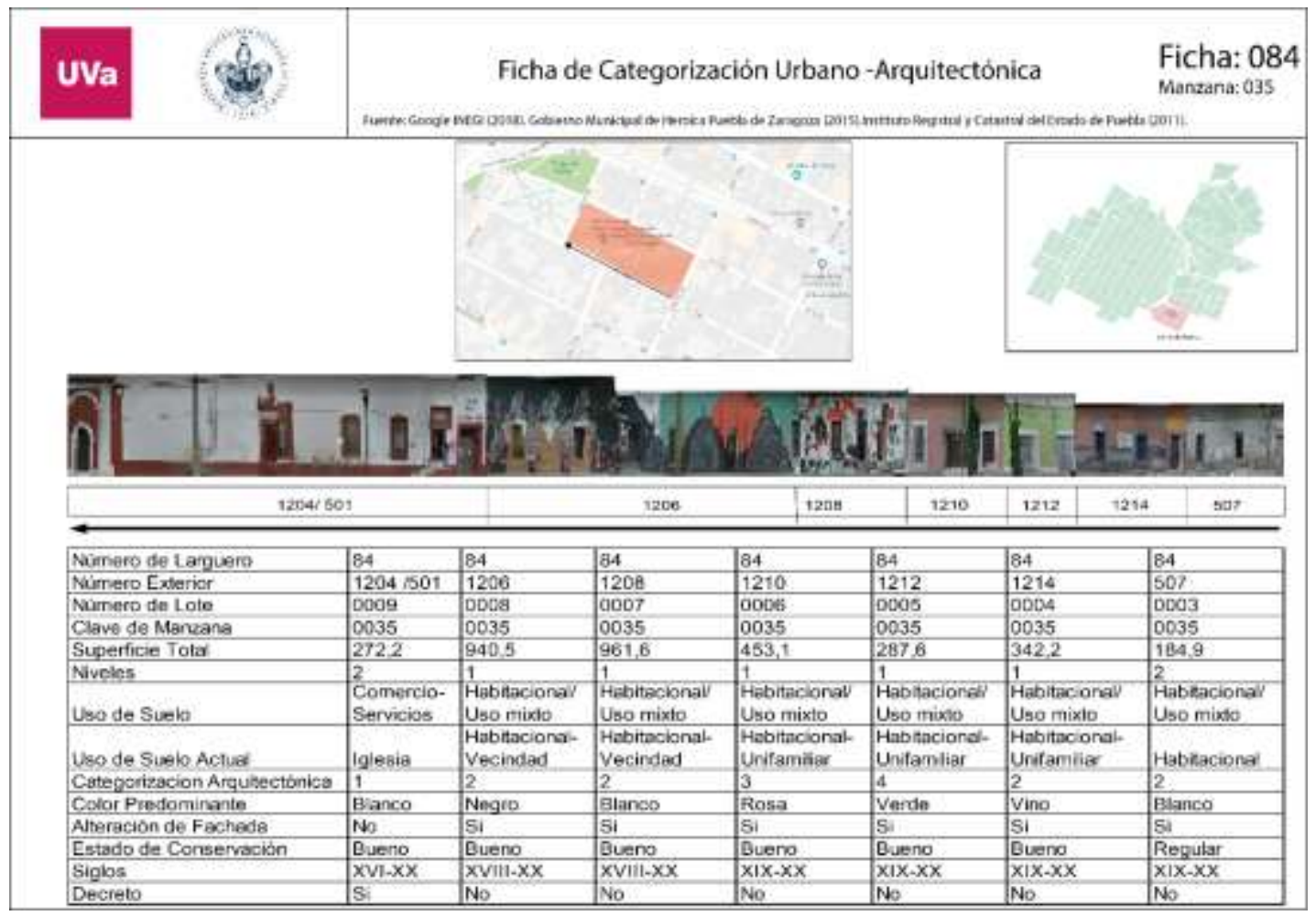

Figura 54 Ficha de categorización arquitectónica n. 084 elaboración propia en base a datos obtenidos de (Google INEGI, 2018), (Gobierno del Estado, 2015) y (Gobierno del Estado, 2011).

En este larguero ubicado en la avenida 7 oriente entre las calles 12 y 14 sur, se encuentra la fachada con el numero exterior 1418 la cual alberga a uno de los últimos hornos de alfarería perteneciente a la familia de artesanos Villarado. (Ver Fig.58). 


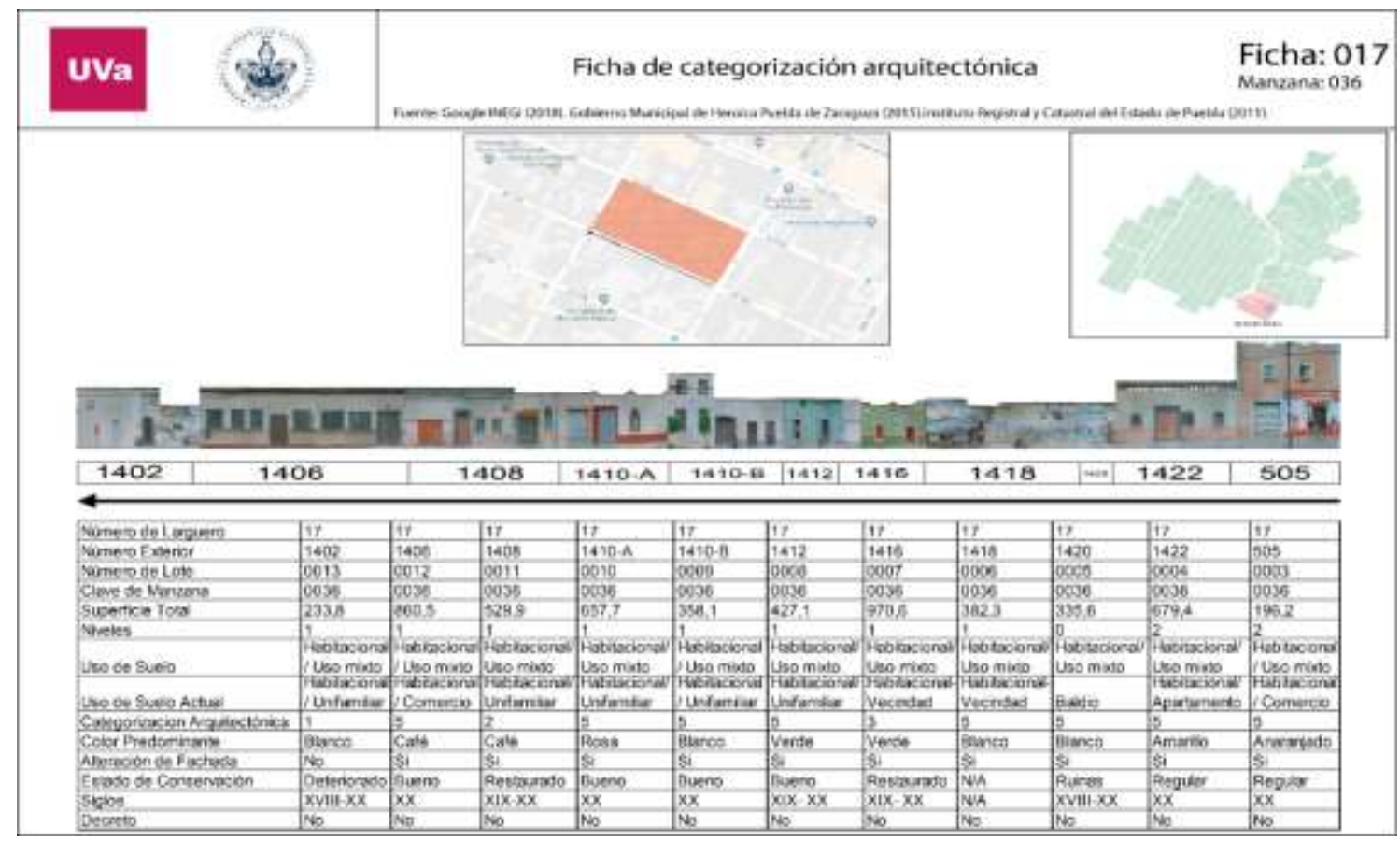

Figura 55 Ficha de categorización arquitectónica n. 019 elaboración propia en base a datos obtenidos de (Google INEGI, 2018), (Gobierno del Estado, 2015) y (Gobierno del Estado, 2011).

En la figura 59 se puede observar que los inmuebles que están en este larguero son, categoría 1, 2 y 3, de los cuales destaca la fachada con el numero exterior 306/1000 el cual cuenta con decreto.

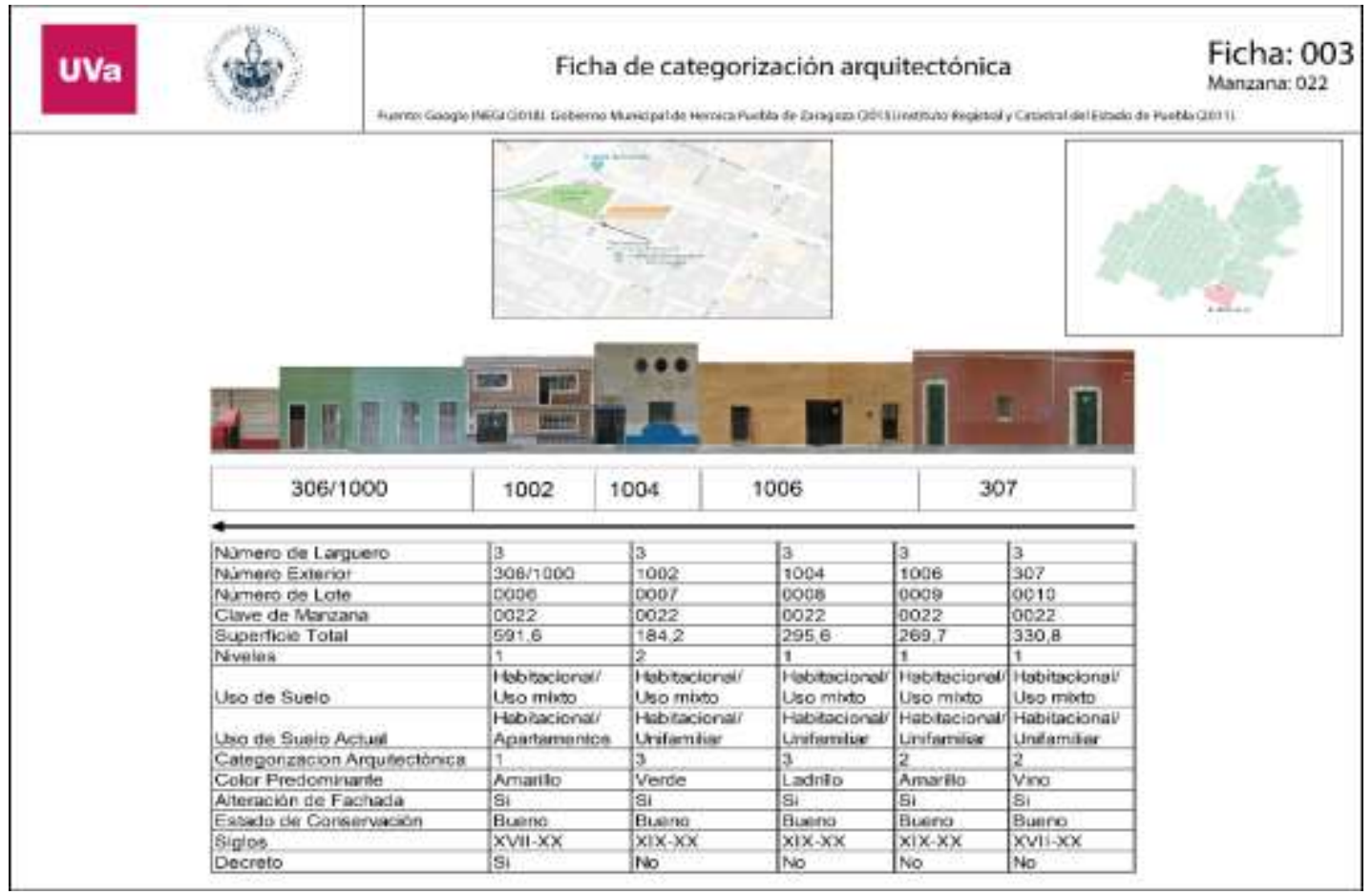

Figura 59 Ficha de categorización arquitectónica n. 003 elaboración propia en base a datos obtenidos de (Google INEGI, 2018), (Gobierno del Estado, 2015) y (Gobierno del Estado, 2011). 
En la ficha 008 se observa que la mayoría de los inmuebles es de un solo nivel y todos son de uso mixto-habitacional, estas fachadas están ubicadas en la avenida 5 oriente entre las calles 10 y 12 sur (ver Fig. 60).

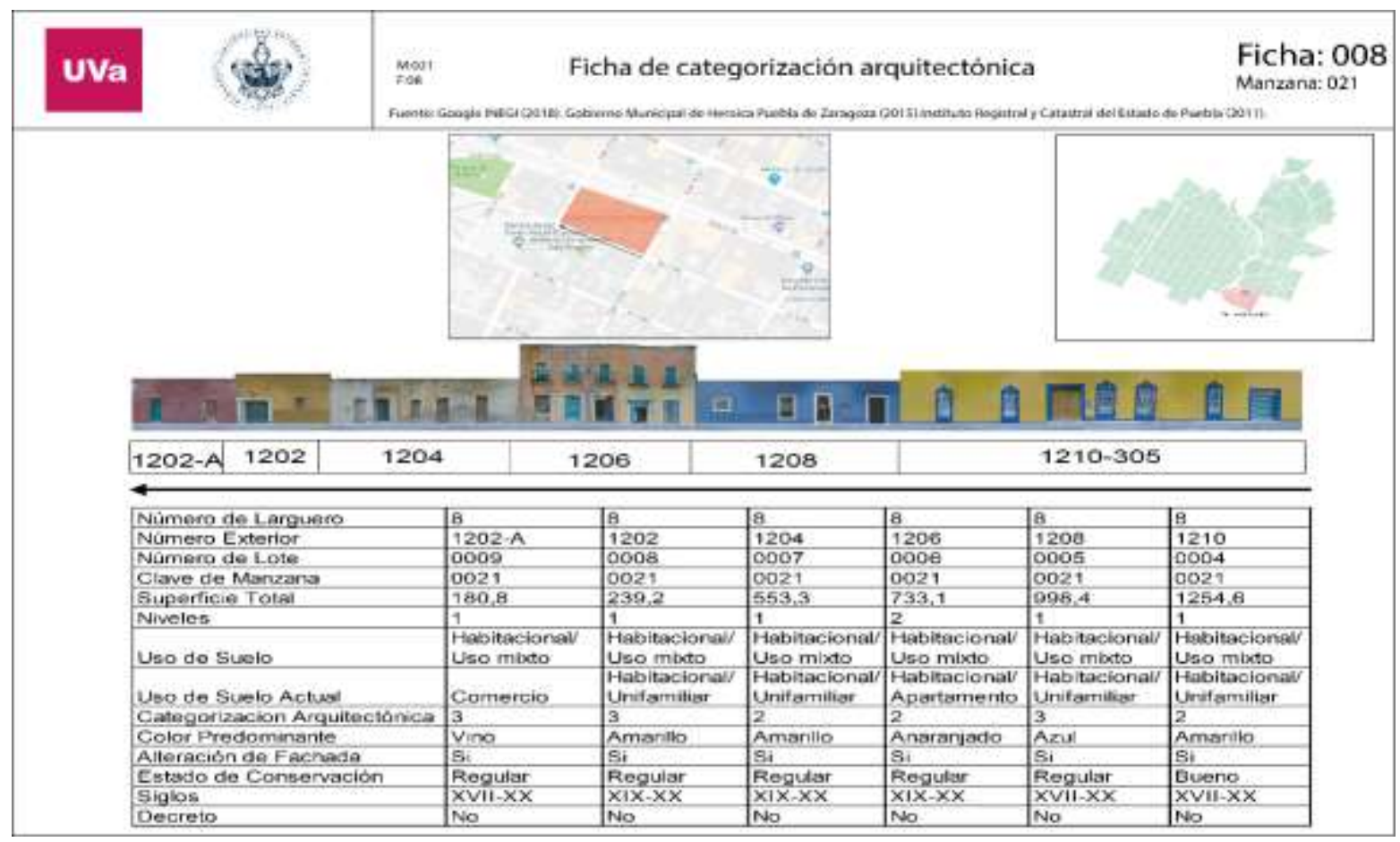

Figura 60 Ficha de categorización arquitectónica n. 008 elaboración propia en base a datos obtenidos de (Google INEGI, 2018), (Gobierno del Estado, 2015) y (Gobierno del Estado, 2011).

Este larguero se ubica en la calle 10 sur entre las avenidas 3 y 5 oriente, es en esta zona donde se da el mayor cambio de alturas y estilos arquitectónicos. El inmueble con el numero exterior 306/1000 está catalogado como categoría uno, a pesar de esto su uso es comercial, actualmente alberga un restaurante de comida japonesa (ver Fig. 61). 


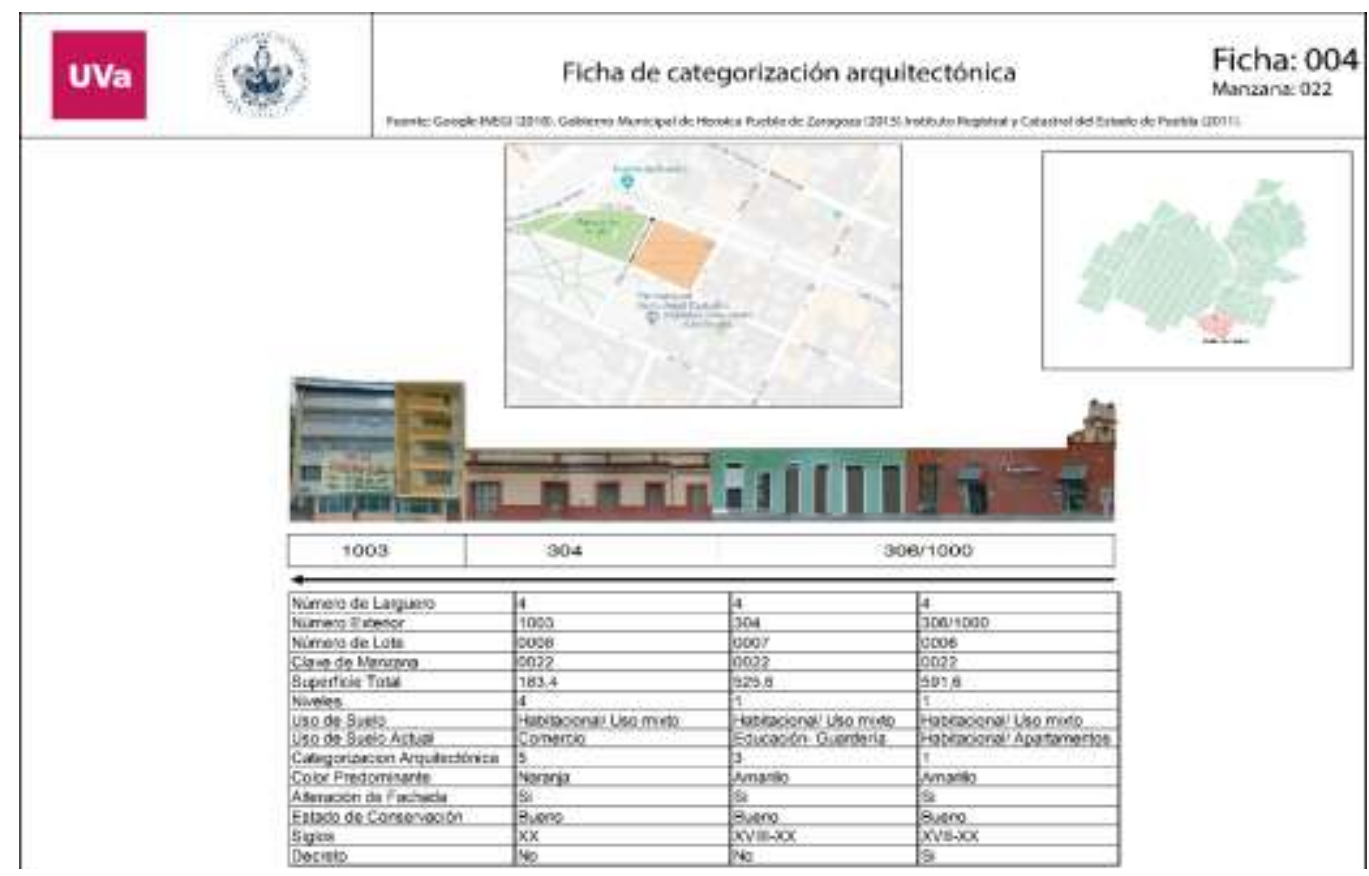

Figura 57 Ficha de categorización arquitectónica n. 004 elaboración propia en base a datos obtenidos de (Google INEGI, 2018), (Gobierno del Estado, 2015) y (Gobierno del Estado, 2011).

En la siguiente Figura 62, se logran aprecian aún más los cambios de los inmuebles conforme nos vamos acercando a la avenida 3 Oriente, los inmuebles de esta ficha son de uso mixto-habitacional y comercial, en su mayoría albergan comercios que se dedican a la venta y compra de antigüedades, accesorios decorativos y de mascotas.

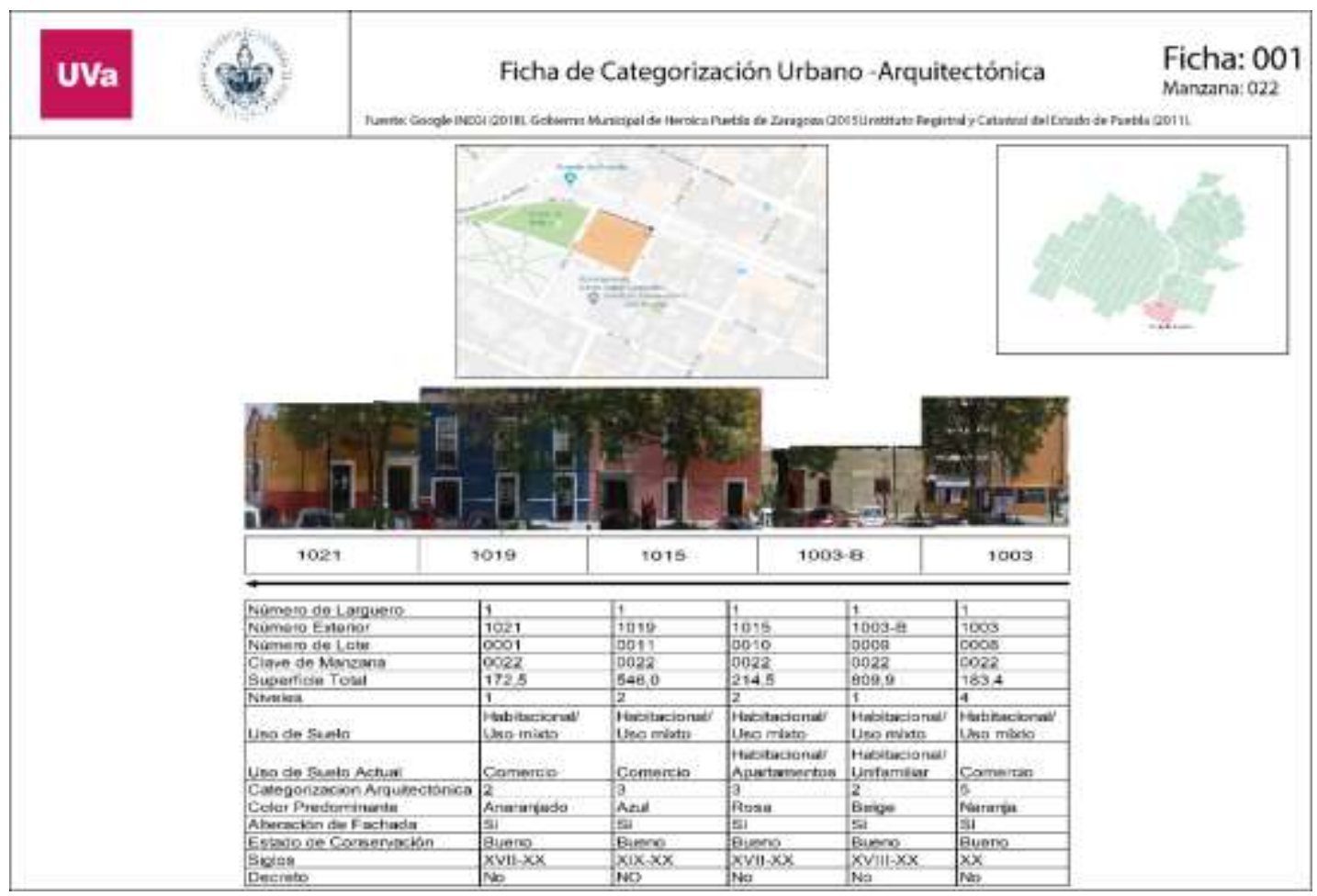

Figura 56 Ficha de categorización arquitectónica n. 001 elaboración propia en base a datos obtenidos de (Google INEGI, 2018), (Gobierno del Estado, 2015) y (Gobierno del Estado, 2011). 
Los inmuebles de la ficha 086 están ubicados en la avenida 3 oriente, entre el bulevar 5 de mayo y la calle 12 sur, cabe mencionar que el inmueble con el numero exterior 1008 corresponde al Museo de la memoria universitaria BUAP, a su lado izquierdo esta la fábrica de vidrio de la luz, mientras que por el lado derecho se encuentra restaurante de comida rápida y un hotel (ver Fig. 63).

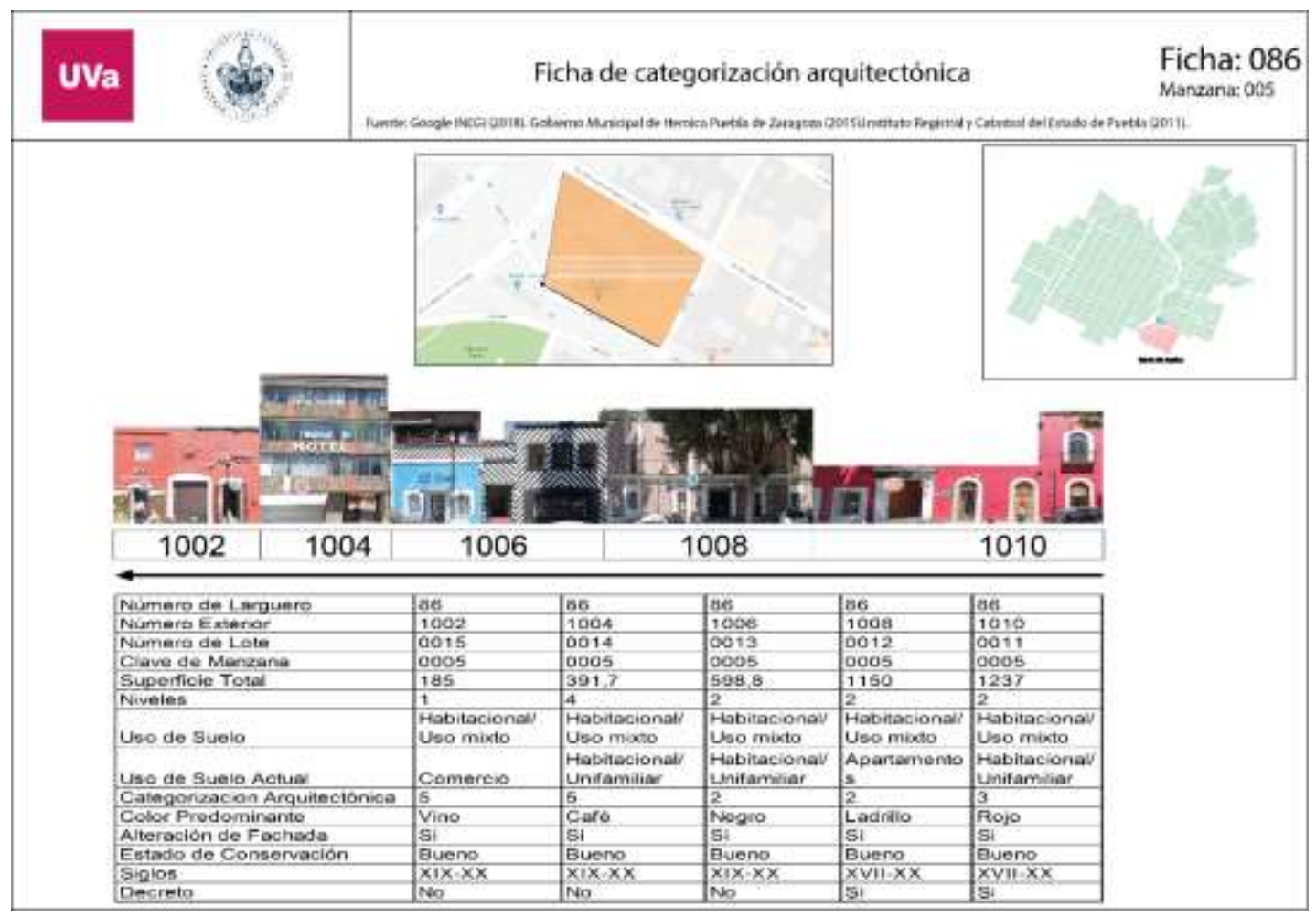

Figura 58 Ficha de categorización arquitectónica n. 086 elaboración propia en base a datos obtenidos de (Google INEGI, 2018), (Gobierno del Estado, 2015) y (Gobierno del Estado, 2011).

Por otra parte, dentro del análisis de la tipología urbano-arquitectónica se muestra un plano de las 5 categorías arquitectónicas del barrio de Analco, además de identificar la época de construcción de sus inmuebles, que de acuerdo con la Carta Urbana del Programa de Desarrollo Urbano Sustentable de Puebla 2007corresponden a: categoría 1, histórico; categoría 2, histórico modificado; categoría 3, histórico muy modificado; categoría 4 artístico; categoría 5, arquitectura contemporánea (ver Fig. 64). 

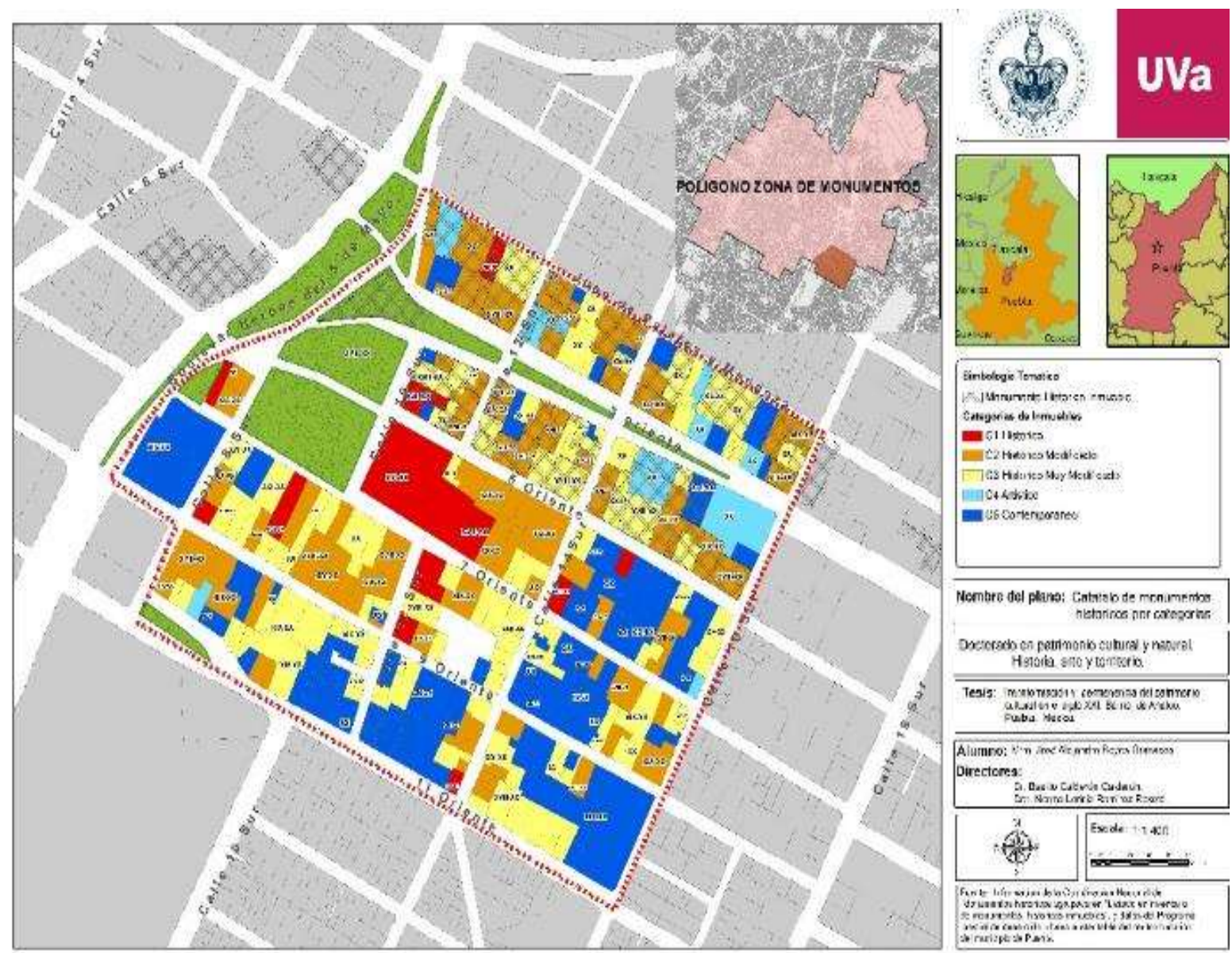

Figura 59. Plano de catálogo de monumentos históricos por categorías, Elaboración propia en base a datos recabados en campo y de (Gobierno del Estado, 2015).

\subsubsection{Infraestructura y servicios urbanos}

En la zona de monumentos existen tres subsistemas que abastecen un total de 25 barrios, colonias y fraccionamientos, de acuerdo a datos obtenidos del Programa Parcial de Desarrollo Urbano Sustentable del Centro Histórico del Municipio de Puebla (2015). En cuanto a la distribución de la energía eléctrica, se cuenta con 3 subestaciones que alimentan a 169.1 MVA, y la demanda por promedio de vivienda es de $0.5 \mathrm{KVA}$. Este servicio es proporcionado para el barrio de Analco por la subestación 5 de mayo. En cuanto al servicio para el abastecimiento de agua potable en el barrio es cada 3 días. 


\subsubsection{Movilidad y accesibilidad}

La ciudad de Puebla presenta un desarrollo urbano exponencial en los últimos años, lo que continuamente ha transformado la estructura del sistema vial en la zona metropolitana. Está compuesta por cuatro vialidades regionales, siendo estas las de principal conectividad entre los estados de México, Veracruz y Tlaxcala. Existen seis vías de comunicación subregionales que se encargan de conectar a los municipios colindantes de la ciudad de Puebla, debido a que algunos de estos son proveedores de materias primas. Durante el desarrollo de la ciudad se crearon anillos interiores, creando una serie de circuitos conformados por vialidades ya existentes, las cuales se reorganizaron para lograr una mejor fluidez en el tránsito vehicular, con el fin de satisfacer las necesidades de la población. El primer anillo de la ciudad está compuesto por el boulevard héroes del 5 de mayo, circuito Juan Pablo II y Diagonal defensores de la república, en el caso del segundo anillo son; el boulevard Esteban de Antuñano, calzada Zavaleta, boulevard Atlixco, boulevard municipio libre, boulevard Vicente Suarez y boulevard Xonacatepec. El ultimo circuito es el Anillo Periférico Ecológico, una de las vialidades más importantes de la ciudad de Puebla.

De esta manera, la jerarquia vial del centro histórico esta relacionada con el sistema vial de la ciudad y en los últimos años con el sistema RUTA, han transformado la función de estos elementos de la estructura urbana, de ser espacios de vida y encuentro, a espacios destinados únicamente a desplazar personas y mercancias, ya que excluyen a los grupos de población más vulnerables, al existir grandes distancias respecto a diversas colonias populares alejadas del centro para llegar a la terminal más cercana.

Así, este sistema RUTA muestra la falta de integración social desde la perspectiva de la accesibilidad y movilidad, para transformarla en una "centralidad de los lugares", que materialice el derecho a la ciudad para todas las personas. Por tanto, se requiere definir estrategias adecuadas para generar lugares y ciudades más competitivas, incluyentes y sustentables, que respondan a las necesidades de cada uno de los grupos que comparten el territorio. De ahí la importancia hacia la accesibilidad y movilidad como elementos regeneradores del tejido urbano y de conexión del centro con la periferia, donde se propicien dinámicas de intercambio cultural entre las personas, promoviendo el encuentro y la sociabilidad; dando lugar a procesos de agregación e identificación colectiva, de producción 
y expresión de identidades; así como de sentido de pertenencia y reconocimiento (ver Fig. $65)$.
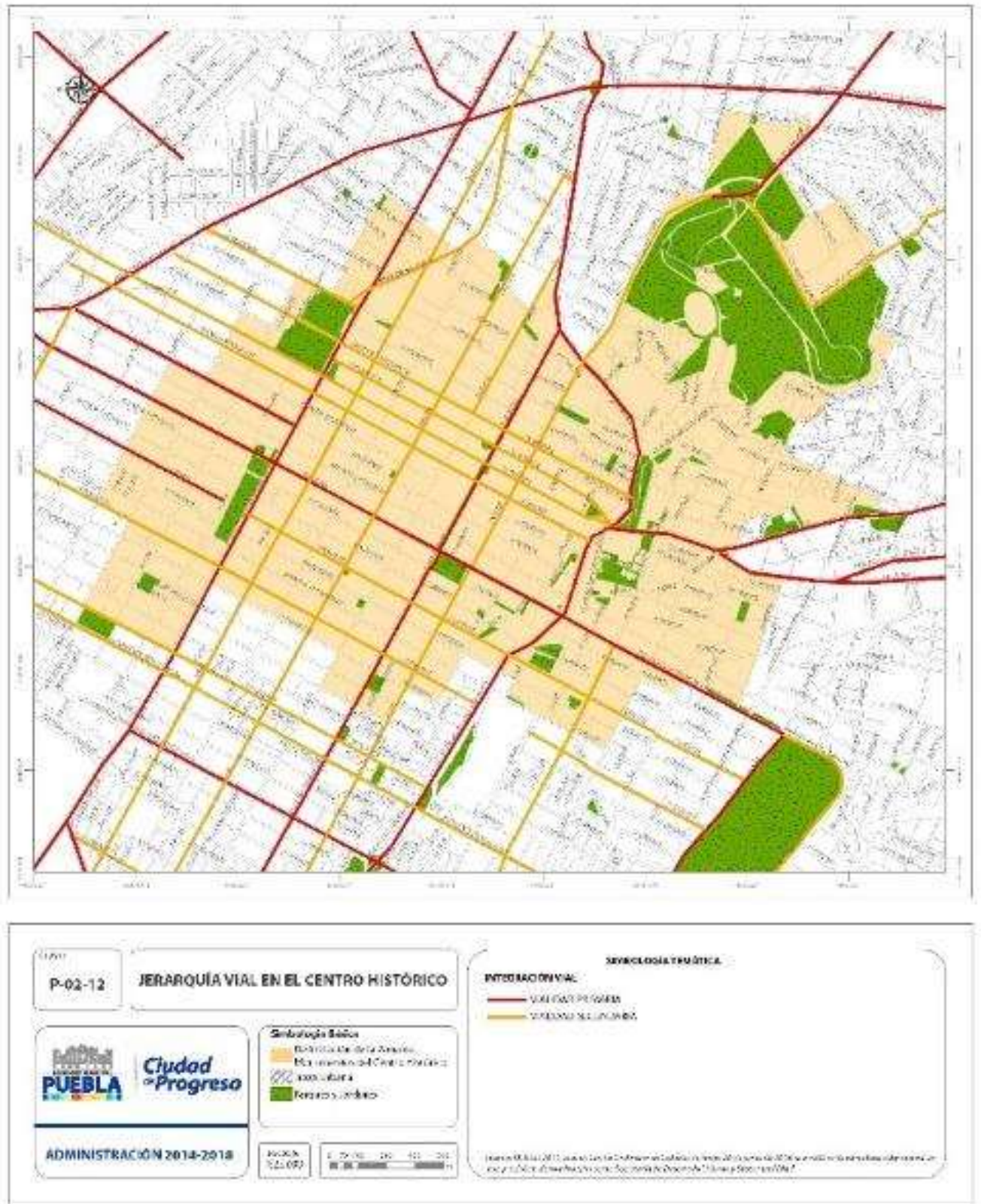

Figura 60.Plano de Jerarquía vial en el centro histórico, Elaboración propia en base a datos recabados en campo y de (Gobierno del Estado, 2015). 


\section{Proyectos de infraestructura y equipamiento turístico}

Es importante señalar que las políticas de intervención actuales en el centro histórico de Puebla para incentivar al turismo cultural conllevan a la formulación de proyectos alternos en temas de infraestructura y movilidad, así como la creación y adaptación de grandes equipamientos orientados al desarrollo turístico donde el principal atractivo lo conforma dicho patrimonio cultural.

Movilidad. Según cifras del Plan de Movilidad Sustentable para el Municipio de Puebla, el centro histórico es el principal polo de atracción de viajes de la Zona Metropolitana PueblaTlaxcala por lo cual se han llevado diversas implementaciones y mejoras en el sistema de transporte. En el año 2015 se puso en operación el segundo troncal de BRT, como parte de la Red de Transporte Articulado de Puebla (RUTA) que conecta el sector norte sur al poniente del centro histórico. En el año 2018 se inauguró un tercer troncal conectando la zona de estudio con la central de autobuses y Ciudad Universitaria de la Benemérita Universidad Autónoma de Puebla. Cabe mencionar que en el año 2011 se realizó una prueba piloto, para implementar un servicio de bicicletas públicas, llamado "Smartbike" en el centro histórico, el cual fue suspendido en el año 2016, para dar pasó a otro sistema de préstamo llamado "Bici Puebla" en el año 2017. Sin embargo, es importante señalar que estas acciones no lograron articular al centro histórico con el resto de la ciudad.

\subsection{Análisis socioeconómico}

En cuanto a las características económicas del barrio se analizó a la población ocupada y económicamente activa. El Instituto Nacional de Estadística y Geografía (INEGI) define a la población ocupada como el conjunto de personas que tiene por lo menos una ocupación, es decir, que en la semana de referencia ha trabajado como mínimo una hora (en una actividad económica). Mientras que los datos de la población económicamente activa se obtienen a través de la integración del número de personas que tienen una ocupación o que sin tenerla la están buscando activamente, es decir, está compuesta por la población ocupada más la población desocupada. 
De acuerdo con los datos recopilados del censo de población y vivienda de INEGI 2010, se conoce que la población económicamente activa dentro del centro histórico es de 18,561 habitantes, es decir, el \%46 de la población total, mientras que en el barrio de Analco ronda entre los 971 habitantes representado el \%2.4 de la población total del centro histórico. Por otro lado, la población total ocupada es de 927 habitantes, predominando la población masculina con él \%58 (ver Fig. 66).

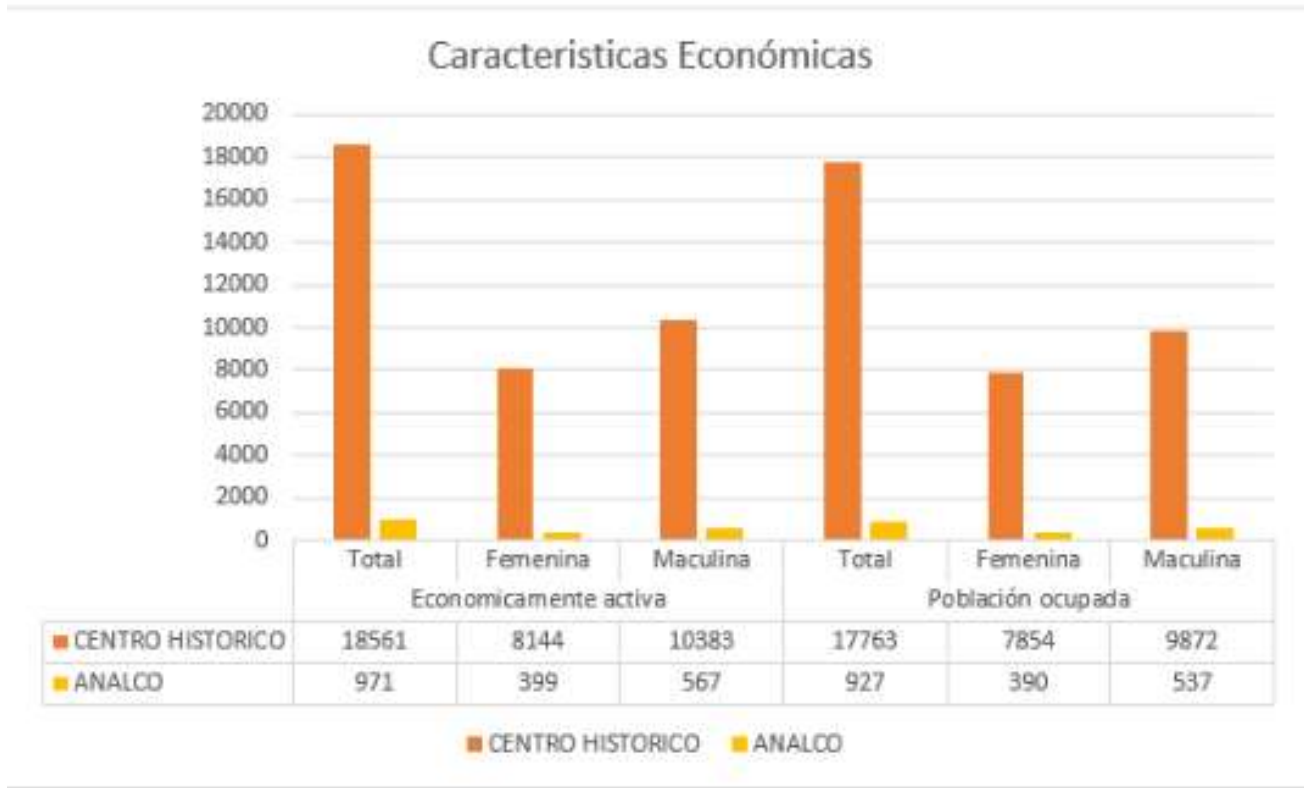

Figura 61. Características económicas. Elaboración propia a partir del (INEGI, 2010)

\subsubsection{Demografía en la Zona de Monumentos}

Para el año 1982 la población en la zona de monumentos era de 282,598 personas, con una densidad de 404 Hab./ha. En 1990, disminuyó un 67\% en su población aproximadamente y tenía una densidad de 128 Hab./ha., para el año 1994 su población era de 81,706 con una densidad de 116 Hab./ha., mientras que en el periodo del año 2000 al 2010 hubo una disminución del 30\% de su población total y una densidad de 59 Hab./ha., de acuerdo a los datos oficiales más recientes del Censo de Población y Vivienda INEGI 2010. 


\subsubsection{Población del barrio de Analco}

Respecto a las estadísticas elaboradas a partir de censo de población y vivienda 2010, se muestran las características de la población, los hogares censales y las viviendas en el Barrio de Analco y el Centro Histórico. Por lo tanto, los indicadores sobre población corresponden a las características educativas y económicas, población y grupos de edad, vivienda, migración, servicios en la vivienda y de salud, hogares censales, directorio de unidades económicas, predios, y estado constructivo por siglo.

\section{Población y grupos de edad}

La población total que reside en barrio de Analco, según datos estadísticos de INEGI (2010) es de 2116 habitantes es decir el 5.25\% del total de la población residente del centro histórico, misma que se encuentra constituida mayormente por hombres y mujeres de 30 a 49 años, predominando la población femenina con un 52.69\% del total de la población en el barrio. (ver Fig. 67).

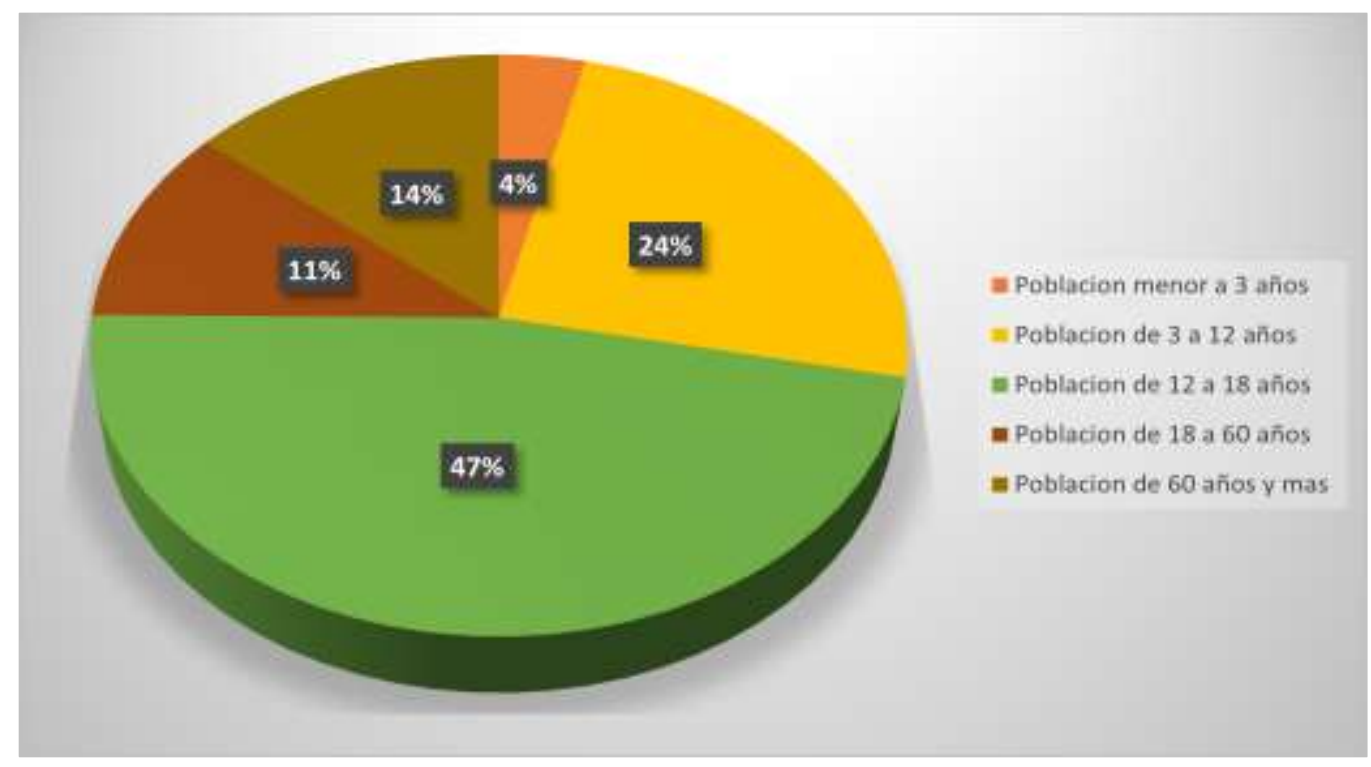

Figura 62. Población por grupo de edad, Elaboración propia en base a datos obtenidos de (INEGI, 2010). 
La población masculina constituida por 996 hombres y la población femenina con 1,120 mujeres. En cuanto a la población que habla alguna lengua indígena de acuerdo con el Censo de Población y vivienda de INEGI 2010 nos muestra que el 2.7\% de la población total de 3 años y más pertenece a este grupo de los cuales se dividen en 29 hombres y 69 mujeres. El total de población de los hogares censados es de 2,034 mientras que la población indígena solo es un 3.3\% (ver Fig. 68). Recientemente un estudio de mercado del 2019 estima que el número de habitantes del barrio es de 4000 personas contabilizando al $50 \%$ de personas con edades de entre 30 y 59 años, casi el doble de lo establecido en el censo de población del 2010, esto podrá ser comprobado con los datos que se publicaran el próximo año, resultado del censo de población del 2020, ( Market Data, 2019).
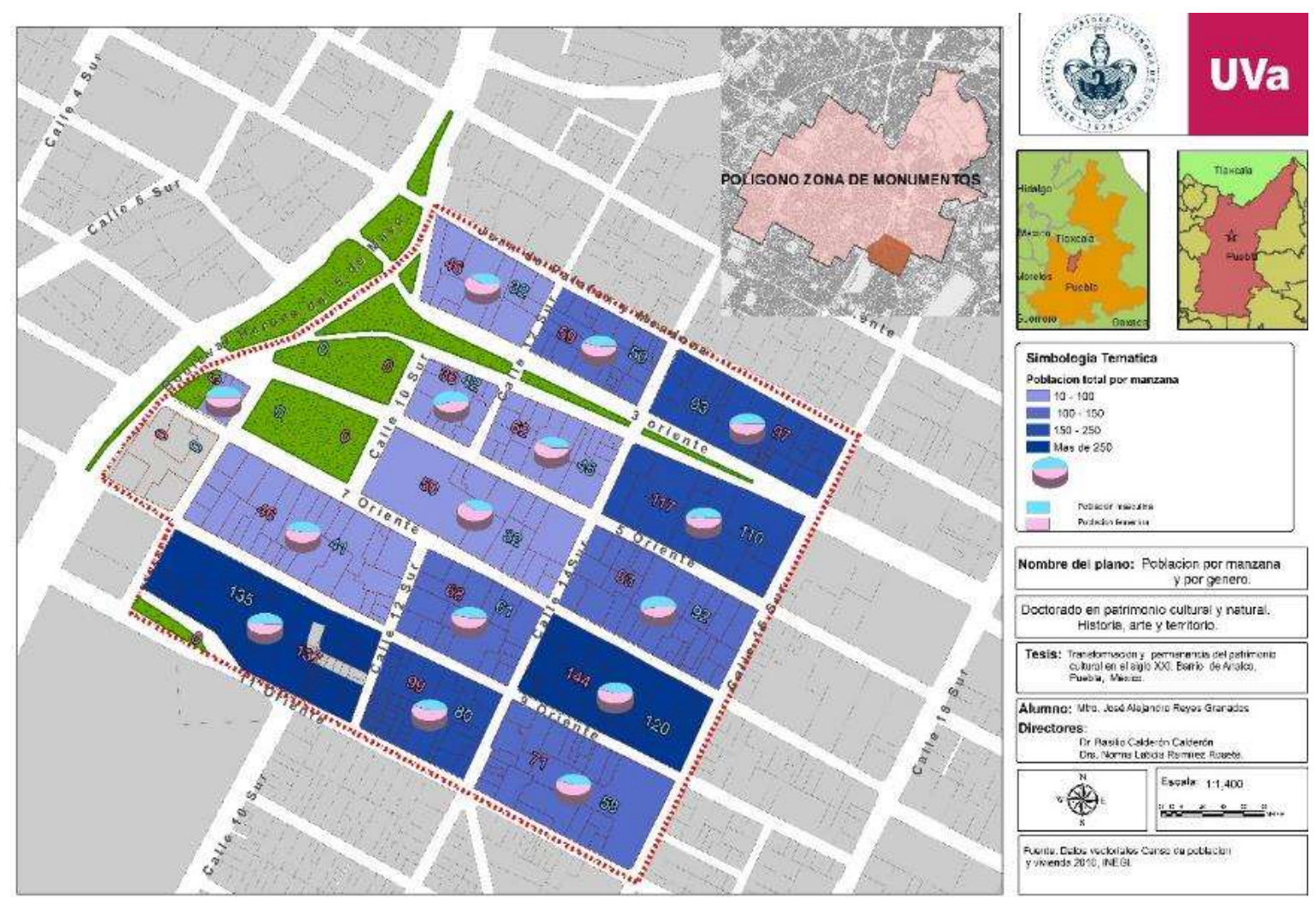

Figura 63. Población total por manzana y por género del barrio de Analco, Elaboración propia en base a datos de (INEGI, 2010). 


\subsubsection{Vivienda}

El barrio de Analco tiene 875 viviendas aproximadamente repartidas en 15 manzanas, cada vivienda cuenta con más de tres habitaciones y el promedio de ocupantes por viviendas son 3 personas, en su mayoría cuentan con los servicios básicos como, agua potable, drenaje y electricidad (ver Fig. 69).
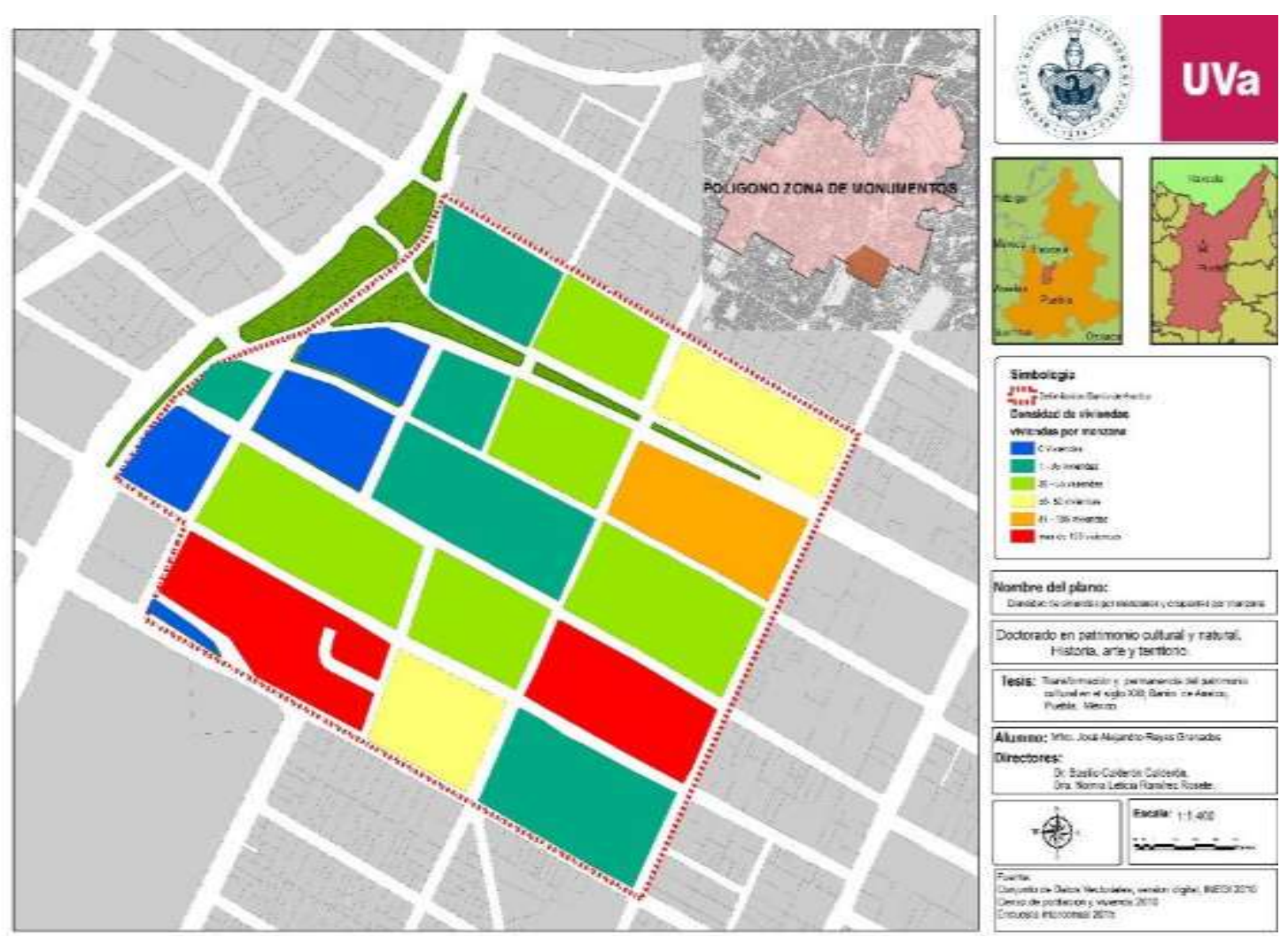

Figura 64. Densidad de viviendas por manzanas, Elaboración propia a partir de (INEGI, 2010).

En el centro histórico existen 17,268 habitantes, de este total aproximadamente el 5\%, es decir, 864 viviendas corresponden al barrio de Analco, pero no todas estas viviendas están habitadas, el $7.8 \%$ de estas viviendas se encuentran deshabitadas y por lo que se abandonó las va deteriorando. De las viviendas que se encuentran en el centro histórico 318 cuentan con un dormitorio, mientras 303 cuentan con más de dos dormitorios, los ocupantes por vivienda son de un promedio de 2.5 ocupantes por dormitorio. 


\subsubsection{Escolaridad}

En cuanto a la educación de la población de Analco podemos observar en la figura 70, que es menos la población analfabeta que la alfabeta y el grado de escolaridad que alcanza la población en promedio es hasta el nivel de educación básica, es decir, primaria y secundaria.
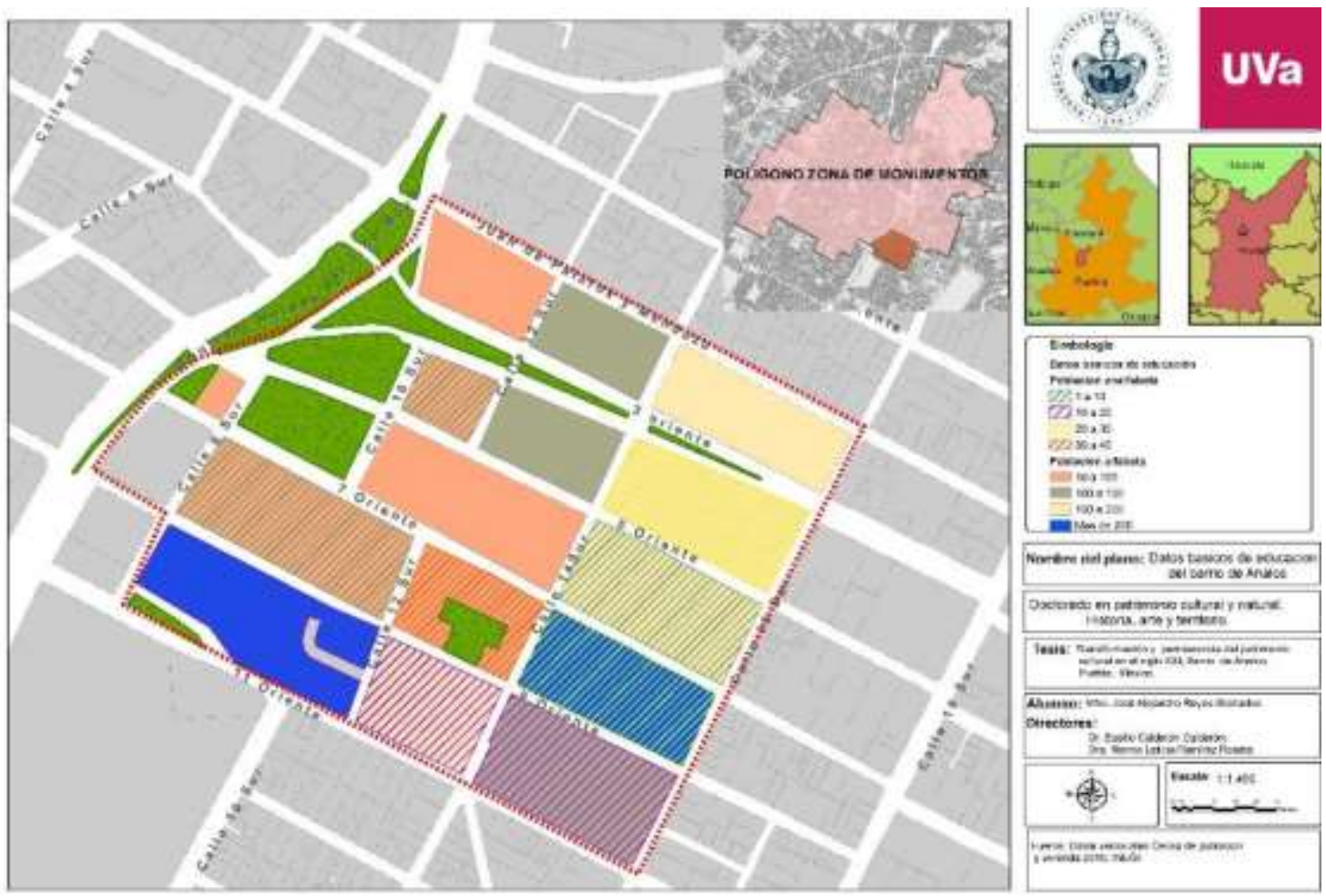

Figura 65. Datos básicos de educación del barrio de Analco, Elaboración propia en base a datos obtenidos de (INEGI, 2010).

\section{Principales resultados}

Actualmente el centro histórico muestra la ausencia de políticas y estrategias efectivas que incentiven el uso habitacional y la inserción de vivienda social. Esto favorece el despoblamiento aunado a diversas problemáticas como la saturación de comercio y equipamiento. Lo anterior, aumenta la oferta de hospedaje y servicios especializados para el turismo a través de plataformas digitales que no está regulado, lo cual pone en riesgo la habitabilidad de los barrios, atrayendo también a un nuevo tipo residente con un mayor estatus económico que es la base para la gentrificación. 
Como resultado se deduce que el impacto del turismo en el patrimonio cultural de Puebla es ambivalente, pues está definido de dos maneras opuestas: "lo que altera y lo que favorece". Aspectos que deben ser considerados por las políticas de gobierno para controlar los impactos negativos en el patrimonio. Por una parte, existe el riesgo de alterar la imagen histórica de esta bella ciudad patrimonio cultural de la humanidad, pero, por otra parte, está el hecho de que el turismo extranjero genera oportunidades de empleo, incrementando los ingresos económicos (públicos-privados) y tasas de Producto Interno Bruto (PIB), desarrollando infraestructura para seguir innovando y manteniendo relaciones con otras partes del mundo. 


\section{CAPITULO VI. REFLEXIONES FINALES: \\ La percepción de vulnerabilidad urbana en Analco}




\section{REFLEXIONES FINALES - La percepción de vulnerabilidad urbana en Analco}

\subsection{Análisis de la transformación, cambios y permanencias en el Barrio de Analco}

Este apartado se revisa bajo un enfoque sistémico sustentado en una reflexión teórica, lo cual permite explicar el impacto del turismo en el patrimonio cultural del barrio de Analco, así como sus efectos en la economía, cultura e identidad de sus habitantes. Esta indagación científica surge a partir de un elemento clave identificado como gentrificación, que poco a poco ha sido absorbido en la categorización de patrimonio y turismo cultural, así como en las políticas urbanas y de desarrollo turístico de los barrios en particular y de la ciudad de Puebla en general, en donde al mismo tiempo se integran al proceso de gentrificación cuya polémica gira en torno a la revalorización arquitectónica, económica y social vs. la permanencia de los habitantes originarios de los barrios de la zona fundacional de Puebla, así como de su memoria histórica e identidad.

Además de evaluar el factor de valoración y riesgo de las políticas mal orientadas que han conducido a la pérdida del patrimonio tangible e intangible al ser considerado como un recurso y motor de desarrollo económico en las ciudades de gran valor histórico, cultural y natural. En este sentido, es necesario contextualizar el caso de estudio en cuyo escenario convergen el turismo y el patrimonio cultural del barrio de Analco, destacando la evolución o no, de las políticas de protección y conservación del patrimonio cultural desde finales del siglo XX y primeras décadas del siglo XXI.

Así, en la última década del siglo XX, debido al impacto del proyecto implementado en el año 1993 denominado "Paseo de San Francisco", se generó un proceso de cambio de uso del suelo en el barrio de Analco, el cual se ha acelerado en las primeras dos décadas del siglo XXI. Este barrio, es uno de los más antiguos de Puebla, sin embargo, ha tenido que adaptarse a la vida moderna de la ciudad y a sus necesidades cambiantes en función de la transformación de uso del suelo e incremento del equipamiento y servicios turísticos. En consecuencia, estas transformaciones han repercutido en la vida de los habitantes e identidad del barrio, donde en la calle 3 oriente, que es uno de sus límites al norte, se han establecido con el paso del tiempo equipamientos y locales de uso comercial y de servicios. 
Como parte del análisis de estos cambios, observamos como en la figura 71 a la izquierda se observa que en el año 2009 había comercio local con oficios originarios del barrio, se identifica el anuncio de una carpintería como muestra de los oficios en el barrio, además de algunos locales que son ocupados también como vivienda; en la segunda imagen a la derecha podemos observar otro tipo de comercio ajeno a la vocación de la comunidad del barrio y con predominio de uso mixto.

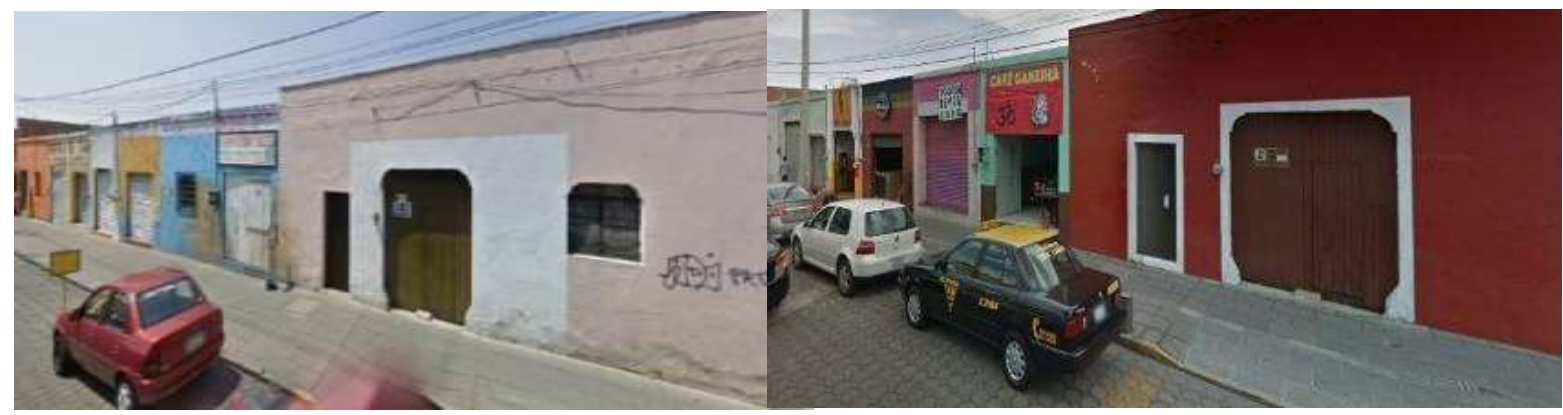

Figura 66. Comparación de la calle 3 oriente entre a calle 16 sur y 14 sur (mayo 2009 y mayo del año 2019).

En la figura 72, observamos que en el año 2009 el inmueble era de uso habitacional y para el año 2019 se transforma a uso mixto (servicio y comercio) con la instalación de una tienda de conveniencia junto al hotel boutique y la construcción de una terraza, lo que llevó a remodelar y modernizar el taller de la fábrica de vidrio pasando a ser parte del hotel boutique.

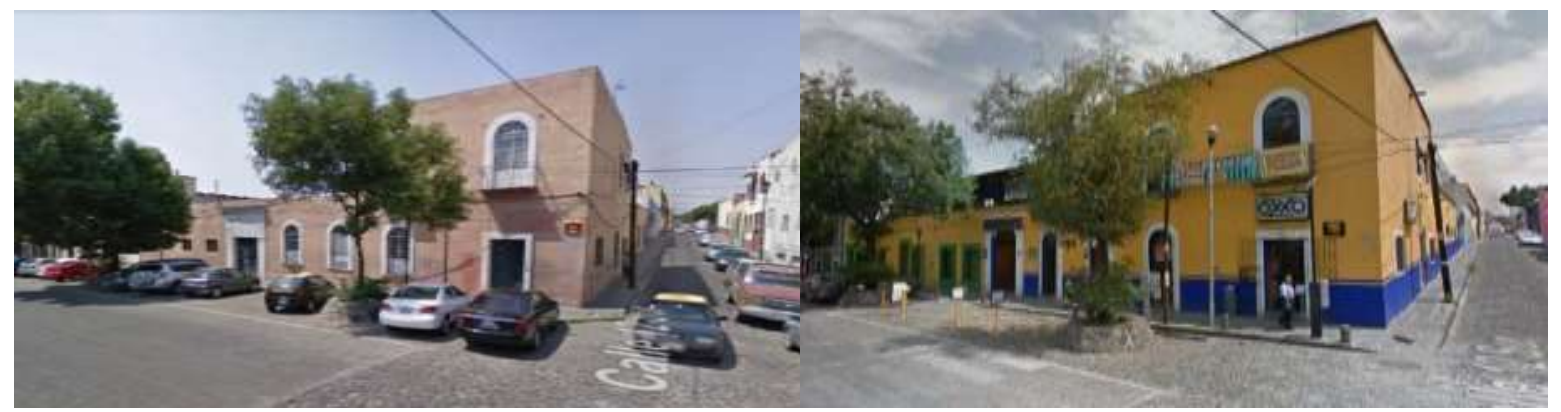

Figura 67. Inmueble de la calle 3 oriente y 12 Sur del año 2009 y el año 2019. Fuente: Reyes (2020). 
Se puede identificar que, en la figura 73, que hubo un cambio en el uso de suelo del año 2009 al año 2016, generando la expansión establecimiento de ocio (bar), donde existían anteriormente casas habitadas, no obstante, las alturas se respetaron.

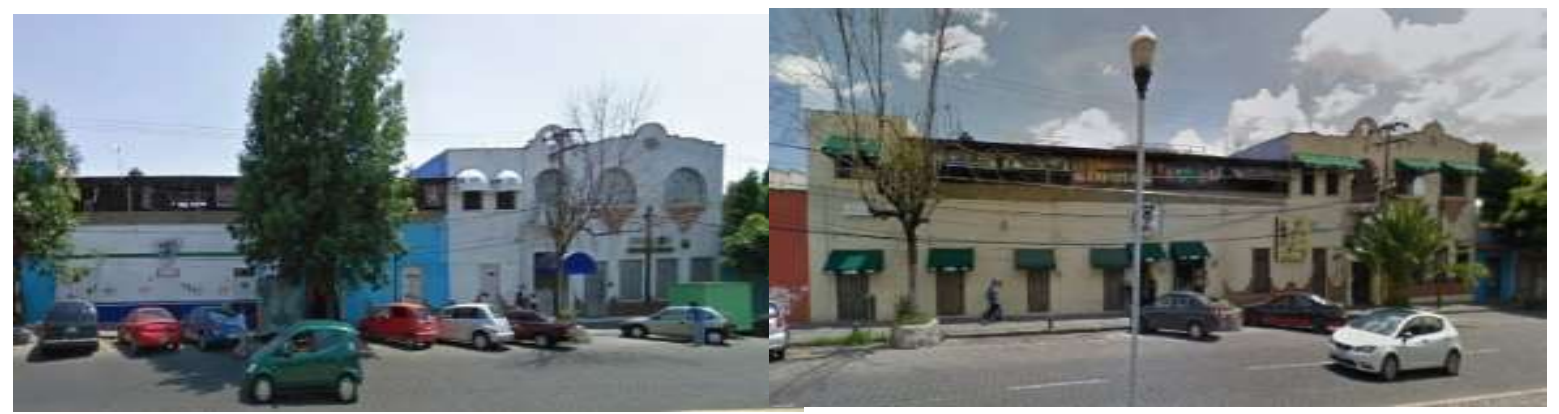

Figura 68. Comparación de la fachada del bar "El baño" de mayo del año 2009 y junio del 2016. Fuente: (REYES, 2020)

El inmueble de la figura 74, corresponde a la facultad de psicología de la Benemérita Universidad Autónoma de Puebla, que en el año 2009 albergaba una bodega de materiales de construcción; después se convirtió en un estacionamiento general y escuela de educación superior de negocios. Sin embargo, es notable la adhesión de una construcción que sobresale en altura y rompe con el perfil urbano imagen del barrio.

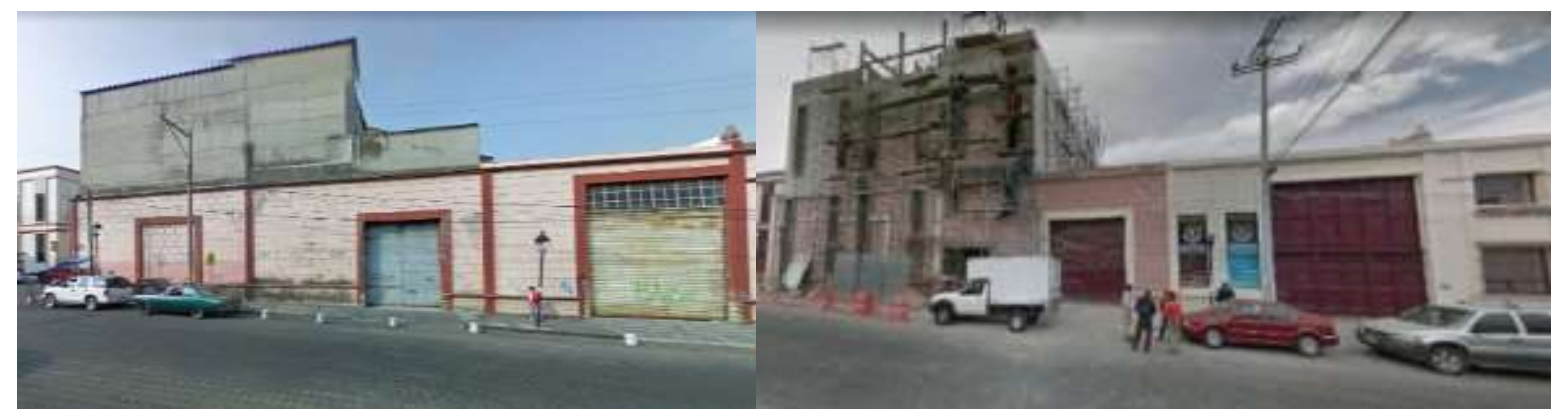

Figura 69. Comparaciones de la fachada de la actual facultad de psicología de la BUAP del año 2009 y el año 2018. Fuente: (REYES, 2020)

El actual hotel boutique Casona María inicia su función como tal en el año 2013, sin embargo, como se ve en la figura 75, lado izquierdo, anteriormente su uso era mixto ya que 
el edificio era utilizado como vecindad y bodega hasta el año 2005, de acuerdo con encuestas realizadas a vecinos del barrio de Analco; en el año 2012 inicia la remodelación para su aprovechamiento como hotel boutique, adhiriéndose una terraza que por su diseño contrasta con el resto de la edificación. Actualmente el hotel cuenta con un estacionamiento y se incluye un segundo predio cerca del hotel, interponiéndose un edificio de departamentos entre ambos.

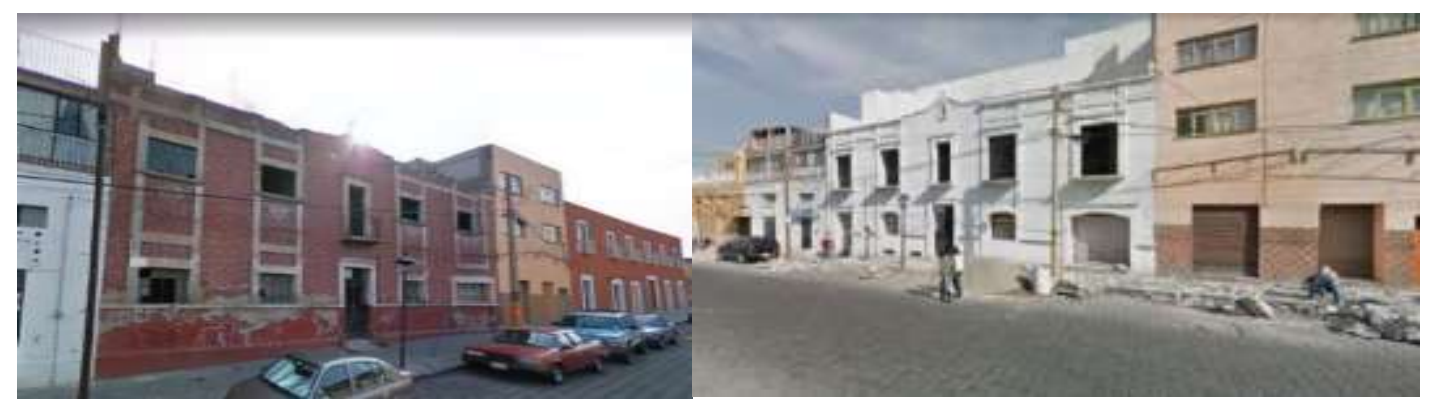

Figura 70. Hotel boutique casona María comparación de mayo del 2009 y mayo del año 2012.

En la figura 76 del lado izquierdo, se observa un inmueble de uso mixto ya que anteriormente se utilizaba como horno de una fábrica de vidrio, perteneciente a una familia originaria del barrio de La Luz, además de ser una vecindad; alrededor del año 2010, el edificio fue remodelado, conservando el uso de tienda o fábrica de vidrio, pero además paso a formar parte del actual Hotel Boutique "Al otro lado del rio".

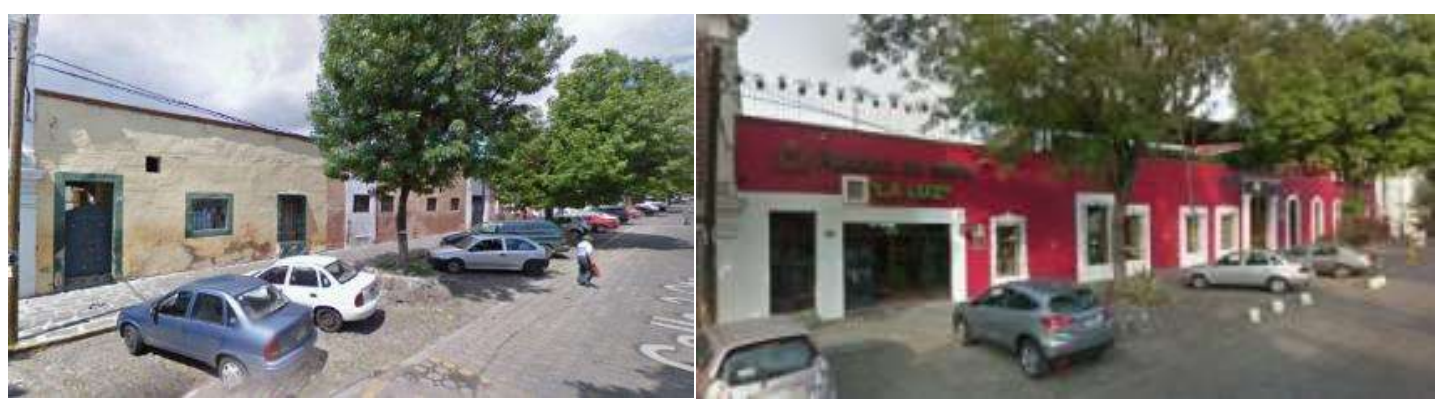

Figura 71. Comparación de la fábrica de vidrio La Luz, entre el año 2009 y el año 2019. 
En este análisis, encontramos edificaciones abandonadas, como es el caso de la que se muestra en la figura 77, donde se observa el deterioro avanzado de una vivienda deshabitada, ubicada frente a la parroquia del Santo Ángel Custodio de Analco. Sería aventurado mencionar la causa de su abandono, sin embargo, esta situación en la actualidad favorece su uso para actos vandálicos, lo que atenta contra la seguridad de los habitantes del barrio, además de que su estructura dañada es un peligro para los edificios contiguos y peor aún para los transeúntes.

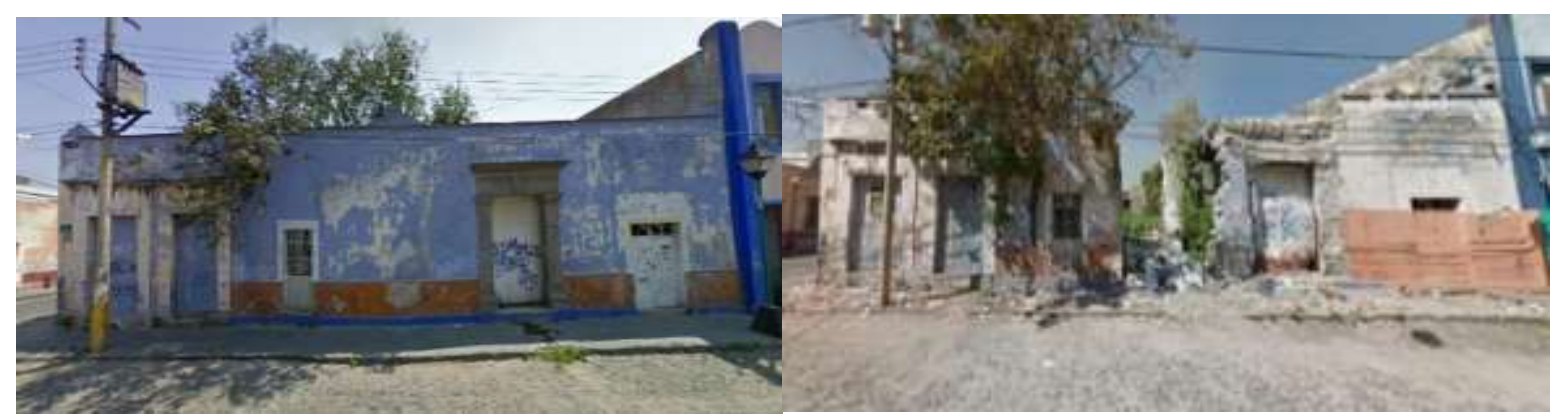

Figura 72. Comparativa de edificio abandonado en la calle 7 oriente a partir de mayo del año 2009 y mayo del año 2018. Fuente: elaboración propia.

Entre el año 2012 y 2015, el edificio que se observa en la figura 78 cambio su uso de habitacional a equipamiento y servicios educativos, y fue en este periodo que el Instituto Carls Rogers se estableció en el barrio de Analco adquiriendo dos predios que eran viviendas multifamiliares, alterando tanto el partido arquitectónico original como la imagen urbana del barrio.

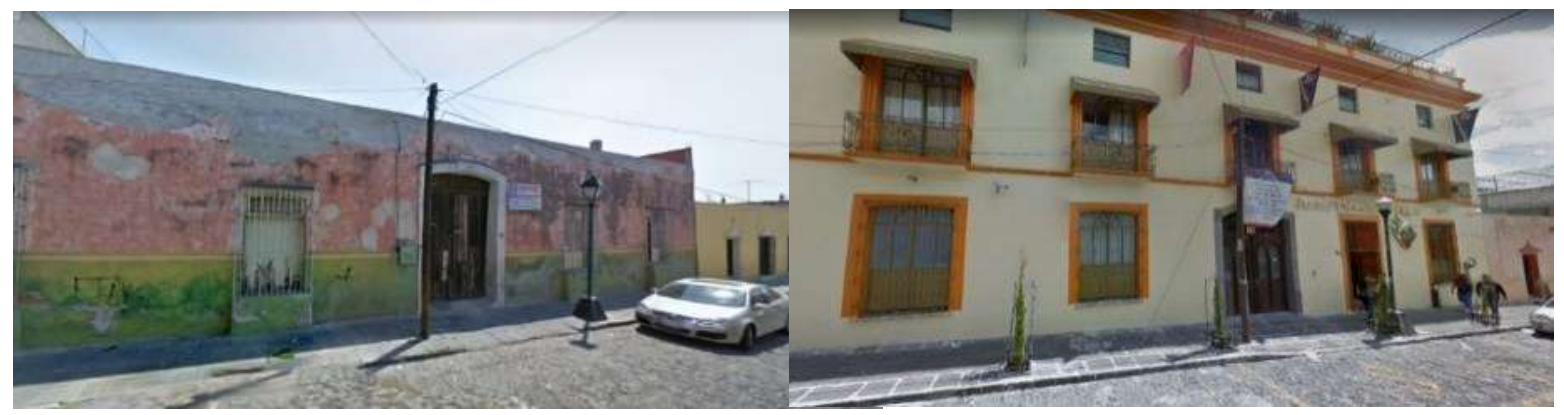

Figura 73. Comparación de la calle 5 oriente n. 1206 actualmente Instituto Carls Rogers comparación, del año 2009 y 2016. Fuente: (REYES, 2020). 
Un claro ejemplo del inicio de la gentrificación que menciona Duque (2010), ocasionada quizá por el deterioro paulatino y la falta de mantenimiento que lleva a la ruina de las viviendas, lo podemos observar en la figura 79, en donde vemos del lado izquierdo que el inmueble aún era habitado en el año 2009. En este punto y coincidiendo con los autores que han sido la base de nuestro marco teórico para esta investigación con respecto a este tema, existen diversos factores que bien pueden ser la causa del abandono que sufren estos inmuebles, desde el posible abandono por problemas legales de la propiedad o por el deterioro del inmueble y la consecuente falta de atención; o la intención de mejora de la vivienda por parte de los habitantes e incluso la movilidad hacia lugares que no mejoran el entorno de los habitantes pero que necesariamente se ven obligados a emprender dicha movilidad, en cualquier caso, como se aprecia en la imagen de la derecha, en el año 2019, el deterioro del inmueble ha evolucionado con la casi nula posibilidad de ser reutilizados.

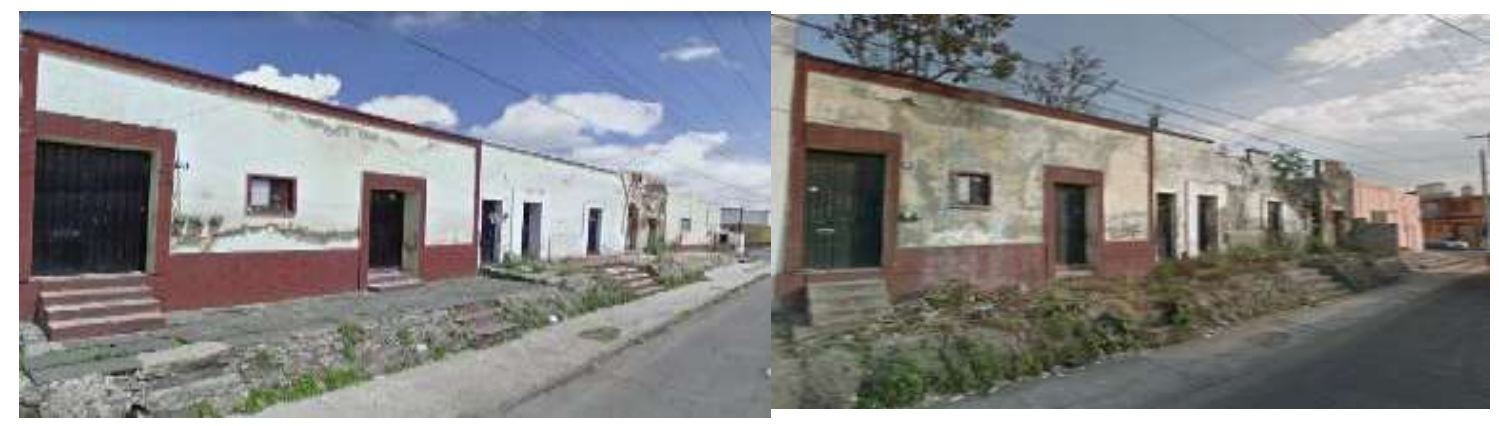

Figura 74. Comparación de la calle 5 oriente n. 1206 actualmente Instituto Carls Rogers comparación, del año 2009 y 2016. Fuente: (REYES, 2020).

Vale la pena destacar casos como el hotel ubicado sobre el boulevard 5 de mayo y la calle 3 oriente, el cual durante el año 2010 tuvo una transformación consistente en la eliminación de una terraza y la construcción de un espacio cerrado, sin embargo, esta modificación ha permitido la permanencia en el uso y función del inmueble, conservando las alturas de los edificios colindantes además de respetar la imagen de la fachada como se puede observar en la imagen 80 . 

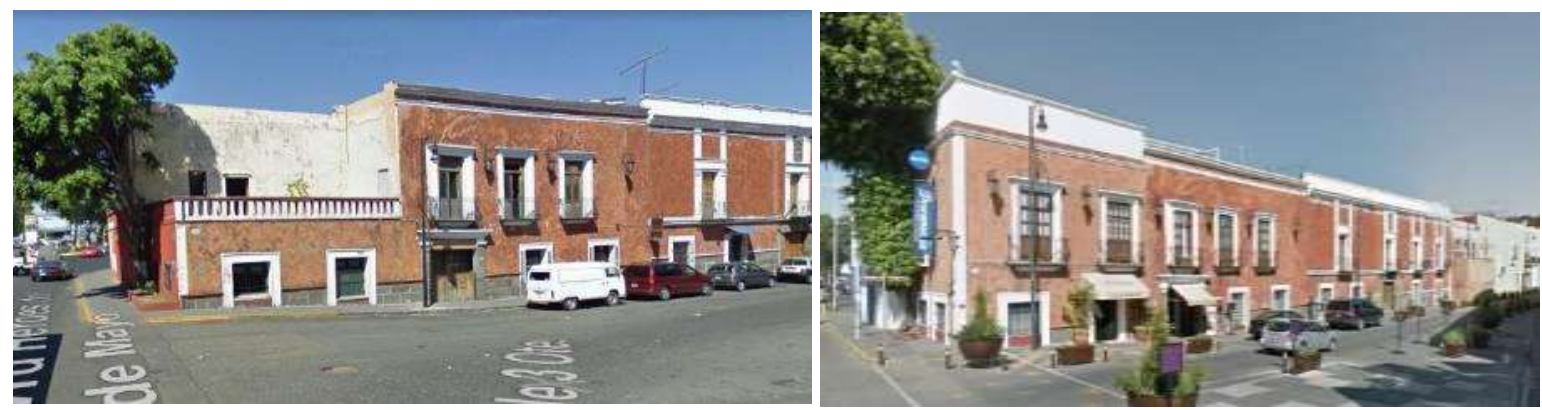

Figura 75. Transformación y permanencia del hotel ubicado en boulevard 5 de mayo del año 2009 y e1 año 2019. Fuente: elaboración propia.

En la figura 81, analizamos el cambio gradual del edificio ubicado en el límite poniente del barrio, que en el año 2011 fungía como pensión de vehículos y estacionamiento; para el año 2013 aproximadamente, se comenzó la construcción del actual Hotel Cartesiano, donde se aprecia una fusión de estilos arquitectónicos entre el colonial por demás característico del barrio de Analco con la arquitectura contemporánea propuesta, con elementos que rebasan los niveles de altura de la zona, siendo este un ejemplo claro del proceso de gentrificación que sufren los barrios de la ciudad.

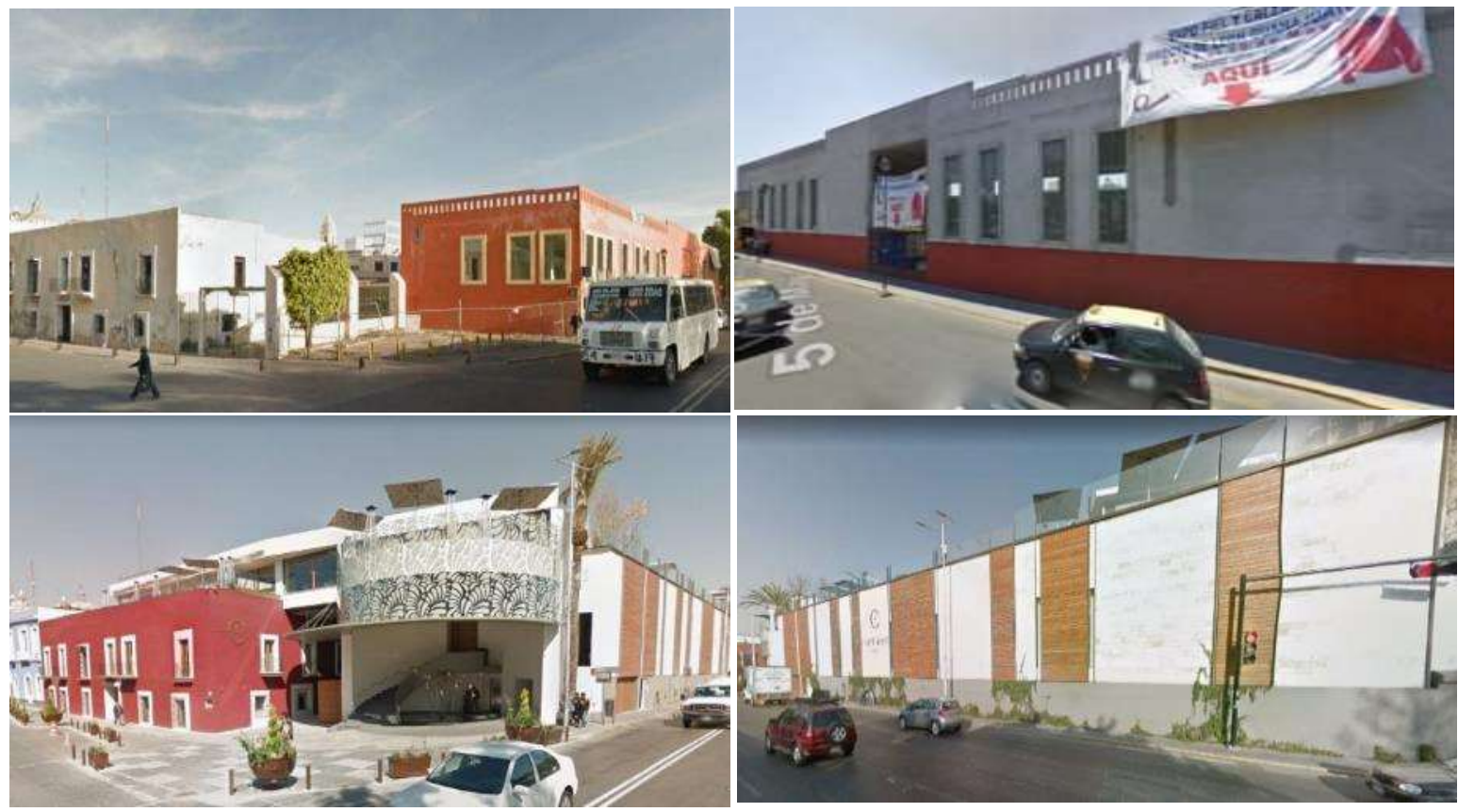

Figura 76. Comparación del actual hotel Cartesiano ubicado sobre boulevard 5 de mayo y avenida 3 oriente entre el año 2011 y el 2018. Fuente: (REYES, 2020) 
Es importante destacar también los cambios de las áreas comunes, ya que, como hemos encontrado al interior del barrio, existen espacios públicos que se encuentran en total abandono siendo este nuevamente un factor que propicia el apoderamiento de grupos delictivos y el mal uso de los espacios. Como ejemplo tenemos el parque Jerusalén, que durante el año 2009 se benefició con una remodelación ya que anteriormente estaba en completo abandono. Posteriormente, en el año 2015, nuevamente sufrió las mismas consecuencias gracias a la falta de uso y apropiación por parte de los grupos antes mencionados; finalmente, en el año 2018, el colectivo Tomate ${ }^{19}$ fue quien ayudo a reformar el parque con un enfoque participativo conjuntamente con los vecinos del barrio de Analco, con el único fin de que los vecinos encuentren y reconozcan su identidad cultural, sin embargo, hoy en día, no se ha logrado una apropiación por parte de la población (ver Figura $82)$.

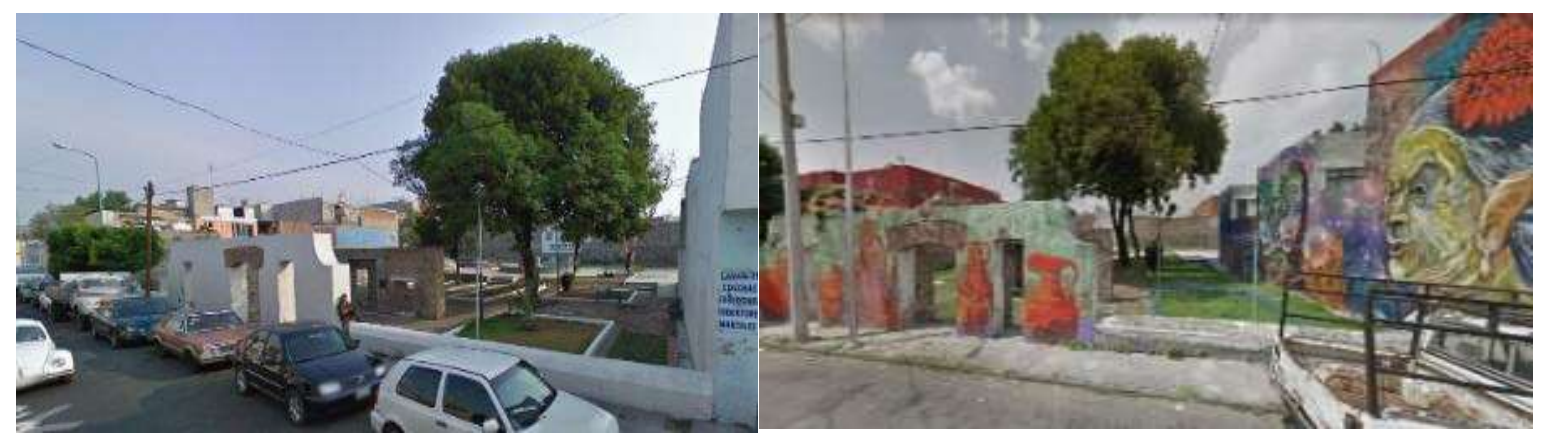

Figura 77. Intervención y rescate del parque Jerusalén en el año 2009 y el año 2018. Fuente: elaboración propia.

En la figura 83, se muestra el edificio ubicado en la esquina de la calle 14 sur con la calle 7 oriente, que actualmente es sede de un proyecto universitario de desarrollo comunitario llamado Casa-Analco, orientado bajo un enfoque de trabajo comunitario y de preservación del patrimonio cultural a través de la vinculación, compromiso y corresponsabilidad social de diversos sectores públicos y privados para diseñar y promover políticas culturales encaminadas a la protección, preservación y salvaguarda del patrimonio

\footnotetext{
${ }^{19}$ Colectivo Tomate es una organización civil con base en Puebla conformada por 20 artistas, abogados, arquitectos, diseñadores, nutriólogos y administradores que han intervenido alrededor de ocho ciudades en todo México para invitar a las personas a tomar acción en las calles para generar una transformación y demostrar el poder del ciudadano en las comunidades, así como fortalecer los lazos de las comunidades. Fuente: https://www.archdaily.mx/mx/889249/muralismo-mexicano-con-accion-social-ciudad-mural-villahermosacolectivotomate\#: :text=Colectivo\%20Tomate\%20es\%20una\%20organizaci\%C3\%B3n,generar\%20una\%20t ransformaci\% $\mathrm{C} 3 \% \mathrm{~B} 3 \mathrm{n} \% 20 \mathrm{y} \% 20 \mathrm{demostrar}$
} 
cultural como elemento de identidad y tradición fundamental. Durante los últimos años, esta edificación ha pertenecido a la Benemérita Universidad Autónoma de Puebla (BUAP) y hace aproximadamente 5 años fue asignado a la Facultad de Arquitectura y a pesar de ello, el inmueble continuó deteriorándose ya que se encontraba abandonado; es hasta el año 2018 que fue asignado al grupo de investigadores dirigido por la Dra. Adriana Hernández Sánchez y la Dra. Norma Leticia Ramírez Rosete para dar vida a este proyecto de investigación.

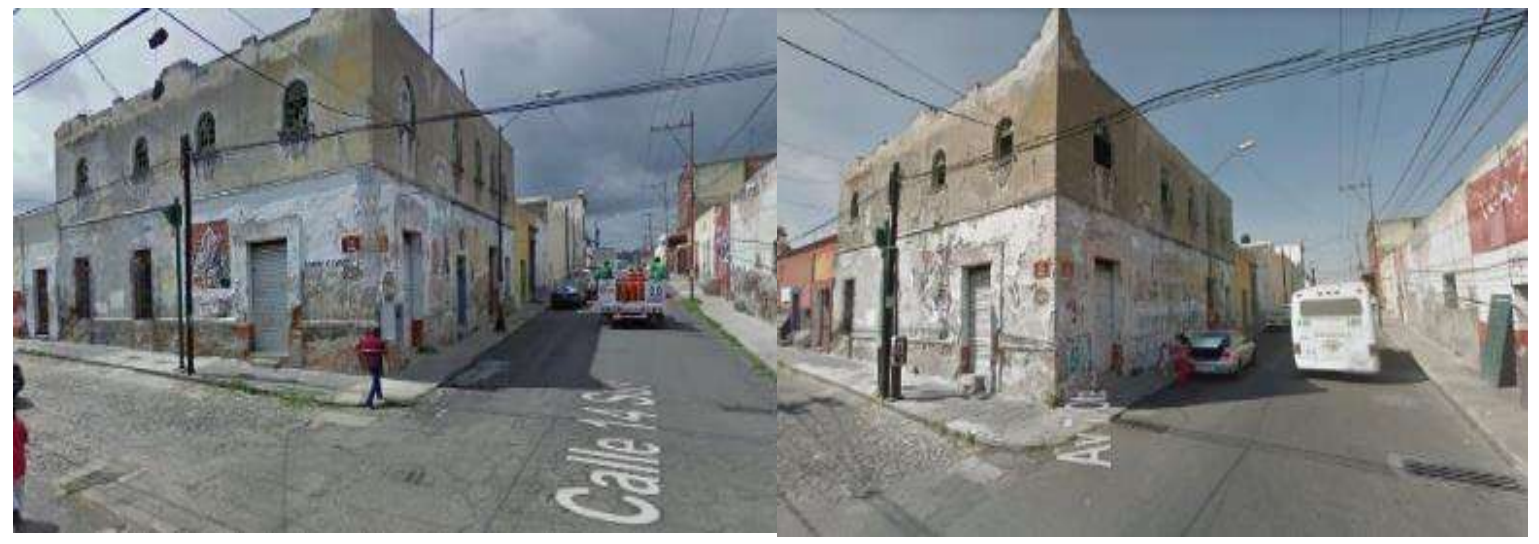

Figura 78. Casa Analco, proyecto de investigación FABUAP 2018. Fuente: elaboración propia.

En este análisis, hemos encontrado la diversidad de factores que originan los diferentes procesos de gentrificación descritos por los autores consultados en este trabajo de investigación; destacan edificaciones con mínimas adhesiones a las construcciones existentes que respetan altura y estilos arquitectónicos, pero también están a la vista otros casos en donde paulatinamente, las transformaciones registradas rompen completamente con la imagen urbana de esta zona, sin mencionar los procesos que a mayor o menor escala debieron pasar en cada caso particular.

Con el contexto anterior, resulta fácil concluir que, a pesar de que se siguen elaborando diversos instrumentos con el objetivo de proteger, conservar, rehabilitar y revitalizar el patrimonio arquitectónico y urbano de la zona de monumentos de la ciudad de Puebla, las estrategias siguen avalando tanto el cambio de uso del suelo como el reciclaje de inmuebles para alojar servicios y comercio destinado al turismo y población fluctuante. Por esta razón, no ha habido una orientación efectiva para incentivar políticas de vivienda y equipamiento urbano que contribuya a mejorar las condiciones de habitabilidad de la 
población residente, que, además, promueva una mixticidad social y desarrollo local. Por lo tanto, se requiere trabajar de manera conjunta con los diferentes actores sociales para generar alternativas de solución a estos conflictos, mediante una gestión territorial participativa y acorde a las necesidades de los habitantes de los barrios.

\section{Análisis de la encuesta aplicada en el Barrio de Analco}

En este apartado, analizamos información obtenida a partir de una encuesta elaborada particularmente para este documento durante el mes de enero de 2018, se realizó de manera aleatoria a una muestra de 150 habitantes de 1,770 (INEGI, 2010) que ocupan el barrio de Analco. De este modo, se obtuvo información puntual y relevante acerca de este barrio, así como de aquellos lugares que lo representan, las principales problemáticas que lo agobian, los elementos que para esta población tienen más valor e incluso el conocimiento que la gente tiene sobre la historia de su barrio.

También podremos conocer el nivel de equipamiento y servicios con que cuenta nuestra área de estudio, así como la existencia o no y el tipo de organización entre los vecinos. Otro punto relevante será conocer los cambios que ha habido en el barrio y el beneficio que ha traído a sus habitantes.

Iniciaremos señalando que, de los encuestados, 77 fueron mujeres y 73 hombres, principalmente entre 18 y 35 años de edad, teniendo la mayor representación de la población joven del barrio. De este modo, sabemos que, entre los habitantes de esta área de estudio, el $65 \%$ identifica como el elemento más representativo cultural y socialmente a la iglesia del Santo Ángel Custodio, seguido con el 19\% del Puente de Ovando que, además de ser un hito urbano de valor patrimonial en la zona, también lo ha sido al interior de la ciudad de Puebla; también el jardín o plaza ubicado frente a la iglesia de la que ya se ha dado referencia, el 12\% de los encuestados menciona que es uno de los elementos representativos del barrio debido a que además de ser uno de los puntos de principal afluencia social y turística, también ha sido un punto de afluencia económica, aunque solo sea en fines de semana y quizá descartando un beneficio económico para los habitantes del barrio. 
Hablando de los principales problemas que vive el Barrio de Analco, al igual que en el estado y en el resto del país, la inseguridad que viven sus habitantes, puede ser una de las principales causantes de otro de los problemas que identifica la gente del barrio como es el abandono, que no solo implica el abandono de los espacios físicos, sino que además repercute en el deterioro de los mismos, en la perdida de vitalidad y sustancia del barrio, es decir de su identidad. Para apenas el 9\% de la representación de los entrevistados, el comercio se vuelve una problemática, probablemente por el caos vial que esta actividad pudiera generar, por no mencionar la obstrucción de accesos o exceso de basura en la vialidad.

Como ya lo vimos, la inseguridad es una de las principales problemáticas del barrio, por ello, es preciso ahondar un poco más sobre el tema; para el 38\% de la población, los grupos vandálicos son la principal causa de inseguridad en el barrio, seguido del $21 \%$ y $16 \%$ que piensa que los asaltos y los espacios banalizados respectivamente ponen en riesgo la seguridad del barrio.

Por otra parte, y como era de suponerse, uno de los elementos que más valora el 68 $\%$ de la población en su barrio, es la arquitectura de los inmuebles que ahí se albergan, por lo que nuevamente hace presencia la iglesia del Santo Ángel Custodio que se identifica como un inmueble de interés cultural y arquitectónico por su estilo Barroco Indígena y que cuya construcción data de los años 1618 a 1632; otro elemento que los habitantes del Barrio de Analco es su localización, ya que por su ubicación geográfica forma parte de la zona de monumentos en lo particular y del centro histórico en general. Solo el 17\% de los habitantes, consideran que la gente del propio barrio es uno de los valores con que cuenta, seguido del $2 \%$ que piensa que la cultura es uno de los principales elementos dignos de valorar. No esta demás decir que solo el $48 \%$ de la población conoce la historia del Barrio de Analco.

Otros aspectos a analizar en el Barrio de Analco, es el equipamiento y los servicios, y es importante saber para este estudio saber si es suficiente o satisfactorio para sus habitantes, por lo que derivado de la encuesta podemos saber que para el $61 \%$ de la población del barrio existen suficientes parques y jardines; el 13\% menciona que el comercio y abasto son satisfactorios para abastecerse; el $10 \%$ piensa que las escuelas. 
Actualmente, sabemos que es difícil que los vecinos organicen, sin embargo, en este barrio, encontramos que la gran mayoría de los habitantes no conoce algún tipo de organización en su barrio, ya sea porque no le interesa o porque no tiene tiempo de integrarse a los grupos existentes, incluso el 59\% de los encuestados no sabe de la existencia de algún líder dentro del barrio; pero, por otro lado, sabemos que en la gran mayoría de colonias y barrios existe una mesa directiva organizada por los vecinos en cada caso y el Barrio de Analco no es la excepción y mejor aún, existen todavía, algunos grupos ocupados de hacer faenas en beneficio de su calle, sus fachadas o incluso particularmente para beneficio de la vecindad.

Como parte importante de este estudio, es menester conocer los cambios que ha tenido el barrio en diferentes vertientes, ya sean de uso de suelo, su aspecto físico, el comercio y la afluencia de turismo o en su caso la disminución de la población y hasta el valor patrimonial del barrio. Para todos ellos, la percepción que tiene la población de los cambios, es que han sido benéficos, lo cual nos conduce a pensar que, si los cambios en el uso habitacional son buenos, es porque a pesar de la disminución de la población original del barrio, también ha habido permanencia del uso habitacional y por consecuencia el aspecto físico de las viviendas se ha conservado en buen estado, es decir, sin pasar al abandono y en consecuencia a su detrimento. Esto lo podemos corroborar, cruzando información con las estadísticas oficiales, que nos muestran que, en el barrio, existe una ocupación de viviendas del 77\%, y solo 233 viviendas de 994 que se ubican en el área de estudio se encuentran desocupadas.

Estos acontecimientos reflejan nuevas inquietudes del turismo por la cultura como elemento prometedor del desarrollo de las economías en la mayoría de los destinos turísticos que debe ser considerado en la elaboración de las políticas para su protección. En este sentido podemos concluir reiterando que actualmente la interacción de la actividad turística en la ciudad de Puebla se da a partir del aprovechamiento del patrimonio cultural como recurso económico. Por lo tanto, se consideran algunas de los principales impactos del desarrollo turístico cultural que bien pueden generar por una parte la degradación del patrimonio, pero por otra, contribuyen inversión en la recuperación de algunos elementos culturales para su inclusión como parte del catálogo de atractivos de las ciudades históricas. 


\section{CAPITULO VII. CONCLUSIONES: TRANSFORMACION DEL BARRIO DE ANALCO}




\section{CONCLUSIONES - TRANSFORMACION DEL BARRIO DE ANALCO}

Como ya hemos mencionado, en el año de 1987, la ciudad de Puebla recibió el nombramiento como Patrimonio Cultural de la Humanidad, situación que ha beneficiado no solo al turismo que en ella se desarrolla, sino también ha potenciado la economía de la ciudad repercutiendo tanto a nivel regional como nacional. Por su parte el turismo cultural, en los últimos años se ha constituido como una de las más importantes actividades turísticas para la sociedad y por sus características permite su análisis desde distintos enfoques.

Por otro lado, en cumplimiento de los objetivos planteados para este estudio, han quedado establecidos en el capítulo primero, una serie de conocimientos en cuanto al origen y evolución de nuevos conceptos en torno al patrimonio histórico-cultural y su utilización como recurso turístico. De esta manera, existe una estrecha relación entre el patrimonio, turismo, cultura. medio ambiente y vulnerabilidad, que ha sido abordado con mayor conocimiento derivado de aquellas situaciones que resultan en la interacción de la actividad turística en el desarrollo y planeación de la ciudad de Puebla. En este sentido, se han promovido propuestas de intervención para solucionar las problemáticas detectadas, así como contribuir a la salvaguarda del patrimonio material e inmaterial y su utilización dentro de las políticas actuales de gobierno como recurso turístico.

Cabe mencionar que la vulnerabilidad es un concepto que se vuelve relativo en el sentido de que se mide de acuerdo al contexto de un espacio determinado, en donde sin duda habrá cifras oficiales e instrumentos que nos ayuden a medirla, siendo estos elementos que dan paso al análisis sociológico aun con las dificultades que pudiéramos encontrar para un análisis detallado en espacios inferiores al nivel municipal.

Por lo tanto, con base a este segmento teórico conceptual y al apoyo de las comparativas con los casos análogos en ciudades de México y España, se han podido identificar tanto, problemáticas comunes como actuaciones estratégicas que bien podrían ser aplicables al centro histórico de la ciudad de Puebla. En consecuencia, se considera reorientar el aprovechamiento de los recursos turísticos culturales con la finalidad de adquirir un 
sustento para el desarrollo de la economía local tanto de la ciudad como del país, que se complementa con la planeación estratégica de una óptima gestión, promoción y comercialización de los productos turísticos en el mercado nacional e internacional sin poner en riesgo su identidad.

Cabe destacar que entre las consecuencias e impacto que trae consigo el Turismo Cultural, destaca la valoración económica del patrimonio como recurso potencial apoyado en los elementos arquitectónicos-urbanísticos y medioambientales con que cuenta la ciudad. En este sentido, en los instrumentos de planificación para su conservación, protección y salvaguarda, se deberán concretar las estrategias y líneas de acción en el rescate de inmuebles para uso habitacional, regulando los equipamientos donde se asignan nuevas funciones (hoteles, cultura, museos, centros de negocios y comerciales, etc.). Por lo que a través de estas iniciativas se llevaría a cabo la recuperación de importantes sitios históricos que contengan elementos arquitectónicos, históricos y urbanos, y que, además, contribuyan a la economía local, regional y nacional.

\section{Impacto Sociocultural}

Sin duda, turismo y cultura, son conceptos que, como describen (HIRIART PARDO \& ALVARADO SIZZO, 2013) se relacionan de "manera simbiótica", pudiendo comprobar, que, sin duda, son complementarios, y que "funcionan bajo lógicas y necesidades distintas". De este modo, podemos concluir que el turismo, es la vía a través de la cual podremos explotar de manera planificada y organizada el patrimonio cultural, siendo este un proceso que deberá ser sustentable en torno a su propia conservación. De este modo, el turismo cultural es de mayor importancia para el turista ya que, culturalmente tiene un gran valor ya que define la identidad de cada sitio y comunidad, y de ser solo paseo común, pasa a ser un "viaje que nos podría colmar de conocimiento, comprensión y disfrute de otras sociedades o grupos sociales a través de sus elementos distintivos, materiales, espirituales, intelectuales y afectivos".

En el contexto anterior, el turismo se implica como un "fenómeno socioeconómico" que, relacionado con el patrimonio cultural, es considerado como recurso histórico 
“identitarios culturalmente de cualquier territorio o región” (HIRIART PARDO \& ALVARADO SIZZO, 2013). El turismo ha sido objeto de análisis durante las últimas décadas desde el enfoque de las instancias públicas y privadas a partir de la preocupación por los daños que este pudiera causar al patrimonio histórico, por ello, se han elaborado estrategias que están en constante actualización con el objetivo de fomentar un turismo responsable y sustentable, por un lado, y por el otro, mitigando cualquier repercusión negativa, fundado en la conservación sostenible del patrimonio cultural y natural.

Tradicionalmente, los gobernantes, han considerado benéfico el impacto del turismo en la economía; por el contrario, los impactos socioculturales consideran que tienden a ser negativos. El turismo debe ser una experiencia positiva en las ciudades donde las políticas fomentan la preservación histórica y cultural de su comunidad y promueven la interacción e interés entre visitantes y residentes, además de potenciar su atractivo turístico. En esta forma los gobiernos, contribuyen a la conservación, preservación y difusión de las costumbres locales, teniendo como resultado un "intercambio cultural con los residentes de la región” (SANCHO, 1998, pág. 37).

En este sentido es importante conocer la evolución de las políticas de protección y conservación del patrimonio cultural en México a lo largo del siglo XX, que han ido avanzando paralelamente a las del ámbito internacional. Por tanto, Puebla al formar parte de la OCPM le ha permitido consolidar algunos proyectos de gran impacto como los que se ya han comentado en este documento. Sin embargo, es necesario que las instancias de gobierno realicen una revisión y actualización de las leyes, normas y reglamentos que rigen tanto el desarrollo turístico sustentable y resiliente, como la planeación, protección y conservación del patrimonio histórico-cultural, para evitar un estado obsoleto que no atienda las necesidades y problemáticas actuales.

Por otra parte, en los estudios realizados por la Secretaría de Turismo del Estado de Puebla y el INEGI, hemos visto el comportamiento de la actividad turística respecto a la oferta y la demanda existente en la ciudad de Puebla, observando su incremento debido al aprovechamiento de los atractivos turísticos principalmente culturales. No obstante, para el beneficio del patrimonio y de los recursos turístico-culturales, es necesaria la elaboración de estudios específicos como el Plan para la Recuperación de la Zona de Monumentos del 
Centro Histórico de la Ciudad de Puebla realizado en el año 2000, que contengan nuevas propuestas de atracción, conservación, recuperación y rehabilitación, principalmente enfocadas al desarrollo de los recursos turísticos que integren actividades culturales y artísticas con el propósito de lograr una mayor captación de visitantes al tiempo y promover este patrimonio donde sea participe la población residente.

Es indiscutible la capacidad que posee el patrimonio cultural como uno de los principales recursos y factor de desarrollo económico, especialmente en la ciudad y centro histórico de Puebla, pero sin duda, lo es aún más cuando es concebido por el valor e identidad que proporcionan sus habitantes. En este sentido, y coincidiendo con las acciones de protección y para asegurar su correcta utilización, es necesario continuar con la puesta en marcha de políticas de protección, conservación y rehabilitación del patrimonio históricocultural. Para ello, es necesario hacer un balance de las acciones que se han realizado y las que se han quedado en el intento, con el fin de que los instrumentos de planificación aborden problemáticas concretas. Por otra parte, es imprescindible que los instrumentos de planificación se consideren las políticas de desarrollo que se establecen entre los diversos documentos, nacionales e internacionales (convención de 1972, ICOMOS, etc.) y las propuestas y estrategias que deriven de grupos como la OCPM o la Asociación Nacional de Ciudades Mexicanas del Patrimonio Mundial.

Por lo tanto, al momento de plantearnos los problemas que afectan la relación entre la conservación del patrimonio cultural y el desarrollo del turismo en la zona de monumentos de la ciudad de Puebla, se observan las principales dificultades que impiden el óptimo desarrollo de la actividad. Sin embargo, con la revisión de los instrumentos de planeación, pudimos darnos cuenta de la importancia que atribuyen las distintas administraciones de gobierno a los elementos que conforman la infraestructura y equipamiento destinados al turismo. No obstante, por la complejidad económica y social que presentan suelen ser inviables y deficientes para la población residente, aunado a problemáticas como la gradual motorización y excesivo transporte urbano, saturación de actividades comerciales y contaminación auditiva, visual y medioambiental que deteriora los inmuebles.

En este sentido, sería conveniente hacer una revisión a fondo de los programas realizados concretamente para la rehabilitación del centro histórico con el fin de llevar a cabo 
propuestas estratégicas más apegadas a una realidad económica y social determinada, que provoque una mayor incidencia tanto en los visitantes como en la población local favoreciendo su desarrollo económico.

Finalmente, el proceso y desarrollo de este trabajo toma en cuenta las consideraciones pertinentes respecto a las estrategias y acciones para la protección y conservación del patrimonio histórico, así como para los factores que se vinculan con el turismo cultural que marca una tendencia que han de regir el desarrollo de las actividades turístico-culturales en las ciudades históricas tanto españolas, como mexicanas y en general de cualquier parte del mundo. Dentro de las limitantes en la elaboración de este documento, destaca la falta de datos recientes y acceso a la información que es escasa.

Considerando que el objetivo de esta investigación consiste en determinar las causas y factores que propician la transformación y permanencia del patrimonio cultural en el barrio de Analco durante el siglo XXI, evidenciando como el cambio del uso del suelo se vincula con la transformación de inmuebles, lo cual no ha permitido identificar su impacto de naturaleza social, cultural, económica y urbana que lo conducen hacia un proceso de gentrificación. Además, de analizar como las políticas hasta este momento, han actuado ante la disyuntiva por transformar o preservar el patrimonio cultural para las generaciones futuras.

Por lo tanto, otro de los resultados corresponde al análisis del impacto del turismo en el patrimonio cultural del centro histórico de Puebla derivado de una amplia oferta turística, además, de evidenciar los problemas derivados de algunos factores como el cambio del uso de suelo que actualmente favorece a la gentrificación como un fenómeno de mejoramiento y transformación urbana cuyo impacto social recae directamente en los residentes originarios de los barrios. Esta situación se visibiliza ante la ausencia de políticas orientadas hacia un proyecto de ciudad donde la participación ciudadana sea clave para fortalecer estrategias urbanísticas, sociales, culturales y económicas que impulsen un mejoramiento equilibrado y sustentable.

No obstante, actualmente estas políticas de carácter económico y enfocadas al turismo aceleran el despoblamiento de los barrios poniendo en riesgo su identidad. Por tal motivo esta investigación aporta algunas recomendaciones orientadas hacia la búsqueda de una 
relación armónica entre el turismo y el patrimonio cultural para lo cual es necesario poner en práctica políticas urbanas, sociales y económicas para la conservación del patrimonio arquitectónico histórico-cultural, que controlen el acelerado proceso de gentrificación asegurando la protección del valor cultural e identidad de sus barrios, los cuales actualmente solo resultan atractivos para dichas políticas de desarrollo turístico y económico de esta ciudad.

\section{El turismo cultural como recurso económico}

Ante la necesidad de definir los términos de turismo, cultura y su combinación, se han detectado debilidades y fortalezas, que permiten configurar una categoría de turismo cultural, traducida en una herramienta de competitividad y crecimiento económico, y con gran potencial de generación de empleo en las ciudades históricas. Por otra parte, el turismo comprende actualmente una necesidad para la economía de las ciudades, pero también es un factor de riesgo para preservar el patrimonio cultural. Así, "en la décimo tercera reunión de Organización Mundial del Turismo (2001), se acordó el código ético para el turismo, en el artículo 4 determina al turismo como factor de aprovechamiento y enriquecimiento del patrimonio cultural de la humanidad; los recursos turísticos que pertenecen al patrimonio común de la humanidad; y los derechos y obligaciones particulares de las comunidades en su territorio (Moreira, 2017).

Es importante señalar que el turismo es una actividad muy importante dentro de la economía de la ciudad de Puebla, y estas actividades están ligadas con los recursos naturales y culturales que existen en la ciudad. La preocupación surge en cuestionar de qué forma contribuye a preservar el patrimonio, ya que el gobierno en turno capitaliza todos los recursos, “entre más valor económico represente un recurso cultural, mayor va a ser su posicionamiento en el sector turístico" (García Moreira, 2017, pág. 13). Sin embargo, muchas veces el turismo mal orientado provoca un perjuicio ocasionando la desvalorización de los recursos.

Hemos analizado de qué forma afectan o benefician las actuales políticas de turismo cultural a la transformación del patrimonio cultural y paisaje urbano del barrio de Analco y 
con ello, la problemática en torno a la mala orientación del turismo en el barrio de Analco; observamos cómo va cambiando en la medida que su patrimonio es considerado como recurso económico y sus residentes solo son atendidos de manera superficial, mientras que el aumento de la especulación inmobiliaria incrementa los costos de vida de la zona a causa de los equipamientos costosos, infraestructura y servicios dirigidos a usuarios de alto poder adquisitivo. Sin duda, será importante concientizar a las autoridades sobre la necesidad de promover estrategias que beneficien a la población originaria, así como revalorizar sitios y zonas de interés cultural por encima de otros actores, además, será importante difundir entre los habitantes sobre su riqueza patrimonial para fortalecer sus valores tradicionales e identidad cultural.

Por lo anterior, se considera necesario promover y mantener los vínculos necesarios entre las comunidades e instituciones preocupadas por la preservación y conservación del patrimonio cultural; mejorar las estrategias de planeación turística y de conservación de los bienes culturales con el fin de proteger su autenticidad y además aprovechar los efectos positivos del turismo cultural. De igual forma, promover la participación conjunta de los sectores sociales, culturales, económicos y políticos vinculados con la comunidad con el propósito de promover un desarrollo que satisfaga a todos los sectores involucrados.

Con pesar, hemos visto como las estrategias de revitalización están enfocadas a resolver las problemáticas relacionadas con las actividades comerciales y de servicios que generan contaminación visual y medioambiental, y que deteriora los inmuebles históricos de la ciudad. Por lo anterior, consideramos importante el trabajo a través de un sistema integrado de las instancias de gobierno ocupadas del turismo y el patrimonio cultural conjuntamente con la participación social. Por ello, es necesario trabajar equitativamente para la conservación de los espacios públicos comunes, la economía local y la vivienda, entre otros aspectos de la vida. También es importante continuar la investigación y planificación, así como el diálogo estrecho y constante entre las autoridades locales, la industria del turismo, sociedad civil y residentes locales.

El turismo como hemos podido comprobar, puede ser una herramienta de desarrollo local y el medio para la difusión del patrimonio, sin embargo, será importante regular y orientar los procesos para disminuir las problemáticas antes mencionadas. Para este proceso, 
será importante integrar a 4 principales actores, iniciando con su comunidad, entre la que se deberá tener presente la conservación y valor de su patrimonio, tradiciones y oficios por encima de cualquier otro interés económico; el segundo actor, es el gestor cultural como operador, en comunidades pequeñas, sería recomendable que fuera alguien de la misma población, comprometido a vigilar que toda la actividad se desarrolle sin poner en riesgo su patrimonio. El tercer actor son las instancias de gobierno, cuyas atribuciones impliquen acciones en el centro histórico y zona de monumentos. El cuarto actor es el visitante y turista cultural, debiendo tener el interés real de conocer el sitio, bajo la conciencia de conservación y respeto para con la comunidad que lo recibe.

En lo que respecta al estudio de la morfología urbana consideramos que sería imposible tener un diagnóstico real de las afectaciones en las ciudades históricas a causa del uso turístico, puesto que cada una de ellas se ha desarrollado en contextos urbanísticos, sociales y económicos diferentes. Por lo tanto, entre los impactos destaca, la alteración de la morfología de la ciudad y traza urbana como uno de los elementos urbanísticos más representativos, así como de los inmuebles. En este sentido, otras afectaciones que podemos observar, corresponden a la excesiva circulación motorizada, que además provoca problemas de estacionamiento y aglomeración vial en horas punta, que ya es en sí mismo un problema que padece la ciudad de Puebla al que se anexa la saturación de las actividades turísticas que ahí se desarrollan. También se debe destacar la invasión que ejercen las actividades económicas formales e informales en calles, plazas y espacios públicos en general, que agudizan el problema en aquellas vialidades que forman parte de las rutas y circuitos turísticos, aumentando la contaminación visual y auditiva que impiden el desplazamiento de peatones, ocultando las cualidades históricas y culturales de los inmuebles y espacios públicos de la ciudad.

En el contexto de la ciudad global, a primera vista pareciera que la conservación, restauración y preservación del patrimonio edificado es un asunto tratado y resuelto en aquellas convenciones y coloquios organizados con este fin. Sin embargo, existen factores que a veces quedan fuera del control de las administraciones, como suele ser el cambio radical de uso del suelo, la situación jurídica de los inmuebles, el comercio informal, la 
contaminación visual y auditiva e inseguridad, aunado a la degradación de los inmuebles y del patrimonio en general.

Actualmente, las estrategias de conservación del patrimonio en la ciudad están orientada a la restauración de los edificios con el fin de integrarlos a un escenario histórico en la ciudad, asignándoles usos de comercio y servicio referente a hoteles, restaurantes, edificios comerciales o el asignado a la administración pública. Esto se justifica con la intención de crear recursos para su restauración o rehabilitación y de esta forma mantener la identidad y calidad del propio inmueble, ya que el uso habitacional es menos rentable.

En este contexto se origina también la comercialización de la cultura, donde la oferta se realiza a través de su propia exhibición y posibilidades de atracción, lo que explica la transformación de los usos del suelo y la readaptación de edificios que pierden su funcionalidad, aunado al interés artístico que pueda desprender el propio edificio. Por otro lado, el apogeo del turismo cultural se relaciona, según Herrero, (2003) a la aparición de nuevas clases medias distinguidas por su estatus social reflejado en las actividades cotidianas como son las educativas, de ocupación y de consumo de mercancías, mismas en las que de algún modo se mantiene una estrecha relación con el sector cultural. Otra característica y consecuencia a la vez del postmodernismo cultural es la valorización que alcanzan las localidades y las regiones donde se ubican los bienes patrimoniales a través de lo cual se justifica el elevado nivel de desarrollo tanto cultural como económico de los sitos; así, entre los agentes que más aportan al desarrollo del turismo cultural, destacan la recuperación y puesta en valor del legado patrimonial, sin importar donde se ubique este ni a qué cultura pertenezca, al tiempo que genera estabilidad y diversidad a la economía local.

Finalmente, para adentrarnos en el tema de la gentrificación en el caso de Analco podríamos decir que existe una transformación local lenta pero que sin embargo existen flujos continuos qué bien pueden ser de origen económico cultural o social a causa del comercio y el turismo qué se origina en el barrio, por lo que es muy probable que estos flujos suceden únicamente con los visitantes y no con los habitantes del barrio sin embargo esto podría detonar la transformación y reutilización de inmuebles abandonados. Los límites de los espacios van siendo cambiantes y difusos, en consecuencia, en lo urbano ya no pueden contemplarse espacios bien delimitados, más bien los limites se van redefiniendo de manera 
pragmática como lo destaca Susino: "la ciudad llega hasta dónde llega la gente que la vive" (Duque 2010:22).

\section{Discusión: Cómo incide el turismo cultural en la gentrificación del centro histórico}

Con esta investigación, hemos podido Identificar como el cambio del uso del suelo se vincula con la transformación de inmuebles y su entorno, orientado hacia un proceso de gentrificación, por ello es que, como parte de las conclusiones de este documento, y desde una perspectiva general podemos afirmar que el turismo cultural no afecta de una forma directa, ni premeditada a una ciudad ni su patrimonio, por el contrario, el turista visita cierta ciudad para conocer las características y cultura de su gente, respetando los límites establecidos para no poner en riesgo el patrimonio cultural tangible e intangible de la ciudad. Con asombro, vemos que en realidad es la orientación política local la que, con la idea de innovar y crear espacios comerciales y de servicios turísticos, consciente o inconscientemente atentan contra el uso habitacional e identidad de los habitantes, sin duda incurriendo en un hecho comprobado en donde sigue prevaleciendo la idea de generar más dinero a costa de la mercantilización de la cultura, sin pensar en la preservación de la memoria historia de las ciudades y barrios, debido a que son proyectos turísticos innecesarios ajenos al bien social y que redundan en la especulación y generación de recursos para las autoridades y otros actores responsables de esta atracción turística.

Podemos asegurar que Puebla no necesita una transformación para ser más atractiva al turismo, solo requiere de la correcta puesta en marcha de planes estratégicos colaborativos que consideren los valores históricos y culturales, como recursos inalienables con que cuentan las ciudades históricas, los cuales a medida que pase el tiempo deben ir tomando más importancia por su capacidad de integración y aprovechamiento. Como resultado de la información obtenida en la encuesta, sabemos que no existe una organización entre los habitantes del barrio que tenga como objetivo trabajar para que Analco siga conservando los elementos que lo identifican desde su origen, creemos conveniente establecer dicha organización con el fin de detener el proceso de gentrificación, que conjuntamente con la 
explotación del turismo cultural, muy probablemente se refleje un mayor uso turístico y comercial en vez del habitacional.

Aunado a lo anterior, se suma otro dato importante de esta investigación, respecto al impacto de la creación de infraestructura y equipamientos turísticos que como ya pudimos verificar también se involucra con el proceso de gentrificación mencionado, situación que consideramos conveniente atender y controlara través de los planes y programas de protección al patrimonio cultural, para controlar el desequilibrio en las ciudades históricas que aun cuentan con esta riqueza cultural, pero también para detener la reorganización estructuralmente económica, que deja de lado valores identitarios como el arraigo al legado histórico de una ciudad. Es importante mencionar, que esta "reorganización" es respaldada por los responsables en la toma de decisiones que apoyan las inversiones con intereses especulativos dentro del sector inmobiliario, que justifican las intervenciones a partir de la renovación y conservación de espacios degradados, haciéndolos atractivos para personas con ingresos económicos mayores. El resultado es una revalorización del suelo que incrementa los precios de los alquileres y disminuye el comercio tradicional provocando el desplazamiento de la población originaria de los barrios a otros puntos de la ciudad, irrumpiendo así en un modo de vida, hábitos, tradiciones, costumbres, etc. Estas, son razones de peso para promover estudios como el que nos ocupa, con el fin de demostrar como las políticas que promueven el turismo en Puebla están generando de forma indirecta un proceso de gentrificación, determinando la conveniencia de buscar un equilibrio en las estrategias planteadas en beneficio del patrimonio cultural, trabajándolas mediante una planeación estratégica que genere políticas reorientadas teniendo como base este motor económico hacia ciudades culturales habitadas, más equitativas y sostenibles. 


\section{Bibliografía}

Gobierno Federal. (2015). Datos vectoriales del Directorio Estadístico Nacional de Unidades Económicas. Mexico.

H. Ayuntamiento del Municipio de Puebla. (25 de Julio de 2008). Orden Juridico. Obtenido de Orden Juridico:

http://compilacion.ordenjuridico.gob.mx/obtenerdoc.php?path=/Documentos/ESTADO/PU EBLA/TODOS\%20LOS\%20MUNICIPIOS/o2711198.doc\&nombreclave $=02711198$.doc

Market Data. (12 de Marzo de 2019). Market Data Mexico Inteligencia Comercial. Obtenido de https://www.marketdatamexico.com/es/article/Colonia-Barrio-El-Analco-Puebla-Puebla

2017, I. (Noviembre de 2017). ICOMOS. Obtenido de Icomos.org: https://www.icomos.org/charters/towns_sp.pdf

Alvarez, E. E. (1990). Arquitectura Porfirista.

Arenas, M. C. (2012). Historia, Paisaje y Gestion en Metepec, Puebla. Universidad de Girona, España.

Ávila, G. M. (mayo de 2001). Proyecto de investigación, vivienda y revitalización urbana en el Centro Histórico de la Ciudad de Puebla, México . Puebla, Puebla, Mexico.

Ayuntamiento de Salamanca. (6 de Septiembre de 2019). Ayuntamiento de Salamanca. Obtenido de Ayuntamiento de Salamanca: http://www.aytosalamanca.com/es/tuciudad/historia/

Ayuntamiento Municipal. (2002). El programa de desarrollo regional Angelopolis y el municipio de Puebla, 1993- 2002. Puebla, Mexico: Direccion de Desarrollo Municipal.

BAUMAN, Z. (2003). Comunidad. En buxca de seguridad en un mundo hostil, Siglo XXI. España: Siglo XXI.

Blanco, A. (s.f.). Castilla y León presente y futuro del turismo. 169.

Blanco, A. (s.f.). Conclusiones y perspectivas de futuro. 293-294.

Bolfy, C. (2001). Patrimonio Cultural Nacional: El marco jurídico y conceptual. 86.

Bonilla, J. A. (1996). El desarrollo de la fisonomía urbana del Centro Histórico de la ciudad de Puebla (1531-1994). Puebla: Puebla : Universidad Popular Autónoma del Estado de Puebla, .

Brandis García, D., \& del Río Lafuente, M. I. (1998). La dialéctica turismo y medio ambiente en las ciudades históricas una propuesta interpretativa. Dialnet, 229-240.

Castells, M. (1974). La cuestión urbana. grupo editorial siglo ventiuno.

COHEN, E. (1988). Traditions in the qualitative sociology of tourism. Annals of Tourism Research, 15(1), 29-46.

CONACULTA. (2010). Atlas de infraestructura y patrimonio cultural de México. México. 
CONACULTA. (28 de Agosto de 2019). Guanajuato Rutas Culturales. Obtenido de Guanajuato Rutas Culturales: https://patrimonioculturalyturismo.cultura.gob.mx/guias/guia7_5.php

Congreso de Puebla. (2011). SIC, CULTURA. Obtenido de SIC, CULTURA: https://sic.cultura.gob.mx/documentos/646.pdf

Cruz de los Ángeles, Pérez Paredes, Torralba Flores, Bonilla Gasca. (Agosto de 2017). Dialnet. Obtenido de Dialnet: https://dialnet.unirioja.es/servlet/articulo?codigo=6132923

D. Raymond Lemaire y D. Herb Stovel. (Noviembre de 2018). INAH, 2018. Obtenido de INAH: https://conservacion.inah.gob.mx/normativa/wp-content/uploads/Documento127.pdf

De la Calle Vaquero, M., \& García Hernández, M. (2016). Políticas locales de turismo en ciudades históricas españolas. Génesis, evolución y situación actual. PASOS. Revista de Turismo y Patrimonio Cultural, 259.

EFE. (24 de Mayo de 2019). EFE Edicion España. Obtenido de EFE Edicion España: https://www.efe.com/efe/espana/politica/gentrificados-barrios-invivibles-para-sus-vecinosde-toda-la-vida/10002-3984114

Espinoza, S. G. (01 de agosto de 2005). Centros historicos ¿Herencia del pasado o construcción del presente? Revista Electrónica de Geografía y Ciencia Sociales, IX(194(39)), 2-3.

Flores, M. I., \& Guerra, M. P. (2016). Entre lo local y lo foráneo: Gentrificación y discriminación en San Miguel de Allende, Guanajuato. Revista Legislativa de Estudios Sociales y de Opinión Pública, 185, 187, 204.

Florescano, E. (1980). El poder y la lucha por el poder en la historiografía mexicana. Ciudad de México: Instituto Nacional de antropología e Historia.

García Moreira, D. (2017). EL PATRIMONIO CULTURAL Y SU APORTE ECONOMICO MEDIANTE EL TURISMO. "SISTEMA DEL TURISMO CULTURAL". Ecuador.

Gobierno de Mexico, S. (15 de enero de 2016). Sistema de Información Cultural Mexico. Obtenido de Marco Jurídico Cultural: http://sic.gob.mx/ficha.php?table=marco_juridico\&table_id=768

Gobierno de Puebla. (14 de Febrero de 2014). Transparencia Fiscal. Obtenido de Transparencia Fiscal: http://www.transparenciafiscal.puebla.gob.mx/index.php?option=com_docman\&task=doc_ download\&gid $=4230 \&$ Itemid $=63$

Gobierno de Puebla. (29 de Diciembre de 2017). Puebla.gob. Obtenido de Puebla.gob: https://ojp.puebla.gob.mx/index.php/leyes/item/ley-sobre-proteccion-y-conservacion-depoblaciones-tipicas-y-bellezas-naturales-del-estado-de-puebla

Gobierno del Estado. (29 de Marzo de 1994). Orden Jurídico Poblano. Obtenido de Orden Jurídico Poblano:

http://compilacion.ordenjuridico.gob.mx/obtenerdoc.php?path=/Documentos/ESTADO/PU EBLA/o810495.doc\&nombreclave=o810495.doc

Gobierno del Estado. (2011). Instituto Catastral y Registral del Estado de Puebla. Puebla, Mexico. 
Gobierno del Estado. (Viernes 23 de Octubre de 2015). Programa Parcial de Desarrollo Urbano Sustentable del Centro Histórico del Municipio de Puebla:Puebla, Mexico. Publicado en el periodico oficial del estado de Puebla, pág. N ${ }^{\mathrm{a}} 15$. Quinta sección.

Gobierno del Estado. (2018). Indicadores Básicos de la Actividad Turística en Puebla año 2010 al 2018. Obtenido de www.turismo.puebla.gob.mx

Gobierno del Estado de Puebla. (07 de Junio de 2017). Transparencia Fiscal. Obtenido de Transparencia Fiscal:

http://www.transparenciafiscal.puebla.gob.mx/index.php?option=com_docman\&task=cat_v iew \&gid=463

GOBIERNO DEL ESTADO, D. P. (31 de enero de 2005). Diario Oficial del Estado de Puebla. Puebla, Puebla, México.

Gobierno Federal. (1917). Constitución Política de los Estados Unidos Mexicanos. México: Autor.

Gobierno Federal. (1972). Ley federal sobre monumentos y zonas arqueológicos, artísticos e históricos. México: Autor.

Gobierno Federal, S. d. (12 de Julio de 2019). Diario Oficial de la Federación. Obtenido de Diario Oficial de la Federación:

https://www.dof.gob.mx/nota_detalle.php?codigo=5565599\&fecha=12/07/2019

GOBIERNO, d. E. (2010 - 2016). Indicadores Básicos de la Actividad Turística en Puebla. Obtenido de file:///C:/Users/13-

V001LA/Downloads/Indicadores_Turisticos_Puebla_20161.pdf

GOBIERNO, d. E. (2015). Plan Parcial de Desarrollo Urbano Sustentable del Centro Histórico del Municipio de Puebla. Puebla, México.

GOBIERNO, d. E. (2017 - 2019). Datos Abiertos. Obtenido de Secretaría de Cultura y Turismo: http://datos.puebla.gob.mx/grupo/secretaria-de-cultura-y-turismo

GOBIERNO, M. d. (2014). Puebla Plan Municipal de Desarrollo 2014-2018. Puebla.

Gobierno, s. g. (2013). LEY SOBRE PROTECCIÓN Y CONSERVACIÓN DE POBLACIONES TÍPICAS Y BELLEZAS NATURALES DEL ESTADO DE PUEBLA. Puebla.

González, I., \& Varas Ibañez. (2006). Conservación de bienes culturales. Teoria, Historia, principios y normas. Dialnet, 43-44.

Gutiérrez, J. A. (2013). La vulnerabilidad urbana en España. Identificación y evolución de los barrios vulnerables. En J. A. Gutiérrez, a vulnerabilidad urbana en España. Identificación y evolución de los barrios vulnerables (pág. 76). Madrid.

H. Ayuntamiento del Municipio de Puebla. (15 de Noviembre de 2018). Gobierno Abierto. Obtenido de Gobierno Abierto: https://gobiernoabierto.pueblacapital.gob.mx/mejoraregulatoria/catalogo-municipal-de-regulacion-de-tramites-y-servicios/registro-municipalde-regulaciones/organismos-descentralizados/item/5567-codigo-reglamentario-para-elmunicipio-de-puebla 
Hardoy, J. E., \& R. Dos Santos, M. (1983). impacto de la urbanización en los centros históricos latinoamericanos. Buenos Aires, Aargentina.

Herrero, P. L. (2011). El turismo cultural en España: un sector estrategico. (A. B, Ed.) Papeles de economía española, 16.

HIRIART PARDO, C. A., \& ALVARADO SIZZO, I. (2013). Una reflexión sobre el modelo de turismo cultural en Morelia: escenarios y tendencias para consolidar un turismo cultural sustentable. Revista MEC-EDUPAZ, 39.

ICOMOS. (2005 de January de 2005). Internacional Counsil on Monuments and Sites. Obtenido de http://www.international.icomos.org

IMPLAN. (15 de Octubre de 2018). Puebla Capital. Obtenido de Puebla Capital: http://www.pueblacapital.gob.mx/images/Plan_Municipal_de_Desarrollo_Oficial.pdf

INAH. (2012). Informe de Rendición de Cuentas de la Administración Pública. Mexico. Obtenido de Informe de Rendición de Cuentas de la Administración Pública.

INEGI. (2010). Datos vectoriales del Censo de Poblacion y Vivienda.

jakobradlgruber. (20 de Abril de 2017). 123RF. Obtenido de https://es.123rf.com/profile_jakobradlgruber?page=1\&word=plaza+mayor\&srch_lang=es\& reverse_search_mobile $=\&$ mediapopup $=44635955$

Leicht, D. H. (1986). Las Calles de Puebla. Puebla.

LEZAMA, L. Y. (2008). Las políticas públicas para la conservación del centro histórico de Santiago de Querétaro, Qro. (2004-2006): una visión desde la perspectiva de su conservación integrada. Memorias del 7mo. Congreso Internacional Patrimonio Cultural: Salvaguardia y Gestión. Tema: Gestión y Manejo. La Habana, Cuba (2008) (pág. 13). La Habana, Cuba: Ministerio de Cultura.

Lima, P. G. (2003). Patrimonio Cultural Regional: Estudio Comparativo Sobre la Legislacion Protectora en las 32 Entidades Federativas Mexicanas.

Lombrado, S. (1997). El patrimonio nacional de México. México.

Lopez E. y Ibarra, X. (1996). Diferentes formas de Habitar el espacio urbano en URIAS, M. REVISTA CIUDADES,(31), 29-35.

LUGO, A. R. (5 de Junio de 2019). Linea Directa. Obtenido de https://lineadirectaportal.com/mexico/mexicanos-cambian-la-playa-por-destinos-fuera-delo-comun-revela-airbnb_20190605-729883/

Marchena Gómez, M., \& Repiso Rubio, F. (1999). Turismo Cutural: El Caso de Sevilla. Cuadernos de Turismo, 33-55.

Mauleón, D. (3 de Octubre de 2019). EL DICTAMEN. Obtenido de https://www.eldictamen.mx/yucatan/descubre-la-magia-de-estos-tres-barrios-en-yucatan/

Medina, J. M. (1754). Google Arts \& Culture. Obtenido de https://artsandculture.google.com/asset/plano-de-la-ciudad-de-puebla-1754-josephmarianus-a-medina-joseph-marianus-a-medina/jgErGcfcyaisAA 
Mexicanos, E. C. (2015). LEY ORGÁNICA DEL INSTITUTO NACIONAL DE ANTROPOLOGÍA E HISTORIA. México.

Morales, M. (2 de Febrero de 2017). RIZOMARTE. Obtenido de RIZOMARTE: https://www.rizomarte.org/post/salamanca-cinco-siglos-de-historia-xii-xvii

Moreira, D. G. (2017). EL PATRIMONIO CULTURAL Y SU APORTE ECONOMICO MEDIANTE EL TURISMO. "SISTEMA DEL TURISMO CULTURAL".

Munguía, C. A., \& Sánchez, E. C. (s.f.). Desarrollo urbano de Valladolid-Morelia, 1541-2001. Morelia, Mich. : Universidad Michoacana de San Nicolás de Hidalgo, 2001.

Niglio, O., Cervantes, L. A., \& Sánchez Cruz, P. A. (2015). Mexico, Restauracion y Proteccion del Patrimonio Cultural. España: Aracne Editrice.

Puebla, G. d. (2018). Pan Estatal de Desarrollo 2017-2018. Puebla.

Ramírez Rosete, N. L., Reyes Granados, J. A., \& Calderón Calderón, B. (2020). El turismo y su impacto en el patrimonio cultural del centro histórico de Puebla. Antrópica. Revista de Ciencias Sociales y Humanidades., 129-154.

Ramírez, R. N. (2014). Rehabilitación Urbana Sostenible. Estrategias de integración para los barrios del Centro Histórico de la Ciudad de Puebla. Puebla: Fomento Editorial, BUAP.

REYES, G. J. (2020). Transformación y permanencia del patrimonio cultural urbano en el siglo XXI: Barrio de Analco Puebla-México (tesis de pregrado). Valladolid, España: Universidad de Valladolid.

S/F. (1972). Grupo Español de Conservacion, Intrnacional Institute for Conservation of Historic and Artistic Works. Obtenido de https://geiic.com/files/Cartasydocumentos/Carta_del_restauro.pdf

Saiko3p. (10 de abril de 2018). depositphotos. Obtenido de https://sp.depositphotos.com/portfolio1002280-st200.html

Sánchez, A. H. (2000). La vivienda en los barrios tradicionales de Puebla ( el alto, Analco, La Luz y Xanenetla). Ciudad de México.

SANCHO, A. (1998). Introduccion al Turismo. Madrid.

Senabre, D. (1 de Agosto de 2003). Scripta Nova. Obtenido de http://www.ub.edu/geocrit/sn/sn146(139).htm

ToSeeMexico. (3 de Septiembre de 2019). toseemexico.com. Obtenido de toseemexico.com: https://www.toseemexico.com/cc-san-miguel-allende.htm

Troitiño Vinuesa, M. Á. (1996). El patrimonio cultural como recurso estrategico de la ciudad de Cuenca. 115-130.

Turismo, S. d. (2015). Perfil y Grado de Satisfacción del Visitante. Obtenido de PERFIL SOCIODEMOGRÁFICO: culturayturismo.puebla.gob.mx 
UNESCO. (1972). Convención sobre la protección del patrimonio mundial, cultural y natural. La conferencia General de la Organización de las Naciones Unidas para la educación. la ciencia y la cultura, (págs. 1-16). Paris.

UNESCO. (Octubre de 2016). Agenda 21. Obtenido de Agenda 21: http://uploads.habitat3.org/hb3/file_93zxcQC02Q.pdf

Unión Guanajuato. (2 de Octubre de 2017). UNIÓN. Obtenido de UN1ÓN:

http://www.unionguanajuato.mx/articulo/2017/10/02/cultura/san-miguel-de-allendehistoria-de-su-fundacion

UNIÓN, C. D. (2019). LEY GENERAL DE ASENTAMIENTOS HUMANOS, ORDENAMIENTO TERRITORIAL Y DESARROLLO URBANO. México. 


\section{Índice de Figuras}

FIgURA 1 UbicACIÓN DE LA CIUDAD DE PUEBLA, ELABORACIÓN PROPIA CON BASE A DATOS (INEGI, 2010) .........................13

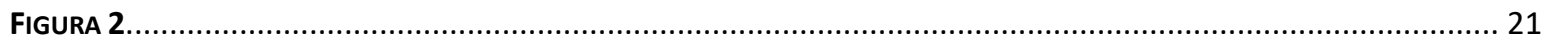

Figura 3 Delimitación de la Zona de Monumentos, DeCreto del año 1977. Fuente: Plano tomado del (GobieRno

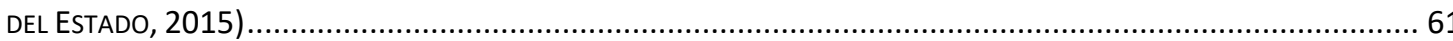

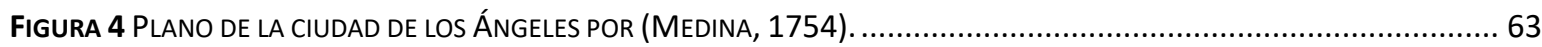

FIgURA 5 DESCRIPCIÓN ESQUEMÁTICA DE LA VIVIENDA EN BARRIOS TRADICIONALES, IMAGEN TOMADA DE. (SÁNCHEZ, 2000) . 66

FIgURA 6. CAMBIO DE USO DE SUELO A SERVICIO TURÍSTICO, AVENIDA 3 ORIENTE ENTRE 14 Y 16 SUR, BARRIO DE ANALCO....... 68

FIgURA 7. CAMBIO DE USO DE SUELO A EQUIPAMIENTO EDUCACIÓN SUPERIOR, FACULTAD DE PSICOLOGÍA DE LA BUAP, AVENIDA 3

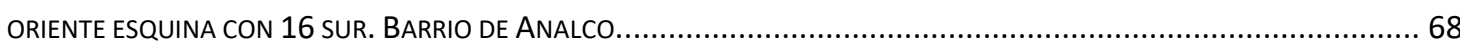

FIgURA 8. CAMBIO DE USO DE SUELO A COMERCIAL, AVENIDA 3 ORIENTE ESQUINA CON 12 SUR, BARRIO DE ANALCO.............. 69

Figura 9. CAMBIO de uSO de SUELO A SERVICIO TURÍstico (HOTEL), AVENIDA 14 ORIENTE ESQUINA CON 10 NORTE, BARRIO DEL ALTO.

Figura 10. Proyecto "Ciudad Mural", rescate del patrimonio, barrio de Xanenetla. Calle 4 norte esquina con 30 ORIENTE.

FIGURA 11. CATEGORÍAS DE INTEGRIDAD Y CALIDAD CONSTRUCTIVA, PLANO TOMADO DE (GOBIERNO DEL ESTADO, 2015)...... 94

Figura 12. Polígonos de ACTUACIÓN, PLANO TOMAdO DE (GOBIERNO DEL ESTADO, 2015). .....................................96

Figura 13. PROGRAMA DEL PASEO DEL Río, CONSISTENTE EN CREAR Un COMPLEJO TURÍSTICO, CULTURAL Y COMERCIAL SOBRE LOS barrios antiguos del oriente de la Ciudad de Puebla. Retomado de (Ávila, 2001). 100

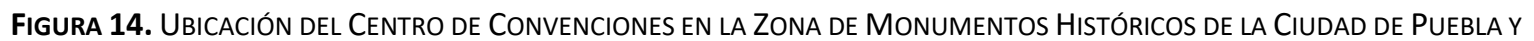
Su CERCANía Con el Palacio Municipal, el Zócalo y la Catedral de Puebla, elaboración PRopia. 101

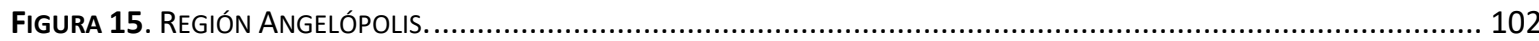

Figura 16. Afluencia de DerRama Económica CD. De Puebla del 2010 al 2019. Fuente: Elaboración propia en base A LOS INDICADORES BÁSICOS DE LA ACTIVIDAD TURÍSTICA EN PUEBLA (GOBIERNO D. E., INDICADORES BÁSICOS DE LA ACTIVIDAD TURÍSTICA EN PUEBLA, 2010 - 2016).

FIGURA 17. BARRIOS HISTÓRICOS Y ACTIVIDAD TURÍSTICA DE LA ZONA DE MONUMENTOS. FUENTE: ELABORACIÓN PROPIA A PARTIR del Programa Parcial de Desarrollo Urbano Sustentable del Centro histórico Municipio de Puebla, 2015.

Figura 18. Afluencia de Visitantes en la CIUdAd de Puebla del 2010 al 2019. Fuente: Elaboración propia EN BASE A

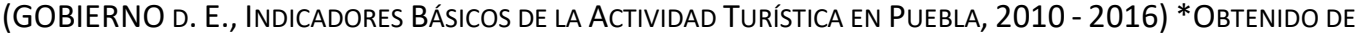
(GOBIERNO D. E., DATOS ABIERTOS, 2017 - 2019)

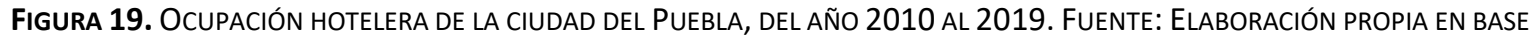
A (GOBIERNO D. E., INDICADORES BÁSICOS DE LA ACTIVIDAD TURÍ́STICA EN PUEBLA, 2010 - 2016). *DATOS 2017 Y 2018 OBTENIDOS DE (GOBIERNO D. E., DATOS ABIERT....

Figura 20. Equipamiento en la Zona de MONumentos de la CD. DE Puebla. Elaboración propia en base a (GOBIERNO D. E., Plan Parcial de Desarrollo Urbano Sustentable del Centro histórico del Municipio de Puebla, 2015)

FIGURA 21. EL TURISMO Y SU RELACIÓN CON EL PATRIMONIO HISTÓRICO-CULTURAL Y LOS VALORES CULTURALES Y MEDIOAMBIENTALES. FUENTE: ELABORACIÓN PROPIA A PARTIR DE BRANDIS, D. Y Río, I. (1998)

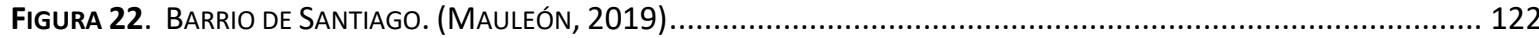

Figura 23. SAn Miguel de AlLende. Foto tomadA DE (LUGO, 2019)....................................................... 124

Figura 24. Catedral de Salamanca, foto de (SAiko3p, 2018). Plaza Mayor, foto de (Jakobradlgruber, 2017).... 126 
Figura 25. Delimitación del CENTRO históRICO DE LA CIUDAD DE PUEBLA REALIZADA A PARTIR DE LA INFORMACION DEL

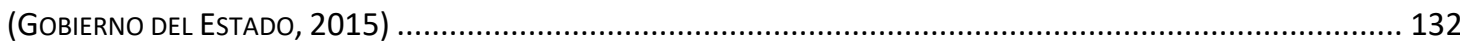

Figura 26. Plano de DELIMITACION DEL BARRIO de ANALCO, ElABORACIÓN PROPIA EN BASE A (INEGI, 2010)................ 133

Figura 27. PLANO dE UBICACIÓN DE LA ZONA DE ESTUdIO EN LA CARTA URBANA VIGENTE. FUENTE: ANEXOS CARTOGRÁFICOS DE (GOBierno d. E., Plan Parcial de Desarrollo Urbano Sustentable del Centro histórico del Municipio de PUEBLA, 2015)

iERROR! MARCADOR NO DEFINIDO.

Figura 28. Plano de uso de suelo. Fuente: anexos cartográficos de (GOBIERNO d. E., Plan Parcial de DesarRollo

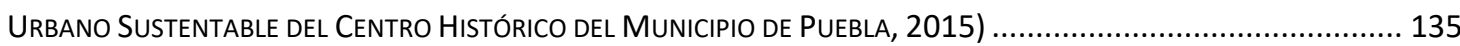

Figura 29. USO DEL SUELO DEL BARRIO DEL AÑo 2015, ELABORACIÓN PROPIA EN BASE A DATOS DE (GOBIERNO DEL ESTADO, 2015) 136

FIgURA 30. USO DE SUELO DEL BARRIO DE ANALCO DEL AÑo 2019, ELABORACIÓN PROPIA EN BASE A DATOS OBTENIDOS EN CAMPO

Figura 31. PLANO UNIDADES ECONÓMICAS DEL BARRIO DE ANALCO, ELABORACIÓN PROPIA EN BASE A DATOS VECTORIALES DE ( GOBIERNO FEDERAL, 2015)

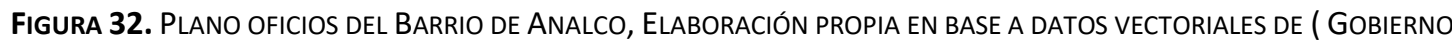
FEDERAL, 2015) 139

FIgURA 33. DISTRIBUCIÓN DEL ESPACIO DEL BARRIO DE ANALCO, ELABORACIÓN PROPIA EN BASE A DATOS OBTENIDOS DE

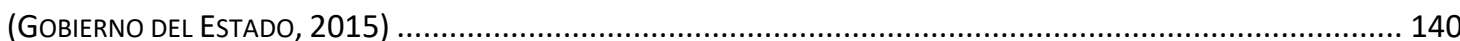

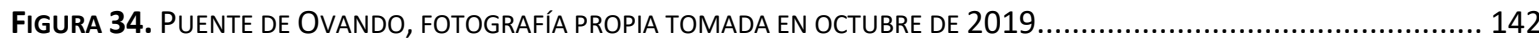

Figura 35. Plano de dEgRAdACIÓN POR ZONAS, EXTRAído dE LOS ANEXOS CARTOGRÁFICOS DE (GobIERNO DEL ESTADO, 2015)

FigURA 36. ESTADO DE CONSTRUCCIÓN DE LOS INMUEBLES DEL BARRIO DE ANALCO. ELABORACIÓN PROPIA EN BASE A DATOS OBTENIDOS EN CAMPO EN 2017

FiguRA 37. PLANO DE ESTAdO DE OCUPACIÓN DE LOS INMUEBLES DEL BARRIO DE ANALCO, ELABORACIÓN PROPIA EN BASE A INFORMACIÓN RECABADA EN CAMPO DE JULIO DEL AÑO 2019 Y ( GOBIERNO FEDERAL, 2015) 145

FIGURA 38 DISTRIBUCIÓN POR PORCENTAJES DE LOS ESPACIOS DE PÚBLICOS DE LA ZONA DE MONUMENTOS, ELABORACIÓN PROPIA CON BASE A INFORMACIÓN EXTRAÍDA DE (GOBIERNO DEL ESTADO, 2015). 145

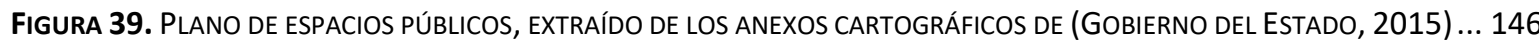

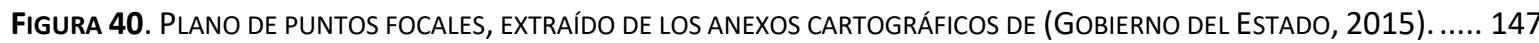

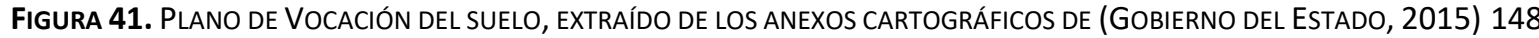

Figura 42. Plano de EQUiPAMIENTO de LA ZONA de MONUMENTOS, EXTRAídO dE LOS ANEXOS CARTOGRÁFICOS DE (GOBIERNO DEL ESTADO, 2015)

149

Figura 43. EQUiPAMIENTO dEL BARRIO DE ANALCO, ELABORACIÓN PROPIA EN BASE A DATOS RECABAdOS EN CAMPO, 2019. 150

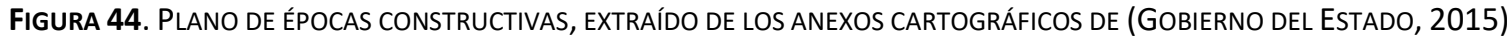
151

FIgURA 45. FICHA DE CATEGORIZACIÓN ARQUITECTÓNICA N. 020, ELABORACIÓN PROPIA EN BASE A DATOS OBTENIDOS DE (GoOGLE INEGI, 2018), (GobIERNO DEL ESTADO, 2015) Y (GOBIERNO DEL ESTADO, 2011). 152

FIGURA 46. FICHA DE CATEGORIZACIÓN ARQUITECTÓNICA N. 021, ELABORACIÓN PROPIA EN BASE A DATOS OBTENIDOS DE (GOOGLE INEGI, 2018), (GOBIERNO DEL ESTADO, 2015) Y (GOBIERNO DEL ESTADO, 2011). 153

FIGURA 47. FICHA DE CATEGORIZACIÓN ARQUITECTÓNICA N. 022, ELABORACIÓN PROPIA EN BASE A DATOS OBTENIDOS DE (GoOGLE INEGI, 2018), (GoBIERNO DEL ESTADO, 2015) Y (GOBIERNO DEL ESTADO, 2011) 154

FIGURA 48. FICHA DE CATEGORIZACIÓN ARQUITECTÓNICA N. 035, ELABORACIÓN PROPIA EN BASE A DATOS OBTENIDOS DE (GoOGLE INEGI, 2018), (GobIERNO DEL ESTADO, 2015) Y (GoBIERNO DEL ESTADO, 2011).

FIGURA 49.. FICHA DE CATEGORIZACIÓN ARQUITECTÓNICA N. 043, ELABORACIÓN PROPIA EN BASE A DATOS OBTENIDOS DE (GoOGLE INEGI, 2018), (GoBIERNO DEL ESTADO, 2015) Y (GOBIERNO DEL ESTADO, 2011) 156

FIgURA 50. FICHA DE CATEGORIZACIÓN ARQUITECTÓNICA N. 054, ELABORACIÓN PROPIA EN BASE A DATOS OBTENIDOS DE (GoOGLE INEGI, 2018), (GobIERNO DEL ESTADO, 2015) Y (GoBIERNO DEL ESTADO, 2011). 157

FigURA 51. FICHA DE CATEGORIZACIÓN ARQUITECTÓNICA N. 072, ELABORACIÓN PROPIA EN BASE A DATOS OBTENIDOS DE (GoOGLE INEGI, 2018), (GobIERNO DEL ESTADO, 2015) y (GoBIERNO DEL ESTADO, 2011) 
FIGURA 52. FICHA DE CATEGORIZACIÓN ARQUITECTÓNICA N. 005, ELABORACIÓN PROPIA EN BASE A DATOS OBTENIDOS DE (GoOGLE INEGI, 2018), (GobIERNO DEL ESTADO, 2015) Y (GoBIERNO DEL ESTADO, 2011).

FIGURA 53. FICHA DE CATEGORIZACIÓN ARQUITECTÓNICA N. 079, ELABORACIÓN PROPIA EN BASE A DATOS OBTENIDOS DE (GoOGLE INEGI, 2018), (GobIERNO DEL ESTADO, 2015) Y (GoBIERNO DEL ESTADO, 2011). 160

FigURA 54. FICHA DE CATEGORIZACIÓN ARQUITECTÓNICA N. 010 ELABORACIÓN PROPIA EN BASE A DATOS OBTENIDOS DE (GOOGLE INEGI, 2018), (GoBIERNO DEL ESTADO, 2015) Y (GoBIERNO DEL ESTADO, 2011). 161

FIGURA 55 FICHA DE CATEGORIZACIÓN ARQUITECTÓNICA N. 019 ELABORACIÓN PROPIA EN BASE A DATOS OBTENIDOS DE (GOOGLE

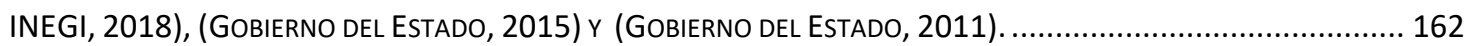

FIGURA 56 FICHA DE CATEGORIZACIÓN ARQUITECTÓNICA N. 085 ELABORACIÓN PROPIA EN BASE A DATOS OBTENIDOS DE (GOOGLE INEGI, 2018), (GOBIERNO DEL ESTADO, 2015) Y (GOBIERNO DEL ESTADO, 2011)......................................... 162

FIGURA 57 FICHA DE CATEGORIZACIÓN ARQUITECTÓNICA N. 084 ELABORACIÓN PROPIA EN BASE A DATOS OBTENIDOS DE (GOOGLE INEGI, 2018), (GOBIERNO DEL ESTADO, 2015) Y (GOBIERNO DEL ESTADO, 2011) ........................................ 163

FIGURA 58 FICHA DE CATEGORIZACIÓN ARQUITECTÓNICA N. 019 ELABORACIÓN PROPIA EN BASE A DATOS OBTENIDOS DE (GOOGLE INEGI, 2018), (GOBIERNO DEL ESTADO, 2015) Y (GoBIERNO DEL ESTADO, 2011). 164

FIGURA 59 FICHA DE CATEGORIZACIÓN ARQUITECTÓNICA N. 008 ELABORACIÓN PROPIA EN BASE A DATOS OBTENIDOS DE (GOOGLE INEGI, 2018), (GOBIERNO DEL ESTADO, 2015) Y (GOBIERNO DEL ESTADO, 2011) ....................................... 165

FIGURA 60 FICHA DE CATEGORIZACIÓN ARQUITECTÓNICA N. 003 ELABORACIÓN PROPIA EN BASE A DATOS OBTENIDOS DE (GOOGLE

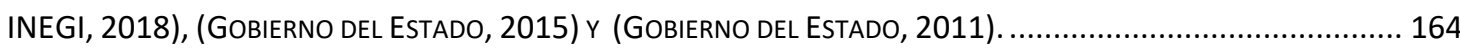

FIGURA 61 FICHA DE CATEGORIZACIÓN ARQUITECTÓNICA N. 004 ELABORACIÓN PROPIA EN BASE A DATOS OBTENIDOS DE (GOOGLE INEGI, 2018), (GOBIERNO DEL ESTADO, 2015) Y (GOBIERNO DEL ESTADO, 2011) ......................................... 166

FIGURA 62 FICHA DE CATEGORIZACIÓN ARQUITECTÓNICA N. 001 ELABORACIÓN PROPIA EN BASE A DATOS OBTENIDOS DE (GOOGLE INEGI, 2018), (GOBIERNO DEL ESTADO, 2015) Y (GOBIERNO DEL ESTADO, 2011) ........................................ 166

FIGURA 63 FICHA DE CATEGORIZACIÓN ARQUITECTÓNICA N. 086 ELABORACIÓN PROPIA EN BASE A DATOS OBTENIDOS DE (GOOGLE INEGI, 2018), (GOBIERNO DEL ESTADO, 2015) Y (GOBIERNO DEL ESTADO, 2011). 167

Figura 64. PLANO DE CATÁLOGO DE MONUMENTOS HISTÓRICOS POR CATEGORÍAS, ELABORACIÓN PROPIA EN BASE A DATOS RECABADOS EN CAMPO Y DE (GOBIERNO DEL ESTADO, 2015) 168

Figura 65.PLANO dE JERARQUía VIAL EN EL CENTRO HISTÓRICO, ELABORACIÓN PROPIA EN BASE A DATOS RECABADOS EN CAMPO

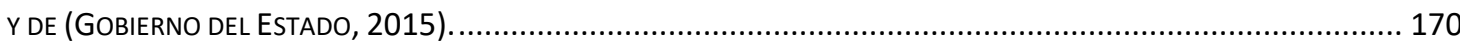

FIGURA 66. CARACTERÍSTICAS ECONÓMICAS. ELABORACIÓN PROPIA A PARTIR DEL (INEGI, 2010) ..................................172

FIGURA 67. POBLACIÓN POR GRUPO DE EDAD, ELABORACIÓN PROPIA EN BASE A DATOS OBTENIDOS DE (INEGI, 2010)......... 173

FIGURA 68. POBLACIÓN TOTAL POR MANZANA Y POR GÉNERO DEL BARRIO DE ANALCO, ELABORACIÓN PROPIA EN BASE A DATOS DE

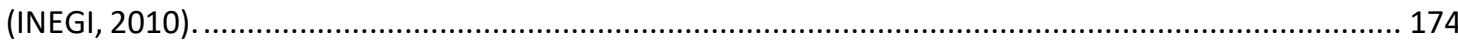

FIGURA 69. DENSIDAD DE VIVIENDAS POR MANZANAS, ELABORACIÓN PROPIA A PARTIR DE (INEGI, 2010)....................... 175

FIGURA 70. DATOS BÁSICOS DE EDUCACIÓN DEL BARRIO DE ANALCO, ELABORACIÓN PROPIA EN BASE A DATOS OBTENIDOS DE

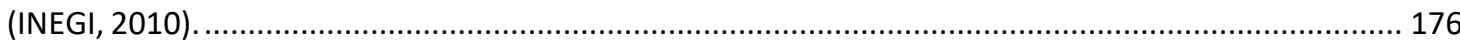

Figura 71. Comparación de la CALle 3 ORIENTE ENTRE A CALle 16 SUR Y 14 SUR (MAYo 2009 y MAYO del AÑo 2019). . 180

FIGURA 72. INMUEBLE DE LA CALLE 3 ORIENTE Y 12 SUR DEL AÑO 2009 Y EL AÑO 2019. FUENTE: ReYES (2020). ..............180

FiguRA 73. COMPARACIÓN DE LA FACHADA DEL BAR "El BAÑO" DE MAYO DEL AÑo 2009 Y JUNIO DEL 2016. FUENTE: (REYES, 2020) 181

FIgURA 74. COMPARACIONES DE LA FACHADA DE LA ACTUAL FACULTAD DE PSICOLOGÍA DE LA BUAP DEL AÑO 2009 Y EL AÑO 2018. FUENTE: (REYES, 2020)

FIgURA 75. HOTEL BOUtIQUE CASONA MARÍA COMPARACIÓN DE MAYO DEL 2009 Y MAYO DEL AÑO 2012 ........................ 182

FIGURA 76. COMPARACIÓN DE LA FÁBRICA DE VIDRIO LA LUZ, ENTRE EL AÑO 2009 Y EL AÑO 2019. ............................... 182

FIgURA 77. COMPARATIVA DE EDIFICIO ABANDONADO EN LA CALLE 7 ORIENTE A PARTIR DE MAYO DEL AÑO 2009 Y MAYO DEL AÑO

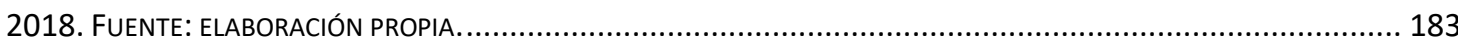

FiguRA 78. COMPARACIÓN DE LA CALLE 5 ORIENTE N. 1206 ACTUALMENTE INSTITUTO CARLS ROGERS COMPARACIÓN, DEL AÑO 2009 Y 2016 . FUENTE: (REYES, 2020). 183

FiguRA 79. COMPARACIÓN DE LA CALLE 5 ORIENTE N. 1206 ACTUALMENTE INSTITUTO CARLS ROgERS COMPARACIÓN, DEL AÑO 2009 Y 2016 . FUENTE: (REYES, 2020). 
Figura 80. TRANSFORMACIÓN Y PERMANENCIA DEL HOTEL UBICADO EN BOULEVARD 5 DE MAYO DEL AÑO 2009 Y E1 AÑO 2019.

FUENTE: ELABORACIÓN PROPIA.

185

FIgURA 81. COMPARACIÓN DEL ACTUAL HOTEL CARTESIANO UBICADO SOBRE BOULEVARD 5 DE MAYO Y AVENIDA 3 ORIENTE ENTRE EL AÑO 2011 Y EL 2018. FUENTE: (REYES, 2020) 185

FIGURA 82. INTERVENCIÓN Y RESCATE DEL PARQUE JERUSALÉN EN EL AÑO 2009 Y EL AÑO 2018. FUENTE: ELABORACIÓN PROPIA. 186

Figura 83. CASA ANALCO, PROYECTO DE INVESTIGACIÓN FABUAP 2018. FUENTE: ELABORACIÓN PROPIA. 187

\section{Índice de Tablas}

TABLA 1 EXCLUSION SOCIAL Y SEGREGACION TERRITORIAL: TIPOLOGIA DE CIUDADES. (ELABORACION I. CRESPO/J.SUBIRATS (IGOP), 2005)

TABLA 2. COMPARATIVA DE LOS VALORES UNITARIOS DEL SUELO DE LOS BARRIOS HISTÓRICOS DE LA CIUDAD DE PUEBLA. (ELABORACIÓN PROPIA CON INFORMACIÓN CATASTRAL 2013,2015 Y 2020).

TABLA 3. LEGISLACIÓN INTERNACIONAL, ELABORACIÓN PROPIA. ¡ERROR! MARCADOR NO DEFINIDO.

TABLA 4. LEGISLACIÓN NACIONAL, ELABORACIÓN PROPIA ¡ERROR! MARCADOR NO DEFINIDO.

TABLA 5 LEGISLACIÓN ESTATAL PUEBLA, ELABORACIÓN PROPIA. 88

TABLA 6. LEGISLACIÓN MUNICIPAL EN PUEBLA, ELABORACIÓN PROPIA.

TABLA 7. Plan PARA la RECUPERACiÓN DE la ZONA DE MONUMENTOS EN LA CiUdAD DE PUEBLA.

TABLA 8. TABla CRONOLÓGICA DE LAS PRINCIPALES ACCIONES PARA El RESCATE DEL CENTRO HISTÓRICO DE LA CiUdAd DE PUEBla (AYUNTAMIENTO MUNICIPAL, 2002)

TABLA 9. EL PORCENTAJE DE VISITANTES POR PUNTO DE INTERÉS EN LA CIUDAD DE PUEBLA. ELABORACIÓN PROPIA EN BASE A (TURISMO, 2015).

TABLA 10. CALlES DEL BARRIO DE ANALCO POR CATEGORÍA ARQUITECTÓNICA, MATERIAL, ESTILO Y SIGLOS DE CONSTRUCCIÓN, ELABORACIÓN PROPIA EN BASE A DATOS OBTENIDOS DE (GOBIERNO DEL ESTADO, 2015) Y DE (GOBIERNO DEL ESTADO, 2011) 


\section{ANEXOS}

\section{Muestra Barrio de Analco}

La muestra de 150 habitantes fue tomada a partir de una población de 1770, utilizando una desviación estándar de 1.3 correspondiente al $90 \%$ de confiabilidad, con un margen de error del $5 \%$.

$u=$ población total $(1770)$

$z=$ Desviación estándar (1.3)

$p=$ Probabilidad de acierto $(0.5)$

$r=$ Rango de error $(0.05)$

$$
\frac{\mathrm{u} \cdot z^{2} \cdot p \cdot(1-p)}{(\mathrm{u}-1) \cdot r^{2}+z^{2} \cdot p \cdot(1-p)}=150
$$

\section{Perfil poblacional}

$\begin{array}{lll}\text { ID } & \text { Perfil poblacional } & \text { Habitantes } \\ 1 & \text { Hombre } & 73 \\ 2 & \text { Mujer } & 77 \\ & & 150\end{array}$

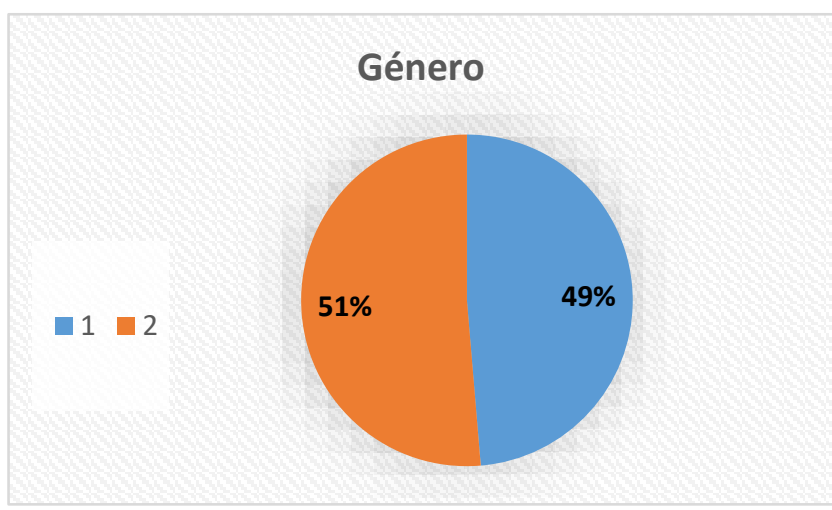

Figura 01. Género. Elaboración propia partir de aplicación de encuesta en el barrio de Analco, enero de 2018. 


\begin{tabular}{|c|c|c|}
\hline \multicolumn{3}{|c|}{ Edad } \\
\hline ID & Edad & Habitantes \\
\hline 1 & $<18$ & 2 \\
\hline 2 & $18-35$ & 97 \\
\hline 3 & $35-60$ & 36 \\
\hline 4 & $>60$ & 15 \\
\hline & Total & 150 \\
\hline
\end{tabular}

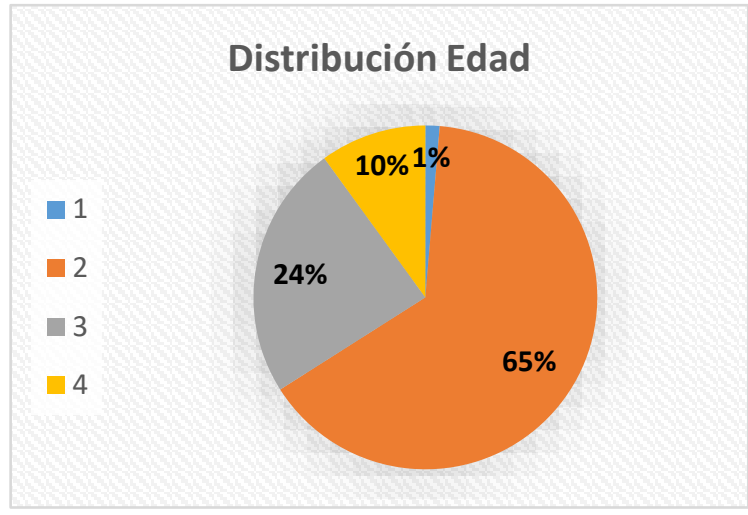

Figura 02. Distribución Edad. Elaboración propia partir de aplicación de encuesta en el barrio de Analco, enero de 2018.

\section{Valoración del barrio}

1. ¿Qué lugares representan mejor al barrio?

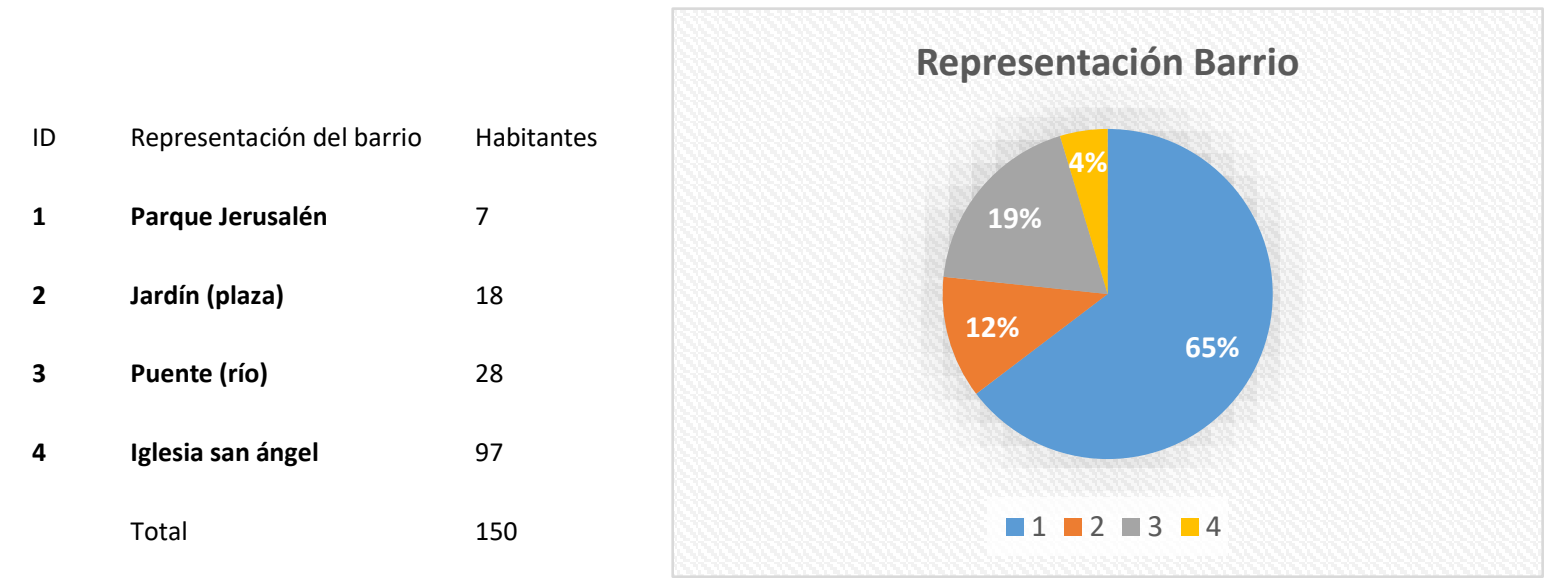

Figura 03. Representación Barrio. Elaboración propia partir de aplicación de encuesta en el barrio de Analco, enero de 2018. 
2. ¿Qué problemas cree que existen en el barrio?

$\begin{array}{lll}\text { ID } & \text { Problemas del barrio } & \text { Habitantes } \\ \mathbf{1} & \text { Comercio } & 14 \\ \mathbf{2} & \text { Abandono } & 32 \\ \mathbf{3} & & \\ \mathbf{4} & \text { Inseguridad } & 104 \\ & \text { TOTAL } & 150\end{array}$

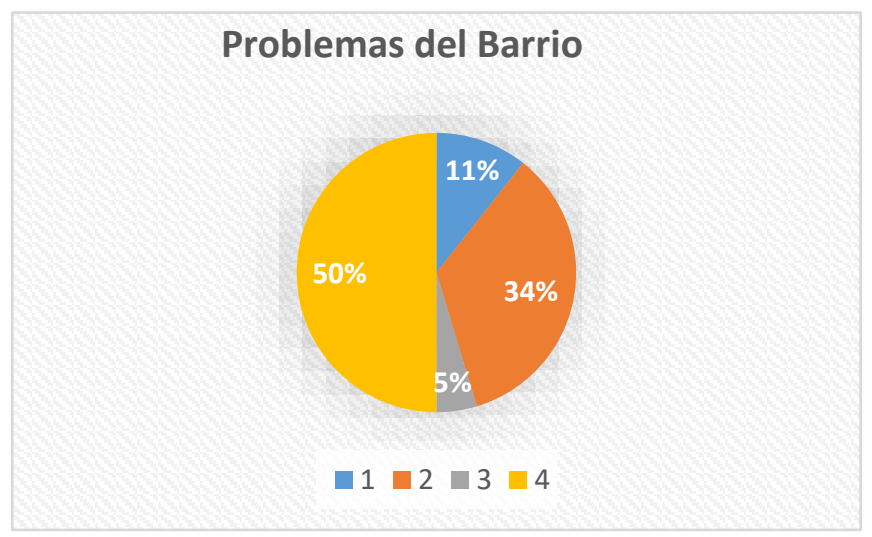

Figura 04. Problemas del Barrio. Elaboración propia partir de aplicación de encuesta en el barrio de Analco, enero de 2018.

3. ¿Cuál de los siguientes elementos VALORA MÁS de su barrio?

$\begin{array}{lll}\text { ID } & \text { Valoración del Barrio } & \text { Habitantes } \\ \mathbf{1} & \text { Paisaje } & 4 \\ \mathbf{2} & \text { Arquitectura } & 102 \\ \mathbf{3} & \text { Cultura } & 2 \\ \mathbf{4} & \text { Gente } & 17 \\ \mathbf{5} & \text { Localización } & 25 \\ & & 150\end{array}$

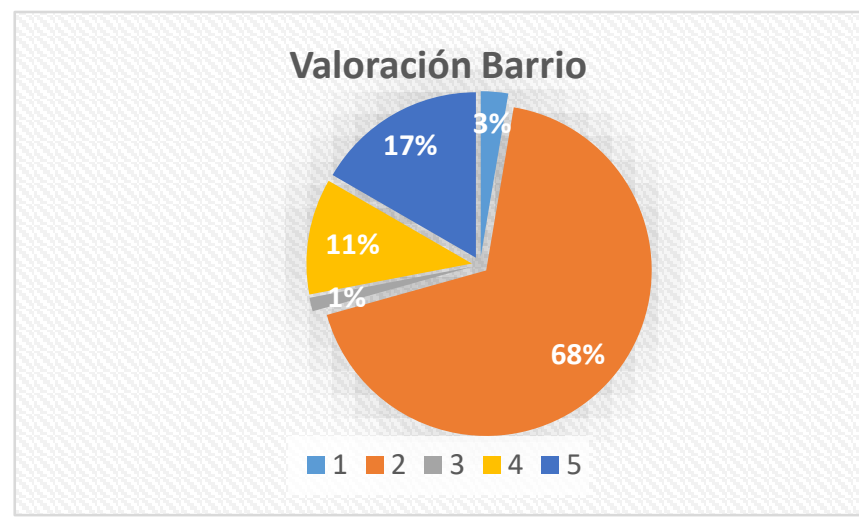

Figura 05. Valoración Barrio. Elaboración propia partir de aplicación de encuesta en el barrio de Analco, enero de 2018. 
4. ¿Conoce la historia de su barrio?

$\begin{array}{lll}\text { ID } & \text { Conocimiento barrio } & \text { Habitantes } \\ \mathbf{1} & \text { Si } & 72 \\ \mathbf{2} & \text { No } & 78 \\ & & \\ & \text { Total } & 150\end{array}$

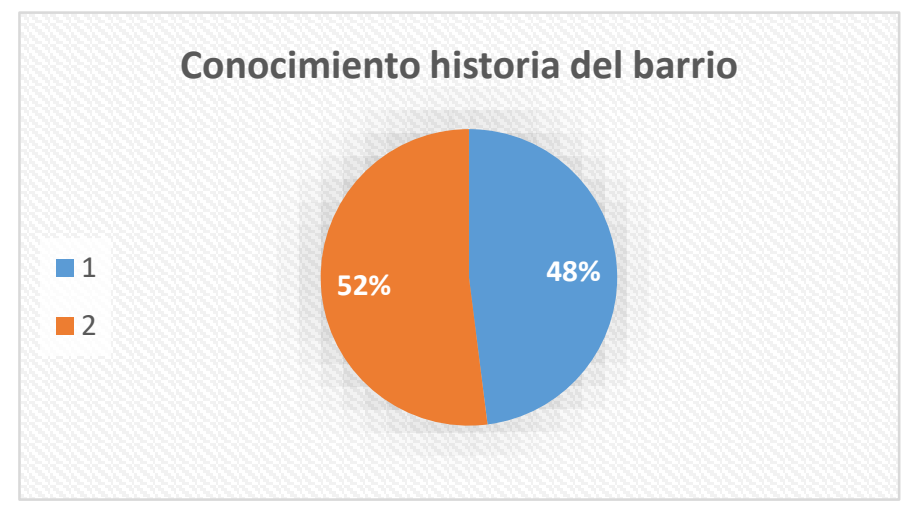

Figura 06. Conocimiento Historia del Barrio. Elaboración propia partir de aplicación de encuesta en el barrio de Analco, enero de 2018.

5. ¿Cree que existe inseguridad y de qué tipo?

ID inseguridad

1 Asaltos

2 Robo de vivienda

3 Robo autopartes

$4 \quad$ Agresión física

$5 \quad$ Agresión sexual

6 Grupos vandálicos

7 Espacios oscurecidos

8 Espacios banalizados

$9 \quad$ Viviendas abandonadas

10 Otros

Total
58

12

24

Habitantes

32

7

3

1

9

0

150

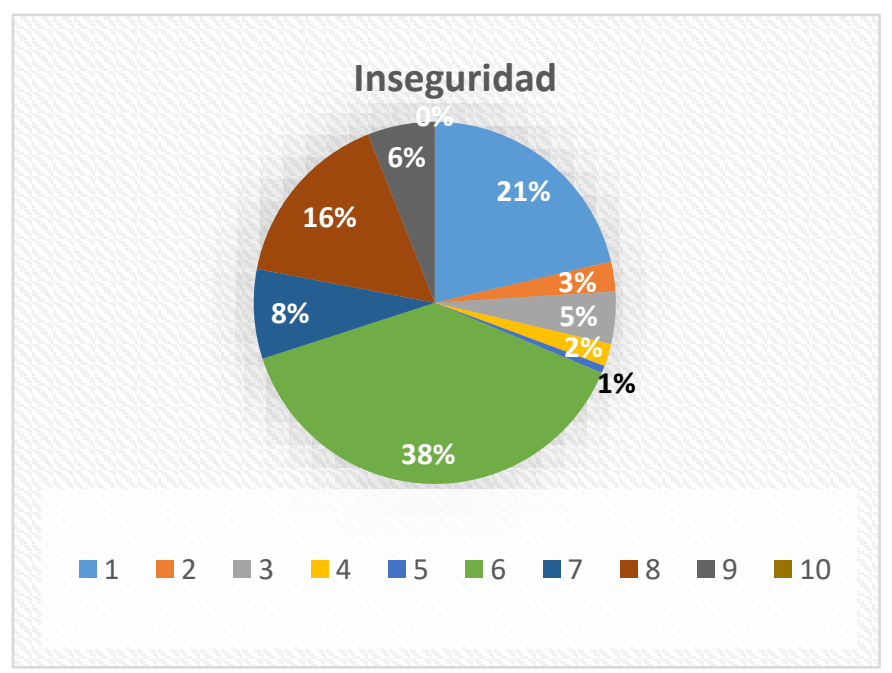

Figura 07. Inseguridad. Elaboración propia partir de aplicación de encuesta en el barrio de Analco, enero de 2018. 
6. ¿Cuáles de los siguientes aspectos valora más en su barrio?

$\begin{array}{lll}\text { ID } & \text { Valoración barrio } & \text { Habitantes } \\ \mathbf{1} & \text { Viviendas } & 8 \\ \mathbf{2} & \text { Arquitectura histórica } & 89 \\ \mathbf{3} & \text { Plazas y parques } & 21 \\ \mathbf{4} & \text { Calles, pasajes } & 1 \\ \mathbf{5} & \text { Mercados locales } & 11 \\ \mathbf{6} & \text { Ferias y festivales } & 4 \\ \mathbf{7} & \text { Vocación y oficios } & 12 \\ \mathbf{8} & \text { Expresiones artísticas } & 4 \\ & \text { Total } & 150\end{array}$

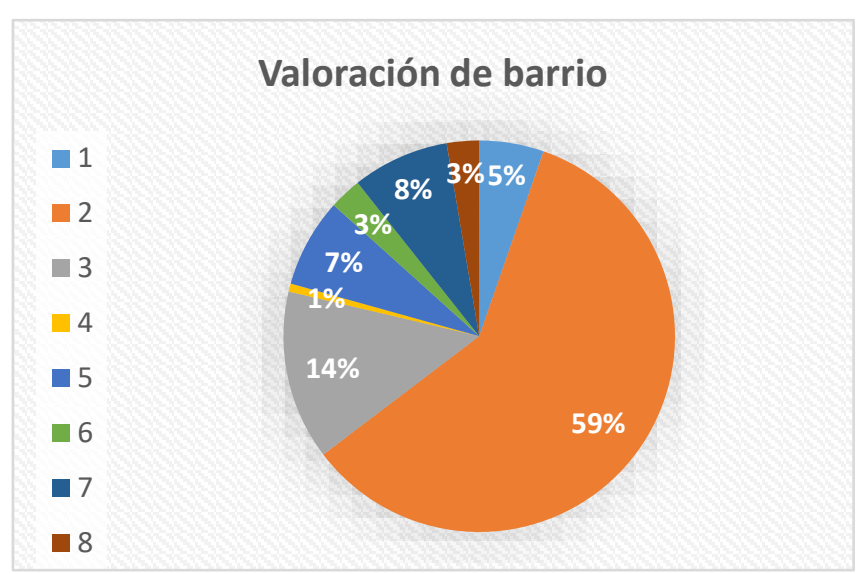

Figura 08. Valoración de Barrio. Elaboración propia partir de aplicación de encuesta en el barrio de Analco, enero de 2018.

\section{Evaluación del equipamiento y servicios}

7. En su barrio, ¿Usted considera que hay suficiente equipamiento?

$\begin{array}{llr}\text { ID } & \text { Equipamiento } & \text { Hab. } \\ 1 & \text { Plazas y parques } & 92 \\ 2 & \text { Alumbrado público } & 13 \\ 3 & \text { Comercio y abasto } & 19 \\ 4 & \text { Servicios profesionales } & 11 \\ & \text { Escuelas } & 15 \\ & \text { Total } & 150\end{array}$

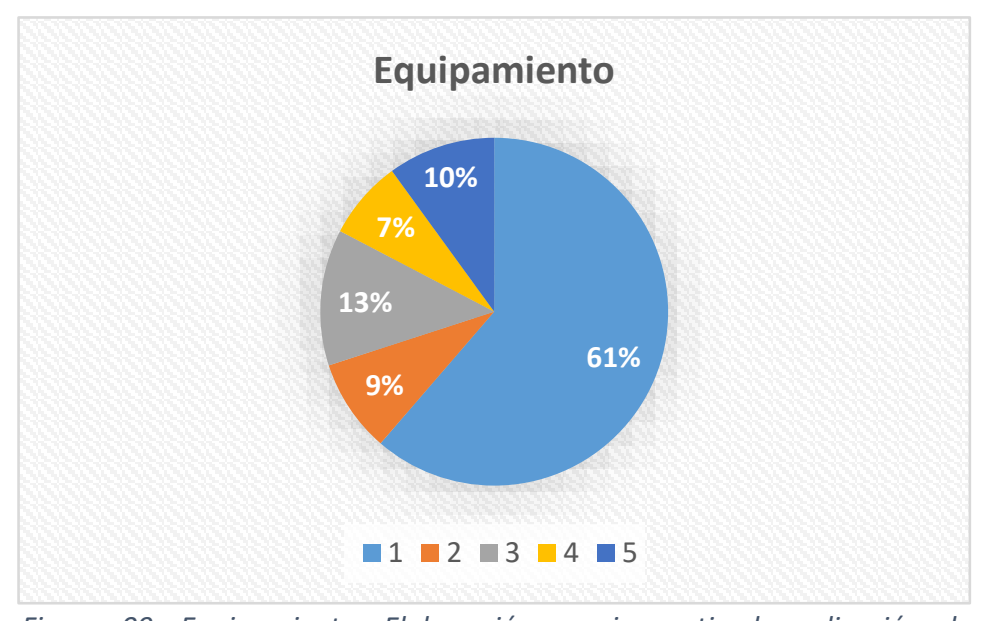

Figura 09. Equipamiento. Elaboración propia partir de aplicación de encuesta en el barrio de Analco, enero de 2018. 


\section{Evaluación de la organización vecinal}

8. ¿Conoce algún tipo de organización en el barrio vecinal, comercial o religiosa?

$\begin{array}{lll}\text { ID } & \text { Asociación vecinal } & \text { Habitantes } \\ \mathbf{1} & \text { puebla 3.0 } & 4 \\ \mathbf{2} & \text { faenas de limpieza } & 16 \\ \mathbf{3} & \text { mesa directiva } & 32 \\ \mathbf{4} & \text { no conoce } & 98 \\ & \text { Total } & 150\end{array}$

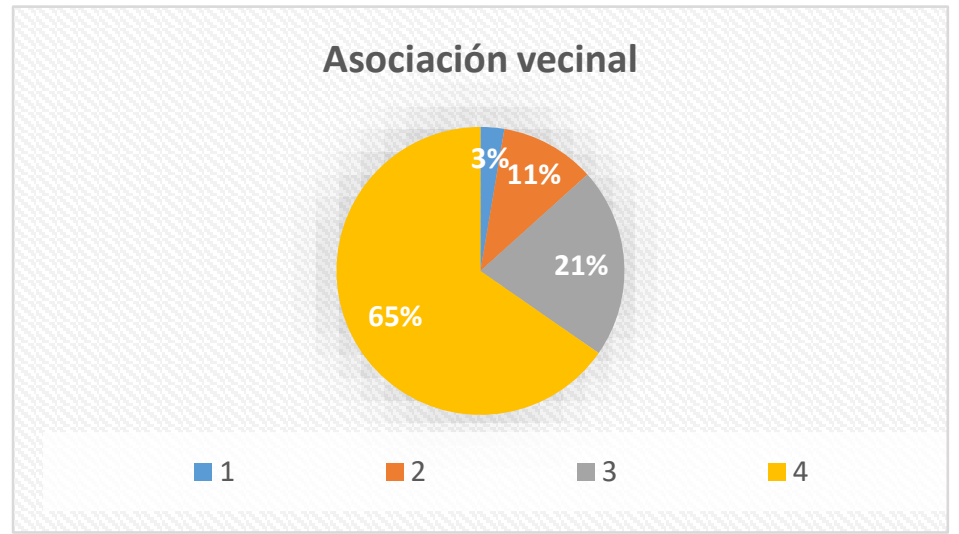

Figura 10. Asociación vecinal. Elaboración propia partir de aplicación de encuesta en el barrio de Analco, enero de 2018.

9. ¿Conoce si existe algún líder?

ID Conocimiento de líder Habitantes

1 Sí

62

2 No

89

Total

151

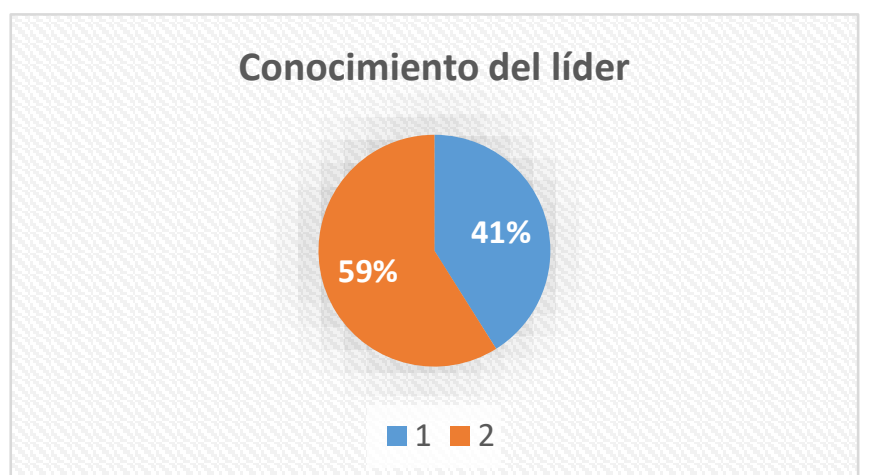

Figura 11. Conocimiento del líder. Elaboración propia partir de aplicación de encuesta en el barrio de Analco, enero de 2018. 


\section{Percepción de cambios en el barrio}

10. ¿Ha habido cambios en el barrio y cómo lo considera?

ID Evaluación de cambios

1 Uso habitacional

2 Aspecto físico

3 Aumento de turismo

$4 \quad$ Tipo de comercio

5 Disminución de población

6 Valor patrimonial

$\begin{array}{ll}\text { bueno } & \text { malo } \\ 132 & 13 \\ 146 & 4 \\ 112 & 38 \\ 149 & 1 \\ 97 & 3 \\ 148 & 2\end{array}$

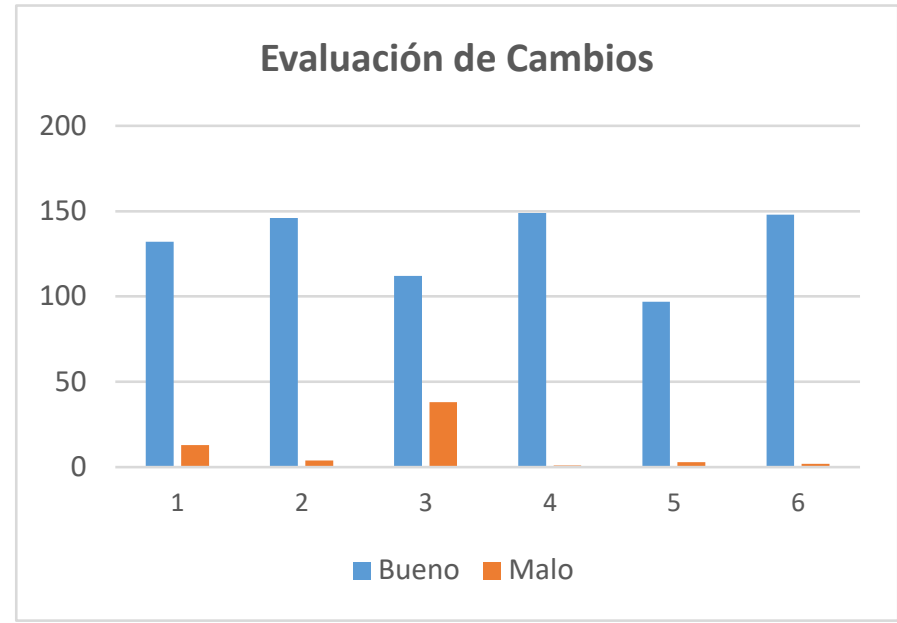

Figura 49. Evaluación de cambios. Elaboración propia partir de aplicación de encuesta en el barrio de Analco, enero de 2018. 